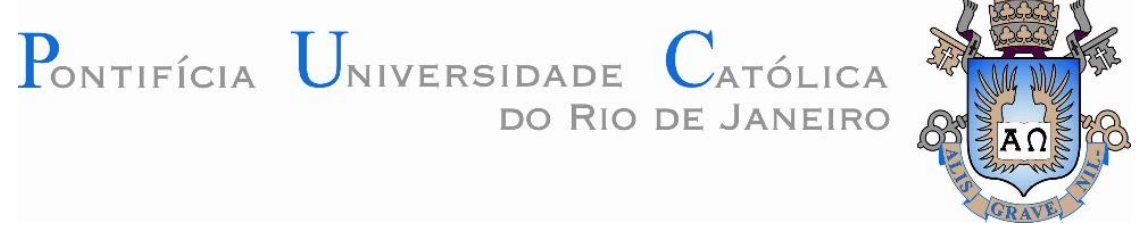

Flávio de Oliveira Coelho Martins

Projetos de casas inteligentes e Design Thinking: geração e seleção de concepções baseadas em soluções tecnológicas inovadoras

Dissertação de Mestrado

Dissertação apresentada como requisito parcial para obtenção do grau de Mestre pelo Programa de PósGraduação em Metrologia (Área de concentração: Metrologia para Qualidade e Inovação) da PUC-Rio.

Orientador: Prof. Rodrigo Flora Calili Coorientadora: Prof ${ }^{a}$ Maria Fatima Ludovico de Almeida

Rio de Janeiro

Maio de 2017 


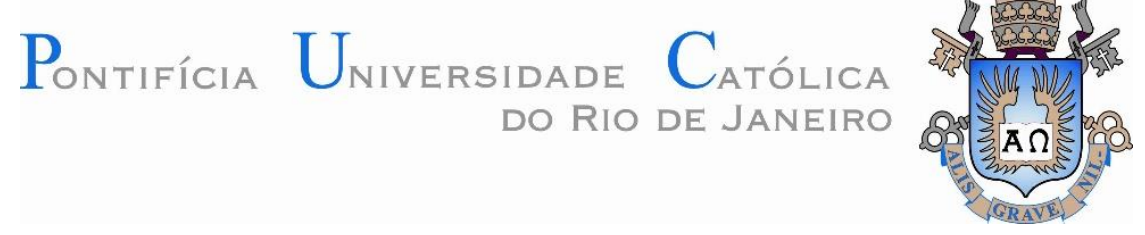

Flávio de Oliveira Coelho Martins

\section{Projetos de casas inteligentes e Design Thinking: geração e seleção de concepções baseadas em soluções tecnológicas inovadoras}

Dissertação apresentada como requisito parcial para obtenção do grau de Mestre pelo Programa de PósGraduação em Metrologia da PUC-Rio. Aprovada pela Comissão Examinadora abaixo assinada.

Prof. Rodrigo Flora Calili

Orientador

Programa de Pós-Graduação em Metrologia - PUC-Rio

Profa. Maria Fatima Ludovico de Almeida

Coorientadora

Programa de Pós-Graduação em Metrologia - PUC-Rio

Prof. Carlos Augusto Caldas de Moraes

Programa de Mestrado em Economia Empresarial - UCAM

Prof. Reinaldo Castro Souza

Programa de Pós-Graduação em Metrologia - PUC-Rio

Prof. Márcio da Silveira Carvalho

Coordenador Setorial do Centro

Técnico Científico - PUC-Rio

Rio de Janeiro, 04 de maio de 2017 
Todos os direitos reservados. É proibida a reprodução total ou parcial do trabalho sem autorização da universidade, do autor e do orientador.

\section{Flávio de Oliveira Coelho Martins}

Formado em Comunicação Social pelas Faculdades Integradas Hélio Alonso do Rio de Janeiro, possui especialização em Marketing e MBA em Gestão de Negócios. Tem experiência em Marketing, Comunicação e Responsabilidade Social. Atualmente Mestrando do Programa de Pós-Graduação em Metrologia pela PUC Rio.

Ficha Catalográfica

Projetos de casas inteligentes e design thinking: geração e seleção de concepções baseadas em soluções tecnológicas inovadoras / Flávio de Oliveira Coelho Martins ; orientador: Rodrigo Flora Calili ; coorientadora: Maria Fatima Ludovico de Almeida. - 2017.

158 f. ; $30 \mathrm{~cm}$

Dissertação (mestrado)-Pontifícia Universidade Católica do Rio de Janeiro, Centro Técnico Científico, Programa de Pós-Graduação em Metrologia para a Qualidade e Inovação, 2017.

Inclui bibliografia

1. Metrologia - Teses. 2. Metrologia. 3. Casas inteligentes. 4. Design thinking. 5. Crowdsourcing. 6. Métodos multicritério de apoio à decisão. I. Calili, Rodrigo Flora. II. Almeida, Maria Fatima Ludovico de. III. Pontifícia Universidade Católica do Rio de Janeiro. Centro Técnico Científico. Programa de Pós-Graduação em Metrologia para a Qualidade e Inovação. IV. Título. 


\section{Agradecimentos}

Agradeço primeiramente a Deus que nos acompanha em toda nossa trajetória, por me ajudar a seguir firme em meus propósitos de vida, pensando no bem-estar de minha família e amigos, assim como as pessoas de bem que fazem parte de minha vida.

Meu especial agradecimento à minha esposa Fernanda por me apoiar em meus desafios e às minhas filhas Carol e Clara, pois embora ainda pequenas, foram compreensivas nos momentos em que não pude estar com elas e fiquei estudando, pesquisando e escrevendo.

Agradeço muito a todos os professores, em especial aos meus orientadores Prof. Rodrigo Calili e Prof ${ }^{a}$ Fatima Ludovico, pelos ensinamentos e diretrizes que me ajudaram a desenvolver esta pesquisa.

Aos membros da Banca Examinadora pelas valiosas contribuições para melhoria do texto final da dissertação.

Aos meus colegas do Pós-MQI, especialmente Agatha Tommasi e Guilherme de Andrade Martins, pesquisadores integrantes da equipe da PUC-Rio no Projeto NO.V.A.

Agradeço à Enel Brasil pelo apoio institucional e à Capes pela bolsa de estudos, que viabilizaram o desenvolvimento do projeto de mestrado. 


\section{Resumo}

Martins, Flávio de Oliveira Coelho; Calili, Rodrigo Flora (Orientador); Almeida, Maria Fatima Ludovico (Coorientadora). Projetos de casas inteligentes e Design Thinking: geração e seleção de concepções baseadas em soluções tecnológicas inovadoras. Rio de Janeiro, 2017. 158 p. Dissertação de Mestrado - Programa de Pós-Graduação em Metrologia. Área de concentração: Metrologia para Qualidade e Inovação, Pontifícia Universidade Católica do Rio de Janeiro.

Nas últimas décadas, vários fatores socioeconômicos têm despertado o interesse por pesquisas sobre casas inteligentes e sua relação com os moradores. Dentre esses fatores, destacam-se as mudanças climáticas e a preocupação crescente com questões ambientais; a longevidade da população mundial; o uso eficiente de recursos naturais e de energia; e novas formas de gerenciar a rotina diária e o lazer. Nesse contexto, o objetivo da dissertação é propor e demonstrar um modelo para geração e seleção de concepções de casas inteligentes baseadas em soluções tecnológicas inovadoras, utilizando-se a abordagem de Design Thinking e integrando-se diversas ferramentas de gestão da inovação, incluindo a combinação de métodos multicritério de apoio à decisão. A pesquisa pode ser considerada descritiva, metodológica e participativa. Quanto aos meios de investigação, a metodologia compreendeu pesquisa bibliográfica e documental; modelagem do processo de geração e seleção de concepções de casas inteligentes baseada em Design Thinking; estudo empírico para demonstração da aplicabilidade do modelo no âmbito de um projeto de casa inteligente no Brasil (Projeto NO.V.A.). Destacam-se como principais resultados desta pesquisa um modelo conceitual desenvolvido segundo uma perspectiva mais empática, que permite colocar as pessoas no centro do desenvolvimento dos projetos de casas inteligentes; e a melhor concepção de casa inteligente para o Projeto NO.V.A., proposta segundo a abordagem de Design Thinking, com suporte de uma plataforma digital cooperativa que envolveu cerca de 35 mil pessoas de vários países, e emprego do método híbrido AHP-TOPSIS.

\section{Palavras-chave}

Metrologia; casas inteligentes; Design Thinking; crowdsourcing; métodos multicritério de apoio à decisão. 


\section{Abstract}

Martins, Flávio de Oliveira Coelho; Calili, Rodrigo Flora (Advisor); Almeida, Maria Fatima Ludovico (Co-advisor). Smart homes projects and Design Thinking: generation and selection of conceptions based on innovative technological solutions. Rio de Janeiro, 2017. 158p. Dissertação de Mestrado - Programa de Pós-Graduação em Metrologia. Área de concentração: Metrologia para Qualidade e Inovação, Pontifícia Universidade Católica do Rio de Janeiro.

In recent decades, several socioeconomic factors have stimulated research on smart homes and their relationship with their residents. Highlights are climate changes and the growing concern with environmental issues; longevity of the world's population; search for more efficient the use of natural resources and energy; and new habits and ways of managing daily routine and leisure. In this context, the objective of this dissertation is to propose and demonstrate a model for generation and selection of conceptions based on innovative technological solutions, adopting the Design Thinking approach, and integrating several innovation management tools, including crowdsourcing and the combination of multicriteria decision support methods. This research can be classified as descriptive, methodological, and participative. From the bibliographic and documentary review on the central themes of the research, a model based on Design Thinking approach was developed to generate and select the best conceptions of smart homes based on innovative technological solutions. Aiming to demonstrate the applicability of this model in the context of a smart home project in Brazil (NO.V.A. Project), an empirical study was carried out during the applied phase of this research. The main contributions are a conceptual model developed from a more empathic perspective, which allows people to be at the center of the development of smart home projects, and the best smart home conception based on based on innovative technological solutions for NO.VA. Project, as the main output of a Design Thinking process, which included a digital collaborative platform and the use of several innovation management tools, such as a hybrid multiple criteria decisionmaking method (AHP-TOPSIS).

\section{Keywords}

Metrology; smart homes; smart houses; Design Thinking; crowdsourcing; multiple criteria decision-making methods. 


\section{Sumário}

1. Introdução

1.1 Definição do problema de pesquisa................................................... 15

1.2 Objetivos: geral e específicos........................................................... 16

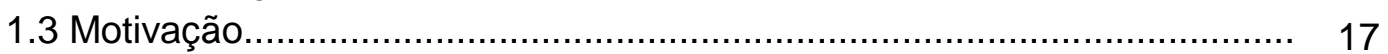

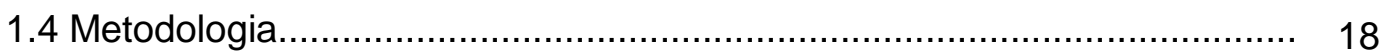

1.4.1 Fase exploratória e descritiva....................................................... 19

1.4.2 Fase aplicada........................................................................... 20

1.4.3 Fase conclusivo-propositiva........................................................ 22

1.5 Estrutura da dissertação................................................................ 22

2. Casas inteligentes: objetivos, serviços e funcionalidades .................. 24

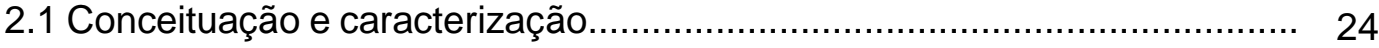

2.1.1 Categorias de serviços................................................................. 26

2.1.2 Funcionalidades associadas aos serviços........................................ 31

2.2 Revisão dos modelos de casas inteligentes ....................................... 32

2.2.1 Gator Tech Smart House (EUA) ..................................... 33

2.2.2 Matilda Smart House (EUA) ............................................. 35

2,2.3 Duke University Smart House (EUA)................................................. 36

2,2.4 Drexel Smart House (EUA) ........................................................ 37

2,2.5 MIT Smart House (EUA)................................................................ 39

2.2.6 Aware Home (EUA)................................................................ 40

2.2.7 CASAS Smart Home (EUA).......................................................... 41

2.2.8 Smart Home Lab da lowa State University (EUA)............................ 42

2.2.9 Toyota Dream House Papi (Japão).................................................. 43

2.2.10 NICT Ubiquitous Home (Japão) ................................................. 45

2.2.11 Smart Home System (Turquia) ................................................. 46

2.2.12 Escritório Verde da Universidade Federal do Paraná (Brasil).............. 48

2.3 Quadro-síntese dos modelos ............................................................. 51

2.4 Considerações finais sobre o capítulo............................................... 54

3. Soluções tecnológicas para casas inteligentes...................................... 57

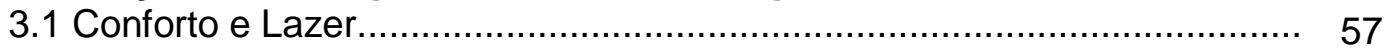

3.1.1 Sistema HVAC................................................................... 57

3.1.2 Sistema endereçável digital de controle de iluminação.......................... 58

3.1.3 Sistema de iluminação............................................................. 59

3.1.4 Sistema de layout interno........................................................ 59

3.1.5 Sistema de fachada em edificações................................................ 60

3.1.6 Rede de interconexão de produtos e sistemas eletrônicos domésticos... 61

3.1.7 Sistema de gerenciamento ambiental interno e externo ....................... 62

3.1.8 Sistema de detecção de posicionamento não invasivo........................... 63

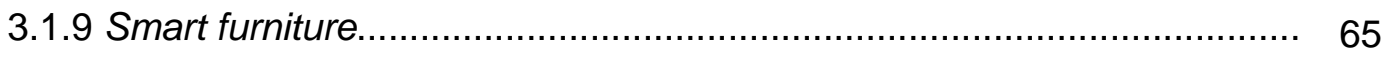

3.2 Automação residencial................................................................. 66

3.2.1 Sistema endereçável de detecção de incêndio e alarme...................... 66

3.2.2 Sistema de dados e telecomunicações (PLC) .................................. 67 
3.2.3 Sistema integrado de gerenciamento de edificações

3.2.4 Sistema de monitoramento da segurança e controle de acesso........... 69

3.2.5 Sistema vertical de transporte...................................................... 70

3.2.6 Outras soluções de automação residencial........................................ 71

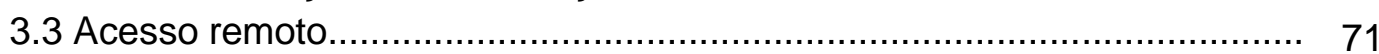

3.4 Segurança de rede e de informação................................................. 71

3.4.1 Sistema de informação e rede de comunicação.................................... 71

3.5 Cuidados com a saúde (Healthcare) ............................................... 72

3.5.1 Sistemas de monitoramento de saúde.......................................... 72

3.6 Uso eficiente de recursos naturais................................................ 78

3.7 Gerenciamento de energia....................................................... 83

3.8 Segurança patrimonial.................................................................. 86

3.8.1 Proteção contra incêndio em casas inteligentes................................ 86

3.8.2 Sistemas de segurança........................................................... 87

3.9 Considerações finais sobre o capítulo................................................ 88

4. Design Thinking aplicado a projetos de casas inteligentes.................. 90

4.1 Design Thinking: breve histórico, conceitos e caracterização................... 90

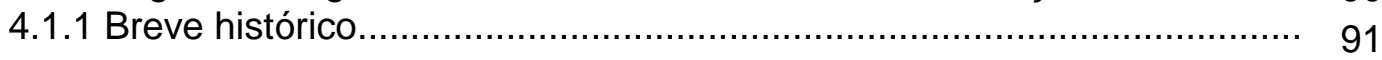

4.1.2 Conceituação e caracterização....................................................... 92

4.2 Perspectivas do processo Design Thinking........................................... 93

4.2.1 Perspectiva da Ideo.................................................................... 94

4.2.2 Perspectiva da Stanford d.school................................................ 96

4.2.3 Perspectiva de Vianna et al........................................................... 97

4.2.4 Análise comparativa das perspectivas selecionadas.................... 101

4.3 Design Thinking aplicado a projetos de casas inteligentes: modelo

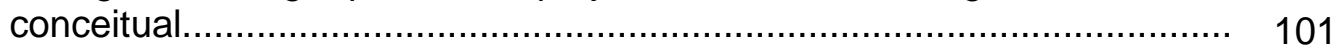

4.3.1 Imersão................................................................................... 102

4.3.2 Análise e síntese....................................................................... 104

4.3.3 Ideação...................................................................................... 105

4.4 Considerações finais sobre o capítulo.................................................. 111

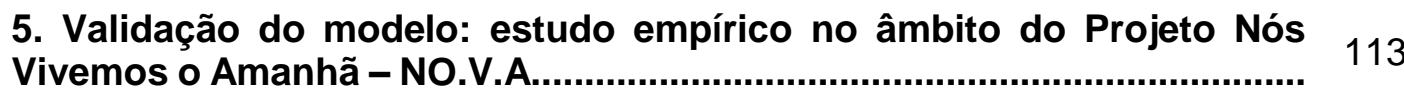

5.1 Contexto de aplicação: Projeto NO.V.A................................................. 113

5.2 Fase de imersão............................................................................. 113

5.2.1 Imersão preliminar: pesquisa exploratória e reuniões de alinhamento.... 114

5.2.2 Imersão em profundidade: o processo de crowdsoursing e sessões generativas................................................................................... 116

5.3 Fase de análise e síntese .......................................................... 117

5.3.1 Grupos focais.......................................................................... 118

5.3.2 Criação das personas................................................................... 118

5.3.3 Definição dos critérios norteadores................................................. 120

5.4 Fase de ideação.......................................................................... 121

5.4.1 Geração de concepções: uso de análise morfológica........................... 123

5.4.2 Seleção da melhor concepção: uso do método AHP-TOPSIS............... 130

5.5 Discussão dos resultados................................................................. 133

6. Conclusões e recomendações.............................................................. 136

Referências bibliográficas................................................................ 138 


\section{Lista de Figuras}

Figura 1.1 - Desenho da pesquisa, seus componentes e métodos......... 19

Figura 1.2 - Mapa conceitual da pesquisa............................................. 21

Figura 2.1 - Vista frontal da Gator Tech Smart House.......................... 33

Figura 2.2 - Tecnologias inteligentes da Gator Tech Smart House ........ 34

Figura 2.3 - Interior da Matilda Smart House............................................. $\quad 35$

Figura 2.4 - Interiores da Duke University Smart House............................. 36

Figura 2.5 - Vista frontal da Drexel Smart House..................................... $\quad 37$

Figura 2.6 - Interiores da MIT Smart House (EUA)................................... $\quad 39$

Figura 2.7 - Uso de câmeras da Aware Home (EUA)............................. 40

Figura 2.8 - Atividade na CASAS Smart House (EUA)............................ 42

Figura 2.9 - Página na web do Smart Home Lab da lowa State

University (EUA) .......................................................................... 43

Figura 2.10 - Interiores da Toyota Dream House PAPI (Japão)................ 44

Figura 2.11 - Uso de sensores no teto e no piso da NICT Ubiquitous Home 46

Figura 2.12 - Interiores da Smart Home System (Turquia)........................ 47

Figura 2.13 - Vista Frontal do Escritório Verde da UTFPR........................ 49

Figura 2.14 - Painel fotovoltaico do Escritório Verde da UTFPR............... 50

Figura 2.15 - Controlador de carga e banco de baterias do EV da UTFPR $\quad 50$

Figura 3.1 - Superfícies pixeladas........................................................ 64

Figura 3.2 - Rota do sistema Z-Tile................................................... 64

Figura 3.3 - Estrutura do tapete inteligente........................................... 65

Figura 3.4 - Distribuição dos módulos remotos (MR) e módulo concentrador (MC) para aquisição de informações....................................... 67

Figura 3.5 - Sensor para monitoramento de atividades.......................... 73

Figura 3.6 - Outro exemplo de sensor para monitoramento de atividades $\quad 73$

Figura 3.7 - Caixa de medicamentos - pillbox...................................... 74

Figura 3.8 - Monitoramento telefônico............................................... 75

Figura 3.9 - Monitoramento de preparação de café.................................... 75

Figura 3.10 - Tatuagem para medição de glicemia........................................

Figura 3.11 - Aparelho medidor de glicemia............................................ $\quad 77$

Figura 3.12 - Aparelho para detecção de pré-diabetes.................................. 78

Figura 3.13 - Corte transversal do coletor PVT (a) e camadas do PVT (b) 83

Figura 3.14 - Estrutura de um sistema fotovoltaico: modems PLC em cada módulo fotovoltaico e um gateway de energia renovável (REG) a inversor..

Figura 4.1 - Processo de Design Thinking segundo a perspectiva da

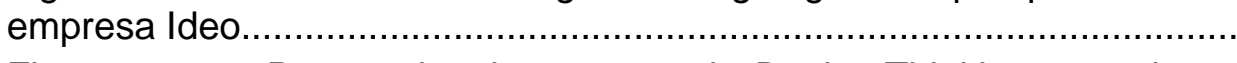

Figura 4.2 - Perspectiva do processo de Design Thinking segundo a Stanford d.school..................................................................................... 96 Figura 4.3 - Perspectiva de Design Thinking segundo Vianna et al........ 98 
Figura 4.4 - Ferramenta matriz de posicionamento

100

Figura 4.5 - Modelo conceitual baseado em Design Thinking para geração e seleção de concepções de casas inteligentes baseadas em soluções tecnológicas inovadora.

Figura 4.6 - Matriz multidimensional aplicável a projetos de casas

Inteligentes

Figura 4.7 - Ilustração didática da geração de uma das concepções

para a casa inteligente.

Figura 4.8 - Exemplo de estrutura hierárquica de problemas de decisão (em três níveis).

Figura 4.9 - Exemplo de matriz de julgamentos para o método AHP.

Figura 5.1 - Exemplo de tema para pergunta aberta.

Figura 5.2 - Exemplo de pergunta fechada com alternativas................. 115

Figura 5.3 - Quadro explicativo de recompensas virtuais....................... 117

Figura 5.5 - Método de análise das ideias adotado pela equipe do

Projeto NO.VA. 


\section{Lista de Quadros}

Quadro 2.1 - S Síntese das principais categorias de serviços...................... 27

Quadro 2.2 - Principais funcionalidades associadas às categorias de serviços...................................................................................... 32

Quadro 2.3 - Principais modelos de casas inteligentes............................ 52

Quadro 4.1 - Principais características da abordagem de Design Thinking 93

Quadro 4.2 - Comparação das perspectivas de Design Thinking............... 101

Quadro 4.3 - Escala para padronizar os julgamentos de valor pelo método

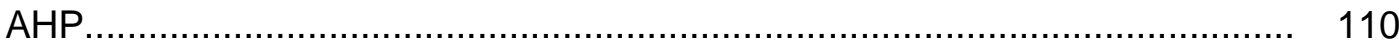

Quadro 5.1 - Critérios norteadores para definição de concepções de casas inteligentes.

Quadro 5.2 - Matriz de análise morfológica construída para a geração de concepções de casas inteligentes para o Projeto NO.V.A.......

Quadro 5.3 - Concepção da Gator Tech Smart House................................. 124

Quadro 5.4 - Concepção da Drexel Smart Home........................................ 125

Quadro 5.5 - Concepção da Aware House................................................ 126

Quadro 5.6 - Concepção da CASAS Smart Home..................................... 127

Quadro 5.7 - Concepção da IOWA Smart Home......................................... 128

Quadro 5.8 - Concepção para a Casa NO.V.A........................................... 129

Quadro 5.9 - Concepções de casas inteligentes hierarquizadas pelo método AHP-TOPSIS e relacionadas às personas...................................... 133 


\section{Lista de Tabelas}

Tabela 5.1 - Comparação pareada entre os critérios norteadores para Moradia-Casa...

Tabela 5.2 - Comparação pareada entre os critérios norteadores para Usuário-Morador.

Tabela 5.3 - Mapa de atributos para hierarquização das concepções de casas inteligentes..

Tabela 5.4 - Análise integrada AHP-TOPSIS.

Tabela 5.5 - Hierarquização das concepções de casas inteligentes pelo método AHP-TOPSIS. 


\section{1 \\ Introdução}

Nas últimas décadas, vários fatores socioeconômicos têm despertado o interesse por pesquisas sobre casas inteligentes e sua relação com seus habitantes. Dentre esses fatores, destacam-se as mudanças climáticas e a preocupação crescente com questões ambientais; a busca por métodos mais eficientes do uso de recursos naturais e de energia; novas formas de gerenciar a rotina diária e de lazer; e a longevidade da população mundial.

Casas inteligentes podem ser caracterizadas como espaços residenciais, que contemplam soluções tecnológicas integradas, de modo a oferecer uma infraestrutura tecnologicamente avançada, que permita aos seus habitantes usufruir de um conjunto de serviços e funcionalidades, tais como conforto; segurança; automação de tarefas domésticas; gerenciamento de energia; mobilidade interna e cuidados com a saúde (healthcare); entretenimento; e sustentabilidade ambiental (Alam et al., 2012; Badica et al., 2013; Wong e Li, 2008; Chan et al., 2008; 2009).

Existem muitos modelos de casas inteligentes no mundo, com propósitos e categorias de serviços e funcionalidades distintas. Com base nas revisões de GhaffarianHoseini et al. (2013); Jeong (2009) e Bolzani (2010) e em consulta direta aos sites institucionais das casas identificadas nesses trabalhos, selecionaram-se para fins da presente pesquisa doze delas localizadas nos Estados Unidos, Japão, Turquia e Brasil. A escolha baseou-se no fato de que essas casas são laboratórios vivos e os exemplos selecionados foram: (i) Gator Tech Smart House (EUA); (ii) Matilda Smart House (EUA); (iii) Duke University Smart House (EUA); (iv) Drexel Smart House EUA); (v) MIT Smart House (EUA); (vi) Aware Home (EUA); (vii) CASAS Smart Home (EUA); (viii) Smart Home Lab da Iowa State University (EUA); (ix) Toyota Dream House Papi (Japão); (x) NICT Ubiquitous Home (Japão); (xi) Smart Home System (Turquia); e (xii) Escritório Verde da Universidade Federal do Paraná (Brasil). 
A análise dessas experiências permitiu concluir que a complexidade, multidisciplinariedade e incerteza são características inerentes aos projetos de casas inteligentes baseados em soluções tecnológicas inovadoras. Por essas características, identifica-se a necessidade de se dispor de modelos para geração e seleção de concepções de projetos de casas inteligentes, segundo uma perspectiva mais empática, que coloca as pessoas no centro do desenvolvimento de um projeto e gera alternativas que venham atender seus desejos, expectativas e necessidades, mas que ao mesmo tempo sejam tecnicamente possíveis de serem transformadas em realidade.

Design Thinking vem ao encontro dessa necessidade, por ser uma abordagem metodológica de gestão da inovação, que usa a sensibilidade e os métodos dos designers para harmonizar as necessidades das pessoas com o que é tecnologicamente viável, buscando-se transformar oportunidades em soluções que agreguem valor. Permite ainda prospectar estados futuros, pensar por meio do processo de Design, assim como gerar novas concepções, produtos, serviços e experiências reais (Brown, 2008; Cooper, Junginger e Lockwood, 2009; Vianna et al., 2011).

No contexto brasileiro, o Projeto "Nós Vivemos o Amanhã - NO.V.A." é uma iniciativa que compõe o conjunto de projetos de P\&D do Grupo Enel no Brasil, desenvolvidos com a chancela da Agência Nacional de Energia Elétrica (Aneel). O projeto tem por objetivo projetar uma casa inteligente, que sirva de laboratório vivo ao entendimento das percepções e expectativas de seus futuros moradores em relação a questões de conforto e lazer, segurança, gerenciamento de energia, automação de tarefas domésticas, mobilidade interna e cuidados com a saúde (healthcare), além da sustentabilidade ambiental.

Liderado pela Enel Distribuição Rio, o Projeto NO.V.A vem sendo realizado em parceria com a Prefeitura de Niterói, com a Fundação Getúlio Vargas (FGV) e com a Pontifícia Universidade Católica (PUC-Rio). A presente dissertação inserese no âmbito deste Projeto e seu desenvolvimento beneficiou-se de um ambiente multistakeholder que permitiu demonstrar a aplicabilidade de um modelo para a geração e seleção de concepções de casas inteligentes baseadas em soluções tecnológicas inovadoras, adotando-se a abordagem de Design Thinking.

Na fase de imersão do Design Thinking, uma plataforma digital interativa (nosvivemosoamanha.com.br) propiciou a contribuição de 35.000 pessoas com 
proposição de ideias para a construção de uma moradia do futuro, sustentável, com tecnologias inovadoras que pudessem facilitar a vida das pessoas e solucionar problemas que existem hoje.

Diante do desafio de se gerar concepções de casas inteligentes baseadas a partir dos resultados do processo de crowdsourcing, identificou-se a oportunidade de incorporar à abordagem de Design Thinking a ferramenta de análise morfológica (Zwicky, 1969) para a geração de alternativas e o uso de um método híbrido multicritério de apoio à decisão para seleção e hierarquização das concepções propostas.

Acredita-se que o desenvolvimento de um modelo para geração e seleção de concepções de casas inteligentes baseadas em soluções tecnológicas inovadoras, adotando-se a abordagem de Design Thinking e integrando-se diversas ferramentas de prospecção e gestão da inovação, permitirá que os decisores e especialistas responsáveis pela coordenação de projetos de casas inteligentes coloquem seus futuros moradores no centro de seu desenvolvimento, gerando e selecionando alternativas que venham atender desejos, expectativas e necessidades dessas pessoas e que sejam tecnicamente possíveis de serem transformadas em realidade.

\section{1}

\section{Definição do problema de pesquisa}

Considerando que:

- os temas domótica e casas inteligentes têm despertado grande interesse de pesquisadores em todo o mundo e que há hoje vários projetos que funcionam como laboratórios vivos e demonstram inúmeros benefícios a seus moradores;

- a complexidade, multidisciplinariedade e incerteza são características inerentes à geração e seleção de novas concepções de casas inteligentes baseadas em soluções tecnológicas inovadoras;

- a necessidade de se dispor de modelos de geração e seleção de concepções de projetos de casas inteligentes, segundo uma perspectiva mais empática, que permita colocar as pessoas no centro do desenvolvimento do projeto e gerar alternativas que venham atender seus desejos, expectativas e necessidades, mas que ao mesmo tempo sejam tecnicamente possíveis de serem transformadas em realidade;

- o potencial de aplicação da abordagem de Design Thinking não tem sido explorado em projetos de casas inteligentes, conforme revisão bibliográfica 
e documental cobrindo o período de 2000- 2016, que indicou a inexistência de trabalhos científicos combinado os temas centrais desta pesquisa 'Smart homes' e 'Design Thinking';

- os métodos multicritério de apoio à decisão poderão ser empregados em um processo de Design Thinking, refinando-se as boas práticas adotadas até o momento;

- o Projeto "Nós Vivemos o Amanhã - NO.V.A.", liderado pela Enel Distribuição Rio, ofereceu um ambiente multistakeholder para se demonstrar a aplicabilidade de um modelo baseado na abordagem de Design Thinking para geração e seleção de concepções de casas inteligentes baseadas em soluções tecnológicas inovadoras;

Enuncia-se a seguinte questão principal da pesquisa:

"Como gerar e selecionar concepções de casas inteligentes baseadas em soluções tecnológicas inovadoras, adotando-se a abordagem de Design Thinking com incoporação de novas ferramentas de gestão e métodos multicritério de apoio à decisão?"

Design Thinking é uma abordagem metodológica de gestão da inovação para desenvolvimento de novos produtos, serviços e negócios, com vistas a um resultado futuro e com foco na identificação de necessidades não atendidas de um determinado público-alvo ou segmento de mercado. Esta pesquisa buscará demonstrar a aplicabilidade dessa abordagem em projetos de casas inteligentes, particularmente na geração de concepções alternativas e seleção da melhor para os objetivos de um determinado projeto.

\section{2}

\section{Objetivos: geral e específicos}

A dissertação tem como objetivo geral propor um modelo para geração e seleção de concepções de casas inteligentes baseadas em soluções tecnológicas inovadoras, utilizando-se a abordagem de Design Thinking e integrando-se diversas ferramentas de gestão da inovação, incluindo a combinação de métodos multicritério de apoio à decisão. Este objetivo geral desdobra-se nos seguintes objetivos específicos:

- Conceituar casas inteligentes e identificar as categorias de serviços e funcionalidades oferecidas a seus moradores; 
- Identificar projetos de casas inteligentes que vem funcionando como laboratórios vivos nos Estados Unidos, Japão, Turquia e Brasil, visando identificar os modelos e soluções tecnológicas que foram adotadas nesses projetos;

- Levantar o estado-da-arte de sistemas inteligentes e soluções tecnológicas inovadoras empregadas em projetos de casas inteligentes;

- Discutir as diversas perspectivas da abordagem de Design Thinking e seu potencial de aplicação em projetos de casas inteligentes;

- Desenvolver um modelo conceitual para geração e seleção de concepções de casas inteligentes baseadas em soluções tecnológicas inovadoras, adotando-se a abordagem de Design Thinking;

- Demonstrar a aplicabilidade do modelo proposto, mediante o desenvolvimento de um estudo empírico no âmbito de um projeto de casa inteligente no Brasil (Projeto NO.V.A.), liderado por uma empresa de distribuição de energia elétrica que atua em 66 municípios do estado do Rio de Janeiro;

- Explicitar os diferenciais metodológicos do modelo proposto em relação a processos de inovação baseados em Design Thinking, ao incorporar um processo de crowdsourcing na fase de imersão e empregar análise morfológica e um método híbrido multicritério de apoio à decisão na fase de ideação.

\section{3 Motivação}

Identificaram-se na literatura vários projetos de casas e ambientes inteligentes que estão sendo desenvolvidos por universidades e empresas (Jeong, 2009; Bolzani, 2010; GhaffarianHoseini et al., 2013; e Tascikaraoglu et al., 2014) e vem funcionando como laboratórios vivos para experimentos, que abrangem desde a infraestrutura e redes de comunicação até o desenho de interfaces, metodologias de controle de dispositivos, questões de segurança, privacidade, tecnologias assistivas; gerenciamento de energia, dentre outros temas de pesquisa.

No entanto, como já comentado, nesta revisão não foram identificados trabalhos científicos referentes ao tema central da pesquisa, que utilizaram a abordagem de Design Thinking para a geração e seleção de novas concepções de 
casas inteligentes. Mais ainda, os artigos sobre aplicação de Design Thinking em outros contextos, além de projetos de casas inteligentes, não exploram o potencial de plataformas digitais para coleta de informações (crowdsourcing) na fase de imersão e de métodos multicritério de apoio à decisão nas etapas de hierarquização das propostas e seleção da concepção mais aderente aos critérios norteadores dos respectivos projetos.

Isso posto, pelo ineditismo e aplicabilidade, considerou-se de alta relevância o desenvolvimento de um modelo de geração e seleção de concepções de projetos de casas inteligentes, segundo uma perspectiva mais empática, que permitisse colocar as pessoas no centro do desenvolvimento do projeto. A geração de concepções alternativas, segundo essa abordagem, tem como critérios norteadores o atendimento dos desejos, expectativas e necessidades dos futuros moradores e a viabilidade técnico-econômica das concepções, a serem transformadas em realidade.

Além das lacunas identificadas na literatura e do potencial de aplicação dos resultados aqui reportados, destaca-se a oportunidade oferecida pelo Grupo Enel, de se demonstrar empiricamente a aplicabilidade do modelo proposto no âmbito do Projeto NO.V.A. - Nós Vivemos o Amanhã, voltado para a construção de uma moradia do futuro na cidade de Niterói, Rio de Janeiro.

\section{4 \\ Metodologia}

Conforme a taxonomia proposta por (Vergara, 2005) a pesquisa pode ser considerada aplicada, descritiva e metodológica (quanto aos fins).

Quanto aos meios de investigação, a metodologia compreendeu: (i) pesquisa bibliográfica e documental sobre os temas centrais da pesquisa, mediante consulta sistemática nas bases de dados Scopus, Web of Science, Science Direct e Google Scholar, cobrindo o período de 2000 a 2016; e (ii) desenvolvimento de um modelo conceitual para gerar e selecionar concepções de casas inteligentes baseadas em soluções tecnológicas inovadoras, utilizando-se a abordagem de Design Thinking e a integração de diversas ferramentas de prospecção e gestão da inovação, incluindo a combinação de dois métodos multicritério de apoio à decisão (MMAD), a saber: Analytical Hierarchy Process (AHP) e Technique for Order of Preference by Similarity to Ideal Solution (TOPSIS). 
A Figura 1.1 apresenta a sequência da pesquisa em suas três grandes fases: (i) exploratória e descritiva; (ii) pesquisa aplicada; (iii) conclusivo-propositiva.
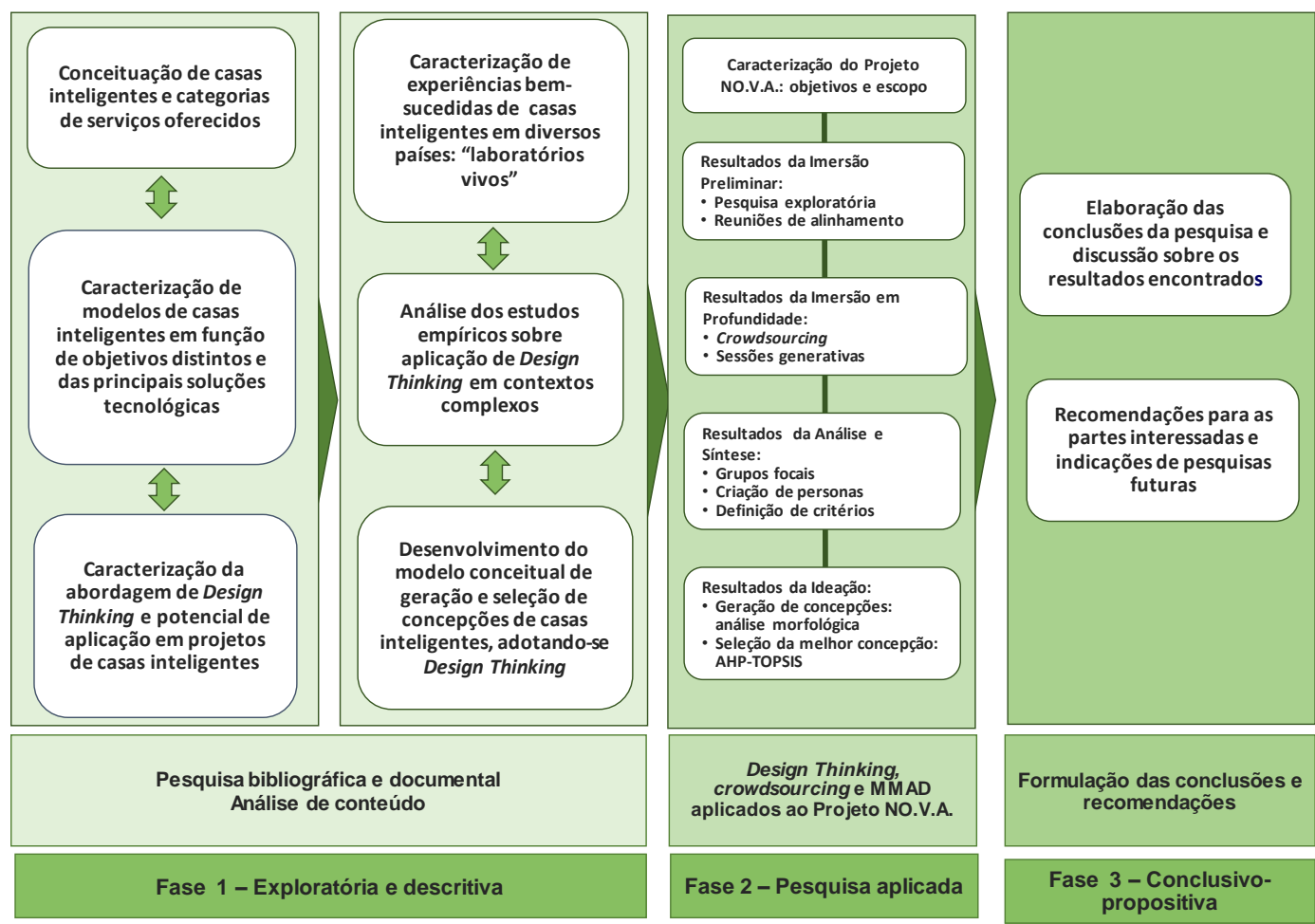

Figura 1.1 - Desenho da pesquisa, seus componentes e métodos Fonte: Elaboração própria.

\subsection{1 \\ Fase exploratória e descritiva}

$\mathrm{Na}$ fase exploratória, procedeu-se a uma revisão bibliográfica e documental sobre os temas centrais da pesquisa, mediante consulta sistemática nas bases de dados Scopus, Web of Science, Science Direct e Google Scholar, cobrindo o período de 1997 a 2017. Adotou-se o método de análise de conteúdo dos documentos para seleção daqueles considerados de maior relevância (Bardin, 1977). Nessa fase, identificaram-se alguns trabalhos científicos recentes de revisão bibliográfica sobre casas inteligentes (Alam et al., 2013; Badica et al., 2013; Chan et al., 2008; 2009; GhaffarianHoseini et al., 2013; Wilson et al., 2015; 2017).

Quanto ao tema Design Thinking, foi encontrada uma grande quantidade de trabalhos no mesmo período da primeira busca, porém quando foram combinados os descritores "Smart homes", "Smart houses" e "Design Thinking" o resultado apontou para uma oportunidade de pesquisa e futura publicação internacional. Não foram identificados trabalhos que exploraram o potencial de aplicação da abordagem de Design Thinking em projetos de casas inteligentes. 
Apresenta-se adiante na Figura 1.2 uma visão geral e esquemática dos resultados desta primeira fase, no formato de um mapa conceitual.

\subsection{2}

\section{Fase aplicada}

Na fase aplicada, caracterizou-se inicialmente o Projeto NO.V.A., seus objetivos e escopo. Na sequência, realizou-se na fase de imersão, uma etapa de pesquisa exploratória, seguida de reuniões de alinhamento, nas quais o pesquisador junto com a equipe do Projeto e instituições parceiras aproximou-se do contexto do problema de conceber uma casa inteligente segundo os objetivos do Projeto.

A segunda etapa da fase de imersão visou identificar as necessidades e oportunidades que iriam nortear a geração de soluções na fase seguinte da aplicação do modelo, denominada ideação.

$\mathrm{Na}$ etapa de imersão em profundidade, foi criada uma plataforma de colaboração digital (crowdsourcing) para identificação das expectativas e necessidades de pessoas dos mais diversos segmentos da sociedade, em relação aos principais serviços oferecidos por uma casa inteligente. Ainda nessa etapa, em complementação ao processo de crowdsourcing, foram realizadas sessões generativas, como previsto na abordagem tradicional de Design Thinking. Participaram desses encontros, o pesquisador junto com a equipe do Projeto e representantes das instituições e empresas parceiras - Fundação Getúlio Vargas (FGV); Pontifícia Universidade Católica do Rio de Janeiro (PUC-Rio); Mutopo; Fabularte; Studio Arthur Casas; Maneco Quinderé e Associados; Enel Soluções; Osborne Construtora; GPE Prime; Noise; Orsini e Yapó Paisagismo; Benfeitora; e Etria.

Em seguida, na fase de análise e síntese, foram formados grupos focais por categoria de serviços da futura casa, empregando-se análise de conteúdo e diagramas de afinidades para classificação e agrupamento de ideias vindas do processo de crowdsourcing. 


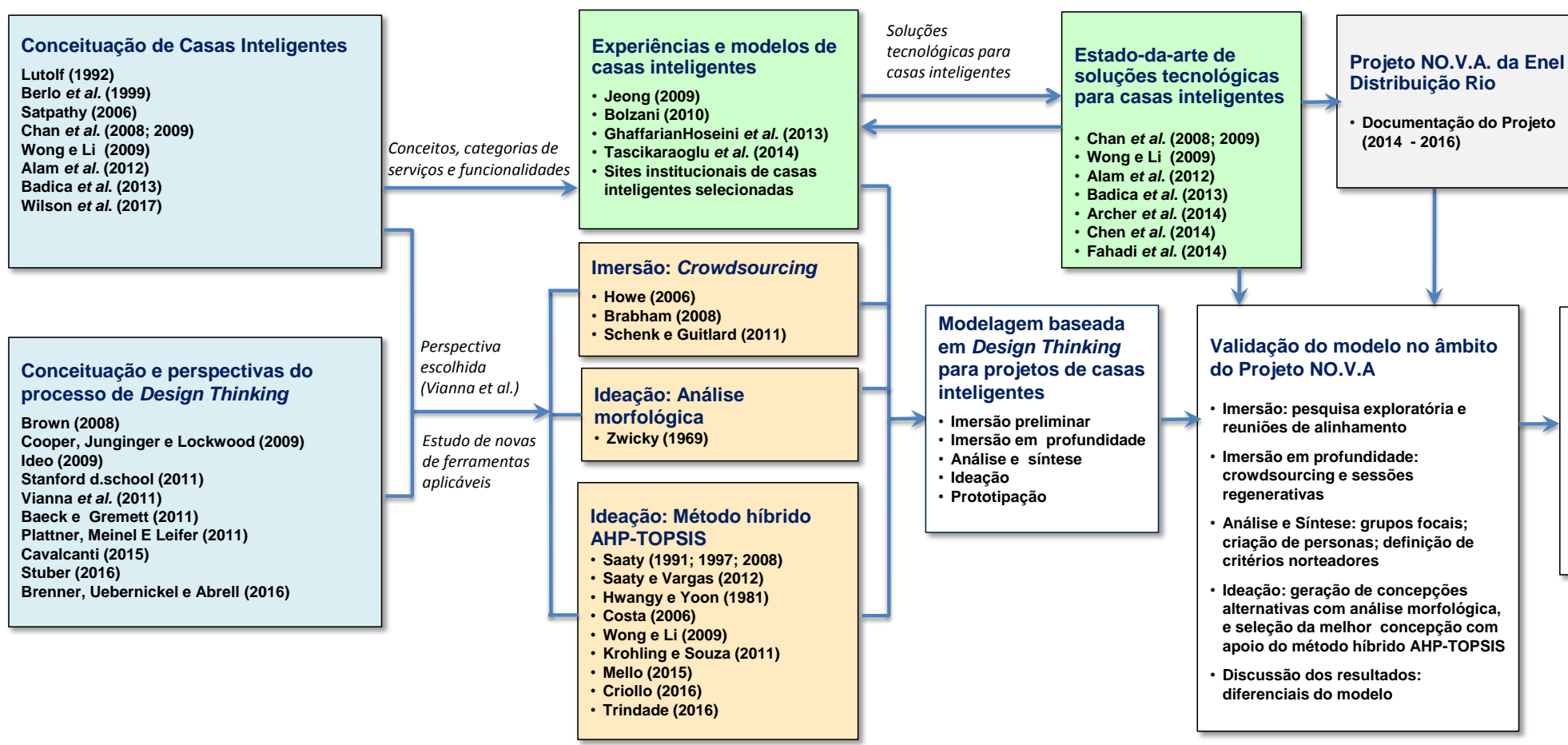

Projetos de casas inteligentes $e$ Design Thinking: concepções baseadas em soluções tecnológicas inovadoras

[Questão principal]

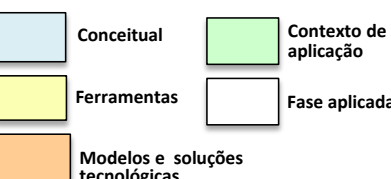

Figura 1.2 - Mapa conceitual da pesquisa

Fonte: Elaboração própria. 
Como resultado dos grupos focais, definiram-se padrões que auxiliariam na compreensão do problema e na futura geração de concepções integradas para o Projeto NO.V.A.

Ainda nesta fase, identificaram-se arquétipos de futuros moradores da casa inteligente (personas), revelando-se características significativas de um grupo mais abrangente. Com base nesses resultados parciais, foi possível definir os critérios norteadores para a seleção pretendida - a melhor concepção para o Projeto NO.V.A.

$\mathrm{Na}$ fase de ideação, geraram-se concepções alternativas com emprego da ferramenta de análise morfológica, concebida por Zwicky (1969). Para a seleção da melhor alternativa, empregou-se um método híbrido multicritério de apoio à decisão (AHP-TOPSIS).

\subsection{3}

\section{Fase conclusivo-propositiva}

Formularam-se as conclusões da pesquisa e um conjunto de recomendações à Enel Distribuição Rio e às instituições parceiras do Projeto NO.V.A., bem como aos interessados na aplicação de um modelo de geração e seleção de concepções de projetos de casas inteligentes, desenvolvido segundo uma abordagem metodológica mais empática - Design Thinking - que permite colocar as pessoas no centro do projeto e gerar alternativas que venham atender seus desejos, expectativas e necessidades, mas que ao mesmo tempo sejam tecnicamente possíveis de serem transformadas em realidade. Encaminharam-se nesta fase propostas de estudos futuros, como desdobramentos naturais da presente pesquisa.

\section{5}

\section{Estrutura da dissertação}

Esta dissertação encontra-se estruturada em seis capítulos, incluindo esta introdução.

No capítulo 2, apresenta-se o marco conceitual de casas inteligentes e identificam-se as principais categorias de serviços e funcionalidades por elas oferecidas, com base em revisão da literatura, contemplando o período de 1997 a 2017. Em seguida, apresentam-se doze projetos de casas inteligentes localizadas nos Estados Unidos, Japão, Turquia e Brasil, que funcionam como 'laboratórios vivos', a exemplo do planejado para o Projeto NO.V.A no Brasil. Busca-se demonstrar o amplo espectro de oportunidades da adoção de soluções tecnológicas inovadoras, selecionadas em 
função do perfil e necessidades dos futuros moradores e do estado-da-arte dos sistemas inteligentes e tecnologias sustentáveis.

No capítulo 3, abordam-se as principais soluções tecnológicas para o funcionamento e integração de casas inteligentes, como resultado da pesquisa bibliográfica e documental sobre este subtema, cobrindo o período de 1997 a 2017. Buscou-se classificar as soluções tecnológicas de acordo com as seguintes categorias de serviços: (i) conforto e lazer; (ii) automação residencial; (iii) acesso remoto; (iv) segurança de rede e de informação; (v) cuidados com a saúde (healthcare); (vi) uso eficiente de recursos naturais; (vii) gerenciamento de energia; e (viii) segurança patrimonial.

No capítulo 4, propõe-se um modelo conceitual para gerar e selecionar concepções de casas inteligentes baseadas em soluções tecnológicas inovadoras, adotando-se a abordagem de Design Thinking e integrando-se diversas ferramentas de gestão da inovação, incluindo um processo de crowdsourcing e a combinação de dois métodos multicritério de apoio à decisão.

Visando demonstrar a aplicabilidade do modelo conceitual apresentado no capítulo 4, o quinto capítulo apresenta e discute os resultados do estudo empírico desenvolvido no âmbito do Projeto NO.V.A, liderado pela Enel Distribuidora Rio, que atua em 66 municípios do estado do Rio de Janeiro.

Finalmente, no capítulo formulam-se as conclusões da pesquisa e endereçam-se propostas para estudos futuros, como desdobramentos naturais e aprofundamento de aspectos relevantes que emergiram da presente pesquisa. 


\section{2 \\ Casas inteligentes: objetivos, serviços e funcionalidades}

Inicialmente, conceituam-se casas inteligentes e identificam-se as principais categorias de serviços e funcionalidades por elas oferecidas, com base em revisão da literatura, contemplando o período de 2000 a 2017 . Na sequência, apresentamse doze projetos de casas inteligentes localizadas nos Estados Unidos, Japão, Turquia e Brasil, que funcionam como 'laboratórios vivos', a exemplo do planejado para o Projeto NO.V.A no Brasil. Visa-se evidenciar o largo espectro de oportunidades da adoção de soluções tecnológicas inovadoras, selecionadas em função do perfil e necessidades dos futuros moradores e do estado-da-arte dos sistemas inteligentes e tecnologias sustentáveis.

\section{1 \\ Conceito e caracterização}

As casas inteligentes oferecem uma melhor qualidade de vida pelo emprego de controles automáticos de aplicações e serviços de apoio e otimizam o conforto do residente, usando o conhecimento do contexto vivido e restrições pré-definidas, com base nas condições do ambiente doméstico. Permitem que seus residentes controlem aparelhos domésticos e dispositivos remotamente e executem tarefas antes de chegar em casa.

Os sistemas inteligentes que monitoram casas inteligentes podem otimizar o gerenciamento da energia elétrica e aprimorar os mecanismos tradicionais de segurança e serviços.

Em 2050, aproximadamente $20 \%$ da população mundial terá pelo menos 60 anos de idade e esta faixa etária enfrentará problemas para viver de forma independente e é mais suscetível a sofrer de doenças crônicas de longo prazo. Segundo a Organização Mundial da Saúde, 650 milhões de pessoas vivem com deficiências em todo o mundo, sendo que as causas mais comuns de incapacidade incluem doenças crônicas, como diabetes, doenças cardiovasculares e câncer, e lesões causadas por acidentes de trânsito rodoviário, conflitos, quedas, minas 
terrestres, deficiências mentais, defeitos de nascimento, desnutrição e HIV/AIDS e outras doenças transmissíveis. Não é possível ou lógico apoiar todos esses pacientes em centros médicos ou casas de repouso por um período de tempo incerto. A solução é acomodar serviços de saúde e tecnologias assistivas no ambiente doméstico dos pacientes (Alam et al., 2012).

As casas precisam ter tecnologias que observem os moradores, forneçam serviços de forma proativa e proporcionem uma vida autônoma às pessoas com deficiência e aos idosos, além de aliviar a carga de trabalho de cuidadores familiares. Uma das principais características de uma casa inteligente é monitorar as atividades, proporcionar segurança e detectar mudanças nas rotinas diárias de seus moradores. Com a disponibilidade de sensores, sinais de radiofrequência e processadores embutidos, casas inteligentes atuais são equipadas com uma grande quantidade de sensores em rede colaborativa que processem e façam deduções a partir dos dados adquiridos sobre a casa, bem como as atividades e comportamentos de seus moradores (Ding, 2011).

Diversas são as definições e termos identificados na revisão da literatura sobre casas inteligentes. Uma das primeiras definições de casas inteligentes foi dada por Lutolf (1992). Segundo este autor, "o conceito de casa inteligente advém da integração de diferentes serviços dentro de uma casa, usando um sistema comum de comunicação, o qual garante uma operação econômica, segura e confortável da casa, além de incluir um alto grau de funcionalidade e flexibilidade".

Esta definição é influenciada pela terminologia de automação residencial e não menciona nada sobre inteligência doméstica, que foi definida mais tarde por Berlo et al. (1999). Na definição desses autores, “casa inteligente é um ambiente residencial, que inclui tecnologias para permitir que os dispositivos e sistemas sejam controlados automaticamente".

De acordo com Winkler (2002), uma "casa inteligente pode ser definida como uma casa que é capaz de mudar proativamente seu ambiente para fornecer serviços que promovam um estilo de vida independente para moradores idosos", o que é um limitador.

Outra definição publicada pela Intertek, empresa envolvida com o Projeto do Departamento de Comércio e Indústria do Reino Unido (Intertek, 2003), refere-se à casa inteligente como "uma habitação, que incorpora uma rede de comunicações, capaz de conectar aparelhos elétricos-chave e serviços, permitindo seu controle, 
monitoramento e acesso remoto". Esta definição omite a inteligência doméstica e coloca mais ênfase no acesso remoto.

Anos depois, Satpathy (2006) propôs um conceito mais apropriado para casas inteligentes. De acordo com este autor, "uma casa inteligente é aquela capaz de ajudar os habitantes a viver de forma independente e confortável com a ajuda da tecnologia. Em uma casa inteligente, todos os dispositivos mecânicos e digitais são interligados para formar uma rede, que permita a comunicação entre os diversos dispositivos e o usuário, criando um espaço interativo". No entanto, Satpathy (2006) não inclui o acesso remoto em sua definição.

Considerando as tendências atuais da pesquisa neste tema, Alam et al. (2012) define casa inteligente como uma aplicação de computação ubíqua, que seja capaz de fornecer aos usuários, serviços sob a forma de inteligência do ambiente, controle remoto da casa ou automação residencial.

Em síntese, as principais características de uma casa inteligente são a capacidade de integrar sistemas, a facilidade de utilização pelo usuário, a facilidade de reprogramação, a autocorreção, a memória, a noção temporal e a possibilidade de acesso remoto. Essa infraestrutura tecnológica permite aos moradores usufruírem de um conjunto de serviços e funcionalidades, tais como conforto; segurança; gestão de energia; automação de tarefas domésticas; entretenimento; mobilidade interna e assistência; e sustentabilidade ambiental.

A construção de casas inteligentes nas áreas urbanas sugere a necessidade de um ambiente construído adaptável inteligente que é integralmente equipada com as novas tecnologias interligadas, considerando proteção do meio ambiente e questões sociais. O objetivo de testar a casa inteligente, considerando-se a proteção ao meio ambiente e as questões sociais, traz consigo o argumento de que a conquista do bem-estar dos usuários requer uma harmonização dos valores ambientais e socioculturais nos espaços funcionais de uma casa, junto à integração da automatização das tecnologias (GhaffarianHoseini et al., 2013).

\subsection{1 \\ Categorias de serviços}

Conforme descrito anteriormente, as casas inteligentes oferecem facilidades e funcionalidades que as tornam um transformador positivo na qualidade de vida 
dos indivíduos. Essas facilidades denominadas soluções tecnológicas foram classificadas em categorias de serviços.

O Quadro 2.1 apresenta as categorias de serviços e respectivos conceitos identificadas a partir da análise de conteúdo dos artigos de revisão da literatura sobre casas inteligentes, publicados por Alam et al. (2012); Badica et al. (2013); Chan et al. (2008; 2009); Wong e Li (2009); e Wilson et al. (2015).

Quadro 2.1 - Síntese das principais categorias de serviços

\begin{tabular}{|c|c|c|}
\hline Categoria & Autores & Conceito \\
\hline Conforto e lazer & $\begin{array}{l}\text { Alam et al. (2012) } \\
\text { Badica et al. (2013) } \\
\text { Wong e Li (2009) } \\
\text { Wilson et al. (2015) }\end{array}$ & $\begin{array}{l}\text { Controle de ambientes e automação } \\
\text { de equipamentos, programação de } \\
\text { acionamento à distância; liberação de } \\
\text { tempo para lazer em função da } \\
\text { automação dos serviços domésticos. }\end{array}$ \\
\hline Automação residencial & $\begin{array}{l}\text { Alam et al., (2012) } \\
\text { Chan et al. (2008; 2009) } \\
\text { Wilson et al. (2015) }\end{array}$ & $\begin{array}{l}\text { Automação de equipamentos e } \\
\text { sistemas por meio de plataforma e uso } \\
\text { de sistema bluetooth, wifi e sensores. }\end{array}$ \\
\hline Acesso remoto & $\begin{array}{l}\text { Alam et al. (2012) } \\
\text { Chan et al. (2008; 2009). }\end{array}$ & $\begin{array}{l}\text { Monitoramento de atividades, controle } \\
\text { de equipamentos e gerenciamento do } \\
\text { tempo. }\end{array}$ \\
\hline $\begin{array}{l}\text { Segurança de rede e de } \\
\text { informação }\end{array}$ & Alam et al., (2012) & $\begin{array}{l}\text { Autenticação do usuário; Sistema de } \\
\text { proteção anti-vírus; Dados } \\
\text { criptografados. }\end{array}$ \\
\hline $\begin{array}{l}\text { Cuidados com a saúde } \\
\text { (healthcare) }\end{array}$ & $\begin{array}{l}\text { Alam et al. }(2012) \\
\text { Chan et al. }(2008 ; 2009)\end{array}$ & $\begin{array}{l}\text { Monitoramento de pacientes e } \\
\text { relatórios de acompanhamento para } \\
\text { clínicos e cuidadores }\end{array}$ \\
\hline $\begin{array}{l}\text { Uso eficiente de recursos } \\
\text { naturais }\end{array}$ & Wong e Li (2009) & $\begin{array}{l}\text { Sistema hidráulico e de drenagem; } \\
\text { gerenciamento e tratamento de } \\
\text { resíduos; captação e tratamento de } \\
\text { água. }\end{array}$ \\
\hline $\begin{array}{l}\text { Gerenciamento de } \\
\text { energia }\end{array}$ & $\begin{array}{l}\text { Alam et al. (2012) } \\
\text { Badica et al. (2013) } \\
\text { Wong e Li (2009) }\end{array}$ & 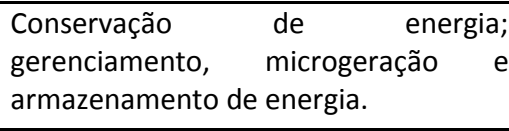 \\
\hline Segurança patrimonial & $\begin{array}{l}\text { Alam et al. (2012) } \\
\text { Badica et al. (2013) } \\
\text { Wong e Li (2009) }\end{array}$ & $\begin{array}{l}\text { Vigilância por vídeo, monitoramento } \\
\text { remoto, alarme e respostas a situações } \\
\text { de emergência. }\end{array}$ \\
\hline
\end{tabular}

Fontes: Elaboração própria baseada em Alam et al. (2012); Badica et al. (2013); Chan et al. (2008; 2009); e Wong e Li (2009); Wilson et al. (2015).

A seguir, discutem as categorias de serviços a serem consideradas em projetos de casas inteligentes.

\section{Conforto e lazer}

Esta categoria refere-se às características de residências confortáveis, flexíveis e eficientes energeticamente tem sido uma aspiração de moradores e proprietários. Para alcançar esse objetivo, diversas soluções e tecnologias têm sido pensadas e desenvolvidas nas últimas duas décadas, visando melhorar o desempenho dessas residências para satisfazer uma variedade de necessidades 
humanas e colaborar com a sustentabilidade ambiental. Muitos produtos foram desenvolvidos neste sentido para prover ao usuário maior conforto e formas de gerenciar e programar os sistemas das casas inteligentes (Alam et al., 2012; Badica et al., 2013 ; Wong e Li, 2009).

Uma classe de funções dos ambientes domésticos inteligentes aborda o conforto e o lazer do usuário. Exemplos são os controles de ambientes referentes a determinadas funções como iluminação, som, refrigeração, ligar e desligar dispositivos estando dentro ou fora da casa, dentre outros. Além disso, as interfaces de uso de equipamentos têm avançado, proporcionando seu acionamento por voz ou gestos, por exemplo, fazendo com que haja uma ampliação das funcionalidades e o aumento do nível de automatização das atividades de rotina.

Um dos principais objetivos dos projetos de casas inteligentes é facilitar a vida diária para aumentar o conforto de seus usuários. Isto é conseguido de duas maneiras: (i) automação relacionada à identificação da atividade humana nos ambientes; e (ii) gestão doméstica remota a partir de locais distantes.

Vale ressaltar que a incompatibilidade de sistemas ainda é um desafio importante a ser superado, pois a existência de um protocolo único e uma plataforma universal daria mais possibilidades de desenvolvimento de produtos e soluções para o usuário.

\section{Automação residencial}

Uma importante característica das casas inteligentes é a automação dos equipamentos e sistemas para que o conforto e o entretenimento do usuário seja o mais pleno possível. Exemplos típicos são o controle de iluminação, som, ar condicionado e demais equipamentos cujas funções possam ser comandadas via aplicativo ou por comando de voz por exemplo. No caso da automação residencial é muito importante que se tenha uma plataforma que converse com todos esses equipamentos via bluetooth e/ou wifi. O uso de sensores de reconhecimento também é muito comum nas interfaces de uso, aumentando o nível de automação das atividades de rotina (Alam et al., 2012; Wong e Li, 2009).

\section{Acesso remoto}

As casas inteligentes contribuem para o acesso e comando remoto de aparelhos e sistemas. Um importante estudo que vem evoluindo é o apoio dos idosos, pessoas com doenças crónicas e pessoas com deficiência que vivem 
sozinhas em casa. Este novo modo de avaliação da saúde pode melhorar a qualidade e a variedade das informações transmitidas ao clínico e aos cuidadores. Medidas de sinais fisiológicos e padrões comportamentais podem ser traduzidas precisamente, e podem ser combinadas com sistemas de alarme como uma plataforma técnica para iniciar ações apropriadas, como por exemplo o monitoramento de queda, e ações de rotina com preparação de café e ingestão de comprimidos. $\mathrm{O}$ monitoramento de doenças crônicas a distância é uma abordagem promissora para o paciente, pois fornece dados precisos e confiáveis, capacita os pacientes, influencia suas atitudes e comportamentos e, potencialmente, melhora sua condição médica.

Além disso, o acesso remoto a dispositivos, eletrodomésticos e câmeras de segurança, por exemplo, permitem programar estes equipamentos a distância, gerenciando o tempo do indivíduo, otimizando recursos e trazendo praticidade e conforto para o mesmo (Alam et al., 2012; Chan et al., 2008; 2009).

\section{Segurança de rede e de informação}

Casas inteligentes são vulneráveis a ameaças de segurança onde a maioria dos problemas estão relacionados com esquemas de uso e de dispositivo de autenticação fracos. (Alam et al., 2012; Badica et al., 2013 ; Wong e Li, 2009).

Outro ponto importante é a privacidade e a segurança de dados quando se tem equipamentos gerenciáveis à distância e sistemas tecnológicos. A segurança de rede de computadores para permitir que o usuário faça operações remotas sem que sua rede seja invadida e seus dados roubados. Para isso, são usados dados criptografados, sistemas de proteção antivírus, dentre outros.

\section{Cuidados com a saúde (Healthcare)}

Casas inteligentes podem fornecer instalações de saúde para os doentes, os idosos e pessoas saudáveis. Os serviços de saúde podem ser implementados como soluções autônomas para gerar relatórios de saúde. Outra maneira eficaz é a utilização de prestadores de serviços de saúde remotos para suporte de emergência.

As casas inteligentes e a saúde tornaram-se questões de pesquisa comuns nas últimas décadas, mas não há evidência científica suficiente para apoiar o uso da casa inteligente e da eficácia deste trabalho à distância. Os estudos e equipamentos disponíveis ainda são muito imprecisos e não se tem algo totalmente confiável para ser posto em prática, principalmente quando pensamos em tecnologias nãoinvasivas. 
Recentes revisões de literatura e trabalhos de pesquisa relataram que a idade, o estado de saúde, o estado racial/étnico, a educação e o gênero estão geralmente associados à satisfação do paciente com os cuidados de saúde. Os custos crescentes de prestação de serviços de saúde a uma população em envelhecimento vão mudar a entrega de hospitais e cuidados residenciais para as redes privadas de assistência saúde e estas podem evoluir para o acompanhamento e medição a distância (Alam et al., 2012; Badica et al., 2013 ; Wong e Li, 2009).

\section{Uso eficiente de recursos naturais}

A elevação dos níveis de produção, comércio e consumo de materiais para responder à crescente demanda por bens de consumo destaca-se como uma das maiores ameaças ambientais de nosso tempo. O crescimento econômico e o atendimento às necessidades básicas da população mundial não podem ser sustentados pelos atuais padrões de produção e consumo. Ao mesmo tempo, uma grande parcela da população mundial ainda está ainda consumindo muito pouco para as suas necessidades básicas. Mudar os padrões de produção e consumo do atual sistema econômico de extração, produção, consumo e desperdício para uma economia verde inclusiva, que imite os processos naturais onde não existe o conceito de "sobra". A promoção do uso eficiente de recursos naturais e a transição para padrões de produção e consumo sustentáveis visam garantir a manutenção da qualidade de vida para todos.

Nessa perspectiva, as casas inteligentes podem contribuir para mitigar os efeitos indesejados dos atuais padrões de produção e consumo, ao introduzir sistemas de gerenciamento de resíduos, de captação e tratamento de água, para citar alguns exemplos (Wong e Li, 2009).

\section{Gerenciamento de energia}

A redução do consumo de energia tornou-se muito importante no contex to do desenvolvimento tecnológico da sociedade moderna com um impacto principal no desenvolvimento futuro da humanidade. Por um lado, o progresso tecnológico requer o uso de mais energia, enquanto que, por outro lado, a energia tornou-se um recurso limitado. A rede elétrica está evoluindo para uma nova rede mais inteligente conhecida como Smart Grid, que melhora o sistema de entrega de eletricidade tradicional com os avanços nas tecnologias de informação e comunicação para 
equilibrar a demanda e oferta de consumo de eletricidade, bem como energias renováveis (Alam et al., 2012; Badica et al., 2013; Wong e Li, 2009).

Os estudos de casas inteligentes visam o gerenciamento da energia. É possível controlar os gastos e gerenciar a quantidade de energia disponível. Além disso, também é possível, por meio de sistemas fotovoltaicos e banco de baterias, gerar energia e armazená-la para usar em momentos em que o custo é mais elevado. Ainda é viável devolver a energia excedente à rede e receber créditos por isso.

\section{Segurança patrimonial}

A segurança refere-se à detecção de situações anómalas dentro dos Ambientes Domésticos Inteligentes, como, por exemplo, incêndios, inundações, quedas de deficientes ou idosos e à detecção de comportamentos criminosos, como por exemplo, assaltos e acesso não autorizado.

Os sistemas de segurança podem abranger desde um alarme de intrusão simples, passando por alarmes de incêndio, de fuga de gás, de inundação, até grandes sistemas monitorados por computadores e circuito interno de TV.

Para a detecção, sinalização e respostas a tais situações de violação de segurança, os ambientes estão equipados com subsistemas para vigilância por vídeo, monitoramento remoto, alarme e resposta de emergência.

As seguranças patrimoniais e pessoais devem ser consideradas como essenciais e importantes na concepção dos projetos de casas inteligentes. Entre os serviços oferecidos para tal, destacam-se os seguintes:

- Controle de acesso;

- Controle de estacionamento de veículos;

- Sistema interligado de comunicação.

\subsection{2}

\section{Funcionalidades associadas aos serviços}

Cada categoria de serviço apresentada no Quadro 2.1 compreende um ou mais serviços associados, que por sua vez são operacionalizados por meio das respectivas funcionalidades.

O Quadro 2.2 sintetiza os serviços e funcionalidades mais importantes na concepção e operação de casas inteligentes, conforme os trabalhos de revisão de Alam et al. (2012); Badica et al. (2013); Chan et al. (2008 ; 2009); Wong e Li (2009); e Wilson et al. (2015; 2017). 
Quadro 2.2 - Principais funcionalidades associadas às categorias de serviços

\begin{tabular}{|c|c|c|}
\hline Categoria & Serviços & Funcionalidades \\
\hline Conforto e lazer & $\begin{array}{l}\text { Prover conforto e bem- } \\
\text { estar pessoal; oferecer } \\
\text { entretenimento }\end{array}$ & $\begin{array}{l}\text { Identificação de atividades e automação } \\
\text { de eventos; controle de luz, temperatura } \\
\text { e acústica (Alam et al, 2012; Badica et } \\
\text { al., 2013; Chan et al., 2009; Wilson et al., } \\
\text { 2015; 2017; Wong e Li., 2009). }\end{array}$ \\
\hline Automação residencial & $\begin{array}{l}\text { Controle de equipamentos } \\
\text { e automação residencial }\end{array}$ & $\begin{array}{l}\text { Telecomando de aparelhos, controle de } \\
\text { voz (Alam et al., 2013; Chan et al., 2009). }\end{array}$ \\
\hline Acesso remoto & $\begin{array}{l}\text { Acesso remoto, } \\
\text { monitoramento e controle }\end{array}$ & $\begin{array}{l}\text { Monitoramento a distância e controle } \\
\text { dos dispositivos locais (Alam et al., 2013; } \\
\text { Wilson et al., 2015; 2017). }\end{array}$ \\
\hline $\begin{array}{l}\text { Segurança de rede e de } \\
\text { informação }\end{array}$ & $\begin{array}{l}\text { Proteção do usuário por } \\
\text { meio de antivírus e dados } \\
\text { criptografados. }\end{array}$ & $\begin{array}{l}\text { Autenticação de usuários e de } \\
\text { dispositivos (Alam et al., 2013; Wilson et } \\
\text { al., 2017). }\end{array}$ \\
\hline $\begin{array}{l}\text { Cuidados com saúde } \\
\text { (Healthcare) }\end{array}$ & $\begin{array}{l}\text { Prover conforto ao idoso, } \\
\text { monitoramento de saúde, } \\
\text { bem-estar, telemedicina, } \\
\text { suporte à distância }\end{array}$ & $\begin{array}{l}\text { Monitoramento de distúrbio respiratório } \\
\text { e do sono; medição de taxas corporais; } \\
\text { apoio às atividades dos idosos e } \\
\text { deficientes (Alam et al.,2013; Badica et } \\
\text { al., 2013; Chan et al.,2009; (Wilson et al., } \\
\text { 2017). }\end{array}$ \\
\hline $\begin{array}{l}\text { Uso eficiente de recursos } \\
\text { naturais }\end{array}$ & $\begin{array}{l}\text { Gerenciar e tratar os } \\
\text { recursos naturais }\end{array}$ & $\begin{array}{l}\text { Sistema hidráulico e de drenagem; } \\
\text { gerenciamento e tratamento de } \\
\text { resíduos; captação e tratamento de } \\
\text { água; produção de alimentos em hortas } \\
\text { (Wong e Li.,2009). }\end{array}$ \\
\hline Gerenciamento de energia & $\begin{array}{l}\text { Uso de sensores e atuares, } \\
\text { microgeração e } \\
\text { armazenamento de energia }\end{array}$ & $\begin{array}{l}\text { Conservação de energia e integração } \\
\text { Smart Grid (Badica et al., 2013). } \\
\text { Mapeamento do uso da energia (Wilson } \\
\text { et al., 2015; 2017); gerenciamento da } \\
\text { eficiência energética (Wong e Li., 2009). }\end{array}$ \\
\hline Segurança patrimonial & $\begin{array}{l}\text { Monitoramento e detecção } \\
\text { de situações anormais de } \\
\text { comportamento. }\end{array}$ & $\begin{array}{l}\text { Monitoramento por câmeras e detecção } \\
\text { de situações de risco (Badica et al., } \\
\text { 2013). }\end{array}$ \\
\hline
\end{tabular}

Fonte: Elaboração própria baseada em Alam et al. (2012); Badica et al. (2013); Chan et al. (2008; 2009); Wong e Li (2009); e Wilson et al. (2015; 2017).

\section{2}

\section{Revisão dos modelos de casas inteligentes}

Existem muitos modelos de casas inteligentes no mundo, com propósitos e categorias de serviços e funcionalidades distintas. Com base nas revisões de Jeong (2009); Bolzani (2010); GhaffarianHoseini et al. (2013); Tascikaraoglu et al. (2014) e em consulta direta aos sites institucionais das casas identificadas nesses trabalhos, selecionaram doze delas localizadas nos Estados Unidos, Japão, Turquia e Brasil. A escolha baseou-se no fato de que essas casas são laboratórios vivos, a exemplo do planejado para o Projeto NO.V.A no Brasil. Visa-se nesta seção evidenciar o largo espectro de oportunidades do emprego de soluções tecnológicas inovadoras, selecionadas em função dos objetivos do projeto de uma casa 
inteligente, definidos de acordo com o perfil e necessidades de seus futuros moradores.

Os casos selecionados foram: (i) Gator Tech Smart House (EUA); (ii) Matilda Smart House (EUA); (iii) Duke University Smart House (EUA); (iv) Drexel Smart House EUA); (v) MIT Smart House (EUA); (vi) Aware Home (EUA); (vii) The CASAS Smart Home (EUA); (viii) Smart Home Lab da Iowa State University (EUA); (ix) Toyota Dream House Papi (Japão); (x) NICT Ubiquitous Home (Japão); (xi) Smart Home System (Turquia); (xii) Escritório Verde da Universidade Federal do Paraná (Brasil).

\subsection{1}

\section{Gator Tech Smart House (EUA)}

A Gator Tech Smart House (GTSH) foi projetada e desenvolvida na Universidade da Flórida para fornecer uma plataforma para a experimentação e análise da aplicação de tecnologias inteligentes para uma casa responsiva, voltada para o bem-estar do indivíduo e para assistência principalmente a pessoas idosas e portadores de necessidades especiais (Figura 2.1). Este ambiente é baseado em um abrangente sistema de computação e integra sensores e atuadores em computadores inteligentes (Helal e Chen, 2009; GhaffarianHoseini et al. (2013).

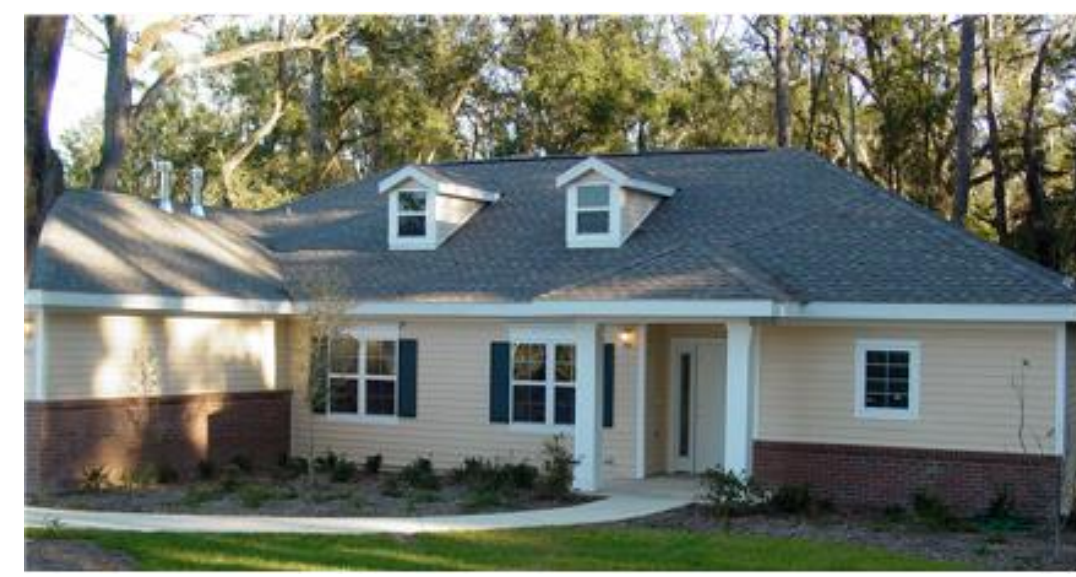

Figura 2.1 - Vista frontal da Gator Tech Smart House (GTSH) Fonte: GhaffarianHoseini et al. (2013).

A GTSH foi projetada para uma única família e destinou-se a testar, analisar, verificar e validar a viabilidade e a eficácia dos aparelhos integrados inteligentes para a criação de espaços inteligentes responsivos. A Figura 2.2 apresenta as tecnologias inteligentes instaladas na GTSH. 


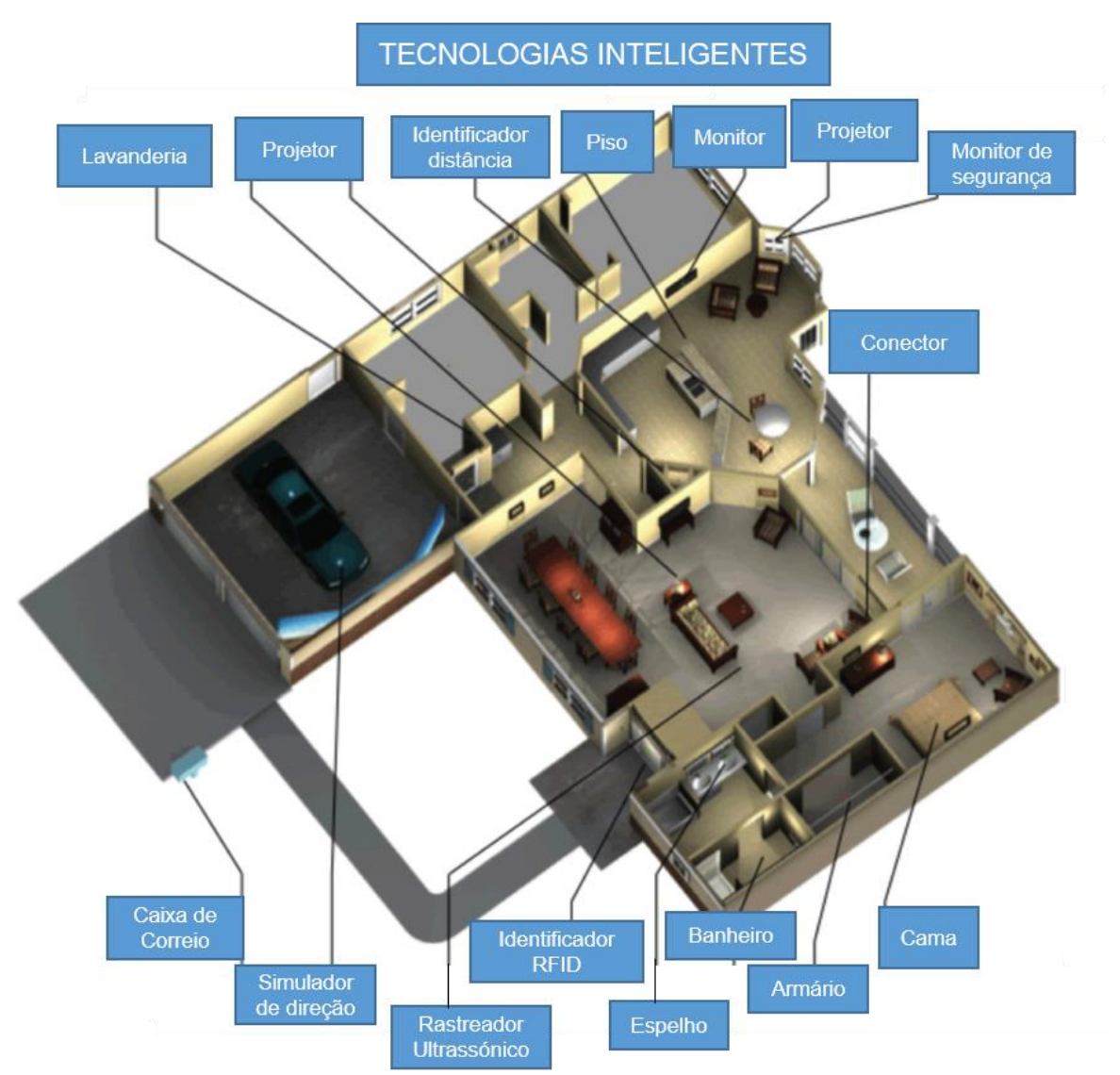

Figura 2.2 - Tecnologias inteligentes da Gator Tech Smart House (GTSH) Fonte: GhaffarianHoseini et al. (2013).

Existem vários sistemas tecnológicos inteligentes no GTSH, incluindo lavandaria inteligente, projetor, persianas, monitor de segurança em casa, cama, armário, banheiro, espelho, piso, identificador na porta da frente, rastreamento de localização, simulador de direção e caixa de correio, todos automatizados.

A casa possui janelas automatizadas que podem ser ajustadas automaticamente para o nível preferido de iluminação, privacidade e fluxo de ar. A cama inteligente pode detectar os padrões de sono dos usuários e ajustar-se automaticamente, além de gravar e monitorar as noites de sono. A lavanderia inteligente combinada com um armário inteligente pode notificar os usuários do tempo para o uso de roupa enquanto um armário inteligente pode categorizar as roupas e propor a melhor alternativa de vestir com base na monitorização do clima, temperatura e outros parâmetros relacionados. Da mesma forma, um espelho inteligente localizado no quarto principal pode lembrar o usuário de mensagens importantes ou notificar o usuário sobre aspectos de saúde. No banheiro inteligente, com descarga, sensor de papel higiênico e chuveiro inteligentes, pode-se determinar e medir a quantidade e temperatura da água, além de ajustar automaticamente o 
dispensador de sabão para monitorar a limpeza do usuário. Monitores inteligentes em todos os espaços integrados da casa podem ser utilizados para entretenimento, informação e mídia. O piso inteligente controla o movimento e localização dos ocupantes de casas e até poderia relatar a situação de emergência para os casos de quedas de idosos. Além disso, através da utilização de uma porta da frente inteligente, que funciona pelo sistema de RFID (identificação por radiofrequência), o usuário pode observar os visitantes e comunicar-se com eles (GhaffarianHoseini et al., 2013).

\section{2 .2}

\section{Matilda Smart House (EUA)}

A Matilda Smart House foi desenvolvida na Universidade da Flórida como um ambiente experimental para pesquisa e implementações no campo de ambientes inteligentes (Figura 2.3).

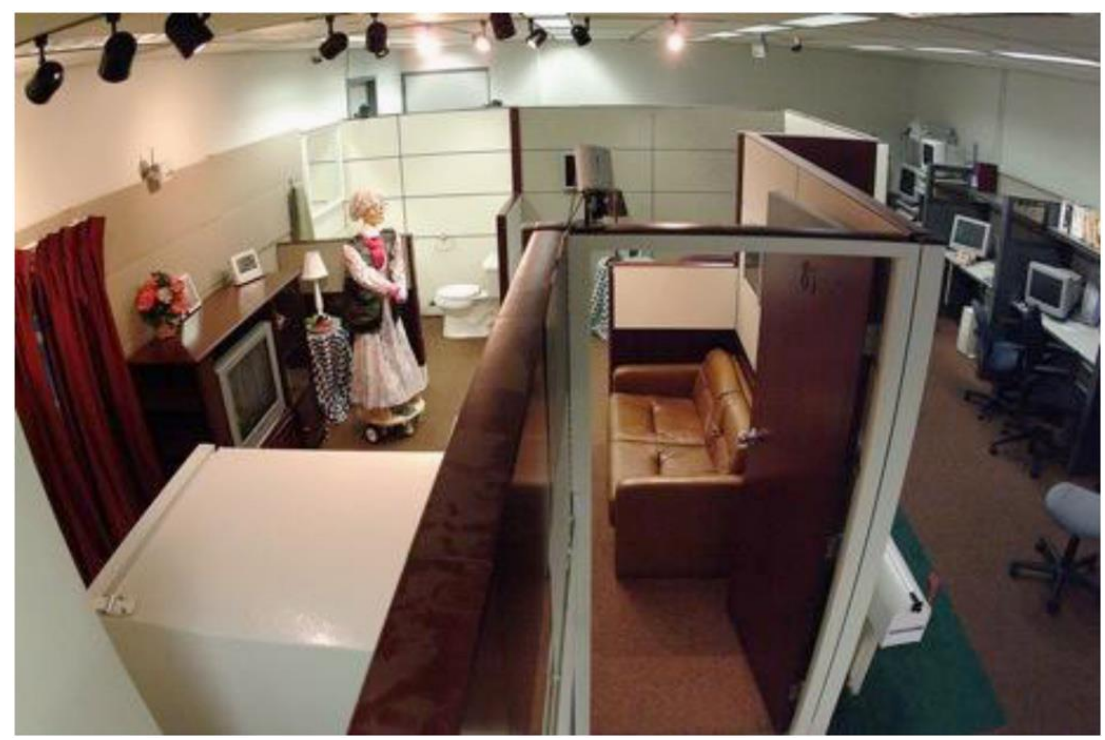

Figura 2.3 - interior da Matilda Smart House

Fonte: GhaffarianHoseini et al. (2013).

A Matilda Smart House é um laboratório experimental que abrange os principais espaços funcionais de uma casa, incluindo cozinha, sala, quarto e banheiro. Esta casa única é dedicada a novas ideias e conceitos inovadores com vista à criação de ambiente de vida inteligente. Concentrando-se nos tipos de tecnologias e aparelhos integrados, o foco principal deste projeto é a automação das necessidades diárias dos usuários. Da mesma forma, a integração de valores 
tecnológicos inteligentes pode ser mais influente, aumentando a vida independente para os usuários.

\subsection{3}

\section{Duke University Smart House (EUA)}

A casa inteligente desenvolvida na Duke University é um laboratório experimental para demonstrar o futuro de projetos residenciais em desenvolvimento. Similar à casa GatorTech, a filosofia principal tem como a integração de valores tecnológicos inteligentes para valorizar a qualidade de vida. A teoria é de que uma casa inteligente não deve ser dedicada a pessoas idosas e usuários com deficiência somente. Este dormitório inteligente é utilizado de forma contínua para a educação e pesquisa baseando-se na integração da tecnologia. Todos os espaços da casa são integrados com dispositivos e aparelhos inteligentes. Há dois objetivos principais do Smartdorm da Duke, que merecem ser mencionados: a concentração na eficiência energética no estilo de vida cotidiana e a integração de valores tecnológicos sustentáveis inteligentes (Figura 2.4).

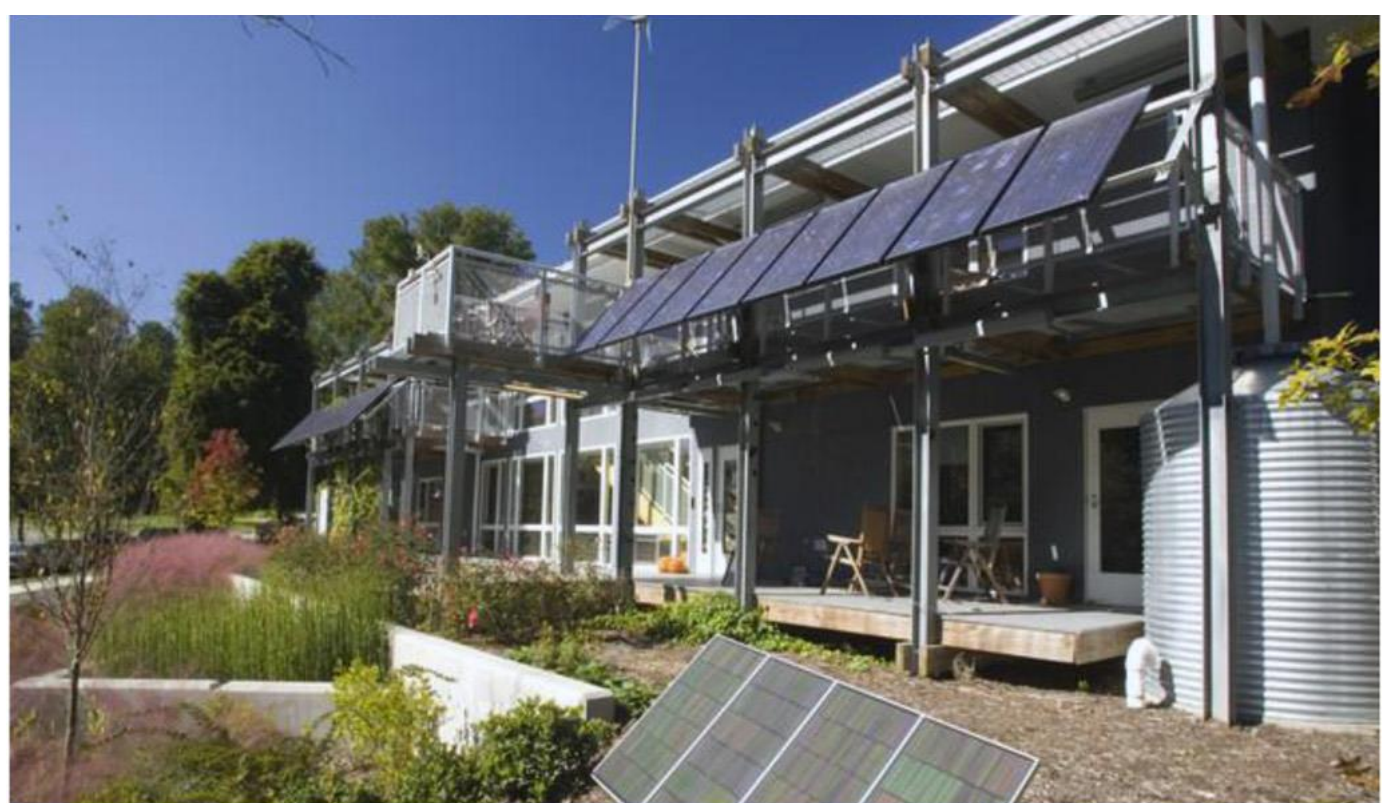

Figura 2.4 - Interiores da Duke University Smart House Fonte: GhaffarianHoseini et al. (2013). 


\subsection{4}

\section{Drexel Smart House (EUA)}

A Drexel Smart House tem o compromisso com a eficiência energética, redução da pegada de carbono e preservação do mundo natural e seu projeto foi apoiado por uma explicação de que cada processo de design deve ser documentado com explicações completas e placas para educar quem visita a casa (Figura 2.5).

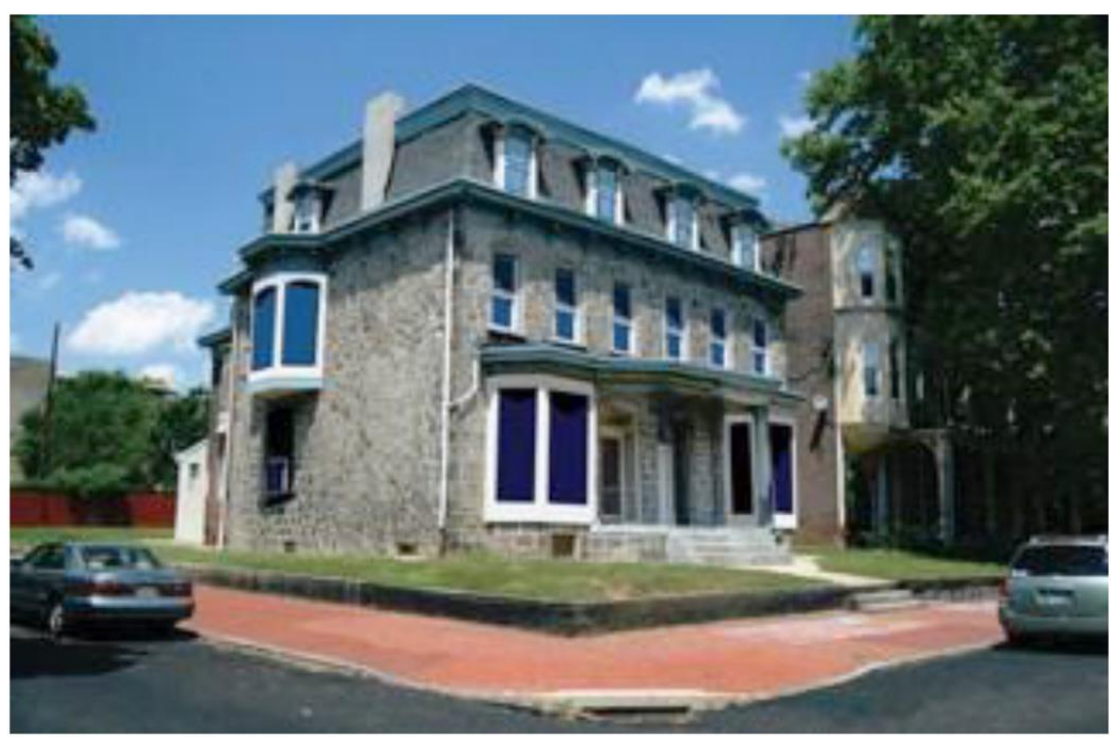

Figura 2.5 - Vista frontal da Drexel Smart House

Fonte: GhaffarianHoseini et al. (2013).

Cada elemento de construção refletiu um compromisso com a eficiência energética, reduzindo a pegada de carbono e preservando o mundo natural. Como resultado, o edifício custou muito menos para operar e manter do que um edifício convencional. O processo de projeto e construção bem documentado e o produto acabado destaca recursos inovadores para demonstrar todas as renovações existentes para a comunidade circundante. O projeto permite que a Drexel Smart House atenda sua finalidade, que é viver e experimentar tecnologias sustentáveis de ponta e servir como um modelo de demonstração para a comunidade.

Uma parceria com a Summalux LLC, a Baiada Center Incubator Company e a Drexel Smart House Spin-off foi realizada, trazendo desafios significativos para os designers que procuram maximizar a integração da luz natural. Além disso, os espaços interiores que incorporam quantidades significativas de luz do dia têm demonstrado aumentar a produtividade e a saúde dos ocupantes, principalmente regulando o ritmo biológico, prevenindo o distúrbio afetivo sazonal (SAD) e outras condições, como a disfunção no trabalho por turnos. A simulação de luz natural, 
possibilitada pela tecnologia LED de baixo consumo de energia, tem o potencial de reproduzir os benefícios da luz solar natural. Estes produtos de iluminação são especialmente adequados para espaços comerciais com exposição solar limitada, bem como ambientes residenciais e de varejo. Os avanços recentes em embalagens de LED, drivers de conversão de energia e tecnologia de gerenciamento térmico estão tornando os produtos de iluminação LED mais acessíveis para uso geral.

A instalação de revestimentos de telhado frescos foi patrocinada pela Agência de Proteção Ambiental dos EUA e também apoiada pela Dow Chemical Company, Divisão de Materiais Avançados e Potter's Industries. Este projeto teve por objetivo desenvolver uma formulação de revestimento de telhado fresco de baixo custo que melhora as propriedades de reflexão infravermelho de revestimentos brancos comercialmente disponíveis. Isto é conseguido através da incorporação de novos materiais com propriedades ópticas únicas e pigmentos e aditivos especialmente concebidos em um acrílico baseado em água aglutinante. Este projeto faz parte da iniciativa Smart House's Heat Island Mitigation.

Solar Gain é em parte responsável por até $56 \%$ da energia consumida por sistemas de refrigeração em edifícios residenciais. Além disso, a alta densidade de construção no ambiente urbano contribui para o efeito de calor urbano. De acordo com o EPA2, regiões que exibem o efeito de calor urbano pode ser tanto quanto 10 ${ }^{\circ} \mathrm{F}$ mais quente do que suas contrapartes rurais, e estas regiões podem ver tão alta quanto uma diferença de $22^{\circ} \mathrm{F}$ na temperatura entre o dia e a noite. Mitigar o efeito de calor urbano tem o potencial para reduzir a demanda de resfriamento, demanda de pico, e doenças relacionadas ao calor e fatalidades. Aplicando revestimentos de telhado frios ao exterior de um edifício, as cargas refrigerando podem ser reduzidas e as ilhas térmicas urbanas podem em parte ser mitigadas. Muitos revestimentos de telhado frios comercialmente disponíveis são formulações brancas da pintura baseadas no dióxido titanium, que embora sejam eficazes, ao espalhar os comprimentos de onda visíveis, eles exibem forte absorção na região infravermelha. Ao incorporar vazios controlados em um revestimento como meio de dispersão, a distribuição do tamanho do vazio pode ser otimizada para dispersão de radiação de banda larga. O objetivo deste projeto é projetar um revestimento utilizando microesferas ocas de vidro como um meio de controlar o diâmetro de vazios para conseguir um teto de ganho solar baixo. 
A Drexel Smart House oferece um modelo inovador de rede de sensores de monitoramento de energia baseada na Web para futuras casas urbanas.

Dentre os benefícios da adoção de soluções tecnológicas inovadoras na Drexel Smart House, destacam-se a redução de impactos ambientais, a oferta de um ambiente mais saudável, com muitos serviços apoiados por tecnologias que simplificam as tarefas diárias. A casa é um campo de testes permanente para soluções tecnológicas inovadoras até a adoção em larga escala, moldando novos mercados. O efeito global é uma demonstração da relação simbiótica entre tecnologia e sustentabilidade no lar inteligente.

\section{2 .5}

\section{MIT Smart House (EUA)}

No MIT Smart House, o destaque principal é para a mudança das tecnologias digitais que estão ocorrendo rapidamente e consequentemente, o estilo de vida individual. Sendo assim, o caminho das comunicações, as interações sociais e desafios tecnológicos também estão mudando. Este projeto interdisciplinar é desenvolvido e criado com base na integração de valores tecnológicos inteligentes e dispositivos inteligentes para ser responsivo, adaptativo, proporcionando simultaneamente espaços de vida automatizados e assistidos (Figura 2.6)

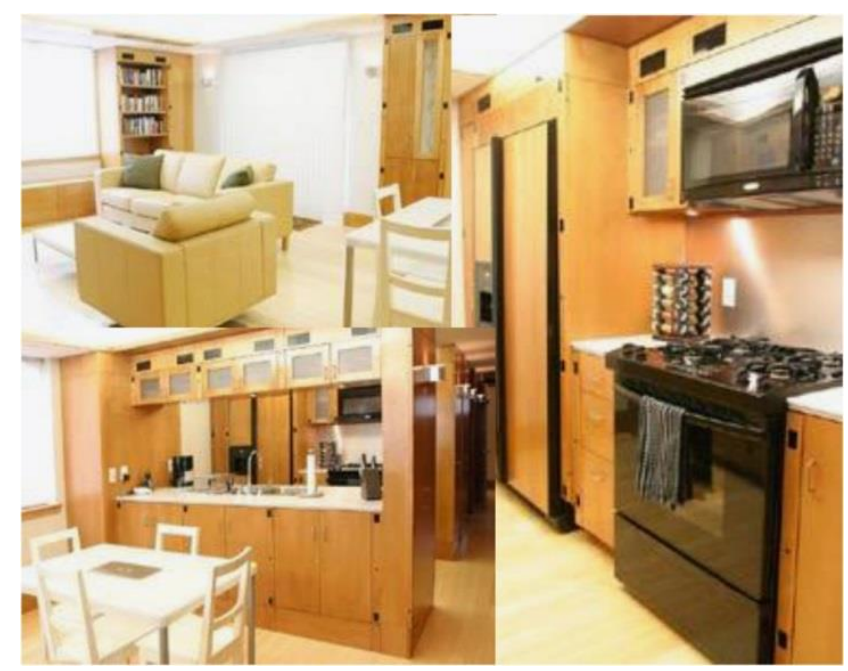

Figura 2.6 - Interiores da MIT Smart House

Fonte: GhaffarianHoseini et al. (2013). 


\subsection{6}

\section{Aware Home (EUA)}

A Aware Home, projeto desenvolvido no Georgia Institute of Technology da University of Georgia, representa uma tentativa bem sucedida para a criação de uma laboratório de casa inteligente, no qual seus residentes podem ter as facilidades das tecnologias inteligentes, enquanto são simultaneamente testadas e monitoradas (Figura 2.7).
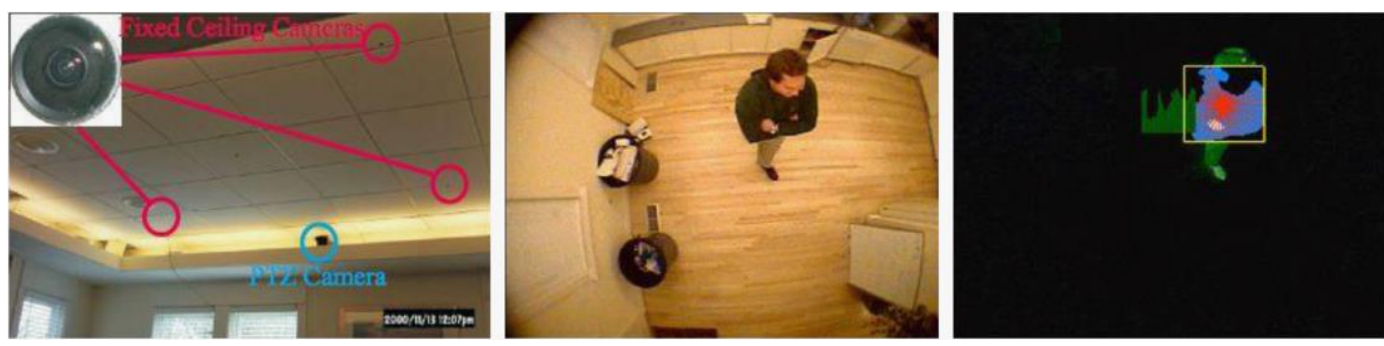

Figura 2.7 - Uso de câmeras da Aware Home Fonte: GhaffarianHoseini et al. (2013).

O conceito utilizado foi a aplicação de sistemas de computação interligados com todas as funcionalidades e atividades que a casa permite realizar. A essência desta casa é derivada da ideia de que os usuários devem ser conscientes para realizar suas atribuições e responsabilidades (GhaffarianHoseini et al., 2013).

De acordo com o projeto, o uso da tecnologia para criar um ambiente responsivo traz um atributo significativo à forma de viver. Por exemplo, ao lado da aplicação de sensores, câmeras inteligentes ajudam na identificação e reorganização dos usuários, a fim para resolver as suas necessidades através de respostas automatizados.

Analisando as suas características, o sistema indica que a utilização de aplicativos com reconhecimento de contexto em que o usuário está inserido é fundamental para o desenvolvimento das casas inteligentes, enquanto os resultados finais solicitados devem ser derivados da incorporação de tecnologia, com orientação humana. Isto pode levar à criação de harmonia entre as tecnologias emergentes e as exigências dos usuários. Por meio da combinação da experimentação e análise de preferências do usuário e índices de satisfação, enquanto residem em ambientes inteligentes, a inteligente da casa em teoria gera uma melhoria da qualidade de vida 


\subsection{7}

\section{The CASAS Smart Home (EUA)}

O projeto CASAS Smart Home é um projeto de pesquisa multidisciplinar conduzido pelo Center for Advanced Studies in Adaptive Systems (CASAS), da Universidade Estadual de Washington (EUA), e tem por objetivo a criação de um ambiente doméstico inteligente.

Este Centro desenvolveu o projeto de uma casa inteligente, segundo a visão de que ela seria mais que uma residência, ou seja, seria um 'agente inteligente' que percebe o seu ambiente através do uso de sensores e pode agir sobre ele mediante o uso de atuadores.

O projeto teve como objetivos gerais maximizar o conforto de seus moradores através do reconhecimento, descobrimento e rastreamento das atividades do usuário para as respostas automatizadas. Por exemplo, pode-se ter a estimativa do nível de consumo de energia, que deve estar ligado a metas estabelecidas para projetos de casas inteligentes e sustentáveis. O segundo objetivo é minimizar o custo de manutenção da casa. Assim, acredita-se que estas duas metas poderiam ser consideradas como princípios importantes para a avaliação da qualidade de vida nos ambientes inteligentes (GhaffarianHoseini et al., 2013).

O projeto CASAS é uma casa inteligente adaptável que usa técnicas de aprendizagem de máquina para descobrir padrões de comportamento do usuário e automaticamente imitar esses padrões. O usuário pode modificar as políticas de automação, fornecer feedback sobre as atividades de automação propostas e introduzir novas solicitações. A CASAS pode identificar automaticamente mudanças no comportamento do residente, pois o algoritmo de mineração de atividade frequente e periódica (FPAM) identifica padrões de atividade frequentes e periódicas após o processamento da informação da atividade. Os padrões são modelados por um modelo de atividade hierárquica para uma política de automação satisfatória usando regularidades temporais e estruturais. Os autores estão planejando adicionar um sistema de reconhecimento de voz, que é uma ferramenta eficiente na criação de uma casa inteligente robusto e interativa (Alam et al., 2013). 


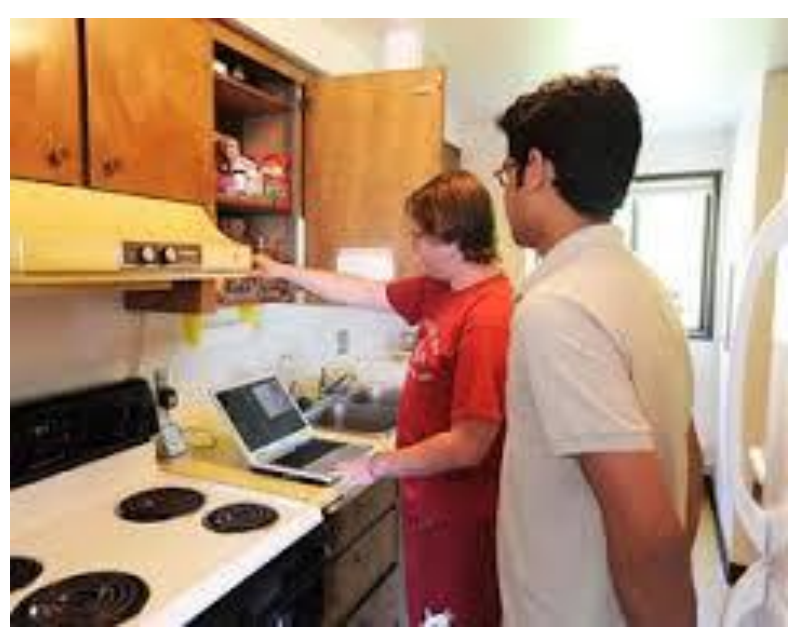

Figura 2.8 - Atividades na CASAS Smart Home Fonte: http://casas.wsu.edu/ (2017)

\subsection{8}

\section{Smart Home Lab da lowa State University (EUA)}

O projeto retrata uma casa segura, que ajuda a monitorar sua saúde, garante o abastecimento da geladeira, ajuda a cozinhar suas refeições, e lembra-lhes a tomar a medicação. Uma casa que ajusta automaticamente a iluminação e a temperatura de acordo com suas preferências ou hora do dia. A tecnologia de casa inteligente IOWA utiliza sensores e aparelhos programáveis para melhorar a qualidade de vida dos moradores. Trata-se de um novo domínio de investigação multidisciplinar que requer a integração da mais recente tecnologia de informática em sistemas incorporados, redes sem fios, interface homem-computador, engenharia de software e muito mais. Além disso, a tecnologia da casa inteligente pode inaugurar uma nova era no cuidado de idosos, gerenciamento de saúde, conservação de energia e recursos, planejamento urbano e arquitetura.

Tecnologias Domésticas Integradas: Uma geladeira que se comunica com o sistema de gestão de medicamentos para verificar a ingestão de alimentos com prescrições para possíveis problemas... um microondas que detecta temperatura de cozimento e tempo para uma preparação mais fácil... uma prateleira despensa para monitorar inventário de alimentos e criar uma lista de compras que pode ser enviada por e-mail para um serviço de compras ou um provedor de cuidados, uma TV que compreende comandos de voz.

Ambiente Inteligente: Os sistemas de sensores incorporados monitoram tudo, desde a condição física dos moradores até o consumo de energia doméstica. Um 
piso inteligente pode notificar os serviços de emergência em caso de queda. Os sistemas de iluminação podem ser automatizados, os sistemas de aquecimento e arrefecimento podem se auto-ajustar para máxima eficiência, e os sistemas de segurança mantêm os residentes seguros. A tecnologia de casa inteligente pode ser ambientalmente consciente, arquitetonicamente interessante e financeiramente acessível.

Smart Medicine: Um sistema de gerenciamento de medicamentos que integra o médico, farmácia e subsistema de casa inteligente. Ele garante a segurança através da verificação de conflitos entre medicamentos, condições de saúde e alimentos. Pesquisadores em ciência da computação, gerontologia e desenvolvimento humano e estudos familiares colaboram para proteger a privacidade do paciente e ajudar a tornar a monitoração e o gerenciamento médico um processo mais simples e integrado.

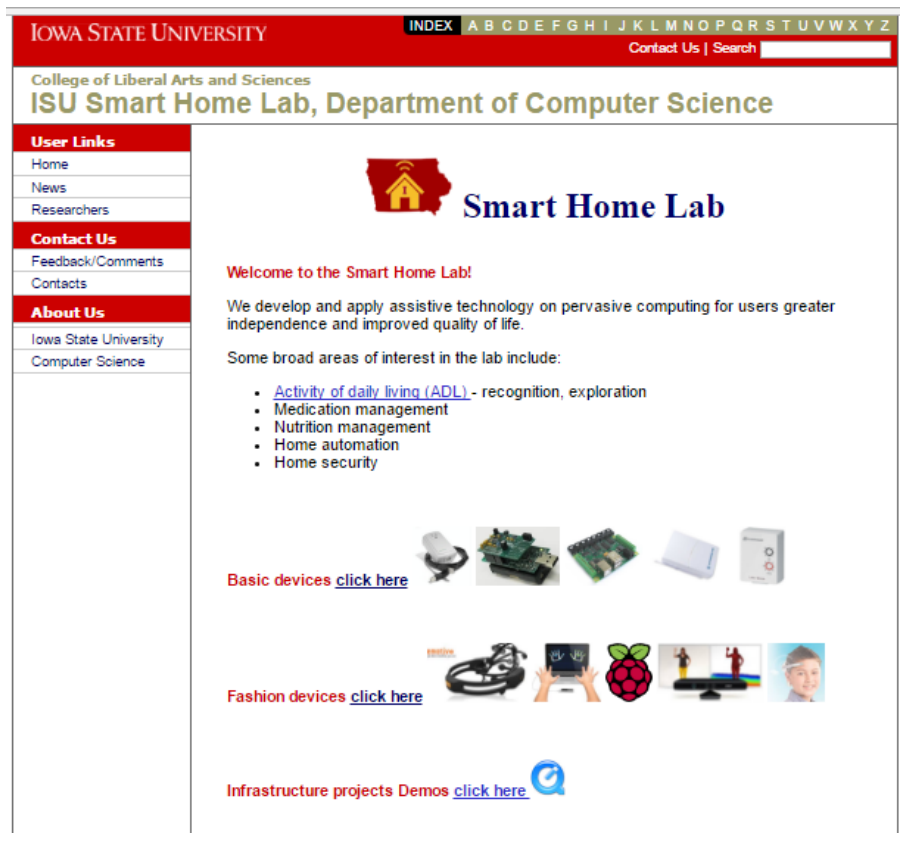

Figura 2.9 - Página na web do Smart Home Lab da Iowa State University Fonte: http://smarthome.cs.iastate.edu/ (2017).

\section{2 .9}

\section{Toyota Dream House PAPI (Japão)}

A Toyota Dream House PAPI levou cinco anos para ser planejada e concluída e fica em um terreno próximo ao Museu Toyota, na Prefeitura de Aichi, com 3.500 $\mathrm{m}^{2}$. A área total da casa é de $689 \mathrm{~m}^{2}$. É feita principalmente de vidro e alumínio, 
que são ambos materiais recicláveis. As grandes janelas de vidro, aliás, têm um revestimento especial que os tornaram autolimpantes quando chove.

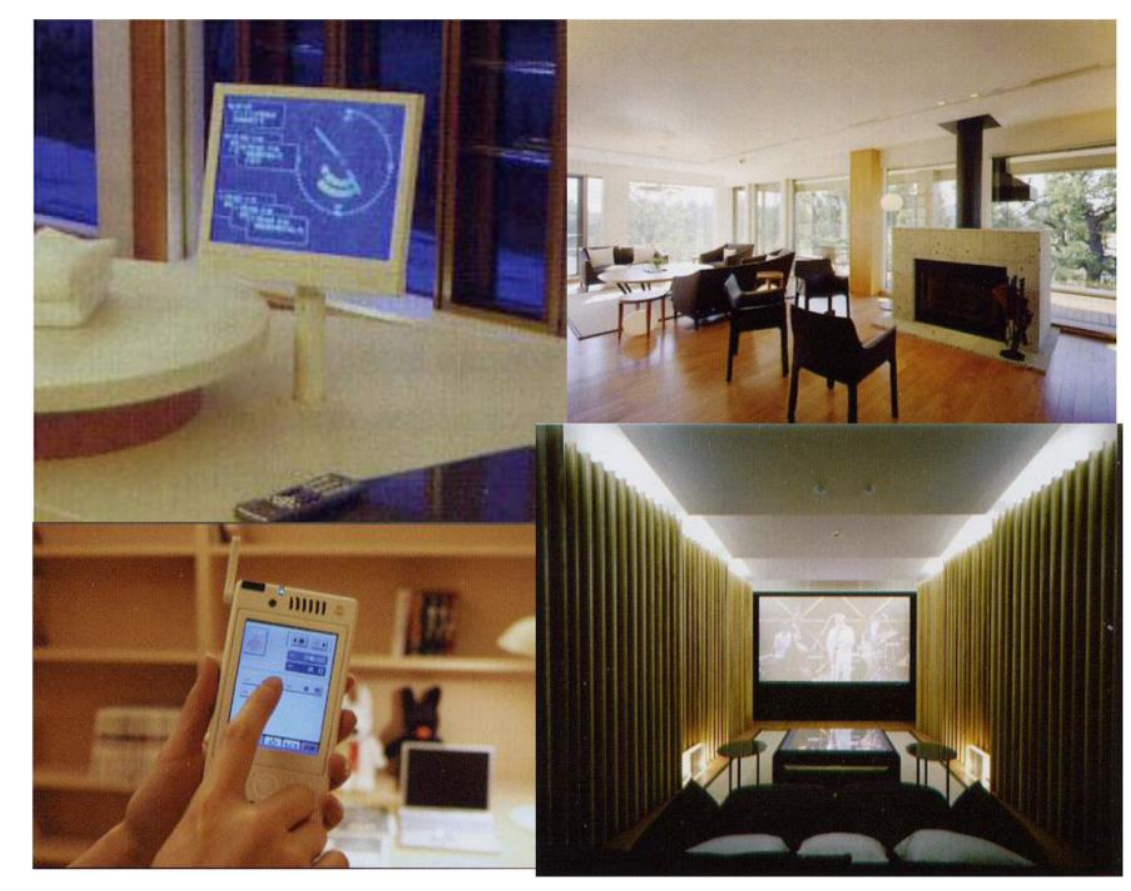

Figura 2.10 - Interiores da Toyota Dream House PAPI Fonte: GhaffarianHoseini et al. (2013).

Os principais objetivos deste projeto foram projetar e realizar um projeto de casa inteligente e ecológico, de economia de energia, no qual as mais recentes tecnologias de computação de rede onipresentes criadas pelo projeto T-Engine poderiam ser testadas e desenvolvidas. Toyota Dream House PAPI foi projetado para interface com outras tecnologias Toyota e uma das mais importantes dessas outras tecnologias é o sedan híbrido Prius da Toyota Motor Corporation, que também pode ser usado para fornecer eletricidade à casa inteligente por 36 horas em uma emergência, como um terremoto que corta os suprimentos elétricos normais. Inversamente, a casa pode fornecer a eletricidade às baterias dos veículos através do carrinho no meio da garagem. Parte dessa energia elétrica pode ser obtida a partir de painéis de células solares que cobrem o telhado, além dos lados da estrutura. A casa também usa aquecimento solar e células de combustível, o que o torna uma espécie de casa de energia híbrida.

Uma das vantagens de uma casa construída no campo é que ele pode ter salas maiores. A lareira também causaria problemas com os vizinhos e, provavelmente, as autoridades locais, em uma área urbana lotada, como Tóquio ou Osaka. Quartos 
amplos e espaçosos, com boa iluminação interna e externa, rodeados por árvores, plantas e outros elementos da natureza, são uma característica do projeto futurista.

O home theater com som surround não é novidade, e está entrando em voga graças aos formatos de vídeo digital de alta definição, aos players de DVD de alta capacidade e às tecnologias de exibição de tela ampla. $\mathrm{Na}$ verdade, muitos fabricantes de eletrônicos consideram o home theater como o próximo grande mercado uma vez que eles podem encontrar o nível de preço certo para vender para as massas.

Na Toyota Dream House PAPI, o já estabelecido conceito de home theater foi desenvolvido um passo adiante. Este home theater 'sabe' onde estão os ocupantes humanos e ajusta a iluminação e o som para seus locais e preferências. Se alguma mudança tiver que ser feita a quaisquer dispositivos na sala, como o ar condicionado ou a ventilação, o Communicator Ubiquitous pode facilmente fazêlos. Esse Communicator Ubiquitous (UC) pode ser usado como controle remoto em toda a casa e à medida que o usuário se move de uma sala para outra, as funções do comunicador mudam, e também identifica a pessoa e suas preferências à medida que ele se move pelo espaço de vida computadorizado.

\subsubsection{0}

\section{NICT Ubiquitous Home (Japão)}

A 'Ubiquitous Home' foi desenvolvida no Instituto Nacional de Tecnologia da Informação e Comunicações (NICT), onde os sistemas inteligentes embutidos são utilizados para controlar todos os serviços da casa enquanto se comunica com os ocupantes.

Trata-se de uma instalação de teste de habitação TIC para a criação de novos serviços úteis para a casa que será possível através da ligação de dispositivos, sensores e dispositivos por meio de redes de dados. O layout da Casa Ubíqua tem uma sala de estar, sala de jantar, cozinha, escritório, quarto e banheiro, estes quartos compreendem um apartamento. Entre o apartamento e a sala de estilo japonês é uma sala de informática chamada Network Operating Center (NOC).

Acima do teto da Casa Ubíqua há um espaço onde os experimentadores podem trabalhar. No espaço, três corredores chamados "passeios de gato" são usados para andar, instalação de máquina e cabeamento, respectivamente. Além disso, o piso da Casa Ubíqua está estruturado para livre acesso a $40 \mathrm{~cm}$ de altura. $\mathrm{O}$ 
espaço da casa está equipado com vários tipos de sensores para monitorar as atividades humanas, cada quarto tem câmeras e microfones no teto para coletar informações de vídeo e áudio. Os sensores de pressão de chão instalados em todo o pavimento contêm unidades de detecção binárias e são utilizados para rastrear residentes ou detectar posições de mobiliário. Sensores infravermelhos são usados para detectar movimento humano.

De acordo com as elaborações sobre a essência de casas inteligentes, o principal significativo dessa casa é a preocupação com os valores tecnológicos inteligentes e o direcionamento para a automação de funcionalidades (Figura 2.11).
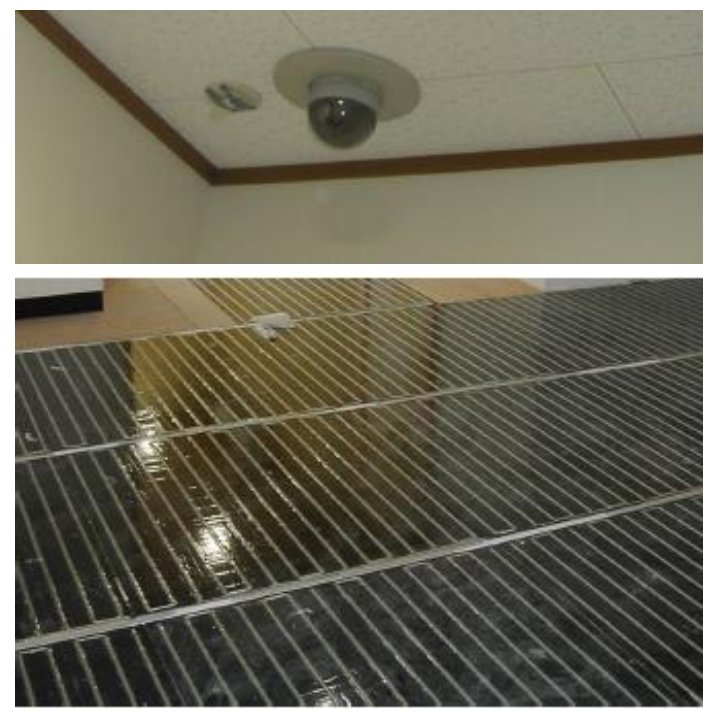

Figura 2.11 - Uso de sensores no teto e no piso da NICT Ubiquitous Home Fonte: Yamazaki. (2007).

\subsubsection{1}

\section{Smart home system (Turquia)}

Foi desenvolvida uma casa inteligente em um ambiente de laboratório na Universidade Técnica de Yildiz, em Istambul, com o propósito de experimentação e aplicação de novos sistemas inteligentes (Tascikaraoglu et al., 2014).

A Figura 2.12 mostra duas vistas de interiores da Smart Home System, na Turquia. 


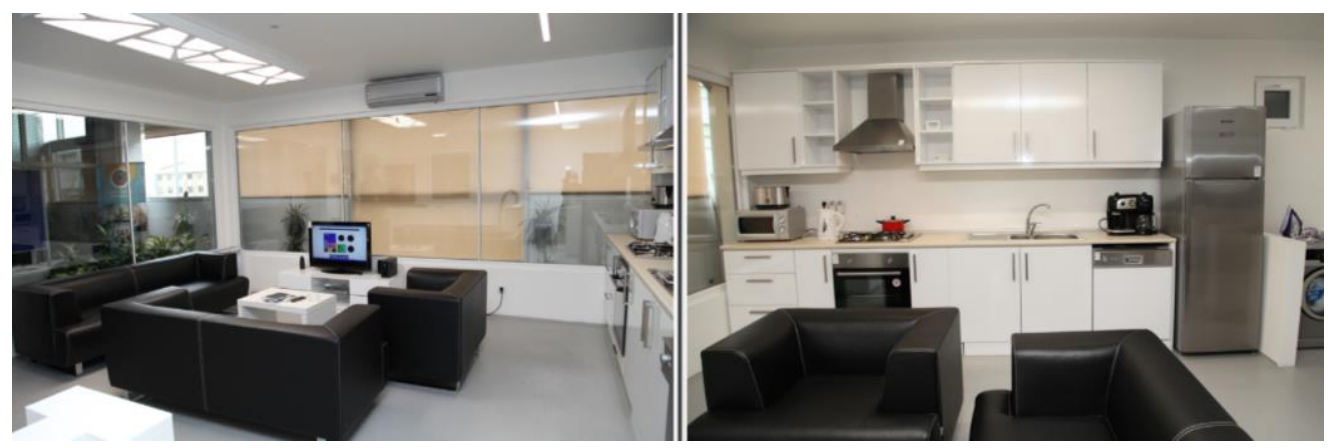

Figura 2.12 - Interiores da Smart Home System

Fonte: Tascikaraoglu et al., 2014.

Com a ajuda de avançadas tecnologias de medição e exibição na casa, o usuário ou o próprio sistema é capaz de diminuir o consumo de energia ou adiar as atividades estabelecidas que consomem energia, direcionando-as para um horário fora do horário de pico visando que o preço da energia seja reduzido em relação ao consumo de gasto necessário ao usuário, garantindo o uso dos aparelhos elétricos um nível razoável de conforto. Esta ação é denominada DSM (demand side management) ou controle pelo lado da demanda.

$\mathrm{Na}$ literatura, indica-se entre 10 e $30 \%$ de redução do consumo de energia doméstica pode ser obtida fornecendo apenas o perfil de consumo dos aparelhos aos consumidores e, consequentemente, ajudando-os a mudar seu comportamento (Yohanis et al., 2008).

Para ampliar o escopo dos sistemas convencionais de gerenciamento de residências inteligentes, um novo esquema de operação e consumo de energia de vários eletrodomésticos em um sistema de casa inteligente conectado à rede que utiliza previsões de energia eólica e solar, informações sobre tarifas de eletricidade, sistemas de armazenamento e prioridades de carga para decidir os tempos ótimos de funcionamento dos aparelhos. Com isso, o sistema visa minimizar as despesas monetárias com decisões autônomas, evitando comprar eletricidade em tempos de preço elevado, deslocando as cargas para os tempos com maior potencial de energia renovável e/ou com preço de eletricidade mais barato (Yohanis et al., 2008; Tascikaraoglu et al., 2014).

A Smart Home gera a sua própria energia principalmente graças às fontes de energia renováveis, tais como turbinas eólicas e painéis solares fotovoltaicos (PV), e armazena ou exporta o excesso de energia por meio de baterias e um veículo elétrico (VE) através de uma estação de carregamento. O monitoramento em tempo 
real dos valores de produção e consumo de energia na casa inteligente mantém os usuários finais informados sobre os dados detalhados requeridos pela família, como valores de consumo imediatos, diários e mensais de cada aparelho. Além disso, os dados armazenados são recuperados a partir de uma aplicação baseada na web, permitindo a monitorização e gestão remotas dos dispositivos.

Além disso, a tecnologia de rede sem fios Zigbee (IEEE Standard 802.15.4) é utilizada para proporcionar comunicação entre os sistemas, subdivididos em três subseções:

- Eletrodomésticos inteligentes, onde os aparelhos elétricos são utilizados em vários períodos de tempo a cada dia, dependendo principalmente do dia da semana;

- Fontes de energia renováveis e sistemas de armazenamento, que foram incluídas no protótipo de smart home proposto afim de reduzir a dependência da rede elétrica e explorar o potencial de energia solar. Além de um grupo de baterias de alta capacidade usado como energia de apoio para suportar a casa em uma condição de deficiência de energia e armazenar o excesso de energia para uso posterior e de um sistema de meteorológico para medir e registrar as séries temporais;

- Comunicação, onde as redes sem fio baseadas em comunicação podem ser candidatas para aplicações domésticas devido à sua disponibilidade para adicionar novos dispositivos ao sistema facilmente. A estação de meteorologia utiliza comunicação com fio devido aos efeitos de atenuação dos pisos e paredes do edifício.

\subsubsection{2}

\section{Escritório Verde da Universidade Tecnológica Federal do Paraná (Brasil)}

O Escritório Verde (EV) da Universidade Tecnológica Federal do Paraná (UTFPR) é uma edificação sustentável modelo de $150 \mathrm{~m}^{2}$, que adotou diversas estratégias de sustentabilidade, em parceria com mais de sessenta empresas (Figura 2.13). 


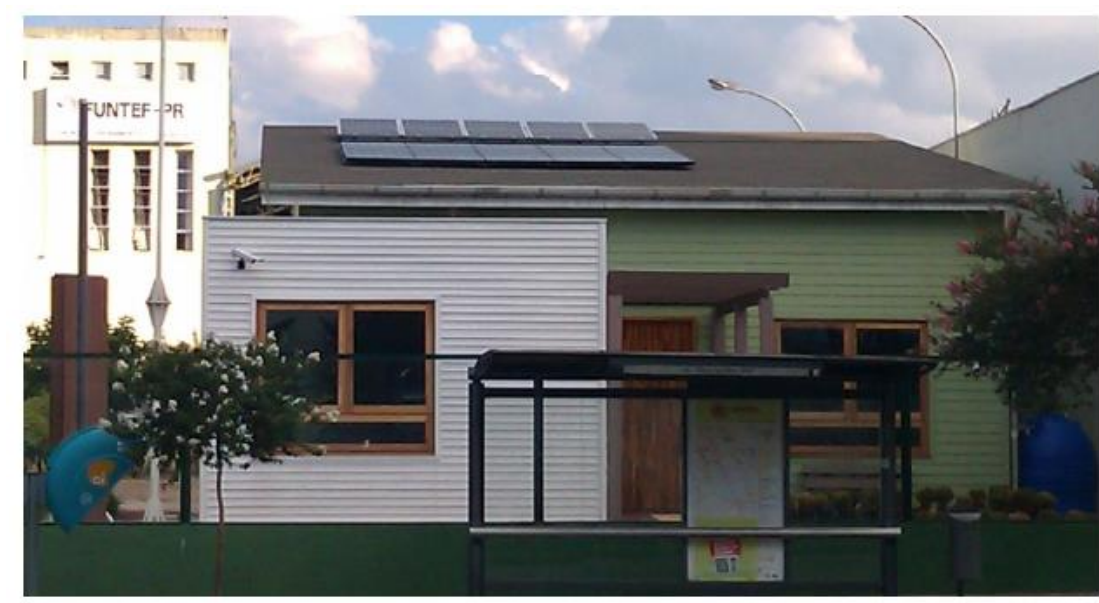

Figura 2.13 - Vista frontal do Escritório Verde da UTFPR Fonte: Urbanetz Jr. e Casagrande Jr. (2012).

$\mathrm{Na}$ fase de projeto, optou-se pela técnica de geração fotovoltaica como linha mestra para prover energia à edificação, em conjunto com o sistema elétrico da concessionária e proporcionar a máxima eficiência energética. O EV da UTFPR possui dois sistemas fotovoltaicos distintos, um sistema conectado à rede elétrica (SFCR) e um sistema fotovoltaico isolado (SFI) (Urbanetz Jr. e Casagrande Jr., 2012).

Um SFCR é basicamente composto de um painel fotovoltaico (FV), que converte a energia do sol em energia elétrica em corrente contínua, e um inversor, que converte a corrente contínua em corrente alternada, com tensão e frequência compatíveis com a rede elétrica da concessionária ao qual o sistema está interligado.

As principais vantagens desse tipo de sistema são elevada produtividade; ausência de banco de baterias e desligamento automático no caso de falta de energia da rede, evitando o fenômeno de ilhamento (ocorre quando parte da rede elétrica é desconectada propositadamente ou acidentalmente do restante do sistema da concessionária, mas essa continua a ser energizada por um ou mais geradores distribuídos conectados a ela, formando um subsistema isolado) (Urbanetz Jr. e Casagrande Jr., 2012; Urbanetz Jr., 2010).

O SFI é basicamente composto de um painel FV, controlador de carga, banco de baterias e inversor. Normalmente são instalados em locais sem acesso à rede elétrica convencional, mas podem também ser utilizados para atender cargas especiais de forma ininterrupta, independente da rede elétrica da concessionária. $\mathrm{O}$ SFI do EV é composto por um painel de 10 módulos, sendo divido em dois subsistemas, oito módulos formam um sistema com barramento CC em $24 \mathrm{~V}$, e os 
outros dois módulos formam um sistema com barramento $\mathrm{CC}$ em $12 \mathrm{~V}$, cada subsistema utiliza um controlador de carga do tipo PWM alimentando um banco de baterias formado por 16 e 12 baterias, respectivamente. As baterias são do tipo chumbo-ácido para uso em sistemas fotovoltaicos. O painel FV do SFI pode ser visualizado na Figura 2.14.
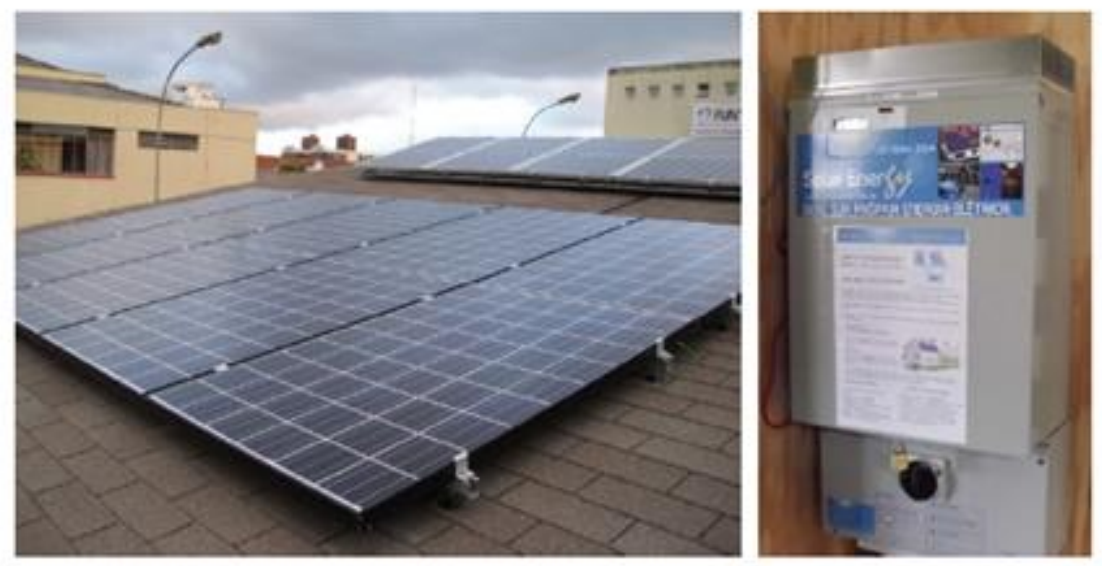

Figura 2.14 - Painel fotovoltaico do Escritório Verde da UTFPR Fonte: Urbanetz Jr. e Casagrande Jr. (2012).

$\mathrm{O}$ barramento $\mathrm{CC}$ em $12 \mathrm{~V}$ alimenta uma motobomba responsável pelo recalque da água armazenada na cisterna que coleta a água da chuva, elevando-a até a caixa d'água que alimenta os vasos sanitários e o sistema de irrigação do EV. (Urbanetz Jr. e Casagrande Jr., 2012).

A Figura 2.15 apresenta um dos controladores de carga e o banco de baterias dos dois subsistemas

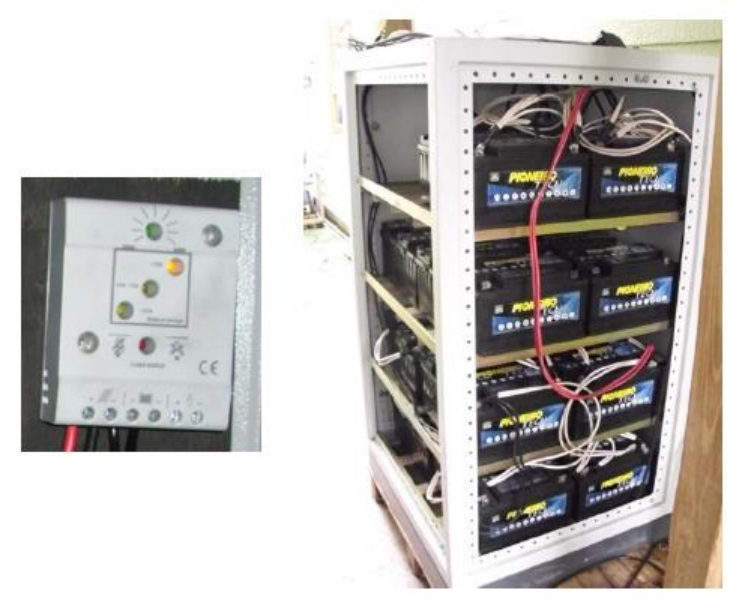

Figura 2.15 - Controlador de carga e banco de baterias do EV da UTFPR Fonte: Urbanetz Jr. e Casagrande Jr. (2012). 
O SFCR do Escritório Verde da UTFPR durante os seis meses de análise gerou em média $217 \mathrm{kWh} /$ mês, energia superior a necessária para atender as cargas existentes na edificação, tornando a mesma uma edificação de energia zero (ZEB zero energy building). Nos meses de verão (maior incidência solar) a geração atingiu $273 \mathrm{kWh}$, o que permitiu exportar energia para as instalações adjacentes, nestes momentos, o EV tornou-se uma edificação de energia positiva. O Sistema SFI não foi avaliado.

\section{3}

\section{Quadro-síntese dos modelos}

Como mencionado anteriormente, uma série de projetos de casas inteligentes já foram desenvolvidos. Além das questões de conforto e lazer, segurança, gerenciamento de energia e outras questões, a revisão dos modelos revelou um número significativo de projetos de casas assistivas destinadas a monitorar idosos com deficiências motoras, visuais, auditivas ou cognitivas (Tang e Venables, 2000; Chan et al., 2008; Chan et al., 2009).

Nessas casas assistivas, vários aparelhos eletroeletrônicos foram equipados com sensores, atuadores e monitores biomédicos. Os dispositivos operam em rede, que, em geral, é conectada a um centro remoto para coleta e processamento de dados. O centro remoto diagnostica a situação em curso e inicia procedimentos de assistência.

De acordo com GhaffarianHoseini et al. (2013) e Jeong (2009), é possível estabelecer modelos de casas inteligentes a partir da análise de seus objetivos, serviços oferecidos e soluções tecnológicas adotadas. O Quadro 2.3 reúne uma síntese de sete modelos de casas inteligentes, conforme caracterização sugerida por Jeong (2009). 
Quadro 2.3 - Principais modelos de casas inteligentes

\begin{tabular}{|c|c|c|c|c|}
\hline Modelo & Instituição & Objetivo & Características & Soluções tecnológicas \\
\hline $\begin{array}{l}\text { Casa } \\
\text { adaptativa }\end{array}$ & $\begin{array}{l}\text { Universidade } \\
\text { do Colorado }\end{array}$ & $\begin{array}{l}\text { Previsão para } \\
\text { as necessidades } \\
\text { dos residentes, } \\
\text { aprendendo os } \\
\text { padrões de vida } \\
\text { dos residentes } \\
\text { e ações }\end{array}$ & $\begin{array}{l}\text { 1. Sistema de conforto } \\
\text { residencial - Conexão entre } \\
\text { temperatura, iluminação, } \\
\text { ventilação, controles de } \\
\text { temperatura da água e } \\
\text { residência; } \\
\text { 2. Previsão e controle - } \\
\text { aprendendo os padrões de ação } \\
\text { do residente, o sistema de casa } \\
\text { inteligente pode prever a } \\
\text { próxima ação do residente e } \\
\text { controlar o ambiente } \\
\text { automaticamente. }\end{array}$ & $\begin{array}{l}\text { ACHE (Controle Adaptativo } \\
\text { de Ambientes Domésticos) }\end{array}$ \\
\hline Casa assistiva & $\begin{array}{l}\text { Universidade } \\
\text { da Geórgia }\end{array}$ & $\begin{array}{l}\text { Desenvolvimen } \\
\text { to de serviços } \\
\text { para idosos } \\
\text { com base na } \\
\text { percepção } \\
\text { humana }\end{array}$ & $\begin{array}{l}\text { 1. Especificação do domínio } \\
\text { conscientização - sugerindo um } \\
\text { domínio específico de aplicação, } \\
\text { especificando um grupo-alvo, } \\
\text { como idosos e desenvolvimento } \\
\text { de aplicações adequadas; } \\
\text { 2. Sensibilização do contexto e } \\
\text { detecção onipresente - } \\
\text { recolhendo as informações } \\
\text { residentes detectando ou } \\
\text { usando a câmera, os sensores } \\
\text { precisam se esconder da visão } \\
\text { do residente ou pode ser } \\
\text { instalado no corpo humano em } \\
\text { formas como colar ou relógio. }\end{array}$ & $\begin{array}{l}\text { 1. Envelhecimento - } \\
\text { Informação de ação dos } \\
\text { idosos. } \\
\text { 2. Encontrar objetos } \\
\text { perdidos - Informação de } \\
\text { localização dos objetos que } \\
\text { os idosos podem facilmente } \\
\text { esquecer; } \\
\text { 3. Carpete inteligente - } \\
\text { Informação de identificação } \\
\text { do residente, detectando o } \\
\text { peso. }\end{array}$ \\
\hline $\begin{array}{l}\text { Casa } \\
\text { customizada }\end{array}$ & MIT & $\begin{array}{l}\text { Construir uma } \\
\text { casa } \\
\text { personalizada } \\
\text { que inclua } \\
\text { sistema } \\
\text { doméstico }\end{array}$ & $\begin{array}{l}\text { 1. Adaptável - Ambiente } \\
\text { personalizado - Sistema pessoal } \\
\text { personalizado (rede doméstica, } \\
\text { aparelhos digitais, novos } \\
\text { materiais de construção). Será } \\
\text { instalado em ambiente } \\
\text { doméstico; } \\
\text { 2. Ambiente de interface } \\
\text { interativa do usuário: } \\
\text { - Obtendo as informações de } \\
\text { ação residentes usando } \\
\text { sensores, controle digital } \\
\text { através da rede doméstica } \\
\text { usando estas informações de } \\
\text { ação (ou seja, a interação entre } \\
\text { os moradores e sua casa é } \\
\text { possível); } \\
\text { 3. Projeto arquitetônico e } \\
\text { visualização do ambiente - } \\
\text { Fornece interfaces digitais e } \\
\text { ambiente de simulação de } \\
\text { projeto. }\end{array}$ & $\begin{array}{l}\text { 1. Baseado em casa } \\
\text { medicina preventiva - } \\
\text { Função de alarme para a } \\
\text { medicina ou para ataque } \\
\text { cardíaco; } \\
\text { 2. Consumo e conforto de } \\
\text { energia / recursos - Para } \\
\text { reduzir o consumo de } \\
\text { energia, função para o } \\
\text { controle de energia e } \\
\text { padrões de ações dos } \\
\text { residentes; } \\
\text { 3. Controle universal - } \\
\text { Controle remoto e função } \\
\text { de integração para } \\
\text { eletrodomésticos, } \\
\text { desenvolvimento de } \\
\text { interface adaptada ao } \\
\text { residente. }\end{array}$ \\
\hline
\end{tabular}


Quadro 2.3 - Principais modelos de casas inteligentes (cont.)

\begin{tabular}{|c|c|c|c|c|}
\hline Modelo & Instituição & Objetivo & Características & Soluções tecnológicas \\
\hline $\begin{array}{l}\text { Casa dos } \\
\text { sonhos }\end{array}$ & LG & $\begin{array}{l}\text { Proporcionar um } \\
\text { ambiente como um } \\
\text { agente inteligente } \\
\text { para donas de casa; } \\
\text { Fornecer um } \\
\text { ambiente de } \\
\text { cozinha que os } \\
\text { moradores possam } \\
\text { controlar } \\
\text { remotamente } \\
\text { através da Internet. }\end{array}$ & $\begin{array}{l}\text { Desenvolvimento do LNCP } \\
\text { que é um protocolo de } \\
\text { comunicação, nomeado o } \\
\text { protocolo de controlo de } \\
\text { rede viva. }\end{array}$ & $\begin{array}{l}\text { Internet, aparelhos } \\
\text { domésticos (por exemplo, } \\
\text { geladeira, ar condicionado, } \\
\text { microondas, lavadora, } \\
\text { fogão), serviço de casa de } \\
\text { sonho, (por exemplo menu } \\
\text { Prestação de serviços } \\
\text { através da Internet, } \\
\text { fornecendo receitas de } \\
\text { pratos). }\end{array}$ \\
\hline Casa digital & Samsung & $\begin{array}{l}\text { Especificar quatro } \\
\text { domínios principais } \\
\text { para a vida em } \\
\text { casa, como feliz, } \\
\text { divertida, } \\
\text { surpreendente, e } \\
\text { vida conveniente, } \\
\text { fornecendo aos } \\
\text { residentes um } \\
\text { ambiente que } \\
\text { possa satisfazer } \\
\text { estes quatro temas } \\
\text { vivos. }\end{array}$ & $\begin{array}{l}\text { Conectando informações } \\
\text { de eletrodomésticos à } \\
\text { rede doméstica; } \\
\text { proporcionando controle } \\
\text { integrado ou } \\
\text { gerenciamento do } \\
\text { ambiente conectado. }\end{array}$ & \\
\hline $\begin{array}{l}\text { Casa que } \\
\text { facilita a } \\
\text { vida }\end{array}$ & Microsoft & $\begin{array}{l}\text { Desenvolvimento } \\
\text { de protótipos e } \\
\text { desenvolvimento } \\
\text { de tecnologias } \\
\text { adequadas para } \\
\text { ambientes } \\
\text { inteligentes onde a } \\
\text { comunicação ativa } \\
\text { é fornecida: } \\
\text { humano e humano, } \\
\text { humano e } \\
\text { computador, ou } \\
\text { humano e } \\
\text { dispositivo. }\end{array}$ & $\begin{array}{l}\text { 1. Espaço autoconsciente - } \\
\text { Investigação da } \\
\text { informação ambiental } \\
\text { para proporcionar reações } \\
\text { adequadas aos pedidos do } \\
\text { residente; } \\
\text { 2. O acesso ocasional a } \\
\text { recursos computacionais } \\
\text { de computação pode ser } \\
\text { fornecido aos residentes } \\
\text { independentemente da } \\
\text { localização e do tempo; } \\
\text { 3. Extensibilidade - O } \\
\text { espaço do Vida Fácil pode } \\
\text { ser estendido juntamente } \\
\text { com a adição de novos } \\
\text { recursos; }\end{array}$ & $\begin{array}{l}\text { 1. Migrando janelas - Uma } \\
\text { tarefa pode ser transferida } \\
\text { entre PCs; } \\
\text { 2. Entre em contato com } \\
\text { qualquer pessoa - a } \\
\text { capacidade de transferir a } \\
\text { mensagem para o recurso } \\
\text { disponível próximo do } \\
\text { residente; } \\
\text { 3. Assistente de assistência } \\
\text { à infância - a capacidade de } \\
\text { notificar os pais quando } \\
\text { uma criança ou um animal } \\
\text { de estimação está em uma } \\
\text { situação perigosa; } \\
\text { 4. Visão baseada em } \\
\text { automação residencial - } \\
\text { iluminação pode ser } \\
\text { automaticamente ajustada } \\
\text { quando o residente ler um } \\
\text { livro ou a sala está vazia. }\end{array}$ \\
\hline
\end{tabular}

Continua... 
Quadro 2.3 - Principais modelos de casas inteligentes (cont.)

\begin{tabular}{|c|c|c|c|c|}
\hline $\begin{array}{l}\text { Casa } \\
\text { ubíqua }\end{array}$ & KJIST & $\begin{array}{l}\text { Fornecer uma } \\
\text { infraestrutura para } \\
\text { gerenciamento / } \\
\text { administração de } \\
\text { vários sensores, } \\
\text { contexto e } \\
\text { aplicação usando } \\
\text { computadores } \\
\text { distribuídos em } \\
\text { um ambiente } \\
\text { Rastrear ou } \\
\text { notificar a } \\
\text { localização, o } \\
\text { gesto, a identidade } \\
\text { e a intenção do } \\
\text { residente, bem } \\
\text { como o } \\
\text { reconhecimento de } \\
\text { um objeto e } \\
\text { localização. }\end{array}$ & $\begin{array}{l}\text { 1. Ambiente de } \\
\text { computação ubíquo - } \\
\text { (enquanto o contexto } \\
\text { produzido por vários } \\
\text { sensores é administrado } \\
\text { pelo servidor em muitos } \\
\text { sistemas inteligentes, } \\
\text { oferece um ambiente de } \\
\text { computação distribuída, } \\
\text { de forma que o processo } \\
\text { que lida com sensores } \\
\text { gera e administra } \\
\text { contextos para si mesmo.) } \\
\text { 2. Ambiente Inteligente - } \\
\text { Rastreamento ou } \\
\text { notificação do local, gesto, } \\
\text { identidade e intenção do } \\
\text { residente, bem como } \\
\text { reconhecimento de um } \\
\text { objeto e sua localização } \\
\text { 3. Ambiente personalizado } \\
\text { - proporcionando um } \\
\text { ambiente familiar } \\
\text { adaptado ou adaptado } \\
\text { que reflete o padrão de } \\
\text { vida do residente. }\end{array}$ & $\begin{array}{l}\text { 1. Serviço de controle de } \\
\text { entrada. } \\
\text { 2. Controle automático do } \\
\text { ambiente do residente. } \\
\text { 3. Encontrar objeto } \\
\text { perdido. } \\
\text { 4. Serviço de prevenção de } \\
\text { perigo. } \\
\text { 5. Controlador universal. } \\
\text { 6. Controlador de comando } \\
\text { de gestos. }\end{array}$ \\
\hline
\end{tabular}

Fontes: GhaffarianHoseini et al. (2013); Jeong (2009).

\section{4 \\ Considerações finais sobre o capítulo}

As casas inteligentes precisam oferecer segurança do ambiente, monitoramento, controle dos equipamentos à distância, automação de tarefas domésticas, controle de som e iluminação, gestão de energia, bem-estar e harmonia das tecnologias com as necessidades do usuário, preocupação com as questões culturais e ambientais, além de ter como premissa ser sustentável, com capacidade de regeneração do ambiente e dos recursos consumidos.

Todos esses protótipos e experimentos de casas demonstrados no capítulo utilizam em seus objetos de estudo a tecnologia de automação para que as casas possam, por meio de sensores e atuadores, trabalhar e funcionar integradamente. Essa integração permite ao usuário, comandar os equipamentos à distância, programar seus horários de funcionamento e determinar maior ou menor intensidade de uso de cada tecnologia, bens e serviços que as casas podem oferecer.

Os sistemas tecnológicos permitem que a casa tenha janelas automatizadas que podem ser ajustadas automaticamente para o nível preferido de iluminação, 
privacidade e fluxo de ar; cama inteligente para detectar os padrões de sono dos usuários e ajustar-se automaticamente, além de gravar e monitorar as noites de sono; lavanderia inteligente combinada com um armário inteligente para notificar os usuários do tempo para o uso de roupa, e o armário inteligente pode ainda categorizar as roupas e propor a melhor alternativa de vestir com base na monitorização do clima, temperatura, tempo e outros parâmetros relacionados; espelho inteligente para lembrar o usuário de mensagens importantes ou notificar o usuário sobre aspectos de saúde; banheiro inteligente, com descarga, sensor de papel higiênico e chuveiro inteligentes, para determinar e medir a quantidade e temperatura da água, além de ajustar automaticamente o dispensador de sabão para monitorar a limpeza do usuário; Monitores inteligentes em todos os espaços integrados da casa para serem usados para entretenimento, informação e mídia; piso inteligente para controlar os movimentos e localização dos ocupantes de casas e até para relatar a situação de emergência para os casos de quedas de idosos; porta inteligente, que funciona pelo sistema de RFID (identificação por radiofrequência), para o usuário observar os visitantes e comunicar-se com eles. Além disso, a casa inteligente deve ter sistemas eólico e fotovoltaico para que possa usar o vento e a luz solar para gerar energia elétrica e, por meio de um banco de baterias, armazenar essa energia para horários em que não incidir a luz solar.

Outro ponto importante de destaque é que essa tecnologia integrada, além de facilitar a vida dos usuários que podem ganhar tempo e praticidade com toda essa automação e facilidade, pode ajudar nos programas de saúde e no monitoramento de idosos e pessoas com deficiência, pois permitem o acompanhamento em tempo real de suas atividades e seus movimentos dentro das residências, o que consequentemente pode trazer uma significativa melhora na qualidade de vida.

Adicionalmente a essas facilidades e funcionalidades, há de se destacar o desenvolvimento dos estudos para se melhorar os sistemas de energia convencionais e proporcionar cada vez mais ao usuário a capacidade de geração própria de energia (microgeração), fazendo com que ela se torne descentralizada. Neste tema em questão, percebe-se que há um conflito, devido ao fato das redes elétricas não estarem preparadas para absorver esse formato de geração e administração de energia gerada em massa pelo consumidor final. A gestão da própria energia gera, consequentemente, a possibilidade de que o usuário também possa armazenar sua própria energia e devolver o excedente produzido à rede 
elétrica, podendo receber bônus e/ou vendê-la conforme a legislação vigente em cada país.

A tendência segundo os estudos será a do usuário final gerenciar seu consumo, administrando sua capacidade de geração e sua disponibilidade de energia, usando as tecnologias e os dispositivos a seu favor, proporcionando maior praticidade, qualidade de vida e bem-estar.

Espera-se, portanto, que as casas inteligentes sejam responsivas, usem sensores e atuadores para que possam ser automatizadas e estar programadas para usar a energia nos horários em que esta for mais barata. 


\section{3 Soluções tecnológicas para casas inteligentes}

A partir da análise de conteúdo dos artigos de revisão da literatura sobre casas inteligentes, publicados por Alam et al. (2012); Badica et al. (2013); Chan et al. (2008; 2009); Wong e Li (2009); e Wilson et al. (2015), identificou-se, inicialmente um conjunto de soluções tecnológicas, classificadas por categoria de serviços, como abordado no capítulo 2. Buscando-se complementar essas informações, acessaram-se os sites institucionais das casas inteligentes focalizadas naquele capítulo 2, além de uma busca complementar em bases de dados para as soluções propostas no processo de crowdsourcing do Projeto NO.V.A.

Neste capítulo, abordam-se as principais soluções tecnológicas para o funcionamento e integração de casas inteligentes, buscando-se classificar as soluções tecnológicas de acordo com as seguintes categorias de serviços: (i) conforto e lazer; (ii) automação residencial; (iii) acesso remoto; (iv) segurança de rede e de informação; (v) cuidados com a saúde (healthcare); (vi) uso eficiente de recursos naturais; (vii) gerenciamento de energia; e (viii) segurança patrimonial.

\section{1 \\ Conforto e lazer}

Apresentam-se as principais soluções tecnológicas referentes à categoria "Conforto e lazer", a saber: (i) sistema HVAC; (ii) sistema endereçável digital de controle da iluminação; (iii) sistema de iluminação; (iv) sistema de layout interno; (v) sistema de fachada em edificações; (vi) rede de interconexão de produtos e sistemas eletrônicos domésticos (HAN); (vii) sistema de gerenciamento ambiental interno e externo; (viii) sistemas de detecção de posicionamento não invasivos; e (ix) smart furniture.

\subsection{1}

\section{Sistema HVAC}

Os sistemas de refrigeração e climatização têm exercido papel de destaque no que tange infraestrutura baseada no uso da energia que permitiu a explosão 
populacional e o conforto que a sociedade desfruta atualmente. Várias metodologias foram adotadas, mas a que se mostrou mais eficiente e que é utilizada de forma predominante é a tecnologia dos ciclos de compressão de vapor. Esses sistemas são vastamente usados em larga variedade de atividades, desde o controle de temperatura e umidade de instalações para o conforto humano até o controle de estoque de produtos alimentícios perecíveis. A parcela de energia elétrica consumida em refrigeração e climatização, doméstica e industrial chega a atingir $37 \%$ do consumo total nos EUA, o que pode ser extrapolado aproximadamente para o resto do mundo. Os sistemas de controle para refrigeração, ar condicionado, aquecimento e ventilação (HVAC-R) comercializados atualmente são majoritariamente baseados nos sistemas de controle tradicional liga-desliga, controle por PID (proporcional, integral, derivativo), controle Fuzzy e controle ANN (redes neurais). Dentre esses, os controles liga-desliga é o que é mais largamente utilizado ainda hoje, apesar de acarretar alto consumo energético, principalmente devido aos picos de corrente ao religar o sistema. Os outros sistemas operam de forma inteligente, modulando os componentes de acordo com a demanda requerida pela carga térmica (Pinnola, 2013).

Wong e Li (2010) abordam o dilema de escolher sistemas de controle predial pertinente para atender às necessidades de determinados projetos de construção inteligentes, devido a disponibilidade de inúmeros produtos de construção “inteligentes" e uma escassez de instrumentos de avaliação.

\subsection{2}

\section{Sistema endereçável digital de controle da iluminação}

O sistema de iluminação vem se desenvolvendo nas duas últimas décadas e há uma gama de tecnologias voltadas para o controle de iluminação nas construções inteligentes. Esses edifícios que fornecem aos ocupantes um ótimo ambiente interno são econômicos e eficazes energeticamente, e frequentemente oferecem um sistema multiuso. Tudo isso é possível devido às tecnologias modernas relacionadas a informática, automação e controle. Uma das muitas possibilidades é o conjunto de parâmetros inteligentes de construção a serem controlados com um sistema autômato programável (PLC). Essa solução é abrangente, mas possui um custo elevado. Desde que desejemos controlar apenas um segmento da gama de parâmetros controláveis, podemos usar uma solução mais barata. 
Dali Bus - O design do controle de iluminação DALI é baseado em um dispositivo que incorpora microcontroladores e componentes controlados que se comunicam mutuamente através do barramento DALI. O DALI Bus (Digital Addressable Lighting Interface) correspondente ao padrão internacional. É um sistema de protocolo aberto o que significa que vários fabricantes podem usá-lo para seus produtos. O DALI Bus oferece uma interface unificada para todos os participantes. O esquema de coordenação respeita a hierarquia do escravo mestre. O mestre geralmente atua como uma unidade de controle começando a comunicação e abordando dispositivos escravos individuais. Deve haver pelo menos uma unidade principal em qualquer sistema do DALI (Sysala, T).

\subsection{3}

\section{Sistema de iluminação}

As ações de poupança de energia podem seguir duas orientações básicas: eficiência e eficácia: eficiência, por novos equipamentos mais eficientes (lâmpadas, aparelhos de controle, etc.) e pela utilização de melhores práticas de iluminação (sistemas de iluminação de tarefas localizadas); e através de melhorias nos sistemas de controle de iluminação para evitar desperdícios de energia por meio da adoção de um sistema técnico de gestão de edifícios (manutenção e medição). Ao controlar a iluminação de tal forma que o nível de iluminação seja sempre correspondente à necessidade real do usuário, permite economizar nos custos de energia e melhorar o conforto humano e eficiência. Estabelecer um conceito de controle de iluminação integrado é uma parte muito importante do processo de design de iluminação. Controlando e gerenciando diretamente o consumo de energia, é possível alcançar alta eficácia na gestão de energia. Na Europa, a quantidade de energia elétrica utilizada na iluminação dos interiores de edifícios médios e grandes é de cerca de 40\% do total consumido (Liang et al., 2014).

\subsection{4}

\section{Sistema de layout interno}

A flexibilidade vem sendo utilizada pelo usuário para adaptar o imóvel residencial às suas necessidades, melhorando assim o desempenho do ambiente construído. As construtoras oferecem formas de flexibilização variadas, porém, encontram problemas e dificuldades no processo de flexibilização inicial dos 
apartamentos. Acredita-se que a observação da forma de flexibilização ofertada e das modificações realizadas nos apartamentos personalizados pode evidenciar aspectos que poderiam ser contemplados no projeto, para facilitar e/ou minimizar as alterações durante a obra, aumentando a satisfação dos clientes e diminuindo desperdícios.

Além dos requisitos de desempenho a serem cumpridos por componentes e pelo edifício como um todo, é importante para o sucesso do empreendimento que a concepção satisfaça as necessidades do público alvo. Embora, para a completa satisfação do usuário, seja importante também atender aos aspectos de caráter psicológico e afetivo do usuário com o ambiente concebido.

Apesar do processo de adaptação continuar durante toda a vida útil de uma edificação, é durante a construção que esse processo pode acontecer de modo mais amplo, com menores custos e com menor desperdício de materiais. Sempre que é necessária a demolição de paredes existentes, troca de instalações ou revestimentos para adaptar o ambiente, existem custos extras de trabalho (mão-de-obra) e materiais que são adicionados ao custo inicial de uma habitação (Ebert e Roman, 2006).

Segundo Brandão e Heineck (1998), a satisfação do cliente quanto ao projeto só pode ser atingida e medida em sua plenitude a partir da ocupação e uso do imóvel. No entanto, a flexibilidade durante a construção, se mostra importante para encurtar a distância entre o projeto básico inicial e aquilo que realmente o cliente idealiza.

\subsection{5}

\section{Sistema de fachada em edificações}

A concepção arquitetônica para o desenvolvimento de uma casa inteligente é o resultado de um conjunto de sistemas. Esses sistemas devem operar de forma integrada, oferecendo um vasto campo de serviços aos usuários, permitindo também a incorporação de novos equipamentos e aplicações ditadas pelos avanços tecnológicos (Mattar, 1994).

Para o desenvolvimento de um projeto com as características de um edifício inteligente deve-se considerar os seguintes pontos básicos: conforto; segurança; confiabilidade; flexibilidade; gestão; automação predial e automação dos escritórios. 
O projeto de uma casa inteligente consta da integração dos vários sistemas de instalação e normalmente apresenta arquitetura arrojada. Nesses Edifícios Inteligentes, o planejamento dos acabamentos, referente aos itens: esquadrias metálicas, revestimentos externos, distribuição de energia, iluminação e condicionamento ambiental são elementos importantes na definição de sua eficiência.

Para um resultado otimizado do processo próprio da edificação, é necessário a integração dos projetos: arquitetônico; estrutural; elétrico; decoração; telefonia e dados. Na elaboração desses projetos, normalmente é necessário considerar alguns conceitos tais como (ABCI, 1993): (i) fachada com visual elegante; (ii) eficiência térmica com a utilização de vidros refletivos e semirrefletivos; (iii) forros modulares e removíveis; e (iv) estudo do clima para definir o volume de massa das paredes (massas maiores para climas com variações bruscas e menores para climas secos e quentes).

As janelas devem ser adequadas quanto ao tamanho, forma de abertura e proteção, pois influenciam fortemente na conservação de energia. É importante a boa vedação, mas devem permitir perfeita ventilação.

A utilização da energia solar para o aquecimento da água dos chuveiros, torneiras térmicas, banheiras, etc., é aconselhável para reduzir o consumo de energia elétrica. (ABCI, 1993).

\subsection{6 Rede de interconexão de produtos e sistemas eletrônicos domésticos (HAN)}

O termo HAN foi definido em 2001 (Rose, 2001) como uma rede de interconexão de produtos e sistemas eletrônicos domésticos, permitindo seu controle e acesso remoto para disponibilizar qualquer conteúdo, como música, vídeo e outros dados.

Segundo Kailas et al. (2012), HAN é uma rede para conectar dispositivos capazes de enviar e receber sinais de outros dispositivos e aplicações. HAN é, portanto, um fator habilitador para a evolução da casa inteligente e outras aplicações, como sistemas de gerenciamento de energia doméstica (HEM). Esta rede que liga dispositivos domésticos é fundamental para o conceito de uma casa inteligente, pois uma HAN pode compreender várias redes diferentes de tecnologias 
para melhor atender aos requisitos do sistema. Dependendo do tipo de rede, a infraestrutura pode ter uma taxa de dados maior ou uma interação de aplicativo mais complexa. Estas características afetam o custo da infraestrutura desta rede. As Hans dependem do IP, que é a base sobre a qual a Internet é construída. De acordo com Kailas et al. (2012), devido à fácil interoperabilidade dos IPs, e sua adoção generalizada, são considerados essenciais para o sucesso dos HANs. A infraestrutura de casa já usa uma rede baseada em IP. O problema que existe é como integrar o enorme número de dispositivos e componentes baseados em IP com dispositivos não baseados em IP. Essa conexão pode ser feita com um gateway multiprotocolo que faz a ponte de uma rede não-IP específica para a rede baseada em IP (Chen et al., 2014).

Existem as HANs com fios e sem fios. As tecnologias com fio foram as primeiras a aparecer, podendo ainda ser adotadas para diferentes propósitos, por exemplo, baixo custo ou o uso de uma infraestrutura pré-existente. HANs com fio podem usar linhas de energia, linhas telefônicas, cabos coaxiais, pares trançados ou tecnologias mais recentes, como fibra óptica como meio de comunicação.

As tecnologias sem fios têm sido intensamente pesquisadas e desenvolvidas nos últimos anos. Espera-se que elas desempenhem um papel fundamental para promover o conceito de casa digital (Vaxevanakis, 2003).

Os HANs sem fio podem variar do popular Wi-Fi e ZigBee em casa, até novos padrões, como o 6LoWPAN que otimiza o IPv6 para uso de baixa tecnologia de comunicação, um padrão da Internet Engineering Task Force (IETF)-off envolve consumo de energia, cobertura de sinal, sensibilidade à interferência, segurança e instalação de infraestrutura (Kailas et al., 2012). Em resumo, os HANs têm diferentes tecnologias que especificam as camadas físicas e de rede.

A proliferação de dispositivos conectados usando um portfólio crescente de tecnologias, padrões de rede e requisitos dificulta muito a manutenção de características de desempenho estável, mas é uma característica-chave para serviços emergentes e aplicações conceituais neste ambiente de casa inteligente.

\subsection{7}

\section{Sistema de gerenciamento ambiental interno e externo}

Os sistemas autoadaptativos são comumente definidos na literatura como aqueles capazes de modificar-se automaticamente em resposta a mudanças em seu 
ambiente operacional (Krupitzer, 2015). Isso requer autoconsciência e conscientização do contexto, ou seja, o sistema deve estar ciente de seu próprio estado por meio do monitoramento de ambos os recursos existentes e seu contexto. Govindan (2014) cita a Internet das Coisas e cita o kit casa inteligente de Shaspa Define como uma plataforma aberta que emprega uma rede de sensores inteligentes para fornecer informações sobre o estado da casa. Estes sensores monitoram sistemas de gerenciamento ambiental interno e externo.

Este sistema de gerenciamento ajuda nos cuidados domiciliários para idosos, pois as casas inteligentes são equipadas com sensores, atuadores e outros aparelhos. Este é também o caso em aplicações de cuidados domiciliares, para as quais são necessários mecanismos para definir e processar a detecção e processamento de sinais biomédicos e ambientais (Mozer, 1998).

\subsection{8}

\section{Sistema de detecção de posicionamento não invasivos}

Kivimäki et al. (2014) comparam diversos sensores não invasivos, que garantem a privacidade dos habitantes da casa, detectando o seu posicionamento em relação aos móveis e cômodos da casa. Tecnologias que, além de complementarem as atividades físicas, podem auxiliar na segurança da casa.

De acordo com Kivimaki et al. (2014), diversos sistemas são usados de forma distinta, principalmente para pessoas idosas, no monitoramento de queda e na realização de movimentação e reconhecimento dentro das casas inteligentes.

O sistema de célula de carga, por exemplo, normalmente coloca as células sob os cantos dos painéis de modo a que cada célula de carga meça a soma das contribuições dos cantos de quatro telhas adjacentes separadas. Estas células sentem a força vertical e permitem que o sistema determine a localização do usuário no chão. A precisão da localização é igual ao tamanho da telha.

Outro sistema de posicionamento é o de superfícies pixeladas que, em vez de usar sensores separados como num sistema de célula de carga, utilizam superfícies pixelizada constituídos de vários sensores individuais (Figura 3.1). 


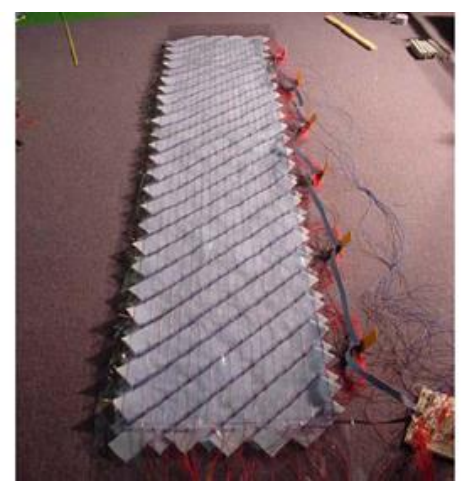

Figura 3.1 - Superfícies pixeladas

Fonte: Kivimaki et al. (2015).

Como os sensores são binários (chaves liga/desliga), este sistema só pode detectar se uma pessoa está em pé sobre o tapete.

Outra opção é o filme eletromecânico (EMFi): um filme de polipropileno fino e flexível disponível no mercado revestido com eletrodos de metal. EMFi é capaz de armazenar uma grande carga permanente. Se uma força externa afeta a superfície da EMFi, ocorre uma alteração da carga entre os eletrodos, detectado como uma tensão. No entanto, como EMFi reage apenas a alterações da pressão, não pode ser usado para detectar as pessoas imóveis, como uma pessoa que tenha caído no chão.

Outro sistema, o Z-Tile usa nós modulares que podem ser conectados para criar áreas de posicionamento de várias formas e tamanhos. Cada nó tem 20 resistores sensíveis à força hexagonais em sua superfície e devido à sua forma, os nós podem se interligar. Os azulejos entrelaçados formam uma rede de autoorganização. Um nó funciona como uma fonte de energia e uma porta de entrada para a rede de dados, como ilustra a Figura 3.2.

A principal desvantagem deste sistema é que o volume dos dados a serem produzidos é tão alta que o processamento de dados é problemático se for para abranger grandes áreas.

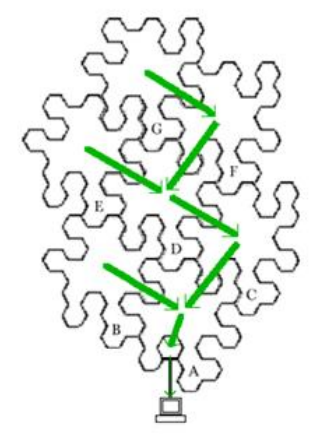


Figura 3.2 - Rota do sistema Z-Tile

Fonte: Kivimaki et al. (2015).

Outro sistema é o tapete inteligente, onde sensores são incorporados em tecidos de um tapete (Figura 3.3). Cada nó é de $15 \times 15 \mathrm{~cm}$ e funciona como uma placa para um sensor capacitivo. Caminhar sobre o tapete ativa esses sensores. $\mathrm{O}$ computador que executa os cálculos de posição conecta-se apenas a um nó. Quando um passo ativa um nó, o nó envia um pacote de ativação do sensor para o nó vizinho, que, em seguida, encaminha o caminho mais curto para o computador.

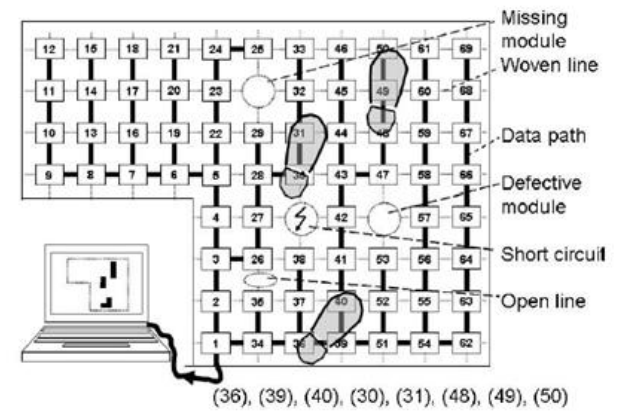

Figura 3.3 - Estrutura do tapete inteligente

Fonte: Kivimaki et al. (2015).

\subsection{9}

\section{Smart furniture}

Dentre as diversas soluções tecnológicas desta subcategoria, destaca-se um sistema de identificação de objetos, devolvendo a posição deles em relação aos cômodos e aos móveis. A intenção ao desenvolver essa solução é encontrar objetos perdidos. O que pode servir, também, para identificar objetos novos dentro do ambiente (Huynh et al., 2014).

Outro diferencial proposto pelo italiano Enrico Denti (2014) seria um "mordomo" para comandar os eletrodomésticos da casa de acordo com as necessidades e desejos do morador, além de coordenar todo o monitoramento de sua saúde e atividades físicas. Esse tipo de coordenação pode influenciar diretamente a vida quotidiana, através de conselhos: economia de energia, água e consumo de produtos em geral. Esse mordomo poderia ser responsável por integrar todas as tecnologias.

Outra tecnologia inovadora, proposta por Denti (2014) refere-se ao uso de aparelhos interativos como um smartphone, projeções 3D e de um "avatar" robótico, por exemplo. 
Govindan, (2014) aborda a 'Internet das Coisas' e cita o kit casa inteligente de Shaspa: é uma plataforma aberta que emprega uma rede de sensores inteligentes para fornecer informações sobre o estado da casa. Estes sensores monitoram sistemas tais como geração de energia e medição; aquecimento, ventilação e ar condicionado (AVAC); iluminação; segurança; e indicadores de desempenho ambiental. Utilizando a ponte de "Shaspa - SmartGate", esta informação é processada e disponibilizada através de um número de métodos de acesso como telas sensíveis ao toque, telefones celulares e navegadores de 3-D. Esta tecnologia, com base na incorporação de banco de dados, ajuda a gerenciar dados diversificados e interativos, além de permitir a provedores de eletrodomésticos combinar a tecnologia com aplicativos de análise de negócios não só para melhorar a experiência do usuário final, mas para ajudar os usuários finais a tomar as decisões na casa.

\section{2}

\section{Automação residencial}

Descrevem-se as principais soluções tecnológicas referentes à categoria "Automação residencial", abordando-se os seguintes tópicos: (i) sistema endereçável de detecção de incêndio e alarme; (ii) sistema de dados e telecomunicação (PLC); (iii) sistema integrado de gerenciamento de edificações; (iv) sistema de monitoramento da segurança e controle de acesso; (v) sistema de iluminação; (vi) sistema de layout interno; (vii) sistema de fachada em edificações; (viii) sistema vertical de transporte; (ix) rede de interconexão de produtos e sistemas eletrônicos domésticos (HAN); (x) sistema de gerenciamento ambiental interno e externo; (xi) sistemas de detecção de posicionamento não invasivos; e (xii) smart furniture.

\subsection{1}

\section{Sistema endereçável de detecção de incêndio e alarme}

A segurança refere-se à detecção de situações anormais dentro da casa inteligente, como por exemplo incêndios, inundações, acidentes, e também à detecção de comportamentos maliciosos, como por exemplo assaltantes e acesso não autorizado. Para a detecção, sinalização e resposta a tais situações de violação de segurança, as casas inteligentes são equipadas com subsistemas para vigilância 
por vídeo, monitoramento remoto, alarme e resposta de emergência (Badica et al., 2013).

Os sensores são elementos essenciais na detecção dessas situações anormais e no caso dos sistemas endereçáveis de detecção de incêndio e alarme são usados sensores para situações de emergência como: gás, fogo, fumaça e enchente.

\subsection{2}

\section{Sistema de dados e telecomunicação (PLC)}

A tecnologia PLC é vista como uma plataforma para diversas aplicações de redes inteligentes, incluindo o monitoramento em tempo real e balanceamento de carga, integrando fontes alternativas de energia para a rede, permitindo medição inteligente em frequentes leituras do medidor fornecendo ao usuário final informações sobre o uso de carga, podendo usar isso para otimizar a geração de energia e realizar o gerenciamento de carga com granularidade cada vez mais fina e assim economizar em custos de energia.

Isso permite que a rede elétrica seja o barramento de comunicação entre o módulo de leitura remoto e o modulo concentrador, que é conectado a um computador. O sistema proposto com os dispositivos distribuídos em uma residência com os MR - Módulo Remoto e o MC - Módulo Concentrador, onde os dados coletados são apresentados no sistema de supervisão livre, SCADABR e também armazenados em um PC, no qual o mesmo foi proposto para o gerenciamento do consumo de energia de equipamentos em uma residência ou pequena empresa (Figura 3.4). 


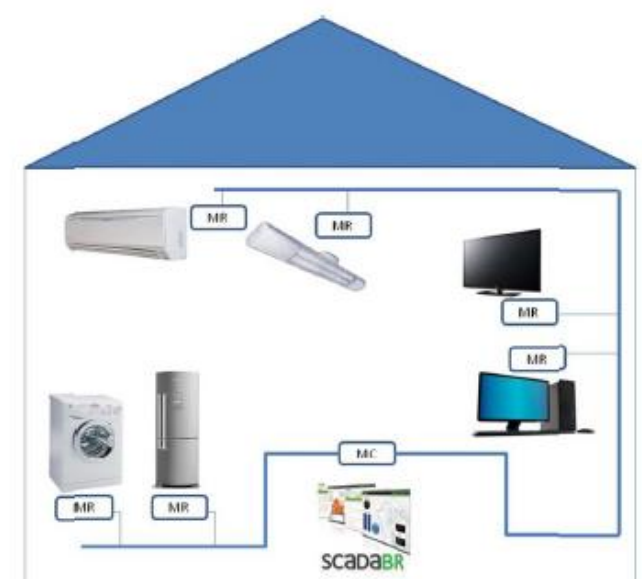

Figura 3.4 - Distribuıçao dos modulos remotos (MK) e Modulo Concentrador (MC) para aquisição de informações

Fonte: Leme (2016).

\subsection{3}

\section{Sistema integrado de gerenciamento de edificações}

A função dos sistemas de gestão de edifícios é controlar, monitorizar e otimizar os serviços de construção, tais como iluminação, aquecimento, segurança, sistemas de televisão e alarme de circuito fechado, controle de acessos, sistemas audiovisuais e de entretenimento, ventilação e climatização, Controle de presenças e apresentação de relatórios (Nguyen et al., 2003).

Um edifício inteligente, que pode ser definido de muitas maneiras, é geralmente entendido como "aquele que fornece um ambiente produtivo e de baixo custo através da otimização de seus quatro elementos básicos, incluindo estruturas, sistemas, serviços e gestão e as inter-relações entre eles". Ou mesmo como "aquele que cria um ambiente que maximiza a eficácia dos ocupantes do edifício, ao mesmo tempo que permite a gestão eficiente de recursos com o mínimo de custo de hardware e instalações"(Wigginton et al., 2002).

De acordo com Balta-Ozkan et al. (2013), uma casa inteligente pode ser caracterizada por quatro aspectos: (i) infraestrutura de rede de comunicação; (ii) controle inteligente e gestão; (iii) rede de sensores ao redor da casa; e (iv) recursos inteligentes, respostas automáticas de sensores e insumos humanos. No entanto, a essência de uma casa inteligente é a tecnologia de informação e comunicação distribuídos em toda a casa, aparelhos e sistemas de coleta e recebimento de informações para fornecer feedback para os usuários e sistemas de automação e gestão inteligente (Wilson et al., 2015; 2017). 


\subsection{4}

\section{Sistema de monitoramento da segurança e controle de acesso}

O sistema de controle de acesso deve funcionar como um supervisor eletrônico da movimentação de todas as pessoas. O sistema deve classificar as pessoas (funcionários, visitantes, técnicos da manutenção e outros) pelas atividades desenvolvidas no recinto, possuindo capacidade de gerenciar a seletividade de entrada, emitindo relatórios de movimentação, controlando inclusive o ponto de frequência dos empregados e das pessoas que se movimentam pelo recinto (Nastrini, 1999).

O monitoramento da porta é um elemento essencial de segurança e facilmente utilizado por pessoas com suas capacidades físicas resguardadas, porém para os cadeirantes, condição comum dos paraplégicos, essa ação não é tão simples, o que reforça a necessidade de um mecanismo que lhes possibilite e facilite essa função. Para tanto, os sistemas CFTV, parecem ser os mais indicados.

Os componentes básicos de um sistema de CFTV são as câmeras e monitores podendo integrar também motores para rotação para maior abrangência do campo de visão. Os modelos de câmeras podem variar muito, assim como seus preços, dependendo de suas aplicações. Vão desde dispositivos pequenos, para não serem percebidos, até os grandes equipamentos, de uso profissional, podendo ou não fazer gravação de sons. Quanto aos monitores, existem vários tipos dedicados a essa função que suprem bem sua finalidade, no entanto, é cada vez mais recomendável fazer uma integração entre o CFTV e o sistema de vídeo de TV a cabo, satélite ou antena, possibilitando aos moradores ter a imagem gerada pelo CFTV em qualquer um dos televisores da casa, num canal designado para este fim.

Em um sistema automatizado, o morador da casa possui sua chave eletrônica que pode abrir todas as portas da residência sem a necessidade de carregar várias chaves comuns. Essas "chaves" não necessariamente são objetos físicos, podendo ser um reconhecimento de voz, facial ou de impressão digital, sendo assim, impossíveis de serem copiadas e extremamente seguras. Se integrada a outros serviços, a chave eletrônica pode ainda servir para desarmar o sistema de alarme e acionar uma cena pessoal de iluminação, acendendo parcialmente as luzes da sala, ligando a TV e/ou reproduzindo uma saudação por voz personalizada. Se alguém tentar desligá-lo ou danificá-lo, todo o sistema de alarmes pode ser acionado avisando o usuário ou empresa de segurança contratada. Todos os eventos são 
registrados e armazenados na central de controle de acessos e na central de segurança para melhor monitoramento (Ferreira, 2010).

\section{2 .5}

\section{Sistema vertical de transporte}

Os sistemas de transporte verticais incluem todos os tipos de meios de transporte dentro de edifícios, tais como elevadores, escadas rolantes, guinchos hidráulicos, transportadores de passageiros, dentre outros. Pode ser considerado o sistema de serviços de edifício mais importante para os prédios com grandes alturas. Cada ocupante de um prédio comercial deste porte precisa usar os elevadores pelo menos quatro vezes por dia, de manhã, durante o almoço e depois do horário de expediente.

Um elevador é uma peça permanente de equipamento de elevação, que serve dois ou mais níveis de pouso, provido de um carro ou plataforma para transporte de passageiros ou frete, rodando pelo menos parcialmente em guias rígidas ou vertical. Existem, em geral, duas grandes categorias de elevadores, nomeados elevadores elétricos e elevadores hidráulicos. Do ponto de vista do objetivo operacional, os elevadores podem ser classificados em quatro ou cinco tipos: elevadores de passageiros, elevadores de mercadorias (frete), elevadores de serviços, elevadores de combate a incêndios e elevadores de veículos. Para aplicações muito especiais, existem outros elevadores, como elevadores de cadeira de rodas, elevadores de observação, elevadores de tesoura e elevadores de cremalheira.

\subsection{6}

\section{Outras soluções}

As soluções tecnológicas referentes a sistemas de iluminação; sistemas de layout interno; e sistemas de fachada em edificações foram abordadas anteriormente nos itens 3.1.3; 3.1 .4 e 3.1.5, respectivamente. As Redes de interconexão de produtos e sistemas eletrônicos domésticos (HAN) foram abordadas no item 3.1.6. Já os sistemas de gerenciamento ambiental interno e externo; sistemas de detecção de posicionamento não invasivos; e smart furniture foram abordados, respectivamente, nos itens 3.1.7; 3.1.8 e 3.1.9. 


\section{3}

\section{Acesso remoto}

As principais soluções tecnológicas referentes a categoria "Acesso remoto" foram abordadas em seções anteriores, a saber: (i) sistema de dados e telecomunicação (PLC), no item 3.2.2; (ii) sistema endereçável digital de controle da iluminação, no item 3.1.2; (iii) sistema integrado de gerenciamento de edificações, no item 3.2.3; e (iv) sistema de fachada em edificações, no item 3.1.5.

\section{4}

\section{Segurança de rede e de informação}

Nesta categoria, descrevem-se as principais soluções tecnológicas referentes a 'sistemas de informação e rede de comunicação'. Outras soluções tecnológicas que integram esta categoria foram abordadas em seções anteriores, a saber: (i) sistema de monitoramento da segurança e controle de acesso, no item 3.2.4.

\subsection{1 \\ Sistemas de informação e rede de comunicação}

As alterações em direção à mudança tecnológica têm se caracterizado por uma progressiva desintegração de atividades de projeto (design) de produtos e serviços das atividades de produção. Uma das causas dessa mudança é a aplicação de melhorias em Tecnologias da Informação e da Comunicação (TICs). A TIC tem facilitado o intercâmbio de informação e conhecimento codificado dos designers para a manufatura. Isto, por sua vez, é consequência do processo de codificação que se iniciou quando as empresas começaram a instalar seus sistemas integrados de Tecnologia de Informação (TI). Como resultado, as atividades de desenho e Pesquisa e Desenvolvimento (P\&D) permaneceriam em países tecnologicamente avançados, principalmente TIC e suas aplicações, ou seja, as atividades inovadoras em serviços, enquanto que países em desenvolvimento estariam confinados às atividades de manufatura (Pavitt, 2002).

Uma rede inteligente é uma rede elétrica inteligente que otimiza a geração, distribuição e consumo de eletricidade através da introdução de Tecnologias de Informação e Comunicação na rede elétrica. Em essência, as redes inteligentes trazem profundas mudanças nos sistemas de informação que os impulsionam: novos fluxos de informação provenientes da rede elétrica, novos players como 
produtores descentralizados de energias renováveis, novos usos como veículos elétricos e casas conectadas e novos equipamentos de comunicação, como medidores inteligentes, sensores e pontos de controle remoto. Tudo isso causará um dilúvio de dados que as empresas de energia terão de enfrentar. As tecnologias Big Data oferecem soluções adequadas para utilitários, mas a decisão sobre qual tecnologia Big Data usar é fundamental (Daki et al., 2017).

\section{5 \\ Cuidados com a saúde (Healthcare)}

Nesta categoria, descrevem-se as principais soluções tecnológicas referentes a 'sistemas de monitoramento da saúde'. Outras soluções tecnológicas que integram esta categoria foram abordadas em seções anteriores, a saber: (ii) sistema integrado de gerenciamento de edificações, no item 3.2.3; (iii) sistema de layout interno, no item 3.1.4; (iv) sistema vertical de transporte, no item 3.2.8; (v) sistemas de detecção de posicionamento não invasivos, no item 3.1.8; e (vi) smart furniture, no item 3.1.9; e sistema de gerenciamento ambiental interno e externo no item 3.1.7.

\subsection{1 \\ Sistemas de monitoramento da saúde}

No campo da medicina, é possível monitorar temperatura corporal, frequência cardíaca, a atividade do cérebro, movimento e outros dados críticos. É importante ter sensores muito leves que podem ser usados no corpo, para executar acompanhamento médico padrão.

É possível medir a pressão arterial usando sensores portáteis através de uma modificação técnica que elimina a necessidade de um manguito de pressão inflável. $\mathrm{Na}$ área do desporto e formação há uma tendência crescente de usar vários sensores portáteis. Algo, como por exemplo, medição da taxa de suor. O uso de sensores portáteis tornou possível o tratamento em casa para os pacientes após um ataque de doenças como ataques cardíacos, apneia do sono, doença de Parkinson e assim por diante. Todos os sinais fisiológicos, bem como atividades físicas do paciente são possíveis de ser monitoradas com a ajuda de sensores portáteis/vestíveis. Durante a reabilitação pós-operatória os sensores portáteis podem fornecer feedback de áudio, imagens de realidade virtual e outros serviços de reabilitação. 
Mukhopadhyay (2015) cita que os sensores abaixo são os mais vulgarmente utilizados para monitoramento de atividade de seres humanos. Sensores capacitivos flexíveis, fabricados a partir de remendos têxteis, e condutores para medir capacitância do corpo humano têm sido usados e podem revelar informações das atividades humanas, como a inclusão da frequência cardíaca e respiração, monitoramento da frequência, reconhecimento de gestos de mão, deglutição, monitoramento e análise da marcha (Figuras 3.5 e 3.6).

No monitoramento de atividades realizadas por idosos destaca-se um sistema abrangendo três atividades: ingestão de comprimidos; uso do telefone; e preparação de café. Foi desenvolvido um conjunto de sensores, chamado DwellSense, projetado para monitorar três diferentes atividades que são importantes pela independência e comumente utilizado em avaliações clínicas. Estas três atividades foram selecionadas porque elas exigem habilidade cognitiva e são realizadas numa base regular, tornando-as assim tarefas ideais para medir a função cognitiva e capacidades do indivíduo ao longo do tempo.

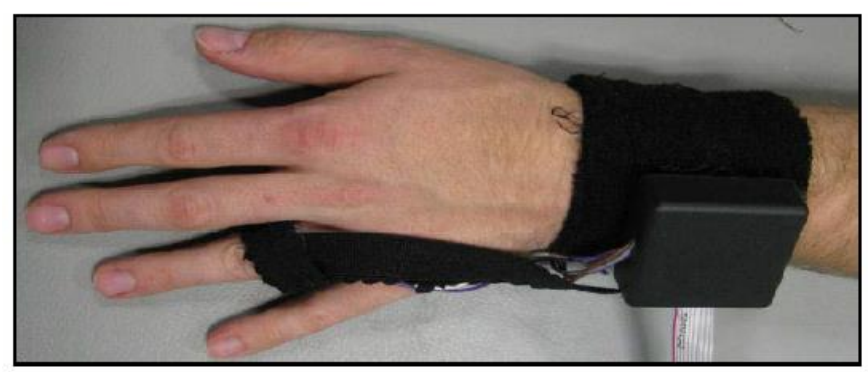

Figura 3.5 - Sensor para monitoramento de atividades Fonte: Mukhopadhyay (2015).

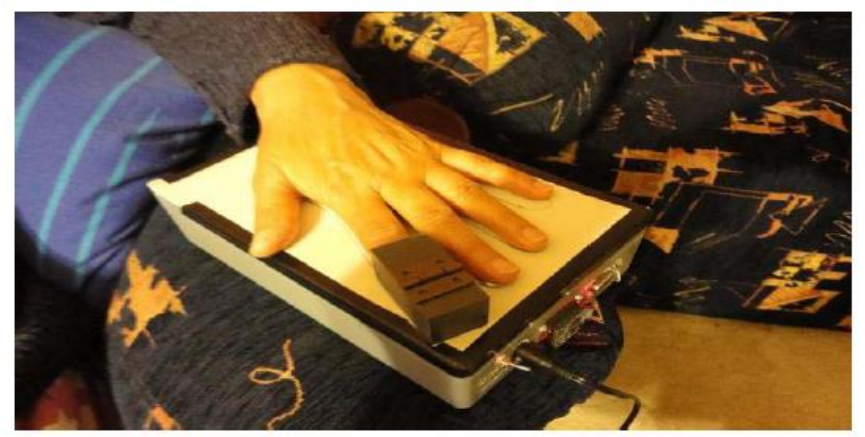

Figura 3.6 - Outro exemplo de sensor para monitoramento de atividades Fonte: Mukhopadhyay (2015). 
Para monitorar a tarefa ingestão do comprimido, desenvolveu-se um inteligente "pillbox" (Figura 3.7) que monitora quando a porta foi aberta e como a caixa foi manipulada. $\mathrm{O}$ projeto acrescenta um acelerômetro que pode controlar a forma como indivíduos lidou com a caixa e se o pillbox foi invertido (uma estratégia comum para remover as pílulas porque os dedos dos adultos mais velhos, muitas vezes não se encaixam confortavelmente dentro da caixa). Os componentes eletrônicos, incluindo um microcontrolador, um cartão ZigBee sem fios, e uma bateria, são montados em um compartimento adjacente (na verdade, uma segunda caixa de comprimidos com os divisores removido). A casamata inteligente é facilmente agarrada e tem uma aparência quase idêntica à de um pillbox (Lee et al., 2015).
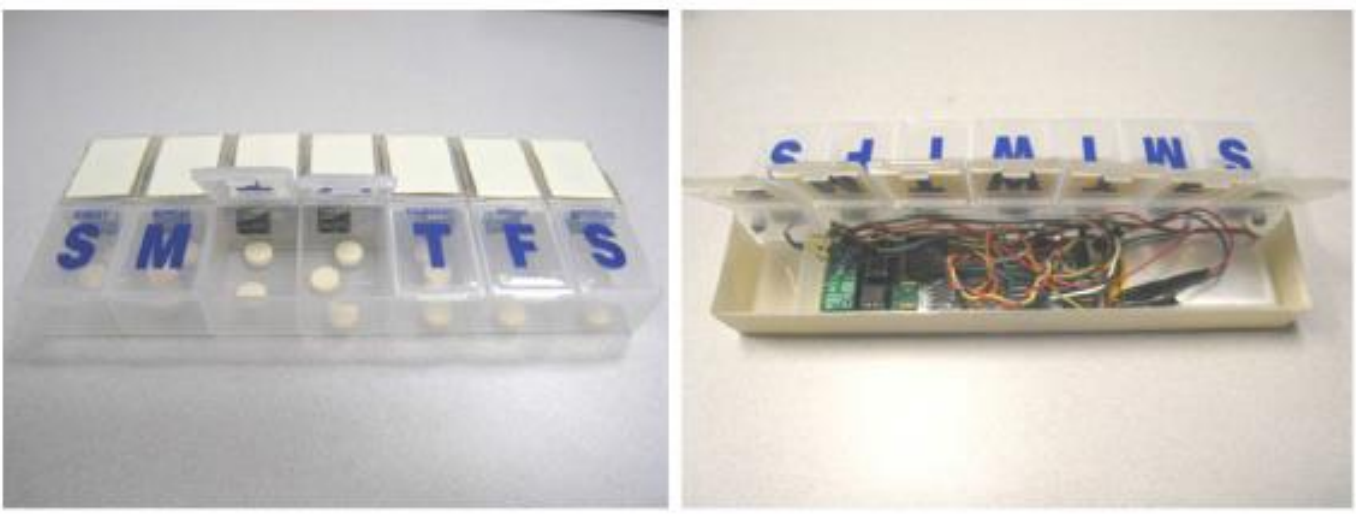

Figura 3.7 - Caixa de medicamentos - pillbox Fonte: Lee et al. (2015).

Para monitorar o uso do telefone, foi desenvolvido um circuito personalizado (Figura 3.8) conectado diretamente à linha telefônica. O circuito usa um chip de decodificação Mitel MT8870 DTMF para monitorar que os números são discados, se o telefone está ligado ou fora do gancho, e a duração das chamadas telefônicas. Um modem monitora as chamadas. Tanto o sensor de telefone e o modem são " invisíveis " em sua operação para o usuário, uma vez que não afeta as chamadas dos usuários (Lee et al., 2015). 


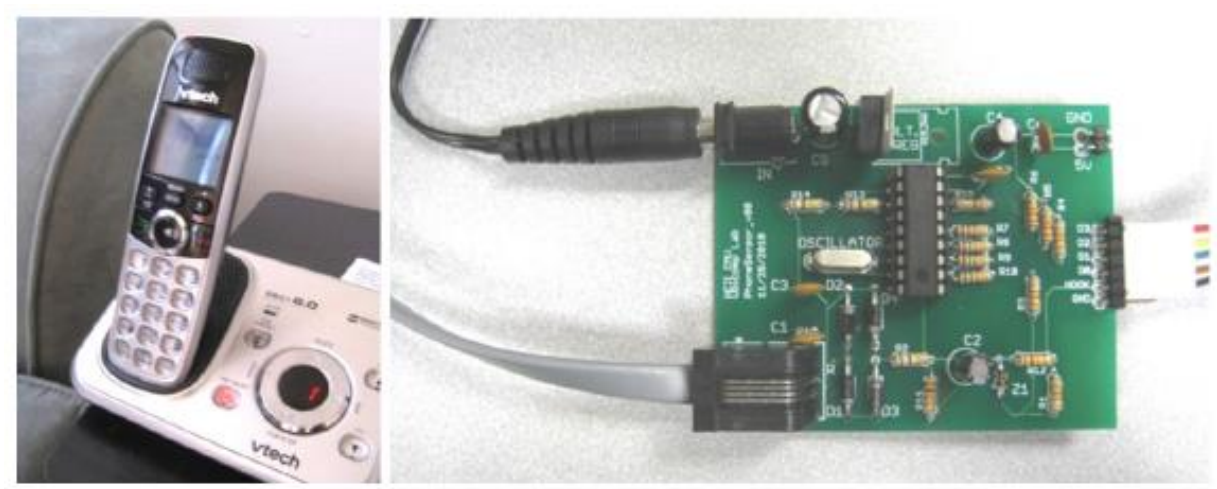

Figura 3.8 - Monitoramento telefônico

Fonte: Lee et al. (2015).

Para monitorar a tarefa multipasso de fazer uma jarra de café, uma máquina de café foi instrumentada com sensores (Figura 3.9) que pisca quando a porta reservatório de água ou filtro é aberto e fechado, se a garrafa estiver no lugar, a quantidade de água utilizada, e se a máquina for ligada ligado ou desligado. Embora existam muitas sequências aceitáveis na ação para fazer café, ainda existem restrições na ordem de passos que podem ser úteis para a identificação de erros ou ineficiências (Lee et al., 2015).

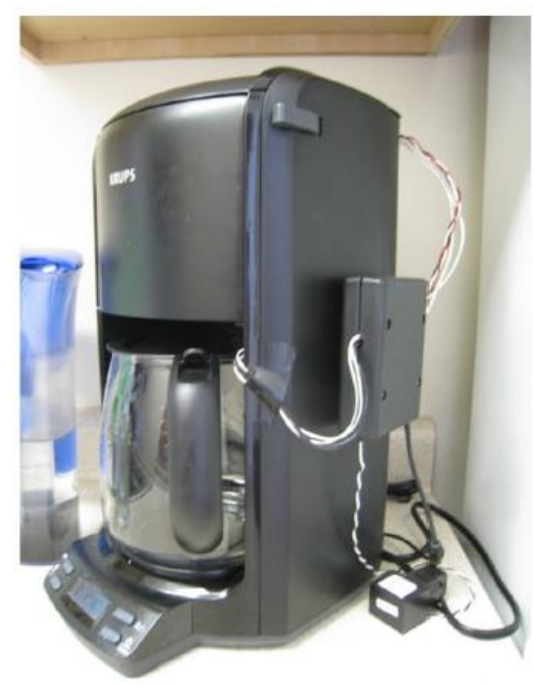

Figura 3.9 - Monitoramento de preparação de café Fonte: Lee et al. (2015).

Chernbumroong (2015) argumenta que a atividade de reconhecimento de uma pessoa pode ser usada para fornecer informações e serviços inteligentes para profissionais de saúde, cuidadores, pessoas idosas e suas famílias para que os idosos possam permanecer em casas de forma independente. Este estudo investiga o uso e contribuição de multisensores usados no pulso para o reconhecimento de atividades. 
Descobriu-se que acelerômetros são os sensores mais importantes e podem ser usados para aumentar a classificação de atividades com diversas frequências cardíacas.

Yuan (2014) apresenta um sistema de saúde generalizado - Context-Aware Real-time Assistant (CARA) - que desempenha um papel crucial através da interpretação de dados de sensores para avaliação da situação e realização de ações. Os componentes do CARA são:

- Sensores sem fio: um componente-chave do sistema é uma rede de área corporal chamado BAN, ou seja, um dispositivo portátil eletrônico capaz de monitorar e comunicar os sinais vitais do paciente, e isso inclui sensores médicos, como o ECG, medidor de $\mathrm{SpO} 2$, sensor de temperatura e o sensor de mobilidade;

- Sensores de casa inteligente: um sistema de controle ambiental equipado com uma rede de sensores sem fio e uma máquina de raciocínio. Um rico conjunto de sensores podem ser utilizados para o monitoramento dos ambientes da casa;

- Sistema de monitoramento remoto: este é responsável pela medição fisiológica remota e contínua dos sinais dos idosos através do BAN, monitoramento do ambiente através da rede de sensores inteligentes para casa, e transmissão em tempo real;

- Sistema de análise de vídeo: projetado para um consultor médico ou cuidador para revisar os dados previamente recolhida a partir do idoso no caso dele estar disponível para o monitoramento em tempo real.

Sinais vitais do paciente são monitorados por diferentes tipos de sensores sem fios dentro de um BAN, e sensores ambientais são implantados para monitorar os arredores de casa. Todos os dados de medição são transmitidos a um gateway (muitas vezes um PC ou um telefone inteligente) através de conexão sem fio. A aplicação móvel faz as leituras de sensores wearable e o próprio telefone inteligente realiza a atividade (sentado, deitado, de pé, movendo-se, de rolamento). Estes, juntamente com outros contextos ambientais e fisiológicos são transferidos para o computador através de uma conexão bluetooth em tempo real.

Amay (2014) apresenta um dispositivo para medição de glicemia através de fluidos da pele (“Tatuagem”). É uma "tatuagem temporária" capaz de medir a glicose e foi projetada para ser aplicada diretamente em um braço e não causar 
desconforto. O dispositivo ultrafino gera uma corrente imperceptível capaz de atrair íons de sódio envolvidos no transporte de glicose presentes no fluido entre uma célula e outra (Figura 3.10).

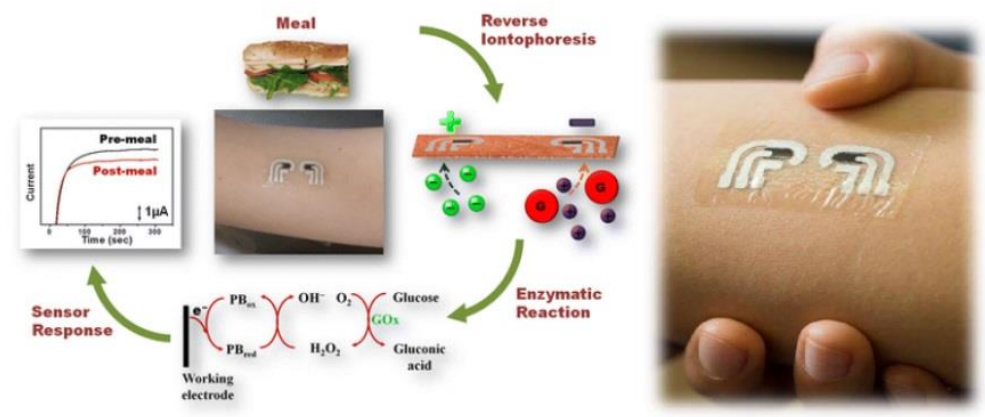

Figura 3.10 - Tatuagem para medição de glicemia

Fonte: Amay (2014).

Outra tecnologia, em desenvolvimento pela Echo Therapeutics, é a medição do nível de glicemia através de sensores bioquímicos sem fio (Figura 3.11).

Trata-se de um sistema de monitoramento contínuo da glicose transdermal através de uma rede sem fio e livre de agulhas chamado Symphony tCGM para diabéticos composto por 3 componentes básicos: o Prelude SkinPrep System, dispositivo aproximadamente do tamanho e forma de um barbeador elétrico, que raspa a superfície morta mais externa da pele (microdermoabrasão), deixando uma mancha do tamanho de uma moeda; um biosensor de glicose que é aplicado em geral no peito ou parte superior das costas e também um dispositivo sem fio que lê os níveis de glicose do biosensor. O sensor contém uma enzima que reage com a glicose e retransmite a indicação como um sinal elétrico. O impulso passa sem fio para um computador de mão, que registra as informações e monitora as leituras.

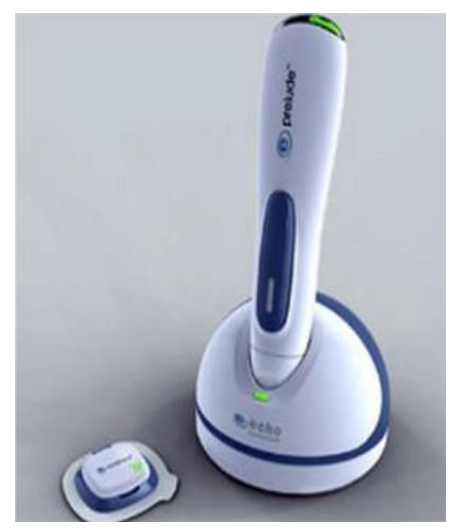

Figura 3.11- Aparelho medidor de glicemia

Fonte: Miraculins, INC (2015) 
A Miraculins INC, do Canadá, desenvolveu o Miraculins SCOUT DS (R), um método altamente sensível e conveniente para a detecção da pré-diabetes e diabetes do tipo 2, que funciona com base na presença de marcadores relacionados com a diabetes encontrados na pele. Não precisa de sangue e não requer jejum. $\mathrm{O}$ paciente coloca um antebraço na unidade portátil de mesa e um resultado quantitativo é relatado em menos de quatro minutos (Figura 3.12).

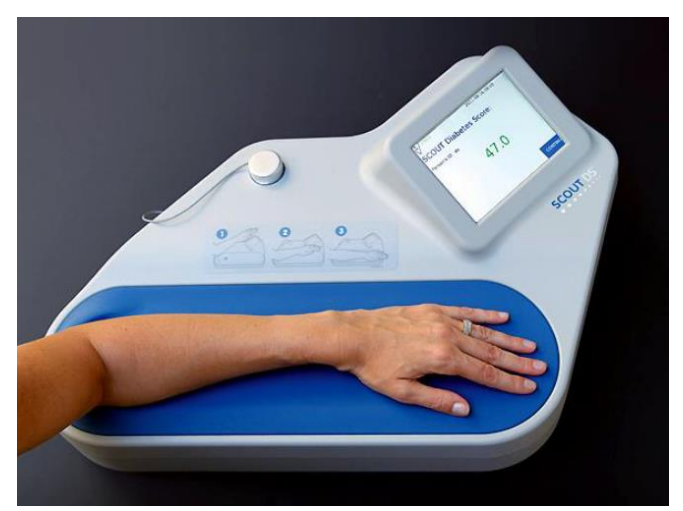

Figura 3.12 - Aparelho para detecção de pré-diabetes Fonte: Miraculins, INC (2015).

\section{6 \\ Uso eficiente de recursos naturais}

Apesar da ausência de uma definição largamente partilhada, o uso da terminologia "construção sustentável" está aumentando rapidamente. O setor de construção está recebendo crescente atenção nas políticas mundiais de desenvolvimento sustentável (UNEP-SBCI, 2009). Esta atenção ao setor resulta do seu consumo de energia e emissões de GEE (Gases de Efeito Estufa) que, nos países desenvolvidos, representam respectivamente 30 e $40 \%$ das quantidades totais (Parry, M et al. 2007.; UNEP-SBCI, 2009).

O Eurostat (2011) mostra que o consumo no setor das famílias é maior do que o consumo nos setores dos transportes ou da indústria. Além disso, os dados da Energy Information Administration (EIA) mostram que o consumo de energia e as emissões de GEE nos edifícios estão aumentando em um ritmo mais elevado do que nos outros setores (Akashi e Hanaoka, 2012; Lombard, 2007). 
O conceito de desenvolvimento sustentável remonta aos anos 70. A Conferência das Nações Unidas sobre o Meio Humano, em 1972, foi a primeira grande reunião internacional para discutir a sustentabilidade em uma escala global. Criou um impulso considerável e uma série de recomendações que mais tarde levaram à criação do Programa das Nações Unidas para o Meio Ambiente (PNUMA). A definição mais famosa foi dada em 1987 pela Comissão Brundtland (WCED, 1987), que afirmava que "o desenvolvimento sustentável é um desenvolvimento que satisfaz as necessidades do presente sem comprometer a capacidade das futuras gerações de satisfazerem as suas próprias necessidades".

Analisando o denominador comum das definições de desenvolvimento sustentável, foram identificadas algumas peculiaridades e incertezas: dependem do tempo, incluem vários níveis de espaço (e escala), múltiplas dimensões e tem dependências sociais (Grosskurth e Rotmans, 2005).

As ferramentas de medição foram recentemente oferecidas por sistemas de avaliação de sustentabilidade que, apesar de várias diferenças, compartilham um quadro comum do que é um edifício sustentável. Ao longo dos anos, esses sistemas têm contribuído para aumentar a conscientização sobre os critérios e objetivos de sustentabilidade, e se tornaram um marco de referência para avaliar a sustentabilidade dos edifícios. De acordo com estes sistemas, um edifício é sustentável se for construído de uma forma ecologicamente orientada que reduz o seu impacto sobre o ambiente (Berardi, 2012).

Um edifício é sustentável se representa um ambiente construído saudável, baseado em princípios ecológicos e eficiência de recursos (Hill e Bown,1997). Ao desagregar esta definição, um edifício sustentável tem de ter alta eficiência no uso de energia, água e materiais e impactos reduzidos na saúde e no ambiente durante todo o seu ciclo de vida (Cassidy, 2003; EPA, 2008). Nessa linha, a redução dos consumos de energia e das emissões de GEE tem sido frequentemente considerada como o parâmetro de avaliação dos edifícios sustentáveis (Lowe, 2007).

O desempenho energético é o parâmetro mais utilizado para avaliar a sustentabilidade de um edifício (Berardi, 2012; Cole, 2004). No entanto, os edifícios sustentáveis são muitas vezes confundidos com edifícios eficientes em energia, como mostra o uso permutável dos termos construção sustentável, construção ecológica e construção de alto desempenho nos EUA (EPA, 2008). 
Considerando as avaliações de longo prazo, impactos multiescala e critérios multidomínio, está surgindo um novo paradigma de edifícios sustentáveis. De acordo com isto, um edifício deve ser projetado e operado para combinar o uso com um impacto ambiental mínimo e deve contribuir fortemente para incentivar melhorias para a sustentabilidade (Berardi, 2011). Isto representa uma evolução significativa da abordagem ambiental simples.

Reed (2007) propôs a mudança do design verde para um projeto regenerativo que considera a evolução do edifício com a natureza de forma sistêmica. Este conceito de construção sustentável ultrapassa a perspectiva ambiental e olha para o edifício como um sistema vivo com fluxos dinâmicos com a natureza. Isto significa que o edifício não pode ser considerado como um simples consumidor de recursos do planeta. Consequentemente, um edifício sustentável deve ser uma entidade ativa que é projetada para ajudar um metabolismo de seres humanos que regenera o ambiente construído dentro do capital natural.

A avaliação da sustentabilidade é sempre realizada com um horizonte temporal e foi demonstrado que a sustentabilidade dos edifícios requer a consideração de todo o ciclo de vida. Isto é difícil de prever porque os edifícios podem existir muito mais do que o esperado. Consequentemente, o que é considerado sustentável em um momento pode ser avaliado como insustentável em outro. A sustentabilidade dos edifícios requer a consideração de requisitos e funções de forma dinâmica, pois os edifícios estão sempre em mutação e são caracterizados por adaptações contínuas de acordo com padrões imprevisíveis de construção, devendo ser capaz de acomodar diferentes mudanças. Um edifício sustentável deve, portanto, aumentar a resiliência do ambiente construído, adaptando-se ao metabolismo de seu contexto.

O sentido de uma comunidade torna-se fundamental para um edifício sustentável. Um edifício sustentável deve aumentar a equidade social, questões culturais e patrimoniais, tradições, saúde humana e infraestrutura social, bem como ambientes seguros e saudáveis.

A Conferência Internacional sobre Construção Sustentável (CIB) reinterpretou as visões de edifícios sustentáveis, originalmente adotadas após a Primeira Conferência Internacional sobre Construção Sustentável em 1994. De acordo com esta nova interpretação (CIB, 2010), foram declarados dez novos princípios para uma construção sustentável: 
- Aplicar os princípios gerais da sustentabilidade e, portanto, promover a melhoria contínua, a equidade, o pensamento global e a ação local, uma consideração de longo prazo da precaução e do risco, da responsabilidade e da transparência;

- Envolver todas as partes interessadas através de uma abordagem colaborativa, de modo a poder satisfazer as necessidades dos ocupantes individual e coletivamente e ser respeitadora e coerente com as necessidades sociais coletivas através da parceria nos processos de concepção, construção e manutenção;

- Integrar-se completamente nos planos e infraestruturas locais relevantes e ligar-se aos serviços existentes, redes, redes urbanas e suburbanas, a fim de melhorar a satisfação das partes interessadas;

- Ser concebido a partir de uma perspectiva de ciclo de vida, abrangendo planejamento, concepção, construção, operação e manutenção, renovação e fim de vida, considerando todas as outras fases durante a avaliação do desempenho em cada fase;

- Ter seu impacto ambiental minimizado ao longo da vida útil (estimada ou remanescente). Isto leva em consideração os requisitos regionais e globais, a eficiência dos recursos, juntamente com a redução de resíduos e emissões;

- Proporcionar valor econômico ao longo do tempo, levando em conta os custos futuros do ciclo de vida de operação, manutenção, remodelação e descarte;

- Proporcionar valor social e cultural ao longo do tempo e para todas as pessoas. Um edifício sustentável deve proporcionar um sentido de lugar para os seus ocupantes, ser visto como um meio de melhorar o status do trabalho para os trabalhadores, e deve ser relacionado e integrado na cultura local;

- Ser saudável, confortável, seguro e acessível para todos. Os critérios de saúde incluem a qualidade do ar interior, enquanto que os critérios de conforto incluem o conforto acústico, térmico, visual e olfativo. Deve permitir condições de trabalho seguras durante a sua construção e vida útil, e plena acessibilidade a todos na utilização das instalações do edifício; 
- Ser 'user-friendly', simples e econômico na operação, com desempenhos mensuráveis sobre o tempo. As regras de operação e manutenção devem estar disponíveis para operadores e ocupantes a qualquer momento. As pessoas devem compreender a filosofia e as estratégias incluídas no edifício e devem ser incentivadas a se comportar de forma sustentável.

- Ser adaptável ao longo da vida útil e com uma estratégia de fim de vida. O edifício tem que permitir a adaptação, alterando os requisitos de desempenho e funcionalidade, de acordo com novas restrições;

A convergência entre estes novos princípios e outros requisitos recentes para a construção sustentável, como os princípios relatados na Declaração de Design de Sustentabilidade da União Internacional de Arquitetos (UIA, 2009), sugere que uma nova visão comum de construção sustentável está surgindo. Resumindo estas recentes interpretações, uma construção sustentável pode ser definida como um projeto fácil e saudável, construída de forma eficiente em termos de recursos, baseando-se nos princípios ecológicos, na igualdade social e no valor de qualidade do ciclo de vida, e promovendo um senso comum de sustentabilidade. De acordo com isso, um edifício sustentável deve aumentar:

- A demanda por construção segura, flexibilidade, valor comercial e econômico;

- A neutralização de impactos ambientais, incluindo seu contexto e sua regeneração;

- O bem-estar humano, satisfação dos ocupantes e direitos das partes interessadas;

- A igualdade social, melhoria da estética e preservação dos valores culturais.

Destacam-se as principais soluções tecnológicas referentes à categoria "Uso eficiente de recursos naturais", a saber: (i) sistema hidráulico e de drenagem; (ii) miniestação de tratamento de águas; (iii) captação de águas pluviais; (iv) miniestação metereológica; (v) biodigestores; (vi) telhados verdes; e (vi) plantação de hortas (solução não tecnológica). 


\section{7 \\ Gerenciamento de energia}

As soluções de geração distribuída de energia encontradas nos artigos publicados para aplicações residenciais e microgrids são predominantemente as que utilizam energia solar, baterias para armazenamento de energia, e dispositivos como boilers, sensores e inversores.

Uma solução a ser aplicada em uma casa inteligente pode ser o módulo PVT ( $P V$ and Solar-Thermal System), ou seja, energia térmica e fotovoltaica montada no mesmo sistema (Figura 3.14).

Este é um sistema que já foi aplicado em países desenvolvidos (Londres, Itália e Canadá), mas não foi encontrado na literatura artigos que falassem desta aplicação em países em desenvolvimento e com grande grau de insolação como o Brasil por exemplo.

Herrando (2014) escolheu-se um PVT comercial. A maioria dos fabricantes instalaram as células fotovoltaicas em cima de um sistema de aquecimento para água, porém esta não é uma tecnologia plenamente madura e sua comercialização está em estágio inicial. Foi utilizado no estudo um PVT/w (water).

(a)

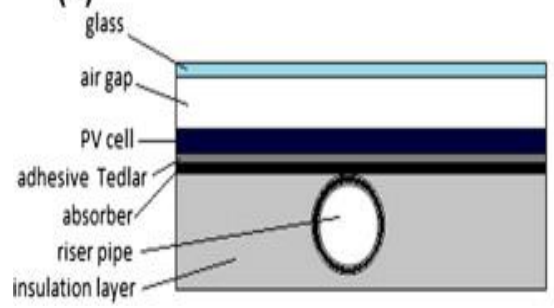

(b)

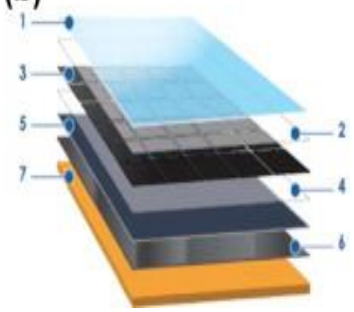

Figura 3.13 - Corte transversal do coletor PVT (a) e camadas do PVT (b) Fonte: Herrando (2014).

Legenda: 1 - Tempered glass (high transmittance); 2 - EVA encapsulating film; 3 - c-Si PV cells; 4. - EVA encapsulating film; 5 - Adhesive plus back-sheet Tedlar; 6 - Aluminium absorber plate plus solar collector ; 7 - Insulating layer

O problema deste sistema é que há um conflito de desempenho, ou eficiência, da parte térmica e da parte fotovoltaica em sistemas deste tipo. Este conflito eleva demais o custo do PVT e é a principal razão deste sistema não ser largamente utilizado. Assim, não é possível ainda maximizar com o PVT, ao mesmo tempo, os dois outputs (eletricidade e energia térmica). Entretanto, talvez a utilização deste sistema em países como o Brasil, com alta insolação, consiga uma boa eficiência deste equipamento. Na hipótese de ter PVT aplicado à uma casa inteligente em 
países com alta insolação, este deve utilizar como fluido a água (PVT/w ou PVT water). Com esta medida, o aquecimento da água para banho seria realizado pela parte térmica do sistema híbrido PVT/w.

Poderiam ser testadas três tecnologias de módulo fotovoltaico (tracking, bifacial e convencional) com a mesma tecnologia de célula e fazermos uma comparação dos três tipos em relação à eficiência. Observando que o tamanho das placas deve ser mesmo.

As tecnologias de módulos com célula fotovoltaica bifacial (Bifacial Solar Cell) são comumente investigadas com o objetivo de reduzir a quantidade de silício e aumentar a eficiência de conversão de energia, pois sua potência de saída também depende da quantidade de radiação solar que incide em seu lado reverso. O rendimento de módulo com célula fotovoltaica bifacial (BPV) e módulo fotovoltaico convencional foi comparado por Obara, (2014).

A capacidade de armazenamento de energia de uma bateria deste sistema pode ser reduzida ajustando a orientação vertical do BPV, e a demanda de energia elétrica ser mais bem atendida.

O sistema Solar Tracking System visa aperfeiçoar o rendimento de um módulo fotovoltaico que é fixado em uma estrutura que permite que sua inclinação seja ajustada automaticamente ao longo do dia para maximizar a radiação solar incidente. Conforme (Kelly, 2011), a captura de energia solar pode ser 30\% maior com o tracking system. Em um edifício, a única instalação viável é uma área com piso horizontal, enquanto em uma casa com telhado inclinado, isto dependeria do posicionamento. Um sensor foi utilizado para mensurar a radiação solar.

O dispositivo PLC (Power Line Communication) é uma solução para fazer a gestão da energia gerada no sistema fotovoltaico em cada uma das placas.

A arquitetura utilizada por (Han, 2014) e representada na Figura 3.15 permite localizar falhas no sistema fotovoltaico com PLC e consertá-las imediatamente. Em sistemas fotovoltaicos usuais, falhas localizadas nos módulos não podem ser identificadas, pois somente os dados dos inversores são monitorados. 


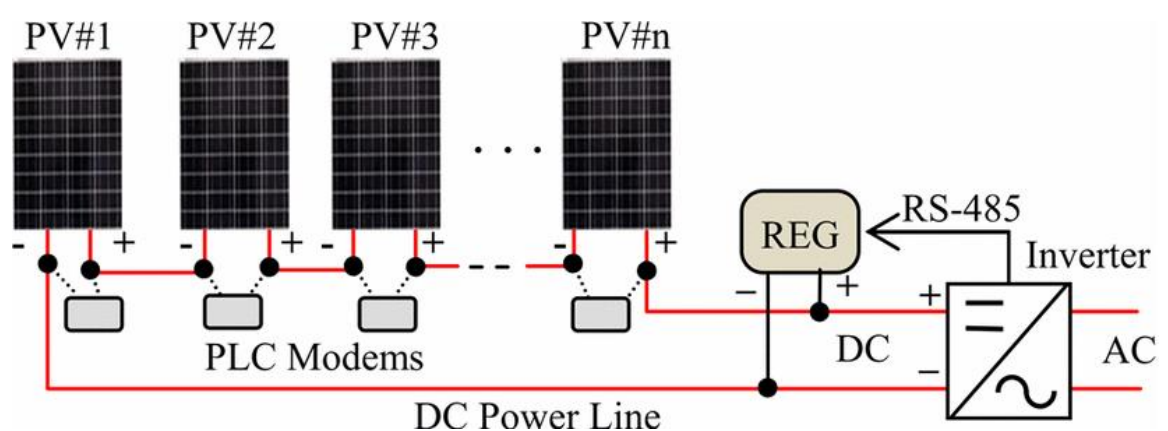

Figura 3.14 - Estrutura de um sistema fotovoltaico: modems PLC em cada módulo fotovoltaico e um gateway de energia renovável (REG) a inversor Fonte: Han (2014).

Outra tecnologia a ser utilizada seria a de micro inversor para sistemas fotovoltaicos. Segundo simulações do fabricante estes inversores podem aumentar em torno de $10 \%$ a eficiência dos painéis.

A PUC-Rio desenvolveu no âmbito de P\&D Aneel, um sistema de gerenciamento de sistemas fotovoltaicos, utilizando um software de gerenciamento da Tigo. Três tecnologias de módulos fotovoltaicas estão sendo testadas (silício amorfo, silício policristalino e silício monocristalino). Escolhida a tecnologia de painel utilizada na casa, este software de gerenciamento deveria ser utilizado, pois ele mede a quantidade de $\mathrm{CO}_{2}$ eq evitado entre os parâmetros do sistema fotovoltaico.

Para a casa ser autossustentável, esta deve ter baterias e boilers, para armazenarem energia elétrica e energia térmica. A bateria íon-lítio é uma tecnologia que possui um alto rendimento (higher round-trip efficiency), e a tecnologia com chumbo-ácido possui menor custo. Baterias de Chumbo-Ácido com Ciclo Profundo - Deep-cycle lead-acid (DCLA) batteries - têm uma eficiência típica entre $85 \%$ e $95 \%$, e é a tecnologia mais avançada para ser utilizada como armazenamento em um sistema de energia renovável (Parra, 2014).

Segundo Berndt (1993), embora as baterias DCLA tenham volumes de energia relativamente pequenos em comparação com outros tipos, são mais vantajosas devido ao seu baixo custo e alta confiabilidade. 


\section{8 \\ Segurança patrimonial}

Esta categoria contempla soluções tecnológicas referentes a: (i) proteção contra incêndio; (iii) sistemas de segurança; (ii) sistema endereçável de detecção de incêndio e alarme.

Abordam-se, a seguir, soluções tecnológicas para proteção contra incêndio em casas inteligentes e sistemas de segurança. Sistema endereçável de detecção de incêndio e alarme foi descrito anteriormente no item 3.2.1.

\subsection{1}

\section{Proteção contra incêndio em casas inteligentes}

Nas casas inteligentes há um grande número de equipamentos automatizados e que necessitam de uma proteção idônea contra incêndio. Além disso é fundamental que a casa esteja preparada para as situações de emergência, conforme recomendações a seguir:

- Saídas suficientes para a rápida retirada de pessoas;

- Equipamentos para combater o fogo durante o seu início;

- Portas das rotas de fuga com abertura no sentido de saída, largura mínima de $1.20 \mathrm{~m}$ e com característica de resistência ao fogo de 90 minutos (portas corta-fogo) (NBR 11.742);

- Portas de saída sem fechaduras, com aberturas para que operem pelo lado de fora;

- Escadas, plataformas e patamares devem ser feitas com materiais não combustíveis e resistentes ao fogo;

- Todas as instalações elétricas, dados, voz, telefonia devem estar acondicionadas dentro de eletrodutos ou canaletas.

No caso da ocorrência de início de incêndio, o sistema deve ser programado para acionar o sistema de alarme, avisar o corpo de bombeiros, desligar as máquinas e os aparelhos elétricos. É importantíssima a observação do material de acabamento da casa inteligente para identificar a classe de fogo e dotá-lo de meios de combate a incêndio. 
As classes de fogo são (NR23):

- Classe A - materiais de fácil combustão com propriedades de queima em superfície e profundidade e que deixam resíduos. Ex.: madeira, papel, fibra.

- Classe B - materiais inflamáveis que queimam na superfície, mas não deixam resíduos. Ex.: óleo, graxa, verniz, tinta.

Para cada pavimento, são necessários dois extintores, no mínimo, independentemente da área ocupada. Devem ficar em locais de fácil visualização e acesso e assinalados com uma seta larga vermelha com bordas amarelas ou com círculo vermelho. Na localização do extintor, deve ser pintado uma área de $1 \mathrm{~m}^{2} \mathrm{e}$ a altura de instalação deverá ser de 1,60 m do piso (Nastrini, 1999).

\subsection{2}

\section{Sistemas de segurança}

Os sistemas de segurança podem abranger desde um alarme de intrusão simples, passando por alarmes de incêndio, de fuga de gás, de inundação, até grandes sistemas monitorados por computadores e circuito interno de TV.

Dentre os sistemas de segurança, os controles e monitoramento de vazamentos são dispositivos de segurança indispensáveis para convivência no mundo atual, pois eles alertam e automaticamente resolvem os problemas de vazamento de gás, água, detectando fumaça e prevenindo incêndios, fechando as devidas válvulas. Para os portadores de deficiências que residem sozinhos, passam a ser essenciais, uma vez que, pela sua própria dificuldade de locomoção, a prevenção ou detecção precoce de ocorrência de vazamentos pode configurar-se em um fator de preservação da vida. $\mathrm{O}$ funcionamento desses sistemas se dá através de sensores dos mais diversos tipos e aplicações que detectam condições anormais em seu ambiente de atuação, emitindo alertas sonoros, luminosos e/ou de texto para um dispositivo móvel previamente configurado. Logo que o problema é detectado pelo sensor, automaticamente inicia-se uma rotina de resolução do problema, para que o mesmo cause o mínimo de danos possível (Ferreira, 2010). 


\section{9 \\ Considerações finais sobre o capítulo}

Desde o início do século 20, o estudo sobre as casas inteligentes vem aumentando e o mercado de automação residencial crescido devido ao aumento da demanda e consequentemente da maior viabilidade técnica e facilidade de adequação das tecnologias.

As redes de automação residencial começam a emergir e ganhar força na formatação de sistemas e aplicações domésticas, onde os estudos de viabilidade para realização das ligações e comunicação entre máquinas tornam-se viáveis e cada vez mais reais. É fato que ainda não há um protocolo universal desses sistemas, o que facilitará a massificação destas soluções tecnológicas, mas há um caminho desenhado para isso, pois apesar de ainda não haver a universalização, a fabricação e desenvolvimento de máquinas, sistemas e aplicativos integrados já existe e está disponível ao consumidor. As máquinas já possuem sensores de reconhecimento e funcionam enviando e recebendo sinais por bluetooth ou wifi com segurança, facilidade e praticidade.

O domínio da automatização doméstica inteligente é caracterizado por uma infraestrutura que permite uma ligação em rede inteligente, com dispositivos que utilizam várias tecnologias sem fios e com fios para proporcionar uma integração perfeita, o que facilita a utilização dos sistemas domésticos enquanto cria um espaço pessoal personalizado e seguro.

A automação residencial se dá com a integração destas máquinas, sistemas e aplicativos, que interligados deixam os edifícios e residências inteligentes. Os sensores necessários ao funcionamento desses sistemas, pelo que se percebe, pelo menos em sua maioria, são sensores já existentes no mercado. O grande diferencial são sistemas que façam a interpretação dos dados coletados e a transformação desses dados em serviços aos seus usuários.

Entende-se que todas essas possibilidades trarão um grande diferencial para as casas inteligentes e para o experimento de novas soluções tecnológicas para os moradores. A medição dessas atividades será de grande valia para os estudos e experimentos de hábitos de consumo e de comportamentos, e, possibilitará a comparação entre os modelos antes e depois da tecnologia. 
Um ponto fundamental que vai de encontro à funcionalidade e importância das casas inteligentes é o monitoramento da saúde e das atividades físicas dos idosos e de pessoas com deficiência, o que permite um acompanhamento remoto e pode aumentar a qualidade de vida dessas pessoas. Conclui-se que monitorar as atividades de ingestão de comprimidos, uso do telefone e preparação de café realizadas por idosos, são importantes para independência e análise das habilidades cognitivas ao longo do tempo.

Outra medição importante é o monitoramento de queda, que pode ser realizado por meio do Tapetes Inteligentes por exemplo, cujo funcionamento se dá através de um sistema eletrônico de sensores incorporados em tecidos de um tapete. Esse monitoramento permite o pronto-atendimento ao idoso em caso de queda. $\mathrm{E}$ por fim, o uso de um sistema mais completo e integrado, que permite a contextualização contínua do estado físico de uma pessoa, a predição de situações de risco, a notificação de situações de emergência, indicando um risco de saúde, e automação residencial comandada/solicitada pelo usuário dentro de um ambiente de casa inteligente. Como tecnologia adicional, podem ser usados os aparelhos portáteis de medição de glicemia de mesa e pela saliva.

A recomendação do uso combinado dessas tecnologias, permitirão o monitoramento constante do estado de saúde dos indivíduos, identificação de situações de risco, prevenção de doenças e consequências graves que possas acontecer por falta de diagnóstico prévio de algumas doenças.

Além disso, cresce a demanda por microgeração de energia, principalmente a solar, cujos painéis podem ser usados para gerar energia e/ou para aquecimento de água. Esta solução tecnológica permite armazenar energia em baterias, usar a energia da rede de distribuição em horários mais baratos e consumir a energia armazenada nos horários mais caros.

A comunicação entre as máquinas e os sistemas de gerenciamento, e a comunicação entre os sistemas e o ser humano permite uma vida inteligente e otimizada. Permite gerenciar o consumo de recursos naturais e otimizar os gastos, tornar o consumo consciente e eficiente sem desperdícios. E, proporciona ao indivíduo a possibilidade de ter uma qualidade de vida muito superior.

Destaca-se também a importância do conceito de desenvolvimento sustentável e como estes conceitos podem influenciar nos edifícios sustentáveis, pois devem considerar tempo, espaço, domínios e o aspecto sociais. Esses fatores 
mostram que a sustentabilidade implica uma taxa consistente de incerteza e sugerem que é mais um caminho de transição, mas com grande apelo ao contexto social e econômico para projetar uma casa inteligente sustentável. A importância de se considerar as relações entre o edifício, o bairro e o indivíduo são fundamentais na concepção das edificações sustentáveis. Uma casa sustentável tem que promover, em uma perspectiva de longo prazo, seu valor econômico, um impacto ambiental neutro, a satisfação humana e a igualdade social. 


\section{4 \\ Design Thinking aplicado a projetos de casas inteligentes}

Propõe-se um modelo conceitual para gerar e selecionar concepções de casas inteligentes baseadas em soluções tecnológicas inovadoras, adotando-se a abordagem de Design Thinking e integrando-se diversas ferramentas de gestão da inovação, incluindo um processo de crowdsourcing e a combinação de dois métodos multicritério de apoio à decisão. A aplicabilidade deste modelo será demonstrada no âmbito de um projeto de casa inteligente no Brasil (Projeto Nós Vivemos o Amanhã - NO.V.A), liderado por uma distribuidora de energia elétrica do grupo Enel, que atua em 66 municípios do estado do Rio de Janeiro. Os resultados do estudo empírico referente ao projeto NO.V.A. serão reportados no capítulo 5.

\section{1}

\section{Design Thinking: breve histórico, conceitos e caracterização}

Apresenta-se nesta seção uma revisão sobre Design Thinking, destacando-se aspectos relevantes de seu histórico, principais conceitos e características desta abordagem. Na sequência, descrevem-se três perspectivas de Design Thinking, que embasaram a fase de modelagem, cujo resultado será apresentado na terceira seção deste capítulo.

\subsection{1}

\section{Breve histórico}

A recente revisão de Cavalcanti (2015) sobre a abordagem de Design Thinking revelou que há divergências em relação às origens desta abordagem entre pesquisadores do campo do Design e da Administração. Hassi e Laakso (2011) ressaltam que autores do campo do Design consideram que o Design Thinking nasceu a partir dos trabalhos de Simon (1969) e Schön (1988; 1992), que já descreviam na época as características do modo de pensar dos designers. No entanto, autores do campo da Administração argumentam que o conceito surgiu na 
Stanford University e foi difundido pela empresa de design IDEO, no início dos anos 2000 (Stuber, 2016).

Segundo Stuber (2016), a abordagem de inovação conhecida como Design Thinking surgiu no curso de Engenharia Mecânica da Stanford University em 1958, particularmente com a criação de uma disciplina de desenvolvimento de produtos centrado no ser humano. A abordagem passou a receber aportes teóricos de outras áreas do conhecimento e despertou a atenção de empresas de diversos setores na década de 1990. Em 2004, foi amplamente difundida com o sucesso da empresa IDEO, liderada por David Kelley e Tim Brown, respectivamente fundador e CEO da empresa.

Para fins da presente dissertação, o breve histórico aqui apresentado enfatiza a visão dos autores do campo da Administração, tendo em vista que a fase de modelagem desta pesquisa baseou-se nas perspectivas da Ideo (2009); da Stanford d.school (2011); e de Vianna et al. (2011).

\subsection{2}

\section{Conceitos e caracterização}

Para fins desta pesquisa, adotou-se o conceito de Design Thinking compartilhado por autores como Brown (2008); Cooper, Junginger e Lockwood (2009); Plattner, Meinel e Leifer (2011); Vianna et al. (2011); Welsh e Dehler (2012); e Brenner, Uebernickel e Abrell (2016).

De acordo com Brown (2008), Design Thinking é uma disciplina que usa a sensibilidade e os métodos dos designers para harmonizar as necessidades das pessoas com o que é tecnologicamente viável, buscando-se transformar oportunidades em soluções que agreguem valor.

Welsh e Dehler (2012) definem Design Thinking como uma abordagem adotada para solução de problemas complexos e que coloca o ser humano no centro do processo. É uma forma de promover a criatividade e a busca por soluções inovadoras por meio da observação e colaboração, a partir do conceito de prototipagem rápida e da análise de diferentes realidades.

Cooper, Junginger e Lockwood (2009) argumentam que a abordagem de Design Thinking permite prospectar estados futuros, pensar por meio do processo de design, assim como gerar novas concepções, produtos, serviços e experiências reais. 
Plattner, Meinel, Leifer (2011) consideram que o Design Thinking parte de uma perspectiva multidisciplinar embasada em princípios de Engenharia, Design, Artes, Ciências Sociais e Administração.

Outra característica é que a abordagem é constituída por um processo multifásico e não linear - chamado fuzzy front end - que permite interações e aprendizados constantes. Isso faz com que o designer esteja sempre experimentando novos caminhos e aberto a novas alternativas (Ideo, 2009; Stanford d.school, 2011; Vianna et al., 2011; Brenner, Uebernickel e Abrell (2016).

Baeck e Gremett (2011) sintetizam no Quadro 4.1 as principais características da abordagem de Design Thinking.

Quadro 4.1 - Principais características da abordagem de Design Thinking

\begin{tabular}{|l|l|}
\hline Característica & Descrição \\
\hline Ambiguidade & $\begin{array}{l}\text { Capacidade de lidar com situações complexas e cuja solução } \\
\text { não é suficientemente clara. }\end{array}$ \\
\hline Colaboração & $\begin{array}{l}\text { Trabalho em equipe durante o desenvolvimento de projeto que } \\
\text { visa encontrar soluções para um problema. }\end{array}$ \\
\hline Construção & $\begin{array}{l}\text { Criação de novas e melhores ideias que são construídas a partir } \\
\text { de ideias existentes. No Design Thinking, as soluções concebidas } \\
\text { podem ser novas ou incrementais. }\end{array}$ \\
\hline Curiosidade & $\begin{array}{l}\text { Aproximação de situações e temas, a partir de uma visão } \\
\text { curiosa, que muitas vezes são desconhecidos. }\end{array}$ \\
\hline Empatia & $\begin{array}{l}\text { Capacidade de ver e entender um problema a partir do ponto } \\
\text { de vista de outro ser humano que esteja envolvido no contexto } \\
\text { estudado. }\end{array}$ \\
\hline Visão holística & $\begin{array}{l}\text { Necessidade de enxergar o contexto que está sendo estudado } \\
\text { de forma integral e holística. }\end{array}$ \\
\hline Interação & $\begin{array}{l}\text { Adoção de um processo cíclico e não linear que visa a concepção } \\
\text { de soluções ou ideias inovadoras. }\end{array}$ \\
\hline Abertura & $\begin{array}{l}\text { Criação de um ambiente no qual as pessoas possam conceber e } \\
\text { propor novas ideias sem serem criticadas por outros membros } \\
\text { da equipe de trabalho. }\end{array}$ \\
\hline Flexibilidade & $\begin{array}{l}\text { Abordagem pode ser adotada em praticamente qualquer } \\
\text { contexto uma vez que seu processo, mindsets, métodos e } \\
\text { ferramentas são aplicáveis a diversas situações e contextos. }\end{array}$ \\
\hline
\end{tabular}

Fontes: Cavalcanti (2015); Baeck e Gremett (2011).

\section{2}

\section{Perspectivas do processo de Design Thinking}

A seguir, apresenta-se o processo de Design Thinking, segundo as perspectivas da empresa Ideo (2009); da Stanford d.school (2011); e de Vianna et al. (2011). Essas três perspectivas embasaram a fase de modelagem da presente pesquisa. 


\subsection{1}

\section{Perspectiva da Ideo}

A abordagem de Design Thinking na perspectiva da empresa Ideo pode ser caracterizada segundo três lentes, que auxiliam os pesquisadores na geração de soluções impactantes para problemas complexos. Segundo essa perspectiva, o trabalho colaborativo com Design Thinking deve partir da aplicação da primeira lente que representa a captação do desejo e das expectativas das pessoas (futuras usuárias do que será gerado pelo projeto). Quando os desejos e expectativas forem percebidos pela equipe de pesquisadores, aplicam-se as lentes de plausibilidade e de viabilidade, indicando-se soluções plausíveis (podem ser executadas) e viáveis (do ponto de vista econômico, ambiental e social).

A Ideo divulga em sua caixa de ferramentas denominada "Human Centered Design (HCD) Toolkit", diretrizes que facilitam o desenvolvimento e a gestão dos projetos de inovação baseados em Design Thinking: (i) formação de equipes multidisciplinares; (ii) uso de um espaço específico para realização de reuniões da equipe, com possibilidade de visualização dos conteúdos produzidos durante o andamento das reuniões; e (iii) definição de prazos para desenvolver cada etapa do projeto.

Do ponto de vista de processo, o HCD Toolkit propõe três etapas, a saber: (i) ouvir (hear); (ii) criar (create); e (iii) implementar (deliver). Essas etapas podem ser visualizadas na Figura 4.1, que ilustra como o pensamento dos pesquisadores poderá alternar do concreto ao abstrato durante as diversas etapas do projeto.

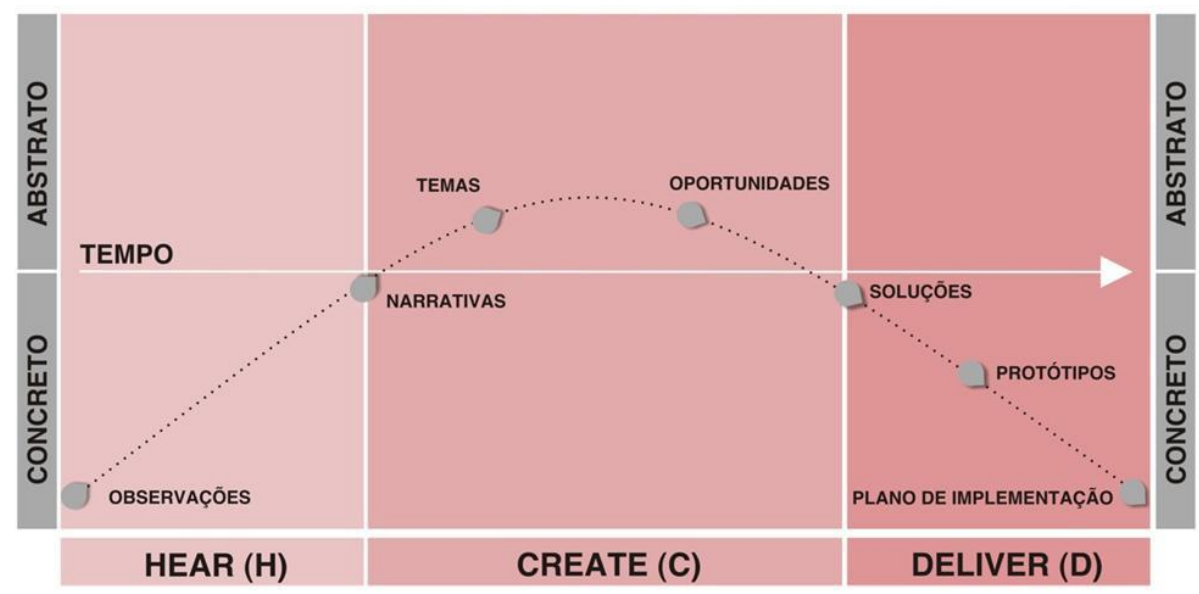

Figura 4.1 - Processo de Design Thinking segundo a perspectiva da empresa Ideo Fonte: Ideo (2009). 
A seguir, descrevem-se de forma sucinta as três etapas que compõem o processo de Design Thinking segundo a perspectiva da Ideo, conforme reportado por Cavalcanti (2015):

- Ouvir (hear): o objetivo nesta etapa é entender as expectativas, desejos e necessidades das pessoas investigadas. Antes de ir a campo para coletar dados, é importante definir um desafio estratégico que irá nortear o projeto colaborativo. O desafio estratégico pode ser lançado pela liderança organizacional ou estabelecido pela própria equipe de trabalho. O importante nessa definição é que o desafio represente uma problemática enfrentada por um determinado grupo de pessoas ou oportunidade que a organização queira explorar. Uma vez definido o desafio estratégico, a equipe deverá se organizar para o levantamento de informações que serão coletadas na forma de observações, entrevistas e, se possível, vivenciando os contextos variados em que os stakeholders estão inseridos;

- Criar (create) - é a etapa mais abstrata do processo e vai demandar dos pesquisadores habilidade de síntese e interpretação das informações coletadas dando enfoque aos possíveis insights ou ideias que tenham surgido na etapa anterior. Isso requer filtragem e seleção de informações traduzindo insights sobre a realidade atual em oportunidade para o futuro. Quando os desejos e necessidades das pessoas estiverem definidos e categorizados, ficará mais fácil revisitar o desafio estratégico e estabelecer o enunciado do problema que irá nortear o projeto daquele ponto em diante. Em seguida, a equipe realiza sessões de brainstorming, nas quais os participantes sugerem uma grande quantidade de soluções concebidas a partir do filtro desejo (Ver Figura 4.1). O próximo passo consiste na seleção das melhores soluções e insights trazidos pela equipe.

- Implementar (deliver) - É o momento em que as soluções propostas e testadas, via prototipagem, são implantadas e seu impacto é monitorado. Para isso, o HCD Toolkit recomenda que a equipe realize uma análise de possibilidade, análise de viabilidade, análise de inovação, desenhe um plano de implantação e um plano de aprendizado. Nessa etapa, também está prevista a implantação de soluções piloto que podem ser testadas pelos stakeholders. Portanto, a prototipagem que começou na fase criar continua presente, de maneira mais estruturada, na terceira etapa do Design Thinking da Ideo.

Cabe ressaltar que o HCD Toolkit (IDEO, 2009) explicita que a proposta metodológica do Design Thinking não é linear. Existe uma articulação entre as etapas que podem ser revisitadas, caso necessário, uma vez que o processo deve ser 
sistêmico e iterativo. Este é um dos princípios da abordagem da Ideo, que também baliza a perspectiva de Design Thinking da Stanford d.school, descrita a seguir.

\subsection{2}

\section{Perspectiva da Stanford d.school}

A Stanford d.school disponibiliza em seu site institucional um material intitulado "Bootcamp Bootleg", que reúne uma compilação de ferramentas centradas no ser humano, que visam a orientar os pesquisadores envolvidos em projetos apoiados por Design Thinking.

A Figura 4.2 apresenta esquematicamente o processo de Design Thinking segundo a perspectiva da Stanford d.school. O "Bootcamp Bootleg" (Stanford d. school, 2011) indica ainda que o Design Thinking usualmente é executado em cinco etapas: (i) empatia; (ii) definir; (iii) idear; (iv) prototipar; e (v) testar.

Steinbeck (2011) argumenta que alguns trabalhos descrevem a primeira etapa (empatia) como sendo dividida em dois momentos - entender e observar. Na Figura 4.2, indicam-se os momentos nos quais o pensamento concreto e o abstrato acontecem ao longo do processo.

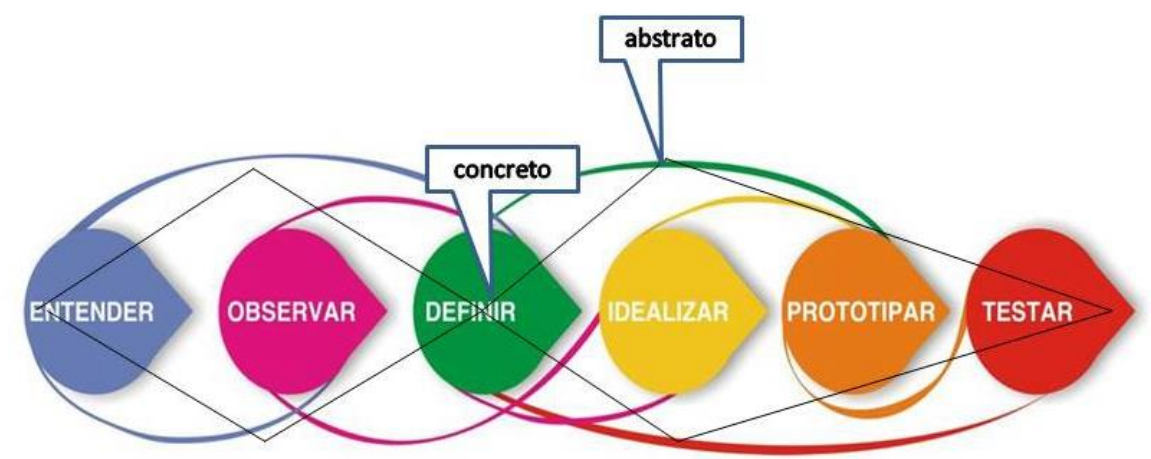

Figura 4.2 - Perspectiva do processo de Design Thinking segundo a Stanford d.school Fontes: Steinbeck (2011); Stanford d.school (2011).

O "Bootcamp Bootleg esclarece também que um problema nunca deve ser aceito da forma como é apresentado. Ao contrário, os pesquisadores devem adotar as formas de pensamento (mindsets) que fundamentam o trabalho colaborativo nessa perspectiva de Design Thinking.

Os mindsets também devem estar alinhados com atitudes e perspectivas da equipe de trabalho, como descrito na revisão de Cavalcanti (2015): 
- focar em valores humanos - um bom design depende, em grande parte, do envolvimento empático na realidade de onde emerge o desafio estratégico. Assim, ouvir e receber feedback dos sujeitos envolvidos no problema analisado é fundamental neste processo;

- ter predisposição para a ação - o enfoque do Design Thinking deve ser colocado na ação e não somente no pensamento;

- colaborar intensamente - a equipe que vai desenvolver um projeto a partir da adoção do Design Thinking deve ser composta por pessoas que tenham variadas formações acadêmicas e trajetórias de vida. Muitos insights, propostas criativas e inovadoras devem emergir desta diversidade de pontos de vista;

- criar clareza da complexidade - no Design Thinking é esperado que a equipe tenha uma visão coerente de problemas complexos. A organização de dados coletados da realidade deve ser feita de tal maneira que estimule a identificação e proposição de soluções;

- adotar a cultura da prototipagem e da experimentação - os pesquisadores que empregam Design Thinking devem criar protótipos para expressar, de forma visual, uma ideia ou solução. A prototipagem é fundamental para a inovação e não deve ser usada simplesmente como uma forma de validar ideias do grupo de trabalho;

- mostrar em vez de contar - no desenvolvimento de um projeto os pesquisadores devem compartilhar histórias, usar ilustrações e recursos visuais para comunicar ideias de uma forma impactante;

- ser consciente do processo - a equipe de trabalho deve conhecer as características de cada etapa do processo de design, quais os métodos a serem adotados e os objetivos a serem alcançados em cada uma delas.

\subsection{3}

\section{Perspectiva de Vianna et al.}

Segundo Vianna et al. (2011), o processo de inovação pela abordagem de Design Thinking compreende quatro fases: (i) imersão; (ii) análise e síntese; (iii) ideação; e (iv) prototipação.

A Figura 4.3 representa graficamente as fases do processo de Design Thinking na perspectiva de Vianna et al. (2011), indicando pelos os loops na parte 
superior que as fases não são necessariamente sequenciadas. A título de ilustração, os resultados da fase de ideação poderão requerer o uso de ferramentas da análise e síntese e reuniões de grupos focais para refinamento das soluções propostas.

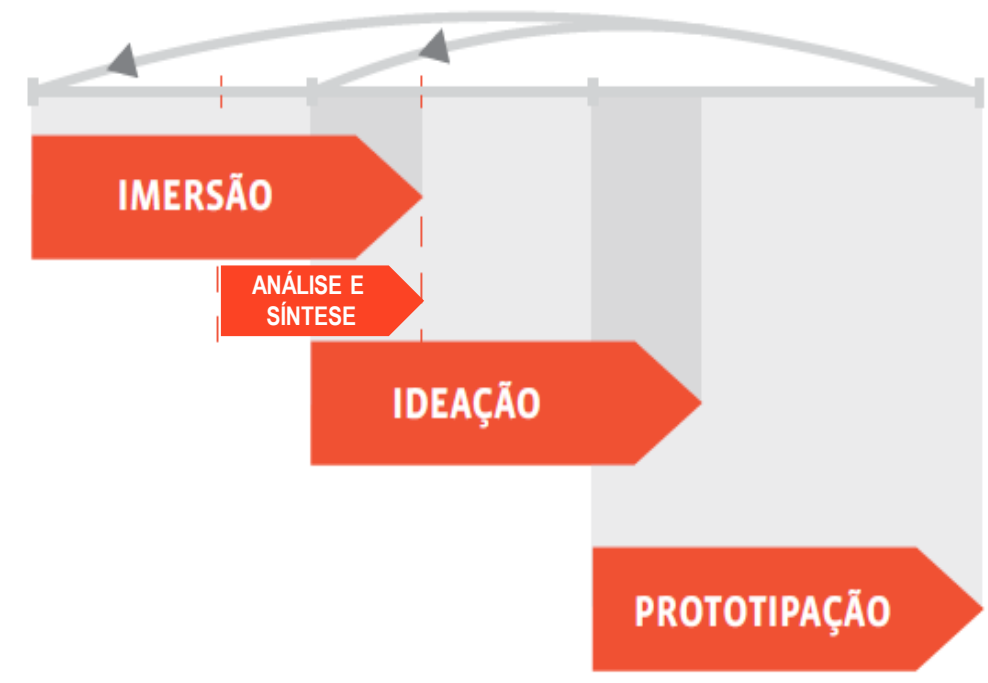

Figura 4.3 - Perspectiva de Design Thinking segundo Vianna et al. Fonte: Adaptado de Vianna et al., 2001.

Na primeira fase - $\underline{\text { imersão }}$ - a equipe do projeto aproxima-se do contexto do problema, tanto do ponto de vista do cliente (contratante), quanto do usuário final (o cliente do cliente). Consiste de duas etapas - preliminar e em profundidade. A primeira tem como objetivo o reenquadramento e o entendimento inicial do problema. Já a segunda visa identificar as necessidades e oportunidades que irão nortear a geração de soluções na fase seguinte do projeto, denominada ideação.

Integram a imersão preliminar, a pesquisa de campo exploratória, o reenquadramento do problema e a pesquisa bibliográfica e documental sobre o tema do projeto. Essa etapa inicia-se com reuniões de alinhamento estratégico entre a equipe que conduzirá o projeto de Design Thinking e profissionais da contratante. Realiza-se, assim, o processo de reenquadramento do problema, sob diferentes perspectivas e diversos ângulos, permitindo, assim, desconstruir crenças e suposições dos atores (stakeholders), ajudando-os a promover mudanças em seus contextos e implantar soluções inovadoras.

Em paralelo, a equipe do projeto conduz uma pesquisa de campo preliminar (pesquisa exploratória) que contribui para a compreensão do contexto do assunto em foco e para a identificação dos comportamentos dos futuros usuários e 
mapeamento de seus padrões e necessidades latentes. Esses aspectos serão estudados mais a fundo em um segundo momento da fase de imersão.

Já a pesquisa bibliográfica e documental (pesquisa desk) é busca de informações sobre o tema do projeto em fontes diversas (websites, livros, revistas, blogs, artigos, entre outros). A pesquisa é qualitativa e não pretende esgotar o conhecimento sobre segmentos de consumo e comportamento.

A etapa de imersão em profundidade consiste em levantar mais informações sobre o contexto de vida dos atores e do assunto em foco. Em geral, procura-se focar no ser humano com o objetivo de levantar informações de quatro tipos: (i) O que as pessoas falam?; (ii) Como agem?; (iii) O que pensam?; e (iv) Como se sentem?

O objetivo da imersão em profundidade é identificar comportamentos extremos e mapear seus padrões e necessidades latentes. A pesquisa é qualitativa e não busca esgotar o conhecimento sobre segmentos de consumo e comportamento. No entanto, ao levantar oportunidades e expectativas de perfis extremos, permite que soluções específicas sejam criadas.

Existem diversas técnicas para a realização dessas pesquisas, dentre elas: entrevistas, registro fotográfico, observação participante, observação indireta, cadernos de sensibilização, dentre outras.

Após as etapas de levantamento de dados da fase de imersão, a próxima fase é a de análise e síntese das informações coletadas, que tem por objetivo organizálas de maneira a obter-se padrões e a criar desafios que auxiliem na compreensão do problema. Nesta fase, empregam-se diversas ferramentas e métodos, como, por exemplo: (i) cartões de insights; (ii) diagrama de afinidades; (iii) mapas conceituais; (iv) definição de critérios norteadores; (v) identificação de personas, que são arquétipos, personagens ficcionais, concebidos a partir da síntese de comportamentos observados entre usuários finais com perfis extremos; (vi) mapa da empatia; (vii) Jornada do Usuário; (viii) blueprint.

A fase de ideação visa gerar ideias inovadoras para o tema do projeto, com suporte de ferramentas que estimulem a criatividade e a geração de soluções que estejam de acordo com o contexto do assunto trabalhado. Além das ferramentas, é importante que haja variedade de perfis de pessoas envolvidas no processo de geração de ideias. O objetivo de reunir diferentes expertises é o de contribuir com 
diferentes perspectivas, o que, por consequência, torna o resultado final mais rico e assertivo.

A fase de ideação inicia-se com a equipe de projeto realizando uma sessão de brainstorming (uma técnica consagrada para geração de ideias) em torno do tema a ser explorado. Em seguida, realizam-se um ou mais workshops de cocriação com usuários ou equipe da contratante, dependendo do escopo e necessidade do projeto. As ideias geradas ao longo desse processo são capturadas em 'Cardápios de Ideias', que são constantemente validadas em reuniões com a contratante utilizando, por exemplo, a ferramenta matriz de posicionamento (Figura 4.4).

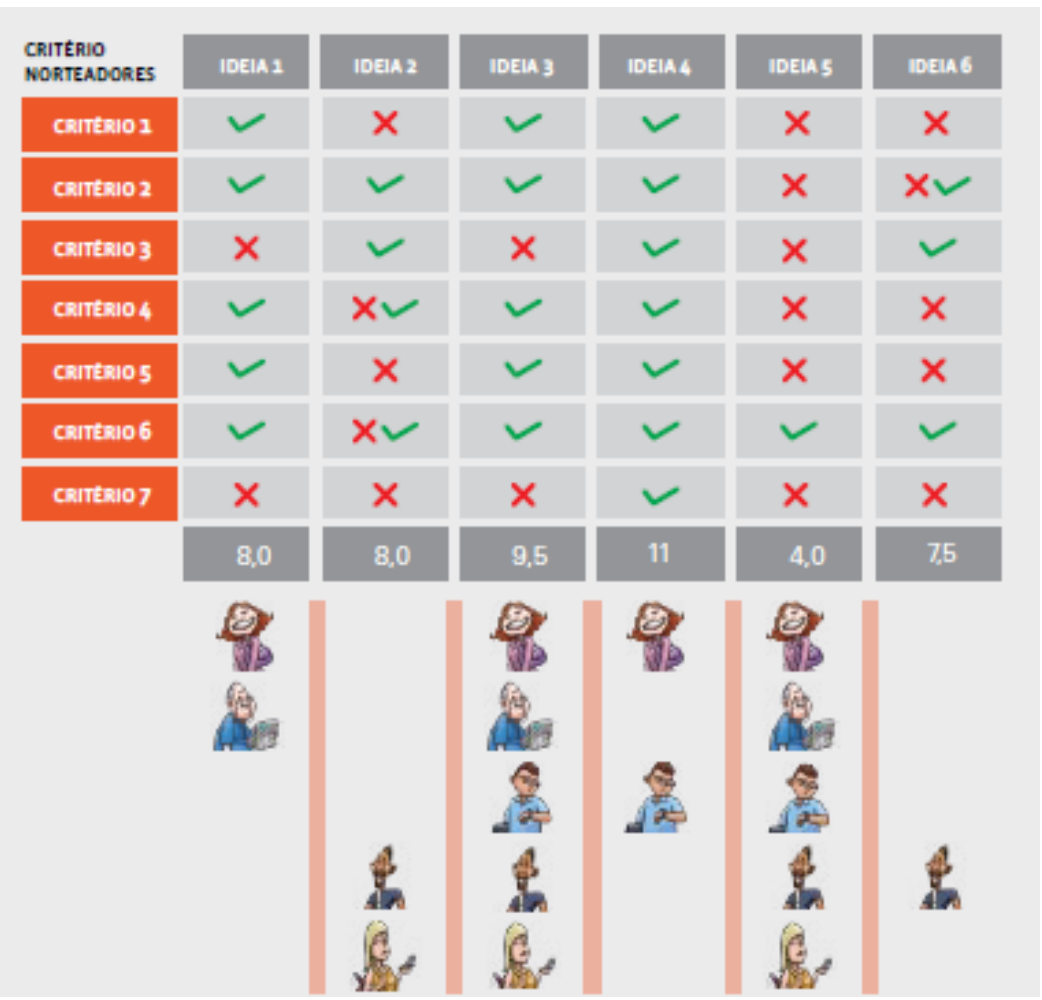

Figura 4.4 - Ferramenta matriz de posicionamento Fonte: Vianna et al., 2001.

A matriz de posicionamento é uma ferramenta de análise estratégica das ideias geradas, utilizada na validação destas em relação aos critérios norteadores, bem como às necessidades das personas criadas durante a fase anterior.

O objetivo desta ferramenta é apoiar o processo de decisão da escolha da melhor ideia, a partir da comunicação eficiente dos benefícios e desafios de cada solução, de modo que as ideias mais estratégicas sejam selecionadas para serem prototipadas (Vianna et al., 2011). 
A última fase - prototipação - busca reduzir as incertezas do projeto através do desenvolvimento de protótipos das soluções inovadoras. Os protótipos constituem uma forma ágil de abandonar alternativas que não são bem recebidas e, portanto, auxiliam na identificação de uma solução final mais assertiva. O processo de prototipação inicia-se com a formulação de questões que precisam ser respondidas a respeito das soluções idealizadas. A partir disso, então, são criados modelos que representem o aspecto em aberto e que viabilizem o teste. Os resultados são analisados e o ciclo pode se repetir inúmeras vezes até que a equipe de projeto chegue a uma solução final que atenda às necessidades e expectativas do usuário e que seja atrativa para a contratante. Assim, quanto mais testes e mais cedo se inicia o processo de prototipação, maior o aprendizado e as chances de sucesso da solução final.

\subsection{4}

\section{Análise comparativa das perspectivas selecionadas}

A análise comparativa das perspectivas de Design Thinking apresentadas nesta seção permitiu identificar as correspondências entre as etapas dos respectivos processos, como pode ser visualizado no Quadro 4.2.

Quadro 4.2 - Comparação das perspectivas de Design Thinking

\begin{tabular}{|c|c|c|c|}
\hline & \multicolumn{3}{|c|}{ Perspectivas } \\
\hline & $\begin{array}{c}\text { Ideo } \\
(2009)\end{array}$ & Stanford d.school (2011) & $\begin{array}{c}\text { Vianna et al. } \\
\text { (2011) }\end{array}$ \\
\hline \multirow{6}{*}{ Etapas } & \multirow[t]{2}{*}{ Ouvir } & Entender & Imersão preliminar \\
\hline & & Observar & Imersão em profundidade \\
\hline & \multirow[t]{2}{*}{ Criar } & Definir & Análise e síntese \\
\hline & & Idear & Ideação \\
\hline & \multirow[t]{2}{*}{ Implementar } & Prototipar & \multirow[t]{2}{*}{ Prototipação } \\
\hline & & Testar & \\
\hline
\end{tabular}

Fonte: Elaboração própria.

\section{3}

\section{Design Thinking aplicado a projetos de casas inteligentes: modelo conceitual}

A partir dos resultados da revisão bibliográfica e documental sobre os temas centrais da pesquisa, desenvolveu-se um modelo conceitual para geração e seleção de concepções de casas inteligentes, compreendendo três das quatro fases da abordagem de Design Thinking - imersão; análise e síntese; e ideação. 
A Figura 4.5 representa graficamente o modelo conceitual, baseado no processo descrito por Vianna et al. (2011).

Pela complexidade inerente a projetos de casas inteligentes, buscou-se incorporar à perspectiva de Vianna et al. novas ferramentas de gestão da inovação e marketing de conteúdo, incluindo a criação de uma plataforma de colaboração digital (crowdsourcing) e o uso de um método híbrido multicritério de apoio à decisão (AHP-TOPSIS).

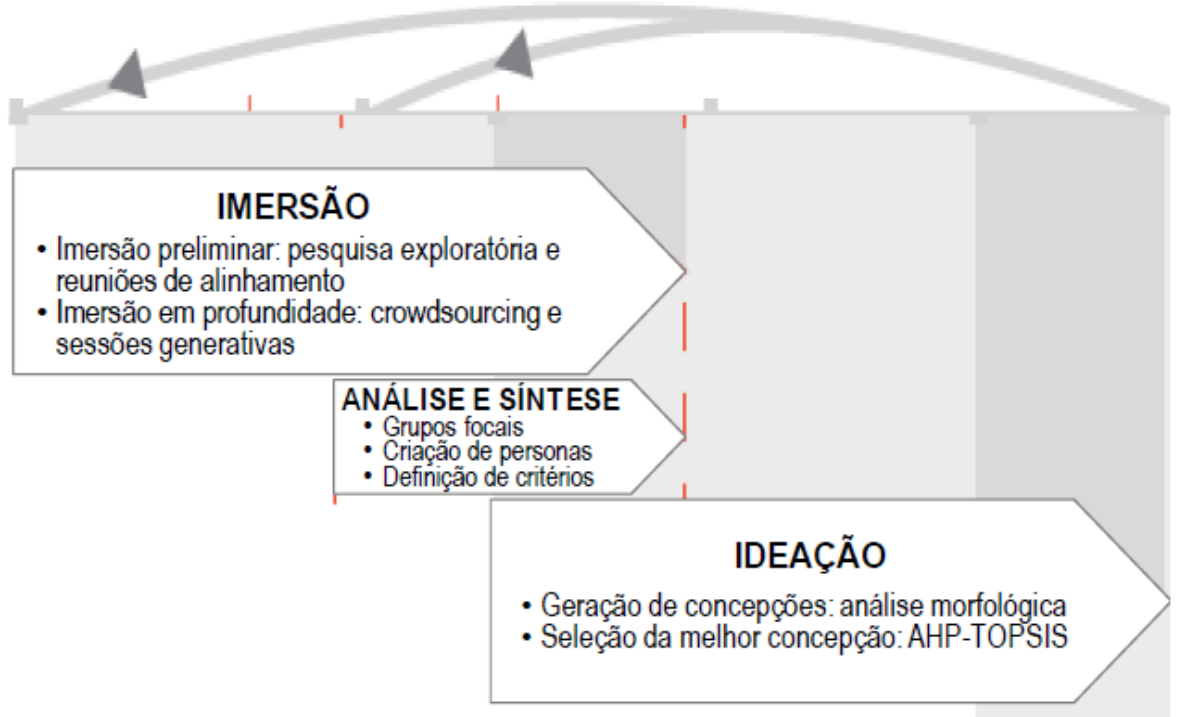

Figura 4.5 - Modelo conceitual baseado em Design Thinking para geração e seleção de concepções de casas inteligentes baseadas em soluções tecnológicas inovadoras

Fonte: Elaboração própria.

\subsection{1}

Imersão

A fase de imersão compreende duas etapas: (i) imersão preliminar; e (ii) imersão em profundidade.

\section{Imersão preliminar: pesquisa exploratória e reuniões de alinhamento}

Na etapa de imersão preliminar, a equipe do projeto deverá realizar pesquisa de campo exploratória junto a grupos de futuros usuários em paralelo à pesquisa bibliográfica e documental (pesquisa desk) sobre modelos de casas inteligentes, desenvolvidos objetivos distintos (capítulo 2 - seção 2.3). Nesta etapa, devem ser realizadas reuniões de alinhamento estratégico entre a equipe que conduzirá o 
projeto da casa inteligente e profissionais da contratante.

Durante as reuniões de alinhamento, busca-se reenquadrar o problema sob as diferentes perspectivas dos atores envolvidos. Para tal a equipe do projeto deverá apresentar um quadro geral das categorias de serviços a serem oferecidas pela casa inteligente e respectivas funcionalidades associadas a cada serviço (capítulo 2 itens 2.1 .1 e 2.1.2).

\section{Imersão em profundidade: uso do processo de crowdsourcing}

Na etapa de imersão em profundidade, propõe-se a criação de uma plataforma de colaboração digital (crowdsourcing), estruturada com base nos resultados das reuniões de alinhamento estratégico, para identificação das expectativas e necessidades de pessoas dos mais diversos segmentos da sociedade, em relação aos principais serviços oferecidos pela casa inteligente.

$\mathrm{Na}$ plataforma de colaboração digital, todas as pessoas interessadas em discutir temas relacionados com o projeto em questão poderão se cadastrar e colocar suas necessidades, expectativas e sugestões sobre como deverá ser a casa inteligente. Alguns exemplos de perguntas que poderão ser colocadas na plataforma: "Que categorias de serviços e funcionalidades deverá oferecer a casa inteligente? e que soluções tecnológicas inovadoras poderão ser instaladas na futura casa?".

Esse método de coleta de informações, denominado crowdsourcing, consiste em um modelo de colaboração (participação) ou resolução de problemas, que ocorre de forma online e distribuída, mediante uma plataforma Web (Howe, 2006; Brabham, 2008; Schenk e Guittard, 2011).

Em um processo de crowdsourcing, os desafios são transmitidos ao público, sob a forma de um convite aberto para soluções. Os membros do público submetem soluções que são, então, de propriedade da entidade que transmitiu o desafio. Em alguns casos, o contribuinte da solução é compensado financeiramente, com prêmios ou com reconhecimento. Em outros casos, as únicas recompensas podem ser elogios ou satisfação intelectual (Brabham, 2008; Howe, 2006).

Segundo Howe (2006), as sugestões vindas das multidões tendem a prover benefícios mais relevantes para o todo, porque estão associadas à colaboração em massa, à produção coletiva, a processos colaborativos, voluntários, gratuitos e de autoria não identificada. 


\section{Imersão em profundidade: sessões generativas}

Em paralelo ao processo de crowdsourcing, propõe-se a realização de sessões generativas, que são encontros nos quais atores envolvidos no projeto e futuros usuários das soluções possam compartilhar suas experiências e realizem juntos atividades nas quais exponham suas visões sobre as categorias de serviços e funcionalidades da casa inteligente. A sessão generativa é uma abordagem apropriada para se obter uma visão geral dos atores e usuários, incluindo-se, neste caso, suas experiências diárias em toda sua complexidade.

\subsection{2 Análise e síntese}

Em seguida, na fase de análise e síntese, recomenda-se o emprego de métodos e técnicas de prospecção e gestão da inovação, visando obter-se padrões que auxiliem na compreensão do problema e na definição de critérios norteadores para a seleção pretendida. As ferramentas citadas por Vianna et al. (2011) são: cartões de insights; diagrama de afinidades; mapas conceituais; definição de critérios norteadores; identificação de personas, que são arquétipos, personagens ficcionais, concebidos a partir da síntese de comportamentos observados entre usuários finais com perfis extremos; mapa da empatia; 'Jornada do Usuário'; e blueprint.

\section{Grupos focais}

Para esta fase, propõe-se a criação de grupos focais direcionados para classificar e analisar as informações coletadas no processo de crowdsourcing, que poderão criar diagramas de afinidades, mapas conceituais por categoria de serviços e um mapa conceitual geral com todas as categorias. Esses grupos poderão ser formados por categoria de serviços a serem oferecidos pela casa inteligente ou até por funcionalidade, se for de interesse da coordenação do projeto.

\section{Criação de personas}

Ainda nesta fase, propõe-se a identificação de arquétipos de futuros moradores da casa inteligente (personas), que representam as motivações, desejos, expectativas e necessidades, revelando-se características significativas de um grupo mais abrangente. Personas são representações fictícias dos futuros moradores da casa inteligente e são baseadas em dados reais sobre as características demográficas e comportamento dessas pessoas, assim como uma criação de suas histórias 
pessoais, motivações, objetivos, desafios e preocupações (Rez, 2016).

Elas são criadas através de pesquisas, questionários e entrevistas feitas com o(s) público(s) alvo. A coleta de dados qualitativos e quantitativos permitirá criar a imagem dos moradores ideais da casa inteligente, o que eles valorizam e quais as soluções mais adequadas para eles.

\section{Definição de critérios norteadores}

A definição de critérios norteadores para a fase seguinte - ideação - tem por objetivo estabelecer diretrizes balizadoras para o projeto, evidenciando-se aspectos que não devem ser perdidos de vista ao longo de todas as etapas do desenvolvimento das soluções. Surgem da análise dos dados coletados nas entrevistas para a criação das personas; da síntese dos resultados do processo de crowdsourcing; do escopo determinado para o projeto, além dos direcionamentos sugeridos nas sessões generativas. Servem como base para a determinação dos limites do projeto e do seu verdadeiro propósito. Por exemplo, a concepção da casa inteligente deverá ser para atender as necessidades de um público idoso, que requer a instalação de tecnologias assistivas e de telemedicina. Recomenda-se para esta etapa o artigo de revisão de critérios norteadores para projetos de casas inteligentes de autoria de Wong e $\mathrm{Li}$ (2008).

Os critérios norteadores devem estar sempre presentes durante o desenvolvimento do projeto da casa inteligente, porque parametrizam e orientam a escolha das soluções tecnológicas inovadoras, evidenciando-se sua adequação ao escopo que deve ser respeitado. Os critérios norteadores emergem da sistematização dos dados da fase de imersão, durante a realização de um diagrama de afinidades ou de um mapa conceitual, por exemplo. Assim, assegura-se que nenhuma questão relevante seja negligenciada ou mesmo que as soluções geradas se distanciem do foco da demanda.

\subsection{3}

\section{Ideação}

A fase de ideação tem por objetivo gerar concepções de projetos de casas inteligentes, que venham atender aos critérios norteadores definidos na fase anterior. Propõe-se para esta fase o uso da ferramenta de análise morfológica para a geração de alternativas e o emprego de um método híbrido multicritério de apoio à decisão (AHP-TOPSIS) para seleção e hierarquização das concepções propostas. 


\section{Geração de concepções alternativas: uso de análise morfológica}

A análise morfológica é uma técnica analítico-combinatória, que se baseia na decomposição de um problema, ou objeto de análise, em seus atributos. Zwicky (1969) propôs essa técnica em cinco etapas: (i) formulação e definição do problema (questão que se deseja responder); (ii) identificação e caracterização de todas as variáveis do problema; (iii) construção de uma matriz multidimensional, preenchida com os possíveis estados que cada variável poderá assumir; (iv) identificação de combinações plausíveis dos estados gerados para cada variável, em função da questão que se pretende responder; (v) análise das alternativas com descarte daquelas intrinsecamente inconsistentes, insustentáveis ou economicamente inviáveis.

A Figura 4.6 ilustra uma matriz multidimensional aplicável a projetos de casas inteligentes.

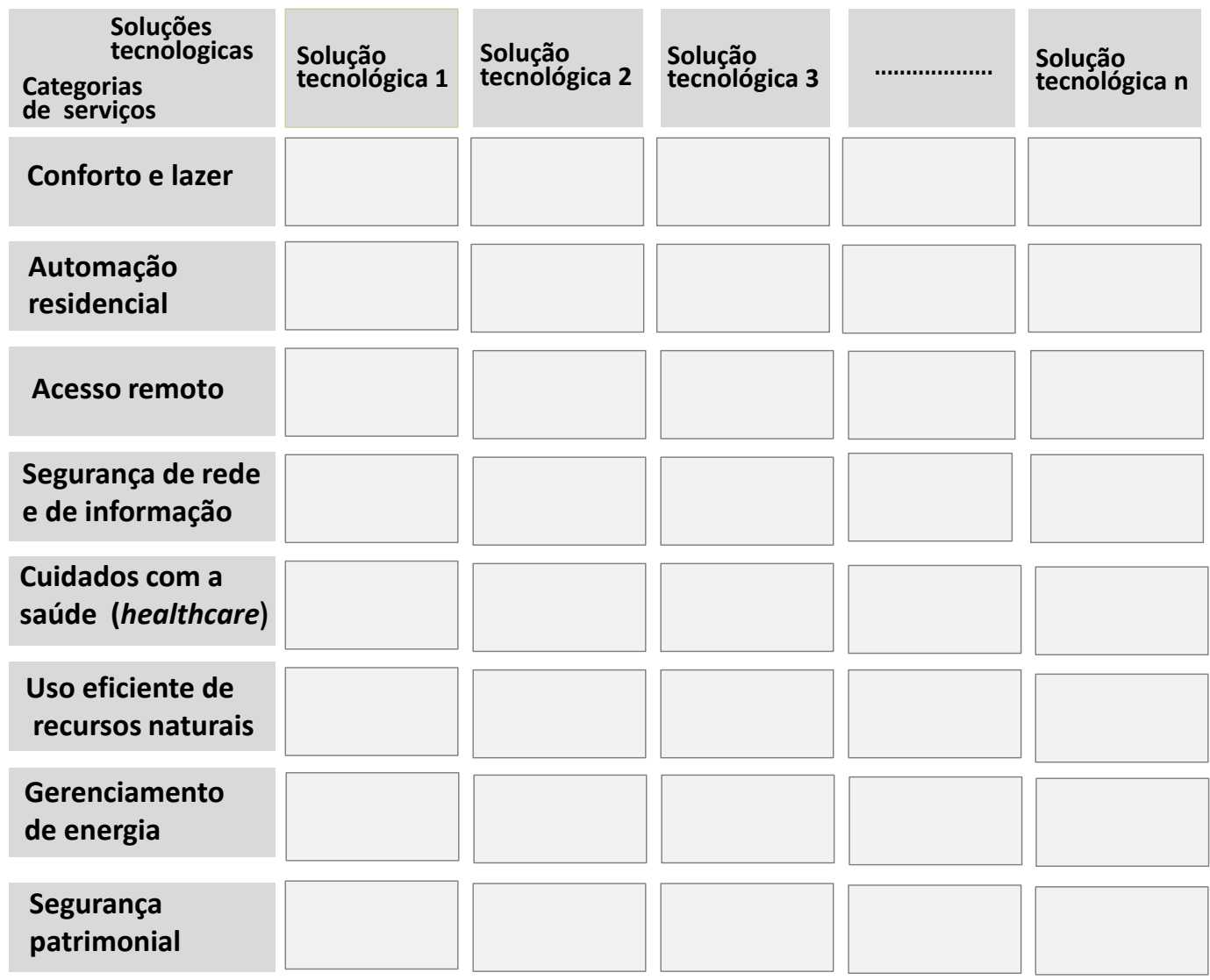

Figura 4.6 - Matriz multidimensional aplicável a projetos de casas inteligentes Fonte: Elaboração própria.

Ressalta-se que o estudo das categorias de serviços e funcionalidades associadas a cada categoria deverá ser feito nas fases de imersão e de análise e 
síntese.

A premissa básica da escolha dessa técnica é a de que um problema complexo como um projeto de uma casa inteligente - pode ser decomposto em variáveis fundamentais (principais categorias de serviços a serem oferecidos pela casa), que passam por uma análise sistemática dos estados possíveis que essas possam assumir, gerando, assim, um conjunto de estados ou valores referentes às variáveis. A lógica da decomposição do problema é lidar com questões menos complexas do que o sistema original, possibilitando, desse modo, uma análise mais profunda das partes (subsistemas com estados e funções distintas).

Ao combinar todos esses estados, pode-se elencar um universo de concepções de casas inteligentes representativas da questão em foco. As combinações intrinsecamente inconsistentes, insustentáveis ou economicamente inviáveis são descartadas. Filtram-se somente as concepções consideradas plausíveis. A seguir, ilustram-se na Figura 4.7 combinações plausíveis que formam uma das concepções alternativas para um projeto de casa inteligente.

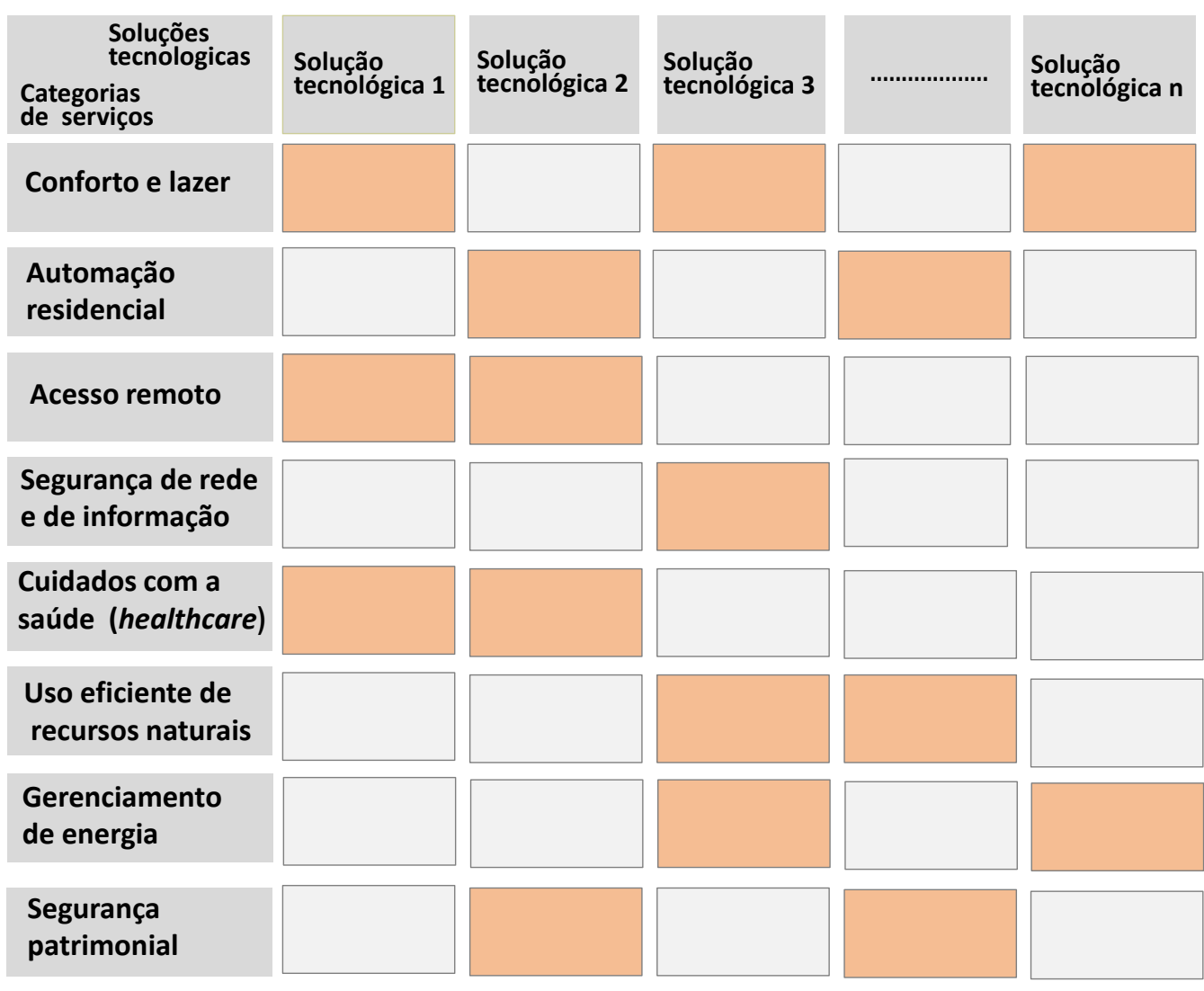

Concepção 1 para a casa inteligente

Figura 4.7 - llustração didática da geração de uma das concepções para a casa inteligente Fonte: Elaboração própria. 


\section{Seleção da melhor concepção: uso do método híbrido AHP-TOPSIS}

Uma vez geradas as concepções de casas inteligentes, consideradas plausíveis segundo os resultados da análise morfológica, parte-se para a segunda etapa da fase de ideação. Esta compreende a hierarquização das concepções de casas inteligentes resultantes da análise morfológica para escolha final da melhor concepção, em função dos critérios norteadores. Destaca-se o trabalho de Wong e Li (2009) sobre o uso do método AHP (Analytical Hierarchy Process) em uma análise multicritério referente à seleção de sistemas tecnológicos para casas inteligentes.

Para fins da presente modelagem, propõe-se o emprego de um método híbrido multicritério de apoio à decisão, que combina os métodos AHP e TOPSIS (Technique for Order of Preference by Similarity to Ideal Solution). Essa recomendação baseia-se nos resultados de pesquisas bem sucedidas desenvolvidas por mestrandos do Programa de Pós-Graduação em Metrologia em outros contextos de decisão (Mello, 2015; Criollo, 2016; Trindade, 2016).

A aplicação deste método híbrido requer a participação de especialistas nas diversas disciplinas referentes ao projeto de uma casa inteligente, devido ao caráter multidisciplinar desse tipo de projeto, e representantes das instituições e empresas envolvidas no projeto.

O método AHP será adotado para definir os pesos dos critérios norteadores, enquanto a técnica TOPSIS será empregada para hierarquizar as concepções geradas e selecionar a melhor, visando atender aos objetivos estabelecidos na fase de imersão preliminar.

O método AHP consiste de quatro etapas, de acordo com a descrição de Saaty (1991; 1997; 2008); Saaty e Vargas (2012) e Costa (2006):

- Organização da estrutura hierárquica, através da identificação do foco principal, dos critérios e subcritérios (quando existirem) e das alternativas, refletindo as relações existentes entre eles;

- Aquisição dos dados e coleta de julgamentos de valor, através da comparação dos elementos dois a dois e estabelecimento das matrizes de comparações;

- Análise das matrizes de comparações geradas na fase anterior, que indicarão a prioridade de cada alternativa em relação ao foco principal;

- Análise dos indicadores de desempenho derivados, como índices de consistência por exemplo. 
No método AHP, os elementos de uma hierarquia para a resolução de problemas de decisão são o foco principal (ou meta), o conjunto de alternativas viáveis e o conjunto de critérios, de acordo com o ilustrado na Figura 4.8.

O foco principal é o objetivo global, o que a resolução do problema trará. As alternativas viáveis são as possibilidades de escolha dentro do problema para que a decisão seja tomada. Por fim, os critérios são as características ou propriedades a partir das quais as alternativas devem ser avaliadas.

Após a hierarquização, o método aponta para os julgamentos de valor, onde o avaliador deve comparar os elementos dois a dois à luz de um determinado critério. O julgamento é então a representação numérica dessa relação e o grupo de todos os julgamentos, considerando a comparação de todos os elementos em relação a um critério específico, pode ser representado através de uma matriz quadrada (Saaty, 1991).

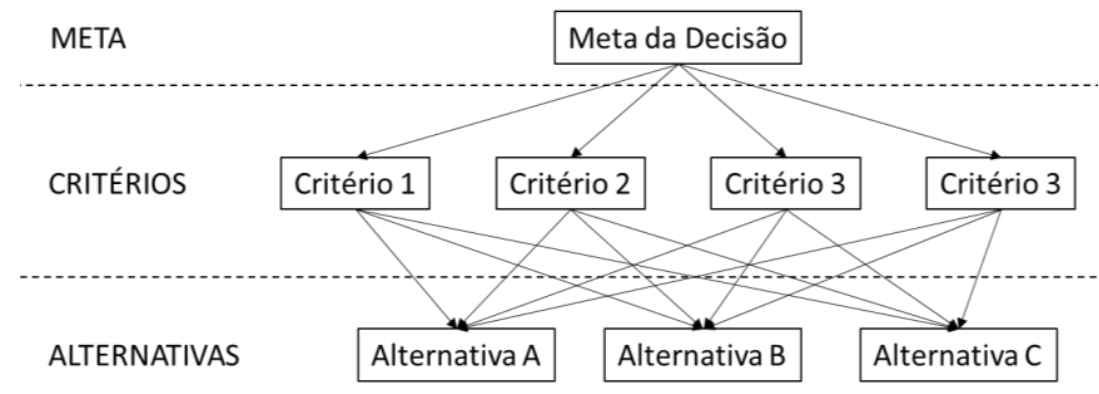

Figura 4.8 - Exemplo de estrutura hierárquica de problemas de decisão (em três níveis) Fonte: Saaty, 1991.

Para o estabelecimento do processo de julgamento, Saaty $(1991 ; 1997 ; 2008)$ definiu uma escala específica para padronizar os julgamentos de valor, escala essa que capta a subjetividade natural existente em variáveis qualitativas. O Quadro 4.3, a seguir, apresenta essa escala. 
Quadro 4.3 - Escala para padronizar os julgamentos de valor pelo método AHP

\begin{tabular}{|c|l|l|}
\hline $\begin{array}{l}\text { Intensidade de } \\
\text { importância }\end{array}$ & Definição & Explicação \\
\hline 1 & Mesma importância & $\begin{array}{l}\text { As duas atividades contribuem } \\
\text { igualmente para o objetivo. }\end{array}$ \\
\hline 3 & $\begin{array}{l}\text { Importância moderada de uma } \\
\text { sobre a outra }\end{array}$ & $\begin{array}{l}\text { A experiência e o julgamento favorecem } \\
\text { levemente uma atividade em relação à } \\
\text { outra. }\end{array}$ \\
\hline 5 & $\begin{array}{l}\text { Importância grande ou } \\
\text { essencial }\end{array}$ & $\begin{array}{l}\text { A experiência e o julgamento favorecem } \\
\text { fortemente uma atividade em relação à } \\
\text { outra. }\end{array}$ \\
\hline 7 & $\begin{array}{l}\text { Importância muito grande ou } \\
\text { demonstrada }\end{array}$ & $\begin{array}{l}\text { Uma atividade é muito fortemente } \\
\text { favorecida em relação à outra; sua } \\
\text { dominação de importância é } \\
\text { demosntrada na prática. }\end{array}$ \\
\hline 9 & Importância absoluta & $\begin{array}{l}\text { A evidência favorece uma atividade em } \\
\text { relação à outra com o mais alto grau de } \\
\text { certeza. }\end{array}$ \\
\hline $2,4,6,8$ & $\begin{array}{l}\text { Valores intermediários entre } \\
\text { os valores adjacentes. }\end{array}$ & $\begin{array}{l}\text { Quando se procura uma condição de } \\
\text { compromisso entre as duas definições. }\end{array}$ \\
\hline
\end{tabular}

Fonte: Saaty, 1991.

O julgamento consiste no reflexo de duas perguntas: (i) qual dos dois

elementos é o mais importante, à luz do objetivo pretendido?; e (ii) com qual intensidade ele é mais importante, utilizando-se a escala de 1 a 9? Para o elemento mais importante, é utilizado um valor inteiro, enquanto que o menos importante recebe o inverso dessa unidade, como ilustrado no exemplo didático da Figura 4.9.

\section{Matriz A}

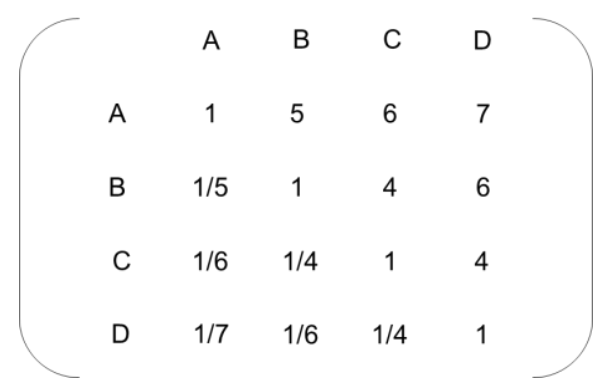

Figura 4.9 - Exemplo de matriz de julgamentos para o método AHP Fonte: Saaty (1991).

As letras A, B, C e D representam os elementos a serem comparados dois a dois. A diagonal da matriz recebe sempre 1 pois é a comparação do elemento com ele mesmo. Para o preenchimento dos outros campos, são feitos os julgamentos para determinar a intensidade de importância, utilizando a escala determinada por Saaty. Para as comparações inversas, ou seja, o que está na parte inferior esquerda da matriz, são adicionados os valores recíprocos referentes a cada julgamento, que estão na parte superior direita da mesma. Com as matrizes recíprocas devidamente 
estruturadas, obtém-se o vetor de prioridades, ou pesos, a partir do cálculo do autovetor normalizado do máximo autovalor.

Uma vez definidos os pesos dos critérios norteadores, os próximos passos são hierarquizar e escolher a melhor concepção de casa inteligente para o projeto em foco. Descreve-se a seguir o método TOPSIS conforme proposto por Hwang e Yoon, (1981). Basicamente, a técnica compreende as seguintes etapas:

- Construção da matriz do problema ou matriz de decisão, que traz as alternativas e critérios selecionados juntamente com as notas e avaliações;

- Cálculo da matriz normalizada, utilizando normalização linear ou por vetor;

- Cálculo da matriz com os respectivos pesos de cada critério, definidos previamente por um ou mais decisores;

- Identificação da PIS (positive ideal solution) e da NIS (negative ideal solution);

- Cálculo das distâncias entre a PIS e cada alternativa e entre a NIS e cada alternativa;

- Cálculo da similaridade para a posição ideal positiva, que vai definir a hierarquização das concepções de casas inteligentes propostas, culminando na escolha da melhor concepção.

Os Anexos 1 e 2 apresentam descrições detalhadas dos dois métodos.

\section{4 \\ Considerações finais sobre o capítulo}

Concebeu-se um modelo para geração e seleção de concepções de casas inteligentes baseadas em soluções tecnológicas inovadoras, que adotou a abordagem de Design Thinking e integrou diversas ferramentas de prospecção e gestão da inovação, incluindo a combinação de dois métodos multicritério de apoio à decisão - AHP-TOPSIS.

A aplicação desse modelo permitirá que os decisores e especialistas responsáveis pelo desenvolvimento de projetos de casas inteligentes coloquem seus futuros moradores no centro do desenvolvimento do projeto, gerando e hierarquizando alternativas que venham atender desejos, expectativas e necessidades dessas pessoas e que sejam tecnicamente possíveis de serem transformadas em realidade.

Destacam-se os aspectos inovadores do modelo baseado em Design Thinking, a saber: (i) a criação de uma plataforma de colaboração digital (crowdsourcing) na 
fase de imersão, (ii) na fase de análise e síntese, identificação de arquétipos de futuros moradores da casa inteligente objeto do projeto, que representam as motivações, desejos, expectativas e necessidades, revelando-se características significativas de um grupo mais abrangente; (iii) definição de critérios norteadores para hierarquização de alternativas baseadas em soluções tecnológicas inovadoras e escolha da melhor concepção de casa inteligente para o projeto em foco; (iv) na fase de ideação, adoção da ferramenta de análise morfológica para geração das concepções alternativas de casas inteligentes baseadas em soluções tecnológicas inovadoras; e (v) a combinação de dois métodos multicritério de apoio à decisão para a hierarquização das concepções propostas e seleção da melhor alternativa para um dado projeto de casa inteligente.

Finalmente, cabe ressaltar que o modelo proposto, ao ser aplicado no âmbito do Projeto “Nós Vivemos o Amanhã - NO.V.A.”, liderado pela Enel Distribuição Rio, contribuirá para a escolha da melhor concepção de casa inteligente e respectivas soluções tecnológicas inovadoras para este Projeto. 


\section{Validação do modelo: estudo empírico no âmbito do Projeto Nós Vivemos o Amanhã - NO.V.A.}

Visando demonstrar a aplicabilidade do modelo conceitual apresentado no capítulo 4, este capítulo apresenta e discute os resultados do estudo empírico desenvolvido no âmbito do Projeto Nós Vivemos o Amanhã - NO.V.A, liderado pela Enel Distribuidora Rio, que atua em 66 municípios do estado do Rio de Janeiro.

O Projeto foi desenvolvido em parceria com duas instituições de ensino superior - a Pontifícia Universidade Católica (PUC-Rio) e a Fundação Getúlio Vargas (FGV).

\section{1 Contexto de aplicação: Projeto NO.V.A.}

Para desenvolver as estruturas necessárias para a primeira etapa do Projeto, que correspondeu à escuta da população, a Enel Distribuição Rio contou com o apoio de algumas empresas, que traçaram os direcionamentos de como deveria ser esse processo, no que ela deveria estar baseada e quais caminhos deveriam ser evitados. Estes processos serão mais bem detalhados na fase de imersão do método de Design Thinking. Para isso, foi considerado que o conceito-chave nesse momento do Projeto era a comunicação com a população. Foram traçadas algumas linhas de ação, dentre elas, dinâmicas em redes sociais, encontros presenciais em forma de meetups e workshops com diversos públicos e o desenvolvimento de uma plataforma digital onde ocorreu a escuta efetiva com a participação do grande público.

\section{2}

\section{Fase de imersão}

O objetivo dessa fase é a aproximação com o contexto do Projeto do ponto de vista do cliente e dos stakeholders. Sendo assim, esta fase serve para embasar o desenvolvimento do Projeto, de forma a contemplar interesses, perspectivas e ideias de segmentos diversos: Grupo Enel, sociedade em geral, formadores de opinião e 
academia. Desse modo, é necessário coletar inúmeros dados: projeções de futuro (determinar quem seriam as pessoas que viveriam nesta casa, o que estas pessoas esperam de uma casa no futuro, quais são os sonhos e expectativas em relação a esta casa etc.), levantamento das tecnologias mais recentes para casas inteligentes e que também seriam usadas numa casa do futuro, conceitos e experimentos de casas inteligentes no mundo, etc. Essa diversidade de inputs ajuda na tomada de decisão e na resolução de problemas menores que contribuirá para a construção deste ambiente ideal, a Casa NO.V.A.

Como apresentado no capítulo 4, a fase de imersão é dividida em duas etapas: imersão preliminar e imersão em profundidade. Nos tópicos a seguir, estas duas fases serão descritas.

\subsection{1}

Imersão preliminar: pesquisa exploratória e reuniões de alinhamento

Nesse primeiro momento da fase de imersão, foram feitos quatro workshops com a finalidade de reunir os parceiros e alinhar os conhecimentos e objetivos, de modo que cada parte pudesse entender o Projeto e as expectativas do mesmo.

Concomitantemente aos workshops, foram realizados encontros com formadores de opinião, grupos de universitários e representantes de segmentos da sociedade em geral, denominados meetups. Nesses encontros, os objetivos foram expor e debater temas do cotidiano e perspectivas de futuro, propiciando a formação de imagem e uma percepção prática para gerar mais conteúdos relevantes e critérios para as fases subsequentes do Projeto.

Em paralelo, foi desenvolvida e iniciada uma fase denominada warm up, com ações focadas no Facebook do Projeto objetivando preparar o público para a fase de diálogo mais aberto que foi implementada mais tarde na plataforma digital do Projeto (www.nosvivemosoamanha.com.br). A condução deste processo foi realizada por meio de depoimentos de 30 especialistas ou formadores de opinião de diversos segmentos (moda, educação, música, esportes, dentre outros). Estas pessoas foram incentivadas a falar sobre "como seriam os seus segmentos no futuro" para provocar a discussão sobre cada tema dentro do Facebook e na produção de cards (imagens personalizadas) com perguntas que instigavam o público a pensar sobre questões que foram indicadas nos primeiros Workshops. 
Nesta etapa, foram utilizadas questões abertas (Figura 5.1) para que o público pudesse colocar abertamente suas opiniões, mas também questões fechadas (Figura 5.2). No segundo caso, o público escolhia somente uma opção.

Mais de 37 mil pessoas acessaram a página do Projeto e mais de 3 milhões de pessoas entraram no Facebook. Nesta etapa, foram gerados insumos (ideias e propostas), que serviram para a produção de conteúdos para a plataforma digital.

As figuras 5.1 e 5.2 ilustram tipos de desafios que foram gerados na plataforma do projeto e que fomentaram as discussões e a proposição de ideias, obtendo, assim, insumos para a construção da casa.

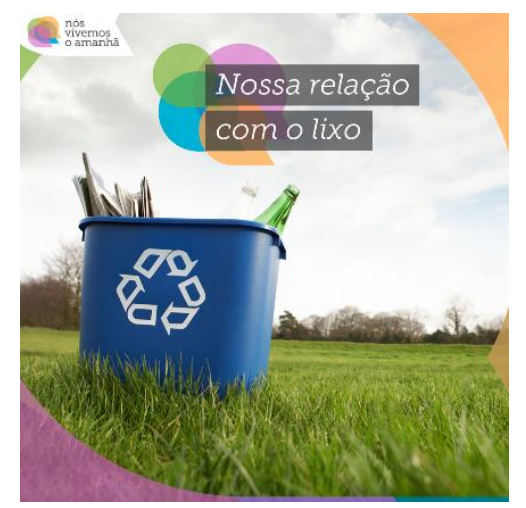

Figura 5.1 - Exemplo de tema para pergunta aberta Fonte: Projeto NO.V.A. (2016).

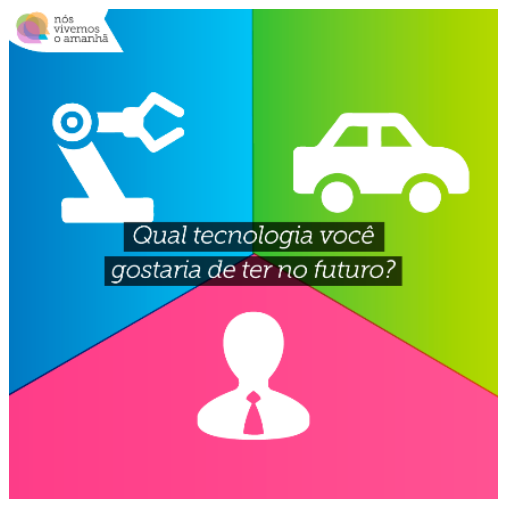

Figura 5.2 - Exemplo de pergunta fechada com alternativas Fonte: Projeto NO.V.A. (2016).

Além disso, na imersão preliminar a Pontifícia Universidade Católica do Rio de Janeiro (PUC-Rio) e a Fundação Getúlio Vargas (FGV), parceiras do Projeto, executaram uma pesquisa exploratória, que consistiu no levantamento bibliográfico referentes ao tema casas inteligentes, de forma a mapear as soluções tecnológicas 
mais inovadoras no mundo e entender quais seriam os perfis de moradores mais estratégicos para o sucesso da fase de implantação do Projeto.

A FGV buscou explorar a percepção acerca dos temas relevantes para o Projeto, interpretando o discurso e estimulando a interação social em dois grupos, a saber: (i) primeiro grupo formado por algumas pessoas que se cadastraram e colaboraram na plataforma digital cooperativa do Projeto NO.V.A.; e (ii) um segundo grupo de especialistas de Instituições de Ciência e Tecnologia (ICT) e das áreas de Inovação, Sustentabilidade e Comunicação da Enel Distribuição Rio.

Em paralelo, a equipe da PUC-Rio realizou uma revisão bibliográfica sobre o estado-da-arte das soluções tecnológicas desenvolvidas para casas inteligentes, como reportado no capítulo 3 , sendo complementada por este autor.

\section{2 .2 \\ Imersão em profundidade: o processo de crowdsoursing e sessões generativas}

Nesse momento da fase de Imersão, foi lançado num site da internet uma plataforma colaborativa para obtenção de ideias sobre casas inteligentes para obter conteúdo advindo da sociedade em geral para uso no Projeto NO.V.A. A proposta foi usar a metodologia de crowdsourcing - modelo de colaboração (participação) ou resolução de problemas que ocorre de forma online e distribuída, através de uma plataforma web (Howe, 2006) -, onde os participantes deveriam responder à seguinte pergunta: "Se você pudesse começar a construir hoje a casa que você vai morar em 2040, como ela seria?"

Em relação ao desenvolvimento dos conteúdos e dinâmicas de engajamento no site colaborativo, foi elaborada uma estratégia de "gameficação" para o site que possibilitou que cada interação dos usuários contasse pontos em um ranking utilizado para premiar os usuários que mais contribuíram. A estratégia era baseada em fazer os usuários retornarem ao site para participarem do game. Para isso, cada usuário, após o cadastro, tinha sua página pessoal onde era possível acompanhar suas interações. Também foram desenvolvidos prêmios virtuais que eram concedidos ao usuário automaticamente pelo site conforme o avanço na pontuação. Além disso, cada participante recebia um bóton de acordo com o tipo e quantidade de participações, por exemplo, um participante que compartilhasse mais de 5 ideias de outros participantes recebia um bóton de Polinizador, assim como uma ideia com 
mais de 300 curtidas e 30 compartilhamentos recebia um bóton de Mirabolante. Os bótons eram cumulativos e quanto mais o participante dava contribuições nas discussões e ideias, o que trazia um valor e prestígio ao gamer (Figura 5.3).

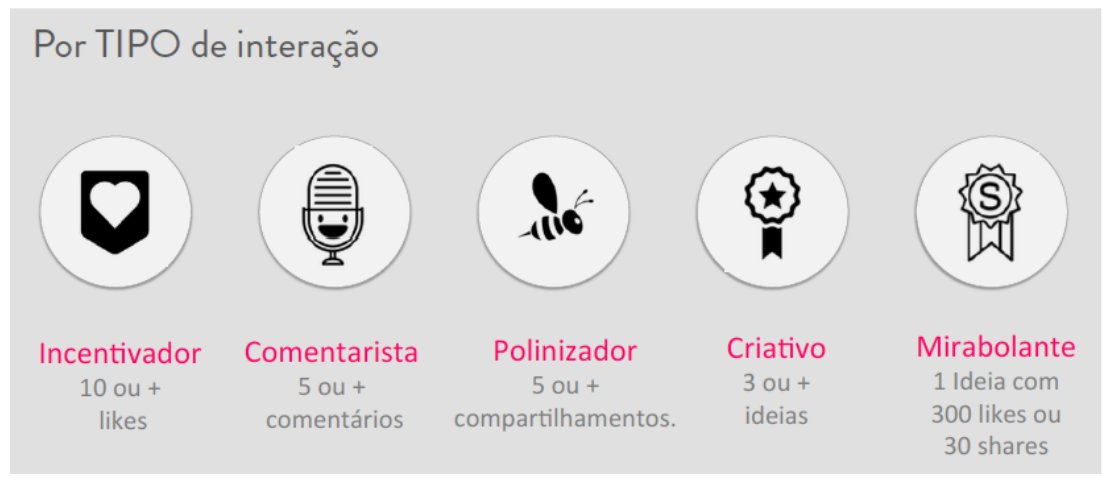

Figura 5.3 - Quadro explicativo de recompensas virtuais

Fonte: Projeto NO.V.A. (2016).

Além disso, a "gameficação" contava com premiações físicas que podiam ser recebidas de acordo com a posição dos participantes no ranking e engajamento no Projeto, sendo a premiação máxima uma viagem para Milão, com direito a ingressos para a ExpoMilão 2015.

Durante o processo de crowdsourcing, foram realizadas sessões generativas com as equipes integrantes do Projeto e representantes das empresas parceiras para compartilhar suas experiências e realizar atividades nas quais puderam expor suas visões sobre as categorias de serviços e funcionalidades da casa inteligente. A sessão generativa foi considerada uma abordagem apropriada para se obter uma visão geral dos atores envolvidos sobre o Projeto NO.V.A, incluindo-se, neste caso, suas experiências diárias em toda sua complexidade.

Durante a fase de crowdsourcing 16 milhões de pessoas foram alcançadas, 47 mil usuários acessaram a plataforma digital, 5,5 mil pessoas participaram com ideias, curtidas e compartilhamentos, e foram geradas 4.600 ideias das quais 550 serviram de insights para as fases seguintes.

\section{3}

\section{Fase de análise e síntese}

O objetivo desta fase foi obter padrões para auxiliar na compreensão do problema e na definição de critérios norteadores para a seleção pretendida. Sendo 
assim, foram usadas as ferramentas: (i) grupos focais; (ii) criação de personas; e (iii) definição de critérios norteadores.

\subsection{1 \\ Grupos focais}

Nesta fase, foram realizadas reuniões entre a equipe do Projeto para análise das necessidades advindas das ideias do site do Projeto. $\mathrm{O}$ trabalho consistia em identificar a proposta de cada ideia e as soluções que elas estavam relacionadas, separando essas ideias por temas. Por exemplo, várias ideias pediam para que a casa fosse capaz de gerar sua própria energia, tivesse iluminação de maneira sustentável ou armazenasse sua energia. Neste caso foi criada a categoria Produção e Uso de Energia. Dessa maneira, foram criados os temas e depois esses temas foram priorizados para serem abordados no Projeto, formando um grande leque de soluções a serem consideradas para a realização do Projeto (Figura 5.4).

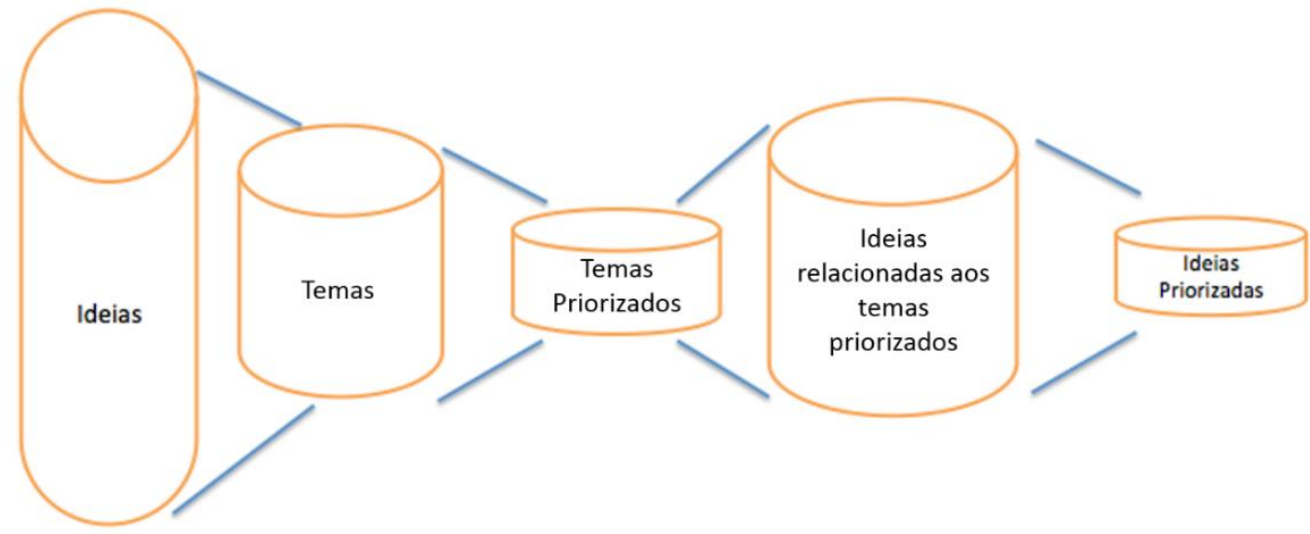

Figura 5.4 - Método de análise das ideias adotado pela equipe do Projeto Fonte: Projeto NO.V.A (2016).

\section{3 .2}

\section{Criação das personas}

Como o objetivo do crowdsourcing do Projeto NO.V.A. foi estimar uma casa típica para o ano de 2040, foi necessário também estimar o perfil das pessoas nesse ano.

Quando é falado sobre os indivíduos do futuro, é fundamental compreender suas características, valores e crenças distintas, e suas atividades do dia a dia. Existem muitas maneiras diferentes para analisar esses arquétipos. Uma forma 
interessante é o conceito de Personas. Sua origem está na palavra latina usada para descrever a máscara usada nos dramas gregos, e significa "a representação fictícia, específica e concreta de usuários-alvo". As personas representam o resultado de um processo profundo de investigação que visa identificar novas interações, compreender as emoções e as conexões que ainda não foram consideradas. As Personas são um retrato integrador dos indivíduos com seus traços e valores, arquétipos de "Indivíduos do Futuro".

Por meio de um workshop realizado com esta finalidade no Projeto, foram traçados os perfis dessas Personas buscando responder as seguintes perguntas relacionadas aos indivíduos no futuro: Quais seriam suas profissões, hobbies e interesses? Quais seriam provavelmente suas características físicas, a sua saúde, dificuldades e talentos? Assim, foram criadas 6 personas representando ficticiamente os prováveis moradores da casa inteligente do Projeto NO.V.A.. A seguir, tem-se a descrição das Personas:

Maria: 74 anos, mora sozinha, aposentada e empreendedora, trabalhadora, ativa, preocupada com a sustentabilidade, possui necessidades especiais de saúde. Ela acredita que depois de uma vida intensa, muitas pessoas da sua geração podem ter uma vida mais saudável e que os espaços podem contribuir para esse processo.

Olivia: 18 anos, maker e estudante, obesa, depressiva, tem um pet robótico Holy, pois não tem paciência para tarefas domésticas. A cada 6 meses ela se muda de residência para mobilizar o movimento dos makers. Ela acredita que o mundo é uma grande caixa de experimentação e vive para criar e conectar o mundo online com os objetos off-line.

Vítor: 55 anos, consultor em fazendas verticais, fisicamente ativo e estressado, tem uma esposa e um cão, todos seus dados estão na nuvem. Ele é um "Silver Hopper" que utiliza a nuvem para seu trabalho e lazer, compartilha sem preocupações suas preferências e com isso torna os relacionamentos e os espaços mais inteligentes.

Beatriz: 32 anos, dataminer, trabalha virtualmente, possui uma companheira e um filho, vida flexível e incerteza de renda, todas suas informações estão na nuvem e monitora a saúde com wearables, cultiva alimentos em uma horta orgânica comunitária. Ela é uma nativa digital, mas sempre encontra tempo para seu filho Jonas e seu desafio é equilibrar o tempo disponível entre saúde, trabalho e família, otimizando o que ela pode. 
Michel: 38 anos, ator virtual, obeso, depressivo, $90 \%$ do tempo no mundo virtual. Ele é famoso no mundo virtual e tem dificuldade de se identificar com o mundo real, que parece pouco flexível e com poucos estímulos criativos. Não gasta quase nada e economiza muito. Acha importante ter um espaço de relaxamento.

Carla: 45 anos, tem dois filhos e dois empregos (cuidadora de dia, End of Life Planner, à noite). Preocupada com a sustentabilidade financeira, apresenta desequilíbrio emocional e seu DNA indica alta probabilidade de demência. Ela vive para ajudar outras pessoas e não tem tempo de se valorizar. Acredita que os idosos deveriam focalizar numa vida mais saudável e na recuperação dos anos perdidos.

\subsection{3}

\section{Definição dos critérios norteadores}

O Quadro 5.1 apresenta a seleção dos critérios norteadores para a definição de concepções de casas inteligentes para o Projeto NO.V.A. com base na análise de conteúdo de trabalhos científicos relevantes sobre casas inteligentes.

Os critérios foram selecionados, levando-se em consideração a convergência verificada nos artigos de GhaffarianHoseini et al. (2013), Alam et al. (2014) e Wong e Li (2009). Esses artigos constituem revisões da literatura sobre casas inteligentes, incluindo critérios e metodologias de escolha de soluções tecnológicas a serem incorporadas a projetos de casas inteligentes. Após a seleção dos critérios, especialistas foram consultados para que fossem dados os pesos para cada um dos critérios, conforme definido no método AHP.

Os artigos de GhaffarianHoseini et al. (2013), Alam et al. (2014) relatam a importância de haver o critério "efetividade de custos" para a definição das tecnologias constantes em uma casa inteligente, porém este não foi considerado pois em nenhuma das concepções de casas inteligentes estudadas foram encontrados dados da relação custo versus benefício para uma casa inteligente. 
Quadro 5.1 - Critérios norteadores para definição de concepções de casas inteligentes

\begin{tabular}{|c|c|c|c|c|}
\hline & \multicolumn{3}{|c|}{ Autores } \\
\hline & & Alam et al., 2012 & GhaffarianHoseini et al., 2013 & Wong e Li,2009 \\
\hline \multirow{7}{*}{ 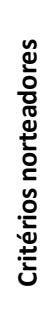 } & Eficiência das funcionalidades da casa & & $\mathrm{x}$ & $\mathrm{x}$ \\
\hline & Eficiência de custos & & $\mathrm{x}$ & $\mathrm{x}$ \\
\hline & Conforto do usuário & $x$ & $x$ & $x$ \\
\hline & Aspectos ambientais & & $x$ & $x$ \\
\hline & Saúde do morador & $x$ & & \\
\hline & Segurança do morador & $x$ & & $x$ \\
\hline & Aspectos tecnológicos & & & $x$ \\
\hline
\end{tabular}

Fonte: Elaboração própria.

\section{4}

\section{Fase de ideação}

Nessa fase, foi empregada a ferramenta de análise morfológica (Quadro 5.2) para a geração de alternativas e o emprego de um método híbrido multicritério de apoio à decisão (AHP-TOPSIS) para seleção e hierarquização das concepções de casas inteligentes propostas.

A construção da matriz multidimensional de análise morfológica foi realizada a partir dos artigos de revisão de Alam et al., 2014 e Wong e Li, 2009; do estadoda-arte apresentado no capítulo 3 e da análise e síntese das ideias geradas no processo de crowdsourcing do Projeto NO.V.A.. A matriz multidimensional de análise morfológica é apresentada no Quadro 5.2, a seguir. 
Quadro 5.2 - Matriz de análise morfológica construída para a geração de concepções de casas inteligentes para o Projeto NO.V.A.

\begin{tabular}{|c|c|c|c|c|c|c|c|c|c|c|c|c|c|}
\hline \multirow[b]{2}{*}{ Cate $\mathbb{J}$} & \multirow[b]{2}{*}{; de Serviço } & \multicolumn{12}{|l|}{ Soluçoes tecnológicas } \\
\hline & & Solução Tecnológica 1 & Solução Tecnológica 2 & Solução Tecnológica 3 & Solução Tecnológica 4 & Solução Tecnológica 5 & Solução Tecnológica 6 & Solução Tecnológica 7 & Solução Tecnológica 8 & Solução Tecnológica 9 & Solução Tecnológica 10 & Solução Tecnológica 11 & Solução Tecnológica 12 \\
\hline$\underset{\frac{1}{n}}{\stackrel{+}{N}}$ & oe Lazer & Sistema HVAC & \begin{tabular}{|c|} 
Sistema endereçável \\
digital de controle da \\
iluminação
\end{tabular} & Sistema de iluminação & $\begin{array}{l}\text { Sistema de layout } \\
\text { interno }\end{array}$ & $\begin{array}{c}\text { Sistema de fachada em } \\
\text { edificações }\end{array}$ & $\begin{array}{c}\text { rede de interconexão } \\
\text { de produtos e sistemas } \\
\text { eletrônicos } \\
\text { domésticos (HAN) }\end{array}$ & $\begin{array}{c}\text { Sistema de } \\
\text { gerenciamento } \\
\text { ambiental interno e } \\
\text { externo }\end{array}$ & \begin{tabular}{|c|} 
Sistemas de detecção \\
de posicionamento \\
não invasivos
\end{tabular} & Smart furniture & & & \\
\hline$\stackrel{\text { ol }}{\frac{2}{Z}}$ & residencial & $\begin{array}{c}\text { Sistema endereçável } \\
\text { de detecç̧ão de } \\
\text { incêndio e alarme }\end{array}$ & $\begin{array}{l}\text { Sistema de dados e } \\
\text { telecomunicação } \\
\text { (ex.:PLC) }\end{array}$ & $\begin{array}{c}\text { Sistema integrado de } \\
\text { gerenciamento de } \\
\text { edificações }\end{array}$ & $\begin{array}{c}\text { Sistema de } \\
\text { monitoramento da } \\
\text { segurança e controle } \\
\text { de acesso }\end{array}$ & $\begin{array}{l}\text { Sistema de layout } \\
\text { interno }\end{array}$ & Sistema de iluminação & $\begin{array}{c}\text { Sistema de fachada em } \\
\text { edificações }\end{array}$ & $\begin{array}{l}\text { Sistema vertical de } \\
\text { transporte }\end{array}$ & \begin{tabular}{|c|} 
rede de interconexão \\
de produtos e sistemas \\
eletrônicos \\
domésticos (HAN)
\end{tabular} & \begin{tabular}{|c|} 
Sistema de \\
gerenciamento \\
ambiental interno e \\
externo
\end{tabular} & \begin{tabular}{|c|} 
Sistemas de detecção \\
de posicionamento \\
não invasivos
\end{tabular} & Smart furniture \\
\hline $\begin{array}{l}0 \\
\text { A } \\
100 \\
10\end{array}$ & remoto & $\begin{array}{l}\text { Sistema de dados e } \\
\text { telecomunicação } \\
\text { (ex.:PLC) }\end{array}$ & \begin{tabular}{|c|} 
Sistema endereçável \\
digital de controle da \\
iluminação
\end{tabular} & \begin{tabular}{|c|}
$\begin{array}{c}\text { Sistema integrado de } \\
\text { gerenciamento de } \\
\text { edificações }\end{array}$ \\
\end{tabular} & $\begin{array}{c}\text { Sistema de fachada em } \\
\text { edificaçōes }\end{array}$ & & & & & & & & \\
\hline 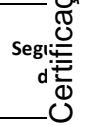 & $\begin{array}{l}\text { I de rede e } \\
\text { irmação }\end{array}$ & $\begin{array}{c}\text { Sistema de } \\
\text { monitoramento da } \\
\text { segurança e controle } \\
\text { de acesso }\end{array}$ & $\begin{array}{l}\text { Sistema de informação } \\
\text { e rede de comunicação }\end{array}$ & & & & & & & & & & \\
\hline cui.o음 & $\begin{array}{l}\text {; de saúde } \\
\text { thcare) }\end{array}$ & $\begin{array}{l}\text { Sistema integrado de } \\
\text { gerenciamento de } \\
\text { edificações }\end{array}$ & $\begin{array}{l}\text { Sistema de layout } \\
\text { interno }\end{array}$ & $\begin{array}{l}\text { Sistema vertical de } \\
\text { transporte }\end{array}$ & Smart furniture & $\begin{array}{l}\text { Wearables, } \\
\text { monitoramento da } \\
\text { saúde }\end{array}$ & $\begin{array}{c}\text { Sistema de } \\
\text { gerenciamento } \\
\text { ambiental interno e } \\
\text { externo } \\
\end{array}$ & & & & & & \\
\hline $\begin{array}{l}\text { U: } \\
\text { recursu }\end{array}$ & $\begin{array}{l}\text { iente de } \\
\text { us naturais }\end{array}$ & $\begin{array}{c}\text { Sistema hidráulico e } \\
\text { de drenagem }\end{array}$ & \begin{tabular}{|c|} 
Mini estação de \\
tratamento de águas
\end{tabular} & $\begin{array}{c}\text { Captação da águas } \\
\text { pluviais }\end{array}$ & $\begin{array}{l}\text { Mini estação } \\
\text { metereológica }\end{array}$ & Biodigestor & Telhado verde & $\begin{array}{c}\text { Cultivo de verduras e } \\
\text { legumes }\end{array}$ & & & & & \\
\hline $\begin{array}{r}\text { Gerenci } \\
\text { en }\end{array}$ & $\begin{array}{l}\text { iamento de } \\
\text { nergia }\end{array}$ & Sistema HVAC & \begin{tabular}{|c|} 
Sistema endereçável \\
digital de controle da \\
iluminação
\end{tabular} & $\begin{array}{c}\text { Sistema de } \\
\text { gerenciamento de } \\
\text { energia }\end{array}$ & Sistema de iluminação & $\begin{array}{c}\text { PVT - módulo } \\
\text { fotovoltaico e térmico }\end{array}$ & $\begin{array}{c}\text { Módulo fotovoltaico } \\
\text { bifacial }\end{array}$ & Sistema fotovoltaica & $\begin{array}{c}\text { Sistema de } \\
\text { gerenciamento } \\
\text { ambiental interno e } \\
\text { externo }\end{array}$ & Sistema de baterias & $\begin{array}{l}\text { Sistema de energia } \\
\text { geotérmica }\end{array}$ & $\begin{array}{c}\text { Sistema de } \\
\text { aquecimento solar de } \\
\text { água }\end{array}$ & Aerogerador eólico \\
\hline Seguranç̨. & a Patrimonial & $\begin{array}{l}\text { Proteção contra } \\
\text { incêndio }\end{array}$ & \begin{tabular}{|c|} 
Sistema endereçável \\
de detecccão de \\
incêndio e alarme
\end{tabular} & Sistema de segurança & & & & & & & & & \\
\hline
\end{tabular}

Fontes: Elaboração própria a partir dos artigos de revisão de Alam et al., 2014 e Wong e Li, 2009; do estado-da-arte apresentado no capítulo 3 e da análise e síntese das ideias geradas no processo de crowdsourcing do Projeto NO.V.A. 


\subsection{1 \\ Geração de concepções: uso de análise morfológica}

Nesta etapa, a análise morfológica serviu para identificar e associar as soluções tecnológicas inovadoras, as concepções de projetos de casas inteligentes apresentados no capítulo 2, incluindo a proposta para a casa NO.V.A..

Vale destacar que as casas Matilda Smart House, MIT Smart House, Toyota Dream House PAPI e Ubiquitous Home não foram analisadas morfologicamente por faltarem dados suficientes a respeito das mesmas na literatura e nas fontes institucionais pesquisadas. Já a Duke Smart House não foi incluída nesta fase por não ter nenhum foco voltado a pessoas idosas, característica considerada importante dentre os objetivos do Projeto NO.V.A.

Os Quadros 5.3 a 5.8 apresentam, respectivamente, as matrizes de análise morfológica para as seguintes casas: (i) Gator Tech Smart House; (ii) Drexel Smart House; (iii) Aware Home; (iv) CASAS Smart Home; (v) Smart Home Lab de IOWA; e (vi) Casa NO.V.A.

Nessas matrizes, destacam-se em cinza as células com soluções tecnológicas empregadas nestas casas inteligentes, cujas informações foram buscadas nos artigos de Alam et al., 2014 e Wong e Li, 2009, nos sites das casas em foco, além das soluções tecnológicas propostas no processo de crowdsourcing do Projeto NO.V.A. 
Quadro 5.3 - Concepção da Gator Tech Smart House

\begin{tabular}{|c|c|c|c|c|c|c|c|c|c|c|c|c|c|}
\hline \multirow{2}{*}{$\begin{array}{l}\text { Categorias de } \\
\text { Serviço }\end{array}$} & \multicolumn{13}{|c|}{ Soluçōes tecnológicas } \\
\hline & $\begin{array}{c}\text { Solução } \\
\text { Tecnológica 1 }\end{array}$ & $\begin{array}{c}\text { Solução } \\
\text { Tecnológica } 2\end{array}$ & $\begin{array}{c}\text { Solução } \\
\text { Tecnológica } 3\end{array}$ & $\begin{array}{c}\text { Solução } \\
\text { Tecnológica } 4\end{array}$ & $\begin{array}{c}\text { Solução } \\
\text { Tecnológica } 5\end{array}$ & $\begin{array}{c}\text { Solução } \\
\text { Tecnológica } 6\end{array}$ & $\begin{array}{c}\text { Solução } \\
\text { Tecnológica } 7\end{array}$ & $\begin{array}{c}\text { Solução } \\
\text { Tecnológica } 8\end{array}$ & $\begin{array}{c}\text { Solução } \\
\text { Tecnológica } 9\end{array}$ & $\begin{array}{c}\text { Solução } \\
\text { Tecnológica } 10\end{array}$ & $\begin{array}{c}\text { Solução } \\
\text { Tecnológica } 11\end{array}$ & $\begin{array}{c}\text { Solução } \\
\text { Tecnológica } 12\end{array}$ & $\begin{array}{c}\text { Solução } \\
\text { Tecnológica } 13\end{array}$ \\
\hline Conforto e Lazer & Sistema HVAC & $\begin{array}{c}\text { Sistema } \\
\text { enderéavel digital } \\
\text { de controle da } \\
\text { iluminaçăo }\end{array}$ & $\begin{array}{l}\text { Sistema de } \\
\text { iluminação }\end{array}$ & $\begin{array}{l}\text { Sistema de layout } \\
\text { interno }\end{array}$ & $\begin{array}{l}\text { Sistema de fachada } \\
\text { em edificaçōes }\end{array}$ & $\begin{array}{l}\text { Home area network } \\
\text { (HAN) }\end{array}$ & $\begin{array}{c}\text { Sistema de } \\
\text { gerenciamento } \\
\text { ambiental interno e } \\
\text { externo }\end{array}$ & $\begin{array}{c}\text { Sistemas de } \\
\text { detecçãa ode } \\
\text { posicionamento não } \\
\text { invasivos }\end{array}$ & Smart furniture & & & & \\
\hline $\begin{array}{l}\text { Automação } \\
\text { residencial }\end{array}$ & $\begin{array}{c}\text { Sistema endereááve } \\
\text { de deteccção de } \\
\text { incêndio e alarme }\end{array}$ & \begin{tabular}{|c} 
Sistema de dados $\mathrm{e}$ \\
telecomunicaçăo \\
(ex.PLC)
\end{tabular} & $\begin{array}{l}\text { Sistema integrado } \\
\text { de gerenciamento } \\
\text { de edificaç̄oses }\end{array}$ & $\begin{array}{c}\text { Sistema de } \\
\text { monitioramento da } \\
\text { seguranga e controle } \\
\text { de acesso }\end{array}$ & \begin{tabular}{|c} 
Sistema de layout \\
interno
\end{tabular} & $\begin{array}{l}\text { Sistema de } \\
\text { iluminação }\end{array}$ & $\begin{array}{c}\text { Sistema de fachada } \\
\text { em edificaçōes }\end{array}$ & $\begin{array}{c}\text { Sistema vertical de } \\
\text { transporte }\end{array}$ & $\begin{array}{l}\text { Home area network } \\
\text { (HAN) }\end{array}$ & $\begin{array}{c}\text { Sistema de } \\
\text { gerenciamento } \\
\text { ambiental intermo e } \\
\text { externo }\end{array}$ & $\begin{array}{c}\text { Sistemas de } \\
\text { detecção de } \\
\text { posicionamento não } \\
\text { invasivos }\end{array}$ & Smart furniture & \\
\hline Acesso remoto & $\begin{array}{l}\text { Sistema de dados e } \\
\text { telecomunicaçăo } \\
\text { (ex.:PLC) }\end{array}$ & \begin{tabular}{|c} 
Sistema \\
enderesável ligital \\
de controle da \\
iluminacăão
\end{tabular} & $\begin{array}{c}\text { Sistema integrado } \\
\text { de gerenciamento } \\
\text { de edificaçōes }\end{array}$ & $\begin{array}{l}\text { Sistema de fachada } \\
\text { em edificaçôes }\end{array}$ & & & & & & & & & \\
\hline $\begin{array}{c}\text { Segurança de } \\
\text { rede e de } \\
\text { informação }\end{array}$ & $\begin{array}{c}\text { Sistema de } \\
\text { monitoramento da } \\
\text { seguranga e controle } \\
\text { de acesso }\end{array}$ & \begin{tabular}{|c} 
Sistema de \\
informaçãe rede \\
de comunuicaçăo
\end{tabular} & $\begin{array}{c}\text { Sistemas de } \\
\text { detecçăo de } \\
\text { posicionamento não } \\
\text { invasivos }\end{array}$ & & & & & & & & & & \\
\hline $\begin{array}{l}\text { Cuidados de } \\
\text { saúde } \\
\text { (Healthcare) }\end{array}$ & $\begin{array}{c}\text { sistema integrado de } \\
\text { gerenciamento de } \\
\text { edificicasoes }\end{array}$ & $\begin{array}{l}\text { Sistema de layout } \\
\text { interno }\end{array}$ & $\begin{array}{c}\text { Sistema vertical de } \\
\text { transporte }\end{array}$ & $\begin{array}{c}\text { Wearables, } \\
\text { monitoramento da } \\
\text { saúde }\end{array}$ & $\begin{array}{c}\text { Sistemas de } \\
\text { detecção de } \\
\text { posicionamento não } \\
\text { invasivos }\end{array}$ & Smart furniture & & & & & & & \\
\hline $\begin{array}{l}\text { Uso eficiente de } \\
\text { recursos } \\
\text { naturais }\end{array}$ & $\begin{array}{l}\text { Sistema hidráulicoe } \\
\text { de drenagem }\end{array}$ & $\begin{array}{c}\text { Mini estação de } \\
\text { tratamento de } \\
\text { águas }\end{array}$ & $\begin{array}{c}\text { Captação da águas } \\
\text { pluviais }\end{array}$ & $\begin{array}{l}\text { Mini estação } \\
\text { metereoologica }\end{array}$ & Biodigestor & Telhado verde & Horta & & & & & & \\
\hline $\begin{array}{c}\text { Gerenciamento } \\
\text { de energia }\end{array}$ & Sistema HVAC & \begin{tabular}{|c} 
Sistema \\
enderecável digital \\
de controle da \\
iluminação
\end{tabular} & $\begin{array}{c}\text { Sistema de } \\
\text { gerenciamento de } \\
\text { energia }\end{array}$ & $\begin{array}{l}\text { Sistema de } \\
\text { iluminação }\end{array}$ & $\begin{array}{c}\text { Sistema de } \\
\text { instalaçăo elétrica }\end{array}$ & $\begin{array}{l}\text { PVT - módulo } \\
\text { fotovoltaico } \\
\text { térmico }\end{array}$ & Módulo fotovoltaico & $\mid \begin{array}{c}\text { sistema de tracking } \\
\text { para fotovoltaica }\end{array}$ & $\begin{array}{c}\text { Sistema de } \\
\text { gerenciamento } \\
\text { ambiental interno e } \\
\text { externo }\end{array}$ & Sistema de baterias & $\begin{array}{c}\text { Sistema de energiala } \\
\text { geotérmica }\end{array}$ & $\begin{array}{c}\text { Sistema de } \\
\text { aquecimento solar } \\
\text { de água }\end{array}$ & Aerogerador eólico \\
\hline $\begin{array}{c}\text { Segurança } \\
\text { Patrimonial }\end{array}$ & $\begin{array}{l}\text { Proteçăa contra } \\
\text { incêndio }\end{array}$ & $\begin{array}{c}\text { Sistema } \\
\text { endereçável de } \\
\text { detecçẫo de } \\
\text { incêndio e alarme }\end{array}$ & $\begin{array}{l}\text { Sistema de } \\
\text { segurança }\end{array}$ & & & & & & & & & & \\
\hline
\end{tabular}

Fonte: Elaboração própria. 


\section{Quadro 5.4 - Concepção da Drexel Smart Home}

\begin{tabular}{|c|c|c|c|c|c|c|c|c|c|c|c|c|c|}
\hline \multirow{2}{*}{$\begin{array}{l}\text { Categorias de } \\
\text { Servico }\end{array}$} & \multicolumn{13}{|c|}{ Soluçōes tecnológicas } \\
\hline & $\begin{array}{c}\text { Solução } \\
\text { Tecnológica } 1\end{array}$ & $\begin{array}{c}\text { Soluçäo } \\
\text { Tecnologica }\end{array}$ & $\begin{array}{c}\text { Soluçāo } \\
\text { Tecrologica } 3\end{array}$ & $\begin{array}{c}\text { Solução } \\
\text { Tecnologica a }\end{array}$ & $\begin{array}{c}\text { Soluşäo } \\
\text { Tecrologica } 5\end{array}$ & $\begin{array}{c}\text { Solução } \\
\text { Tecnologicica } 6\end{array}$ & $\begin{array}{c}\text { Solução } \\
\text { Tecnologica } 7\end{array}$ & \begin{tabular}{|c} 
Solução \\
Tecnológica
\end{tabular} & $\begin{array}{c}\text { Solução } \\
\text { Tecrológica 9 }\end{array}$ & $\begin{array}{c}\text { Soluça } \\
\text { Tecnologicic } 10\end{array}$ & $\begin{array}{c}\text { Soluçăo } \\
\text { Tecnologica } 11\end{array}$ & $\begin{array}{c}\text { Solusăo } \\
\text { Tecnologicic } 12\end{array}$ & $\begin{array}{c}\text { Solução } \\
\text { Tecnologitc a } 13\end{array}$ \\
\hline Conforto e Lazer & Sistema HVAC & 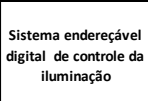 & istema de iluminaşăo & $\begin{array}{c}\text { sistema a le layout } \\
\text { intemeno }\end{array}$ & $\begin{array}{c}\text { sistema de fatchada } \\
\text { em edffiraches }\end{array}$ & $\begin{array}{l}\text { Home arca network } \\
(\mathrm{HANN})\end{array}$ & 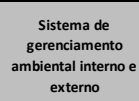 & 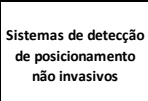 & Smart furitiure & & & & \\
\hline $\begin{array}{l}\text { Automação } \\
\text { residencial }\end{array}$ & 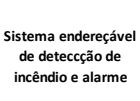 & 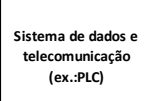 & 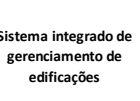 & 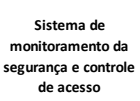 & $\begin{array}{c}\text { Sistema de layout } \\
\text { intermo }\end{array}$ & Sistem a de iuminasăac & $\begin{array}{l}\text { Sisteman det fachada } \\
\text { em edfificases }\end{array}$ & $\begin{array}{c}\text { Sisteman vertical de } \\
\text { transporte }\end{array}$ & $\begin{array}{l}\text { areare netw } \\
\text { (HAN) }\end{array}$ & 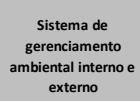 & 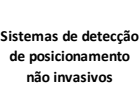 & Smart furniture & \\
\hline Acesso remoto & 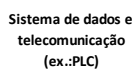 & 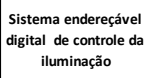 & 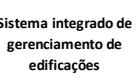 & 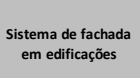 & & & & & & & & & \\
\hline $\begin{array}{c}\text { Seguranga de } \\
\text { rede e de } \\
\text { informagán }\end{array}$ & 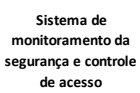 & 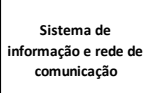 & 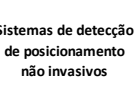 & & & & & & & & & & \\
\hline $\begin{array}{l}\text { Cuidados de } \\
\text { saude } \\
\text { (Healthcare) }\end{array}$ & 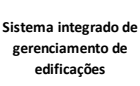 & $\begin{array}{l}\text { Sistema de elayout } \\
\text { interno }\end{array}$ & $\begin{array}{c}\text { Sisteman vertical de } \\
\text { transporte }\end{array}$ & 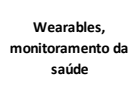 & 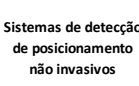 & smart furniture & & & & & & & \\
\hline $\begin{array}{l}\text { Uso eficiente de } \\
\text { recursos naturais }\end{array}$ & 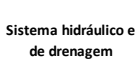 & 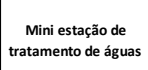 & 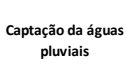 & 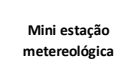 & Biodidestor & Telhaso verde & Horta & & & & & & \\
\hline $\begin{array}{l}\text { Gerenciamento } \\
\text { de energia }\end{array}$ & Sistema HVAC & 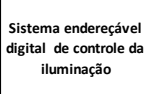 & 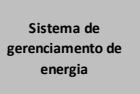 & & $\begin{array}{l}\text { made instalazsac } \\
\text { eletricas }\end{array}$ & 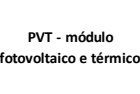 & Módulu fotovortatico & 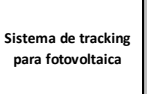 & $\begin{array}{c}\text { Sistema de } \\
\text { serencianento } \\
\text { ambienta interoe } \\
\text { extemeno }\end{array}$ & Sistema de baterias & $\begin{array}{l}\text { Sistema ade energial } \\
\text { geotermitace }\end{array}$ & $\begin{array}{l}\text { Sistema de } \\
\text { uecienento solar de } \\
\text { aguaa }\end{array}$ & Aerogerador eatilico \\
\hline $\begin{array}{l}\text { Segurranca } \\
\text { Patrimonial }\end{array}$ & $\begin{array}{c}\text { Protecerac contra } \\
\text { incendion }\end{array}$ & 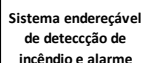 & seguransa & & & & & & & & & & \\
\hline
\end{tabular}

Fonte: Elaboração própria. 


\section{Quadro 5.5 - Concepção da Aware Home}

\begin{tabular}{|c|c|c|c|c|c|c|c|c|c|c|c|c|c|}
\hline \multirow{2}{*}{$\begin{array}{l}\text { Categorias de } \\
\text { Serviço }\end{array}$} & \multicolumn{13}{|c|}{ Soluçöes tecnológicas } \\
\hline & $\begin{array}{c}\text { Soluçăo } \\
\text { Tecológica 1 }\end{array}$ & $\begin{array}{c}\text { Solução } \\
\text { Tecnologica 2 }\end{array}$ & $\begin{array}{c}\text { Solucăo } \\
\text { Tecnologica } 3\end{array}$ & $\begin{array}{c}\text { Solução } \\
\text { Tecnológica } 4\end{array}$ & $\begin{array}{c}\text { Solução } \\
\text { Tecrológica } 5\end{array}$ & $\begin{array}{c}\text { Solução } \\
\text { Tecnologicat } 6\end{array}$ & $\begin{array}{c}\text { Solução } \\
\text { Tecnológica } 7\end{array}$ & $\begin{array}{c}\text { Soluçăo } \\
\text { Tennologica } 8\end{array}$ & $\begin{array}{c}\text { Solução } \\
\text { Tecnológica } 9\end{array}$ & $\begin{array}{c}\text { Solução } \\
\text { Tecrnologica } 10\end{array}$ & $\begin{array}{c}\text { Soluçäo } \\
\text { Tecnologica 11 }\end{array}$ & $\begin{array}{c}\text { Soluçăo } \\
\text { Tecnologica } 12\end{array}$ & $\begin{array}{c}\text { Solução } \\
\text { Tecnologica } 13\end{array}$ \\
\hline Conforto e Lazer & Sistema HVAC & 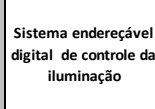 & iststema de iluminaçăo & $\begin{array}{l}\text { Sistema de alayout } \\
\text { intemo }\end{array}$ & $\begin{array}{c}\text { Sistema de fachada } \\
\text { em edificaçoes }\end{array}$ & $\begin{array}{l}\text { Home area network } \\
\text { (HAN) }\end{array}$ & $\begin{array}{c}\text { Sistema de } \\
\text { gereccimento } \\
\text { ambientat intemoe } \\
\text { extemono }\end{array}$ & 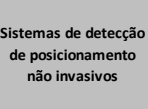 & Smart funiture & & & & \\
\hline $\begin{array}{l}\text { Automação } \\
\text { residencial }\end{array}$ & 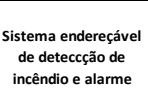 & 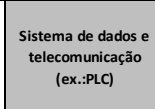 & 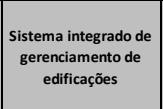 & 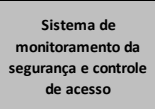 & $\begin{array}{l}\text { Sistema de layout } \\
\text { interno }\end{array}$ & eema de iluminases & $\begin{array}{c}\text { sistema de fachada } \\
\text { em edfificaçoes }\end{array}$ & $\begin{array}{l}\text { Sistema vertical de } \\
\text { transporte }\end{array}$ & $\begin{array}{l}\text { Home area network } \\
\text { (HAN) }\end{array}$ & 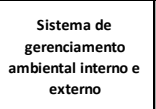 & 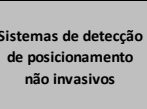 & Smart turiture & \\
\hline Acesso remoto & 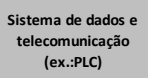 & $\begin{array}{l}\text { Sistema enderesivel } \\
\text { digitial de controle } \\
\text { iluminarafó da }\end{array}$ & $\begin{array}{c}\text { Sistema integrado de } \\
\text { gerenciamento de } \\
\text { edifificasoses }\end{array}$ & $\begin{array}{l}\text { sistema de fachada } \\
\text { em edfificaseses }\end{array}$ & & & & & & & & & \\
\hline $\begin{array}{c}\text { Segurança de } \\
\text { rede e de } \\
\text { informaçăo }\end{array}$ & 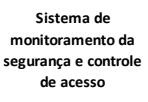 & $\begin{array}{c}\text { Sistema de } \\
\text { informagazo erede de } \\
\text { comunicicasio }\end{array}$ & 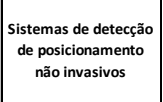 & & & & & & & & & & \\
\hline $\begin{array}{c}\text { Cuidados de } \\
\text { saude } \\
\text { (Healthare) }\end{array}$ & 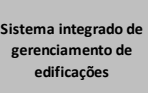 & 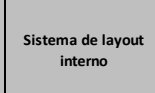 & $\begin{array}{l}\text { Sisteman vertica de } \\
\text { transporte }\end{array}$ & 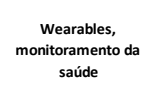 & 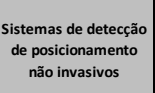 & Smart funiture & & & & & & & \\
\hline $\begin{array}{l}\text { Uso eficiente de } \\
\text { recursos naturais }\end{array}$ & $\begin{array}{l}\text { istem hitraulcoe } \\
\text { de trenangem }\end{array}$ & 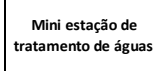 & 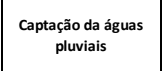 & $\begin{array}{c}\text { Mini estataso } \\
\text { meterealobica }\end{array}$ & Biodiesestor & Telehado verde & Hotra & & & & & & \\
\hline $\begin{array}{c}\text { Gerenciamento } \\
\text { de energia }\end{array}$ & Sistema HVAC & 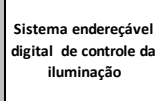 & $\underset{\substack{\text { Sistema de } \\
\text { gerencianento de } \\
\text { energiga }}}{ }$ & stema ad iluminaragó & $\begin{array}{c}\text { Stema de instalaşă } \\
\text { eletrica }\end{array}$ & 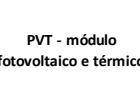 & Mobullo fotovoltaico & $\begin{array}{l}\text { Sistem de deracking } \\
\text { para fotocoutatica }\end{array}$ & $\begin{array}{c}\text { Sistema de } \\
\text { serencianento } \\
\text { ambientat interoe } \\
\text { extereme }\end{array}$ & Sistema de baterias & 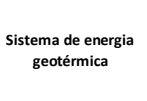 & $\begin{array}{l}\text { Sistema de } \\
\text { uecimento solar de } \\
\text { agua }\end{array}$ & Aerogerador eatico \\
\hline $\begin{array}{l}\text { Segurança } \\
\text { Patrimonial }\end{array}$ & $\begin{array}{c}\text { Protetesc contra } \\
\text { incendio }\end{array}$ & 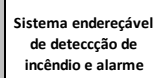 & Sistema de seguranga & & & & & & & & & & \\
\hline
\end{tabular}

Fonte: Elaboração própria. 


\section{Quadro 5.6 - Concepção da CASAS Smart Home}

\begin{tabular}{|c|c|c|c|c|c|c|c|c|c|c|c|c|c|}
\hline \multirow{2}{*}{$\begin{array}{l}\text { Categorias de } \\
\text { Serviço }\end{array}$} & \multicolumn{13}{|c|}{ Soluçõ̃es tecnológicas } \\
\hline & $\begin{array}{c}\text { Solução } \\
\text { Tecnológica } 1\end{array}$ & $\begin{array}{c}\text { Solução } \\
\text { Tecnológica } 2\end{array}$ & $\begin{array}{c}\text { Solução } \\
\text { Tecnológica } 3\end{array}$ & $\begin{array}{c}\text { Solução } \\
\text { Tecnológica } 4\end{array}$ & $\begin{array}{c}\text { Solução } \\
\text { Tecnológica } 5\end{array}$ & $\begin{array}{c}\text { Solução } \\
\text { Tecnológica } 6\end{array}$ & $\begin{array}{c}\text { Solução } \\
\text { Tecnológica } 7\end{array}$ & $\begin{array}{c}\text { Solução } \\
\text { Tecnológica } 8\end{array}$ & $\begin{array}{c}\text { Solução } \\
\text { Tecnológica } 9\end{array}$ & $\begin{array}{c}\text { Solução } \\
\text { Tecnológica } 10\end{array}$ & $\begin{array}{c}\text { Solução } \\
\text { Tecnológica } 11\end{array}$ & $\begin{array}{c}\text { Solução } \\
\text { Tecrológica } 12\end{array}$ & $\begin{array}{c}\text { Solução } \\
\text { Tecnológica } 13\end{array}$ \\
\hline Conforto e Lazer & Sistema HVAC & $\begin{array}{l}\text { Sistema enderescável } \\
\text { digital de controle da } \\
\text { iluminaçâo }\end{array}$ & Sistema de iluminação & $\begin{array}{c}\text { Sistema de layout } \\
\text { interno }\end{array}$ & $\begin{array}{l}\text { Sistema de fachada } \\
\text { em edificaçōes }\end{array}$ & $\begin{array}{c}\text { Home area network } \\
\text { (HAN) }\end{array}$ & $\begin{array}{c}\text { Sistema de } \\
\text { gerenciamento } \\
\text { ambiental internoe } \\
\text { externo }\end{array}$ & \begin{tabular}{|c|} 
Sistemas de detecção \\
de posicionamento \\
năo invasivos
\end{tabular} \mid & Smart furniture & & & & \\
\hline $\begin{array}{l}\text { Automação } \\
\text { residencial }\end{array}$ & $\begin{array}{c}\text { Sistema endereḉvel } \\
\text { de detecçááde de } \\
\text { incêndio e alarme }\end{array}$ & $\begin{array}{l}\text { Sistema de dadoses e } \\
\text { telecomunicaşo } \\
\text { (ex:PLC) }\end{array}$ & $\begin{array}{c}\text { Sistema integrado de } \\
\text { gerenciamento de } \\
\text { edificaşes }\end{array}$ & $\begin{array}{c}\text { Sistema de } \\
\text { monitoramento da } \\
\text { seguranga e controle } \\
\text { de acesso }\end{array}$ & $\begin{array}{l}\text { Sistema de layout } \\
\text { intermo }\end{array}$ & Sistema de iluminação & $\begin{array}{c}\text { Sistema de fachada } \\
\text { em edificaç̄es }\end{array}$ & $\begin{array}{c}\text { sistema vertical de } \\
\text { transporte }\end{array}$ & $\begin{array}{c}\text { Home area network } \\
\text { (HAN) }\end{array}$ & \begin{tabular}{|c} 
Sistema de \\
gerenciamento \\
ambiental interno e \\
externo
\end{tabular} & $\begin{array}{l}\text { Sistemas de detecção } \\
\text { de posicionamannto } \\
\text { não invasivos }\end{array}$ & Smart furniture & \\
\hline Acesso remoto & $\begin{array}{c}\text { sistema de dadose } \\
\text { telecomunnicaşo } \\
\text { (ex:PLC) }\end{array}$ & $\begin{array}{l}\text { Sistema enderecével } \\
\text { digital de controle da } \\
\text { iluminaçáo }\end{array}$ & $\begin{array}{c}\text { Sistema integrado de } \\
\text { gerenciamento de } \\
\text { edificaşoes }\end{array}$ & $\begin{array}{c}\text { Sistema de fachada } \\
\text { em edificaçoes }\end{array}$ & & & & & & & & & \\
\hline $\begin{array}{l}\text { Segurança de } \\
\text { rede e de } \\
\text { informação }\end{array}$ & $\begin{array}{c}\text { Sistema de } \\
\text { monitoramento da } \\
\text { seguranga e controle } \\
\text { de acesso }\end{array}$ & $\begin{array}{c}\text { Sistema de } \\
\text { informação erede de } \\
\text { comunicaşăo }\end{array}$ & $\begin{array}{c}\text { sistemas de detecçăo } \\
\text { de posicionamento } \\
\text { nâo invasivos }\end{array}$ & & & & & & & & & & \\
\hline $\begin{array}{l}\text { Cuidados de } \\
\text { saúde } \\
\text { (Healthcare) }\end{array}$ & $\begin{array}{c}\text { Sistema integrado ode } \\
\text { gerenciamento de } \\
\text { edificaçoses }\end{array}$ & $\begin{array}{l}\text { Sistema de layout } \\
\text { interno }\end{array}$ & $\begin{array}{c}\text { Sistema vertical de } \\
\text { transporte }\end{array}$ & $\begin{array}{c}\text { Wearables, } \\
\text { monitoramento da } \\
\text { saude }\end{array}$ & $\begin{array}{c}\text { Sistemas de deteteção } \\
\text { de posicionemannto } \\
\text { não invasivos }\end{array}$ & Smart furniture & & & & & & & \\
\hline $\begin{array}{l}\text { Uso eficiente de } \\
\text { recursos naturais }\end{array}$ & \begin{tabular}{|c} 
Sistema hidráulico e \\
de drenagem
\end{tabular} & $\begin{array}{l}\text { Mini estação de } \\
\text { tratamento de águas }\end{array}$ & $\begin{array}{l}\text { Captacăóo da águas } \\
\text { pluviais }\end{array}$ & $\begin{array}{l}\text { Mini estaçăo } \\
\text { metereologica }\end{array}$ & Biodigestor & Telhado verde & Horta & & & & & & \\
\hline $\begin{array}{c}\text { Gerenciamento } \\
\text { de energia }\end{array}$ & Sistema HVAC & \begin{tabular}{|l} 
Sistema enderescável \\
digital de controle da \\
iluminaçao
\end{tabular} & $\begin{array}{c}\text { Sistema de } \\
\text { gerenciamento de } \\
\text { energia }\end{array}$ & Sistema de iluminaçăo & , $\begin{array}{c}\text { Sistema de instalaçăo } \\
\text { elétrica }\end{array}$ & $\begin{array}{c}\text { PVT- módulo } \\
\text { fotovoltaico térmico }\end{array}$ & Módul fotovoltaico & $\begin{array}{c}\text { sistema de tracking } \\
\text { para fotovoltaica }\end{array}$ & \begin{tabular}{|c} 
Sistema de \\
gerenciamento \\
ambientat interno e \\
externo
\end{tabular} & Sistema de baterias & $\begin{array}{c}\text { Sistema de energia } \\
\text { geotérmica }\end{array}$ & $\begin{array}{c}\text { Sistema de } \\
\text { aquecimento solar de } \\
\text { aggua }\end{array}$ & Aerogerador eólico \\
\hline $\begin{array}{l}\text { Segurança } \\
\text { Patrimonial }\end{array}$ & $\begin{array}{l}\text { Proteção contra } \\
\text { incêndio }\end{array}$ & \begin{tabular}{|c|} 
Sistema enderesável \\
de detecçăoo de \\
incêndio e alarme
\end{tabular} & Sistema de segurança & & & & & & & & & & \\
\hline
\end{tabular}

Fonte: Elaboração própria. 


\section{Quadro 5.7 - Concepção da IOWA Smart Home}

\begin{tabular}{|c|c|c|c|c|c|c|c|c|c|c|c|c|c|}
\hline \multirow{2}{*}{$\begin{array}{c}\text { Categorias de } \\
\text { serviso }\end{array}$} & \multicolumn{13}{|c|}{ Soluy̌es tecnológicicas } \\
\hline & $\begin{array}{c}\text { Soluşăo Teconologica } \\
1\end{array}$ & $\begin{array}{c}\text { Soluşăo Tecnológica } \\
2\end{array}$ & $\begin{array}{c}\text { Soluçăo Teconológica } \\
3\end{array}$ & $\begin{array}{c}\text { Soluçăo Teconológica } \\
4\end{array}$ & $\begin{array}{c}\text { Soluşä Tecnológica } \\
5\end{array}$ & $\begin{array}{c}\text { Soluşäo Tecnológica } \\
6\end{array}$ & $\begin{array}{c}\text { Soluçä̀ Tecnologica } \\
7\end{array}$ & $\begin{array}{c}\text { Soluşăo Tecnologica } \\
8\end{array}$ & $\begin{array}{c}\text { Soluşăo Teconologica } \\
9\end{array}$ & $\begin{array}{c}\text { Soluçăo Tecnológica } \\
10\end{array}$ & $\begin{array}{c}\text { Soluçăo Tecológica } \\
11\end{array}$ & $\begin{array}{c}\text { Soluçăo Tecológica } \\
12\end{array}$ & \begin{tabular}{|c} 
Soluçăo Teconógica \\
13
\end{tabular} \\
\hline Conforto e Lazer & Sistema HVAC & $\begin{array}{c}\text { Sistema } \\
\text { enderéável digital } \\
\text { de controle da } \\
\text { iluminiaçăo }\end{array}$ & $\begin{array}{l}\text { Sistema de } \\
\text { iluminaş̧o }\end{array}$ & $\begin{array}{l}\text { Sistema de layout } \\
\text { interno }\end{array}$ & $\begin{array}{c}\text { Sistema de fachada } \\
\text { em edfifica̧oes }\end{array}$ & $\begin{array}{c}\text { Home area networ } \\
\text { (HAN) }\end{array}$ & $k \begin{array}{c}\text { Sistema de } \\
\text { gerenciamento } \\
\text { ambiental interno e } \\
\text { externo }\end{array}$ & 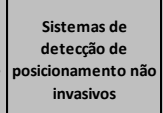 & Smart furniture & & & & \\
\hline $\begin{array}{l}\text { Automąço } \\
\text { residencial }\end{array}$ & $\begin{array}{c}\text { Sistema } \\
\text { endereáavel de } \\
\text { detecccăo de } \\
\text { incêndio e alarme }\end{array}$ & $\begin{array}{l}\text { sistema de dadose } \\
\text { telecomuncicasio } \\
\text { (ex:icc) }\end{array}$ & \begin{tabular}{|l} 
Sistema integrado \\
de gerenciamento \\
de edificasêses
\end{tabular} & $\begin{array}{c}\text { Sistema de } \\
\text { monitoramento da } \\
\text { seguranga } \\
\text { controle de acesso }\end{array}$ & $\begin{array}{c}\text { Sistema de layout } \\
\text { interno }\end{array}$ & $\begin{array}{l}\text { Sistemade } \\
\text { iluminaşio }\end{array}$ & 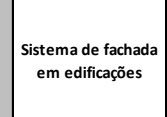 & $\left|\begin{array}{c}\text { Sistemavertical de } \\
\text { transporte }\end{array}\right|$ & $\begin{array}{l}\text { e area network } \\
\text { (HAN) }\end{array}$ & $\begin{array}{c}\text { sistemade } \\
\text { gerencimento } \\
\text { mbientat internoe } \\
\text { externo }\end{array}$ & 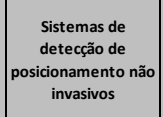 & Smart furniture & \\
\hline Acesso remoto & 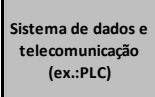 & 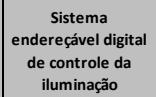 & $\begin{array}{c}\text { Sistema integrado } \\
\text { de gerencizamento } \\
\text { de edificaşes }\end{array}$ & $\begin{array}{l}\text { Sistema de fachada } \\
\text { em edificasōes }\end{array}$ & & & & & & & & & \\
\hline $\begin{array}{l}\text { Seguracha de rede } \\
\text { de intormaģio }\end{array}$ & $\begin{array}{c}\text { Sistema de } \\
\text { montitramento da } \\
\text { segurange } \\
\text { controle de aeesso }\end{array}$ & 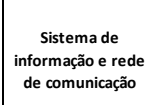 & 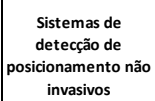 & & & & & & & & & & \\
\hline $\begin{array}{c}\begin{array}{c}\text { Cuidados de saude } \\
\text { (Heath hare) }\end{array} \\
\text { a }\end{array}$ & $\begin{array}{c}\text { Sistema integrado } \\
\text { de gerencicimanto } \\
\text { de edificaşes }\end{array}$ & $\begin{array}{l}\text { sistema de layout } \\
\text { interno }\end{array}$ & $\begin{array}{l}\text { sistema vertical de } \\
\text { transporte }\end{array}$ & $\begin{array}{l}\text { Wearables, } \\
\text { onitioramento da } \\
\text { saude }\end{array}$ & 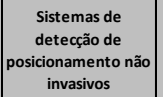 & Smart furniture & & & & & & & \\
\hline $\begin{array}{l}\text { Uso eficiente de } \\
\text { recursos naturais }\end{array}$ & $\begin{array}{l}\text { istema hidráailice } \\
\text { de drenagem }\end{array}$ & \begin{tabular}{|c|c} 
Minie stafăo de \\
tratamentoto de \\
agulas
\end{tabular} & $\begin{array}{c}\text { Captặă da dáguas } \\
\text { pluviaias }\end{array}$ & $\begin{array}{l}\text { Miniestacáa } \\
\text { meterealobicatica }\end{array}$ & Biodiesestor & Tellhado verde & Horta & & & & & & \\
\hline $\begin{array}{l}\text { Gerenciamento de } \\
\text { energia }\end{array}$ & Sistema HVAC & 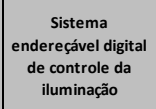 & $\begin{array}{c}\text { Sistemade } \\
\text { gerenciamentio de } \\
\text { energia }\end{array}$ & $\begin{array}{l}\text { Sistemade de } \\
\text { iluminaşá }\end{array}$ & \begin{tabular}{|l} 
Sistem ale \\
instalasfio eletrica
\end{tabular} & $\begin{array}{l}\text { PVT - módulo } \\
\text { fotoovtaicoe } \\
\text { térmico }\end{array}$ & Módul fotovoltal & $\mid \begin{array}{c}\text { Sistema de tracking } \\
\text { para fotovoltaica }\end{array}$ & $\begin{array}{c}\text { Sistema de } \\
\text { gerencianento } \\
\text { ambientaninternoe } \\
\text { exterene }\end{array}$ & istema de bateria: & $\mid \begin{array}{c}\text { Sistitema a e energia } \\
\text { geotérmica }\end{array}$ & 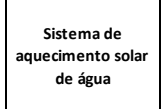 & ere \\
\hline $\begin{array}{l}\text { Segurancas } \\
\text { Patrimonial }\end{array}$ & $\begin{array}{c}\text { Protecăo contra } \\
\text { incêndio }\end{array}$ & 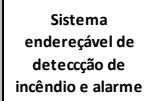 & $\begin{array}{l}\text { Sistema de } \\
\text { seguranca }\end{array}$ & & & & & & & & & & \\
\hline
\end{tabular}

Fonte: Elaboração própria. 
Quadro 5.8 - Concepção para a casa NO.V.A.

\begin{tabular}{|c|c|c|c|c|c|c|c|c|c|c|c|c|c|}
\hline \multirow{2}{*}{$\begin{array}{l}\text { Categorias de } \\
\text { servico }\end{array}$} & \multicolumn{13}{|c|}{ Soluşêes tecnologicicas } \\
\hline & $\begin{array}{c}\text { Soluşö Tecnologica } \\
1\end{array}$ & $\underset{2}{\text { Soluçăo Tenologica }}$ & $\begin{array}{c}\text { Solusăo Tecnológica } \\
3\end{array}$ & $\underset{4}{\text { Soluşăo Tenolǵica }}$ & \begin{tabular}{|c|c|c|} 
Soluşăo Tecnológica \\
5
\end{tabular} & $\begin{array}{c}\text { Soluşăo Tecnológica } \\
6\end{array}$ & 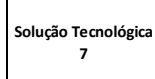 & $\begin{array}{c}\text { Soluy̧ăo Teenológica } \\
8\end{array}$ & $\begin{array}{c}\text { Soluşăo Teenologica } \\
9\end{array}$ & ${ }_{10}^{\text {Soluşăo Tenologica }}$ & $\begin{array}{c}\text { Soluşă Tecnologica } \\
11\end{array}$ & $\begin{array}{c}\text { Soluşăo Tecnológica } \\
12\end{array}$ & $\begin{array}{c}\text { Soluşă Teenologica } \\
13\end{array}$ \\
\hline Conforto e tazer & Sistema HVAC & $\begin{array}{c}\text { Sistema } \\
\text { enderecevivelditital } \\
\text { de controle da } \\
\text { iluminarasio }\end{array}$ & $\begin{array}{l}\text { Sistema de } \\
\text { iluminafăo }\end{array}$ & $\begin{array}{c}\text { Sistema de layout } \\
\text { interno }\end{array}$ & 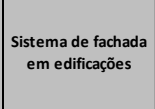 & $\begin{array}{l}\text { (HAN) } \\
\text { (HA) }\end{array}$ & 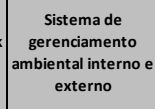 & 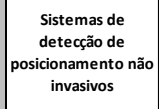 & Smart furniture & & & & \\
\hline $\begin{array}{l}\text { Automaaço } \\
\text { residencial }\end{array}$ & 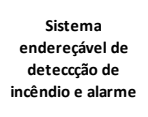 & $\begin{array}{l}\text { sistema de dadose } \\
\text { telecemunicasio } \\
\text { (ex:PILC) }\end{array}$ & $\begin{array}{l}\text { sistema integrado } \\
\text { de erenciamento } \\
\text { de edificasés }\end{array}$ & $\begin{array}{c}\text { Sistema de } \\
\text { monitoramento da } \\
\text { seguranga a } \\
\text { controle de acesso }\end{array}$ & $\begin{array}{c}\text { Sistema de layout } \\
\text { interno }\end{array}$ & 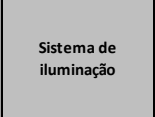 & $\begin{array}{l}\text { Sistema de fachada } \\
\text { em edificagōes }\end{array}$ & $\begin{array}{c}\text { istema vertical de } \\
\text { transporte }\end{array}$ & $\begin{array}{l}\text { Home area netw } \\
\text { (HAN) }\end{array}$ & $\begin{array}{c}\text { sistema de } \\
\text { gerenciamento } \\
\text { ambiental internoe } \\
\text { externo }\end{array}$ & 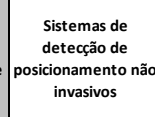 & Smart furniture & \\
\hline Acesso remoto & 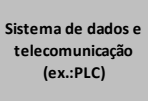 & 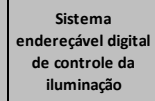 & 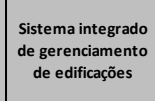 & $\begin{array}{c}\text { Sistema de fachada } \\
\text { em edificasōes }\end{array}$ & & & & & & & & & \\
\hline ade rede 6 & $\begin{array}{c}\text { Sistema de } \\
\text { onititoramento da }\end{array}$ & 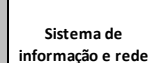 & $\begin{array}{l}\text { Sistemas de } \\
\text { deteçso de }\end{array}$ & & & & & & & & & & \\
\hline & controle de acesso & de comuniracasio & invasivos & & & & & & & & & & \\
\hline $\begin{array}{l}\text { Cuidados de saúde } \\
\text { (theath hare) }\end{array}$ & $\begin{array}{l}\text { Sistema integrado } \\
\text { de erencicamento } \\
\text { de edfificases }\end{array}$ & $\begin{array}{c}\text { Sistemade ayout } \\
\text { interno }\end{array}$ & $\begin{array}{c}\text { sistema verticald de } \\
\text { transporte }\end{array}$ & $\begin{array}{l}\text { Wearables, } \\
\text { onitioramento da } \\
\text { saude }\end{array}$ & $\begin{array}{l}\text { Sistemas de } \\
\text { detecçoo de } \\
\text { sitionamanto nao } \\
\text { invasisos }\end{array}$ & Smart turniture & & & & & & & \\
\hline $\begin{array}{l}\text { Uso eficiente de } \\
\text { recursos naturalis }\end{array}$ & 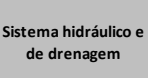 & $\begin{array}{l}\text { Mini estąăa de } \\
\text { tratamento de } \\
\text { agnuas de }\end{array}$ & $\begin{array}{c}\text { Captaçó da a aguas } \\
\text { pluviais }\end{array}$ & $\begin{array}{l}\text { Minie estaça } \\
\text { metereologica }\end{array}$ & Biodigestor & Tellhado verde & Horta & & & & & & \\
\hline $\begin{array}{c}\text { Gerenciamento de } \\
\text { energia }\end{array}$ & Sistema HVAC & 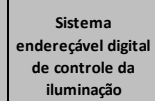 & $\begin{array}{l}\text { sistema de } \\
\text { gererciamento de } \\
\text { energia }\end{array}$ & 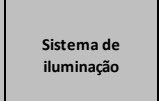 & $\begin{array}{c}\text { Sistema de } \\
\text { instalaşo eletrica }\end{array}$ & $\begin{array}{c}\text { pVT- módulo } \\
\text { fotovotacice e } \\
\text { termico }\end{array}$ & nodul of fotvolt: & $\begin{array}{c}\text { Sistema de tracking } \\
\text { para fotovoltaica }\end{array}$ & 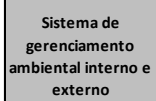 & Sistema de baterias & $\begin{array}{c}\text { Sistema de energia } \\
\text { geotérmica }\end{array}$ & $\begin{array}{c}\text { Sistema de } \\
\text { avecimento solar } \\
\text { de agua }\end{array}$ & \\
\hline $\begin{array}{l}\text { Segurança } \\
\text { Patrimonial }\end{array}$ & $\begin{array}{c}\text { Proteresăcontra } \\
\text { incendio }\end{array}$ & 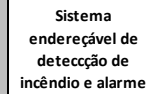 & $\begin{array}{l}\text { Sistema de } \\
\text { seguransa }\end{array}$ & & & & & & & & & & \\
\hline
\end{tabular}

Fonte: Elaboração própria. 


\section{4 .2}

\section{Seleção da melhor concepção: uso do método AHP-TOPSIS}

No método AHP, foram feitas, primeiramente, as análises pareada entre os critérios norteadores relacionados à "Moradia - Casa", em que foram comparados os critérios "Eficiência das Funcionalidades" e "Aspectos Tecnológicos". Para tanto, utilizou-se o sistema computacional IPÊ, versão 1.0 (Costa, 2004).

Pode-se notar na tabela 5.1 que a importância à luz do critério "Moradia-Casa" para estes dois critérios norteadores foi "igual", ou seja, neste caso os critérios possuem o mesmo nível de importância para a moradia e consequentemente o cálculo das prioridades ficou em 0,5 para cada um deles.

Tabela 5.1 - Comparação pareada entre os critérios norteadores para Moradia-Casa

\begin{tabular}{|l|c|c|}
\hline $\begin{array}{c}\text { Critérios norteadores relacionados à } \\
\text { "Moradia - Casa" }\end{array}$ & $\begin{array}{c}\text { Eficiência das } \\
\text { funcionalidades }\end{array}$ & $\begin{array}{c}\text { Aspectos } \\
\text { tTecnológicos }\end{array}$ \\
\hline Eficiência das funcionalidades & 1 & 1 \\
\hline Aspectos tecnológicos & 1 & 1 \\
\hline
\end{tabular}

Fonte: Elaboração própria.

$\mathrm{Na}$ segunda análise pareada para os critérios norteadores relacionados à "Usuário-Morador", foram comparados os critérios "Conforto", "Saúde" e "Segurança". Nesta comparação, a importância à luz do critério "Usuário -Morador" foi feita da seguinte forma:

- Comparação entre os subcritérios "Conforto" e "Saúde", com julgamento entre igual e moderado (nível 2) com maior importância para "Conforto";

- Comparação entre os subcritérios "Conforto" e "Segurança", com julgamento igualado (nível 1);

- Comparação entre os subcritérios "Saúde" e "Segurança", com julgamento igualado (nível 1).

Tabela 5.2 - Comparação pareada entre os critérios norteadores para Usuário-Morador

\begin{tabular}{|c|c|c|c|}
\hline $\begin{array}{c}\text { Critérios norteadores relacionados à } \\
\text { "Usuário-Morador" }\end{array}$ & Conforto & Saúde & Segurança \\
\hline Conforto & 1 & $1 / 2$ & 1 \\
\hline Saúde & 2 & 1 & 1 \\
\hline Segurança & 1 & 1 & 1 \\
\hline
\end{tabular}

Fonte: Elaboração própria. 
Terminada a comparação pareada à luz do critério Usuário-Morador os níveis de importância de acordo com o cálculo das prioridades foi estabelecido da seguinte forma: (i) Conforto: 0,411; (ii) Saúde: 0,261 e (iii) Segurança: 0,328.

Em relação ao critério Aspectos Ambientais não houve hierarquização devido ao fato de não haver subcritérios.

Após construídas as matrizes de análise morfológica, com as concepções de seis casas inteligentes, foi realizada a hierarquização das concepções para escolha final da melhor concepção em função dos critérios norteadores definidos na fase de “Análise e síntese". Para tanto, foi desenvolvido um mapa de atributos, cuja escala de avaliação variou entre 1 e 5, conforme definição abaixo:

- Nota 1 - Não atende aos critérios;

- Nota 3 - Atende moderadamente aos critérios;

- Nota 5 - Atende totalmente aos critérios.

As escalas pares ( 2 e 4 ) se referem aos valores intermediários da escala (Tabela $5.3)$.

$\mathrm{Na}$ avaliação dos atributos foram analisados individualmente cada critério norteador em relação ao que cada concepção de casa inteligente oferecia em termos de soluções tecnológicas.

As notas foram dadas seguindo as premissas de atendimento aos critérios norteadores (escala de 1 a 5) e as características das concepções das casas inteligentes descritas nos tópicos 5.3 a 5.8 .

Tabela 5.3 - Mapa de atributos para hierarquização das concepções de casas inteligentes

\begin{tabular}{|l|c|c|c|c|c|c|}
\hline \multirow{2}{*}{ Alternativas } & \multicolumn{6}{|c|}{ Critérios norteadores } \\
\cline { 2 - 7 } & $\begin{array}{l}\text { Eficiência das } \\
\text { funcionalidades } \\
\text { das casas }\end{array}$ & $\begin{array}{l}\text { Confortó } \\
\text { do usuário }\end{array}$ & $\begin{array}{l}\text { Aspectos } \\
\text { ambientais }\end{array}$ & $\begin{array}{l}\text { Saúde do } \\
\text { morador }\end{array}$ & $\begin{array}{l}\text { Segurança } \\
\text { do } \\
\text { morador }\end{array}$ & $\begin{array}{l}\text { Aspectos } \\
\text { tecnológicos }\end{array}$ \\
\hline $\begin{array}{l}\text { Concepção 1 - } \\
\text { Gator Tech Smart } \\
\text { House (EUA) }\end{array}$ & 4 & 5 & 1 & 3 & 4 & 4 \\
\hline $\begin{array}{l}\text { Concepção 2 - } \\
\text { Drexel Smart } \\
\text { House (EUA) }\end{array}$ & 2 & 2 & 1 & 1 & 1 & 2 \\
\hline $\begin{array}{l}\text { Concepção 3 - } \\
\text { Aware House } \\
\text { (EUA) }\end{array}$ & 3 & 3 & 1 & 2 & 1 & 3 \\
\hline $\begin{array}{l}\text { Concepção 4 - } \\
\text { IOWA Smart Home } \\
\text { (EUA) }\end{array}$ & 3 & 4 & 1 & 2 & 1 & 3 \\
\hline Concepção 5 - & 4 & 5 & 1 & 4 & 3 & 3 \\
\hline
\end{tabular}




\begin{tabular}{|l|c|c|c|c|c|c|}
\hline $\begin{array}{l}\text { CASAS Smart Home } \\
\text { (EUA) }\end{array}$ & & & & & & \\
\hline $\begin{array}{l}\text { Concepção 6 - } \\
\text { Casa NO.V.A } \\
\text { (Brasil) }\end{array}$ & 4 & 5 & 4 & 3 & 4 & 4 \\
\hline
\end{tabular}

Fonte: Elaboração própria.

Após a definição dos pesos via método AHP, foi feita a análise integrada AHPTOPSIS, que possibilitou a hierarquização das concepções de casas inteligentes. Nesta fase, foram usados os resultados do Mapa de Atributos apresentados na Tabela 5.1, aplicados os pesos totais do método AHP apresentados na Tabela 5.4.

Tabela 5.4 - Análise integrada AHP-TOPSIS

\begin{tabular}{|l|c|c|c|c|}
\hline \multicolumn{1}{|c|}{ Etapa } & Critério & $\begin{array}{l}\text { Cálculo das } \\
\text { prioridades }\end{array}$ & Peso & $\begin{array}{c}\text { Razão de } \\
\text { Consistência }\end{array}$ \\
\hline \multirow{2}{*}{$\begin{array}{l}\text { Critérios norteadores } \\
\text { relacionados à } \\
\text { "Usuário-Morador" }\end{array}$} & Conforto & 0,411 & 0,24 & \multirow{2}{*}{0,046} \\
\cline { 2 - 4 } & Saúde & 0,261 & 0,15 & \\
\cline { 2 - 4 } $\begin{array}{l}\text { Critérios norteadores } \\
\text { relacionados à } \\
\text { “Moradia - Casa" }\end{array}$ & $\begin{array}{c}\text { Eficiência das } \\
\text { Funcionalidades }\end{array}$ & 0,328 & 0,19 & \multirow{2}{*}{0,000} \\
\cline { 2 - 4 } & Aspectos Tecnológicos & 0,500 & 0,13 & 0,000 \\
\hline Aspectos Ambientais & Aspectos Ambientais & 1,000 & 0,16 & 0,13 \\
\hline
\end{tabular}

Fonte: Elaboração própria.

Assim, pôde-se obter por meio da distância euclidiana entre cada uma das soluções de casas inteligentes à solução ideal positiva e negativa, índice de proximidade relativa do valor ideal, bem como hierarquização das soluções de casas inteligentes, mostrada na Tabela 5.5.

Como esperado, pode-se verificar que a Casa NO.V.A. teve o maior de proximidade relativa $(0,87)$, considerando os critérios escolhidos para hierarquizar a casa inteligente que melhor descreva as necessidades do projeto NO.V.A..

Tabela 5.5 - Hierarquização das concepções de casas inteligentes por AHP-TOPSIS

\begin{tabular}{|l|l|l|}
\hline Casa & Índice de proximidade relativa & Posição \\
\hline Concepção 6: Casa NO.V.A (Brasil) & 0,87 & 1 \\
\hline Concepção 1: Gator Tech Smart House (EUA) & 0,57 & 2 \\
\hline Concepção 5: CASAS Smart Home (EUA) & 0,54 & 3 \\
\hline Concepção 4: IOWA Smart Home (EUA) & 0,28 & 4 \\
\hline Concepção 3: Aware House (EUA) & 0,24 & 5 \\
\hline Concepção 2: Drexel Smart House (EUA) & 0,00 & 6 \\
\hline
\end{tabular}

Fonte: Elaboração própria.

Todos os resultados intermediários do método TOPSIS empregado estão apresentados no Anexo 1 para se chegar ao ranking apresentado na Tabela 5.5 acima. 
Após esta fase, com vistas a evidenciar se as concepções de casas atenderiam aos anseios das Personas escolhidas e que representam ficticiamente os futuros moradores da casa inteligente do projeto NO.V.A.. elaborou-se o Quadro 5.9. Assim, pôde-se evidenciar se as soluções tecnológicas a serem disponibilizadas nas respectivas casas atenderiam as características das Personas.

Quadro 5.9 - Concepções de casas inteligentes hierarquizadas pelo método AHP/TOPSIS e relacionados às personas

\begin{tabular}{|c|c|c|c|c|c|c|}
\hline & $\begin{array}{l}\text { Concepção 1: } \\
\text { Gator Tech } \\
\text { Smart House } \\
\text { (EUA) }\end{array}$ & $\begin{array}{l}\text { Concepção 2: } \\
\text { Drexel Smart } \\
\text { House (EUA) }\end{array}$ & $\begin{array}{c}\text { Concepção 3: } \\
\text { Aware House } \\
\text { (EUA) }\end{array}$ & $\begin{array}{l}\text { Concepção 4: } \\
\text { IOWA Smart } \\
\text { Home (EUA) }\end{array}$ & $\begin{array}{l}\text { Concepção 5: } \\
\text { CASAS Smart } \\
\text { Home (EUA) }\end{array}$ & $\begin{array}{c}\text { Concepção 6: } \\
\text { Casa NO.V.A } \\
\text { (Brasil) }\end{array}$ \\
\hline AHP/TOPSIS & 0,57 & 0 & 0,24 & 0,28 & 0,54 & 0,87 \\
\hline \multirow{6}{*}{ Personas } & Maria & & & Maria & Maria & Maria \\
\hline & & Olivia & & & & \\
\hline & Vitor & & Vitor & & & Vitor \\
\hline & & & Michel & Michel & Michel & Michel \\
\hline & Beatriz & & & Beatriz & Beatriz & Beatriz \\
\hline & Carla & & Carla & Carla & & Carla \\
\hline
\end{tabular}

Fonte: Elaboração própria.

\section{5 \\ Discussão dos resultados}

O conceito-chave do projeto foi a escuta da população, um formato colaborativo que serviu para ouvir diversos stakeholders de formas distintas, atribuindo grande riqueza de contribuições para o que se esperava ser uma casa inteligente ideal. Os workshops e Meetups na fase de imersão trouxeram a possibilidade de discussão de temas mais profundamente, não somente anseios tecnológicos, comunicação entre equipamentos e dispositivos, mas também a preocupação com o meio ambiente, o cultivo de alimentos e principalmente o uso eficiente de recursos naturais emergiram dessas discussões. Essas discussões ajudaram a definir a pergunta principal da plataforma digital - "Se você pudesse construir hoje a casa que vai morar em 2040, como ela seria?", e também na formatação visual da plataforma e todo o funcionamento da "gameficação".

As dinâmicas em redes sociais testaram possibilidades e deram a oportunidade para a equipe do projeto verificar a aceitação da massa e os melhores caminhos, 
ouvir formadores de opinião digitais sobre suas visões de futuro e engajar seus seguidores a participarem colaborativamente do projeto. As dinâmicas resultaram em um aprofundamento nas discussões e no levantamento de temas que foram colocados no site posteriormente. Também ajudaram na formatação da dinâmica de funcionamento da plataforma digital.

Em seguida, o site colaborativo foi lançado com uma metodologia de gameficação para os participantes. A grande diferença desse "game" era que o mais alto nível de premiação, uma viagem para a Itália com direito à participação na ExpoMilão 2015, não era para a melhor ideia, a mais inovadora ou a mais genial, mas sim para o gamer mais participativo, aquele que curtisse, divulgasse, colaborasse com as sugestões alheias e enviasse várias ideias diferentes. O raciocínio para essa mecânica se deu devido a duas questões: como se julgaria uma melhor e mais genial ideia em se tratando de futuro, de tecnologia e de inovação? E ao mesmo tempo, em se tratando de colaboração da massa, faria sentido promover uma discussão e não apenas receber uma ideia de cada colaborador do site.

O resultado foi o alcance de 16 milhões de pessoas, com 47 mil usuários acessando o site e 4.600 ideias recebidas sobre a casa do futuro vindas de 121 países. Esse alcance e grande participação de indivíduos na discussão trouxeram ideias inovadoras, sugestões de soluções tecnológicas ainda não encontradas na literatura e vários aspectos de sustentabilidade que de fato são possíveis de serem implementadas em uma casa inteligente e que também não estavam reportadas na literatura, trazendo um grande diferencial para a casa inteligente do Projeto.

Destaca-se a importância do método do Design Thinking e Análise morfológica para a chegada do resultado do processo final, sem os quais não seria possível a identificação da melhor concepção de uma casa inteligente.

Por meio do método de Design Thinking foi possível pesquisar de forma estruturada e assertiva sobre as casas inteligentes e soluções tecnológicas promovendo uma reflexão prévia importante para o Projeto. Também foi possível ouvir opiniões e receber ideias da multidão através da metodologia de crowdsourcing que trouxe sugestões ainda não reportadas na literatura, propostas inovadoras e contribuições importantes. Além disso, o método permitiu analisar organizadamente as soluções propostas e estabelecer critérios norteadores para a concepção do Projeto. 
Aliado ao Design Thinking, foi feita uma análise morfológica que serviu para identificar e associar as soluções tecnológicas inovadoras a concepções de projetos de casas inteligentes. Esse método trouxe mais robustez à análise e às concepções de casas inteligentes e geração de alternativas, possibilitando ainda, o emprego de um método híbrido multicritério de apoio à decisão (AHP-TOPSIS) para seleção e hierarquização das concepções propostas.

Os resultados mostraram que para atender os anseios das pessoas na plataforma e que atendessem aos objetivos do projeto, era necessário que os anseios das Personas criadas fossem alcançados. Os diferenciais da casa inteligente do Projeto NO.V.A. (Concepção 6) está, primeiramente pelo fato dessa concepção ter o foco voltado para as pessoas, o pensamento da usabilidade da casa e das soluções tecnológicas pensadas para atender às necessidades do usuário/morador, incluindo o atendimento à idosos e pessoas com deficiências, uma vez que a casa contemplou em seu projeto o monitoramento dos indivíduos e a possibilidade de prover cuidados e monitoramento clínico à distância. Além disso, a preocupação com a sustentabilidade, tanto na geração e armazenamento de energia limpa, como na otimização de recursos por meio de soluções como reuso de água, adoção da ventilação cruzada e claraboias, geotermia, cultivo de alimentos, dentre outras foram determinantes para que esta concepção de casa inteligente aparecesse em primeiro lugar na hierarquização feita pela metodologia AHP-TOPSIS.

Considera-se que os integrantes da equipe técnica do Projeto e os arquitetos que participaram da fase de prototipação do Design Thinking (fase não coberta por esta pesquisa) conseguiram incorporar na concepção da casa NO.V.A os atributos necessários para atender às expectativas dos futuros usuários e aos objetivos propostos pela Enel Distribuição Rio. Como preconizado pelo Grupo Enel, a casa NO.V.A. será um "laboratório vivo", a exemplo da maioria dos casos reportados no capítulo 2 desta pesquisa. 


\section{6 \\ Conclusões e recomendações}

A presente pesquisa contribuiu para o avanço do conhecimento sobre projetos de casas inteligentes, mais especificamente sobre o processo de geração e seleção de concepções de projetos baseados em soluções tecnológicas inovadoras. Nesse sentido, um modelo conceitual foi desenvolvido, tendo como principal abordagem metodológica o Design Thinking, integrada a diversas ferramentas de gestão da inovação e métodos multicritério de apoio à decisão, conferindo ao modelo diferenciais em relação às práticas de Design Thinking reportadas na literatura.

Os resultados obtidos ao longo da pesquisa aqui relatada permitiram que o objetivo geral da dissertação fosse alcançado. Foi possível, com uso da matriz de análise morfológica e de dois métodos multicritério de apoio à decisão, gerar seis concepções de casas inteligentes e selecionar a melhor concepção para o Projeto NO.V.A.

Os marcos conceituais e metodológicos discutidos nos capítulos 2 e 4 fundamentaram o desenvolvimento e aplicação do modelo de geração e seleção de concepções de casas inteligentes baseadas em soluções tecnológicas inovadoras, contribuindo de forma significativa para que os objetivos específicos da dissertação fossem alcançados.

Pelos aspectos descritos e resultados gerados na fase aplicada da pesquisa, considera-se que eles propiciaram à empresa Enel Distribuição Rio, bem como aos diversos atores envolvidos na implementação do Projeto NO.V.A., o ferramental adequado para a escolha das soluções tecnológicas que irão ser incorporadas na fase de construção da casa.

A pesquisa bibliográfica e documental permitiu ainda identificar projetos de casas inteligentes que vem funcionado como laboratórios vivos nos Estados Unidos, Japão, Turquia e Brasil, visando identificar os modelos e soluções tecnológicas que vem sendo adotadas. Foram identificados sete modelos que instrumentalizaram a 
geração de concepções de casas na fase de ideação do processo de Design Thinking do Projeto NO.V.A.

O estudo empírico desenvolvido no âmbito do Projeto NO.V.A. permitiu demonstrar a aplicabilidade do modelo proposto, com resultados relevantes em cada etapa do processo de Design Thinking - imersão, análise e síntese e ideação. A melhor concepção foi a que foi selecionada para o Projeto NO.V.A. como mostrado no Quadro 5.8.

Destacam-se os aspectos inovadores do modelo baseado em Design Thinking, a saber: (i) a criação de uma plataforma de colaboração digital (crowdsourcing) na fase de imersão em profundidade, (ii) identificação de arquétipos de futuros moradores da casa inteligente objeto do projeto, que representam as motivações, desejos, expectativas e necessidades, revelando-se características significativas de um grupo mais abrangente (fase de análise e síntese); (iii) definição de critérios norteadores para hierarquização de alternativas baseadas em soluções tecnológicas inovadoras e escolha da melhor concepção de casa inteligente para o projeto em foco; (iv) na fase de ideação, adoção da ferramenta de análise morfológica para geração das concepções alternativas de casas inteligentes baseadas em soluções tecnológicas inovadoras; e (v) a combinação de dois métodos multicritério de apoio à decisão para a hierarquização das concepções propostas e seleção da melhor alternativa para um dado projeto de casa inteligente.

Para trabalhos futuros de desdobramento da pesquisa e aprofundamento dos resultados, propõem-se:

- Aplicar novas ferramentas de gestão da inovação e de prospecção tecnológica, como roadmapping tecnológico, por exemplo, mantendo-se a abordagem de Design Thinking como a principal para o processo de geração de novos modelos conceituais;

- Explorar novas combinações de métodos multicritério de apoio à decisão na fase de ideação, particularmente nas etapas de hierarquização das concepções e seleção da melhor para o projeto em foco;

- Desenvolver novas taxonomias de casas inteligentes alternativamente à reportada no capítulo 2, considerando especificidades de países em desenvolvimento e economias emergentes. 


\section{Referências bibliográficas}

Associação Brasileira da Construção Industrializada. ABCI.. Inteligência Disponível. Construção, n.2371, p. 23-35, 1993.

AKASHI, O.; HANAOKA, T., Technological feasibility and costs of achieving a $50 \%$ reduction of global GHG emissions by 2050: Mid- and long-term perspectives. Sustainability Science, v. 35, p. 139-156, 2012.

ALAM, M., R.; REAZ, M. B. I.; ALI, M. A. A review of smart homes - past, present, and future, IEEE Transactions on Systems, Man, and Cybernetics - Part C: Applications and Reviews, v.42, n.6, p.1190-1203, 2012.

AMAY, J. et al, Tattoo-Based Noninvasive Glucose Monitoring: A Proof-ofConcept Study. 2014. Disponível em: http://pubs.acs.org> Acesso em 20 Maio 2017

ARCHER, N; KESHAVJEE, K.; DEMERS, C; LEE, R., Online self-management interventions for chronically ill patients: Cognitive impariment and technology issues: International Journal of Medical Informatics, v. 22, p. 264-272, 2014.

BADICA, C.; BREZOVAN, M.; BADICA, A. An overview of smart home environments: architectures, technologies and applications, In BCI'13 Proceedings. Thessaloniki, Greece, p.19-21, , 2013.

BAECK, A.; GREMETT, P. Design Thinking. In: Degen, H; Yuan, X. (Eds.) Best practices: how to achieve more impact with user experience. E-book. McGraw-Hill Osborne Media, 2011.

BAILEY, D.A., Moving 2 mishap: M2M's impact on privacy and safety. IEEE Secur. Priv. v. 22, p. 84-87, 2012.

BALTA-OZKAN, N.; DAVIDSON, R.; BICKET, M.; WHITMARSH. L., The development of smart homes market in the UK. Energy, v. 60, p. 361-372, 2013.

BANDYOPADHYAY, D.; SEN, J. Internet of things: applications and challenges in technology and standardization. Wireless Personal Communications. v.58, p. 4969, 2011. 
BARDIN L. Análise de conteúdo. Lisboa: Edições 70, 977.

BERARDI, U. Beyond sustainability assessment systems: Upgrading topics by upscaling the assessment: International Journal of Sustainable Building Technology and Urban Development, v.2 p. 276-282, 2011.

BERARDI, U. Sustainability assessment in the construction sector: rating systems and rated buildings. Sustainable Development, v. 20, p. 411-424, 2012.

BERNDT, D. Maintenance-Free Batteries: Lead-Acid, Nickel/Cadmium, Nickel/Metal Hydride (Electronic \& Electrical Engineering Research Studies). Research Studies Press, v.3, p. 56-65, 1993.

BOLZANI, M. Análise de arquiteturas e desenvolvimento de uma plataforma para residências inteligentes. Tese (Doutorado), 155 p., Universidade de São Paulo, São Paulo, Brasil, 2010.

BRABHAM, D. C. Crowdsourcing as a model for problem solving: an introduction and cases. Convergence: The International Journal of Research into New Media Technologies, v. 14, n.1, p.75-90, 2008.

BRANDÃO, D. Q.; HEINECK, L. F. M. Formas de aplicação da flexibilidade arquitetônica em projetos residenciais multifamiliares. Produto \& Produção, Porto Alegre, UFRGS, Programa de Pós-Graduação em Engenharia de Produção, v. 2, n. 3, p. 95-106, 1998.

BRANDÃO, D. A personalização do produto habitacional e as novas tecnologias no processo construtivo. 2005. Disponível em: <http://www.infohab.org.br>. Acesso em: 09 abr. 2017.

BRENNER, W., UEBERNICKEL, F. E ABRELL, T. Design thinking as mindset, process, and toolbox: Presents a broad overview of different approaches to Design Thinking. Design Thinking for Innovation: Research and Practice, p.3-21, 2016.

BROWN, T. Design Thinking. Harvard Business Review, v. 86, n. 6, p. 84-92, 2008.

BROWN, T. Design Thinking: uma metodologia poderosa para decretar o fim das velhas ideias. Rio de Janeiro: Elsevier, 2010.

CASSIDY, R., White paper on sustainability: Building design \& construction. 2003. Disponível em: <www.bdcnetwork.com>. Acesso em: 20 mai. 2017.

CAVALCANTI, C.M.C., Contribuições do Design Thinking para concepção de interfaces de ambientes virtuais de aprendizagem centradas no ser humano. Tese de Doutorado, 254 p., Universidade de São Paulo, São Paulo, Brasil, 2015.

CHAN, M. et al. A review of smart homes - present state and future challenges. Computer Methods and Programs in Biomedicine, v.91, n.1, p. 55-81, 2008. 
CHAN, M. et al. Smart homes - current features and future perspectives. Maturitas, v. 64, p. 90- 97, 2009.

CHEN, M.; WAN, J.; GONZALEZ, S.; LIAO, X.; LEUNG, M., A survey of recent developments in home $\mathrm{m} 2 \mathrm{~m}$ networks. IEEE Communications Surveys \& Tutorials, v.16, p.98-114, 2014.

CHERNBUMROONG S.; CANG S.; YU H., Genetic algorithm-based classifiers fusion for multisensor activity recognition of elderly people. IEEE Journal of Biomedical and Health Informatics, v.19, p.282-289, 2015.

COLE, R. J., Changing context for environmental knowledge. Building Research \& Information, v.32, p.91-109, 2004.

CONSEIL INTERNATIONAL DU BÂTIMENT. CIB. Towards sustainable and smart-eco buildings. Summary report on the EU-funded project smart-ECO buildings in the EU: Rotterdam, 2010.

COOPER, R.; JUNGINGER, S.; LOCKWOOD, T. Design thinking and design management: A research and practice perspective. Design Management Review, v. 20, n. 2, p. 46-55, 2009.

COSTA, H. G. IPÊ 1.0: Guia do Usuário. Niterói: Universidade Federal Fluminense, 2004. Disponível em: < http://www.producao.uff.br/conteudo/rpep/volume42004/RelPesq_V4_2004_05.p df $>$.

DAKI, H.; EL HANNANI, A.; AQQAL, A.; HAIDINE, A.; DAHBI,A. Big Data management in smart grid: concepts, requirements, and implementation. Journal of Big Data, 2017.

DENTI, E. Novel pervasive scenarios for home management: the Butlers architecture. 2014. Disponível em: <https://springerplus.springeropen.com>. Acesso em 20 maio 2017.

DUTTON,W.H., Putting things to work: social and policy challenges for the Internet of things. Michigan State University. v.16. p.1-21, 2014.

EBERT, M. R. Avaliação da flexibilidade inicial de apartamentos: em busca do desempenho e qualidade espacial do ambiente construído. Dissertação (Mestrado). Universidade Federal de Santa Catarina, Florianópolis, 2006.

EPA, Environmental Protection Agency, Green Building Strategy - Defines green building and explains EPA's strategic role in facilitating the mainstream adoption of effective green building practices. 2008. Disponível em: 〈http://www.epa.gov>. Acesso em: 15 abr. 2017.

EUROSTAT, Energy consumption by sector in European countries. 2011. Disponível em: <http://epp.eurostat.ec.europa.eu〉. Acesso em: 20 mai. 2017. 
FAHADI, G.L.; KHAN, A.; RAJARAJAN, M. Activity recognition in smart homes with self verification of assignments. Neurocomputing, v. 149, p. 1286-1298, 2014.

FERREIRA, V. A domótica como instrumento para a melhoria da qualidade de vida dos portadores de deficiência. 2010. 41p. Monografia. Instituto Federal de Educação, Ciência e Tecnologia da Paraíba. João Pessoa.

GHAFFARIANHOSEINI, A. H. et al. The essence of future smarthouses: from embedding ICT to adapting to sustainability principles, Renewable and Sustainable Energy Reviews, v.24, p.593-607, 2013.

GOVINDAN, R. Connected devices for smarter home environments: internet of things data bolstered by Informix database embedding advances connected devices at home. 2014. Disponível em <www.ibmbigdatahub.com> Acesso em: 18 abr. 2017.

GROSSKURTH, J.; ROTMANS, J., The scene model: Getting a grip on sustainable development in policy making. Environment, Development and Sustainability, v.7, p.135-151, 2005.

GUILLEMIN, P., FRIESS, P. et al., Internet of things: strategic research roadmap. The Cluster of European Research Projects, 2009.

GUPTA, S., HIRDESH, A., Overview of M2M. Department of Computer and Information Science and Engineering, University of Florida, 2007.

HAN J., PLC-based photovoltaic system management for smart home energy management system: IEEE Transactions on Consumer Electronics, v.60, p. 184189, 2014.

HASSI, L.; LAAKSO, M. Conceptions of Design Thinking in the design and management discourses. In Proceedings of the 4th World Conference on Design Research, IASDR 2011, Delft, Netherlands, 2011.

HEINECK, L. Classificação das formas de aplicação da flexibilidade arquitetônica planejada em projetos de edifícios residenciais. Disponível em: <http://www.antac.org.br/ambienteconstruido> Acesso em: 09 set. 2005. Florianópolis.1998.

HERRANDO M., A UK-based assessment of hybrid PV and solar-thermal systems for domestic heating and power: System performance. Applied Energy, v.122, p. 288-309, 2014.

HILL, R.; BOWN, P., Sustainable construction - Principles and a framework for attainment. Construction Management and Economics, v.15, p. 223-239, 1997.

HOWE, J. The rise of crowdsourcing. Wired Magazine, n. 14, p. 1-5, 2006. Disponível em: <http://www.wired.com/wired/archive/14.06/crowds.html>. 
Acesso em: 15 abr. 2017.

HUYNH, M. S.; PARRY, D.; FONG, A. C. M.; TANG, J. Novel RFID and Ontology based Home Localization System for Misplaced Objects. IEEE Transactions on Consumer Eletronics, v.60, p.402-409, 2014.

HWANG, C.-L.; YOON, K. Multiple Attribute Decision Making: Methods and applications. New York. Springer, p.58-191, 1981.

IDEO. Design Kit: The Human-Centered Design Toolkit. Palo Alto: Ideo, 2009. Disponível em: <https://www.ideo.com/post/design-kit.>. Acesso em: 15 abril 2017.

JEONG, K. Design and operation of smart homes in USA and Korea. $\mathrm{PhD}$ thesis, 224 p., PurdueUniversity, USA, 2009.

JUNG, S.J., CHUNG,W.Y. Wireless machine-to-machine healthcare solution using android mobile devices in global networks: IEEE Sensors Journal, v. 13, n. 5, p.1419-1424, 2013.

KAILAS, A.; CECCHI, V.; MUKHERJEE, A., A survey of communications and networking technologies for energy management in buildings and home automation. J. Computer Network Communication, v. 5, p.56-67, 2012.

KELLY N.A., Increasing the solar photovoltaic energy capture on sunny and cloudy days. Solar Energy, USA, v.85, p. 111-125, 2011.

KIVIMÄKI, T.; VUORELA, T.; PELTOLA, P.; VANHALA, J. A Review on Device-Free Passive Indoor Positioning Methods: International Journal of Smart Home, v.8, p.71-94, 2014.

KOSHMAK G.; LINDEN M.; LOUTFI A., Dynamic Bayesian networks for context-aware fall risk assessment: Sensors, v. 14, 2014.

KROHLING, R. A.; SOUZA, D. T. T. M. Dois exemplos da aplicação da técnica TOPSIS para tomada de decisão. Revista Sistemas de Informação da FSMA, v. 8, p. 31-35, 2011.

KRUPITZER C. et al. A survey on engineering approaches for self-adaptive systems. Pervasive and Mobile, v. 5, p.56-78, 2015.

LEE, MATTHEW L.; DEY, ANIND K. Sensor-based observations of daily living for aging in place, v. 19, p.27-43, 2015.

LEME, M. O.; TROJAN, F.; XAVIER P.; FRANCISCO A. Digital Energy Management for Houses and Small Industries Based on a Low-cost Hardware. IEEE Latin America Transactions, v. 14, p. 36-45, 2016. 
LIANG, Y.; JIA, Z.; YAO, H.; CHEN, J. Housing intelligent lighting control strategy research. IEEE 3rd International Conference on Cloud Computing and Intelligence Systems, 2014.

LOMBARD, L.; ORTIZ, J; POUT, C. A review on buildings energy consumption information. Energy and Buildings. V. 40, p. 394-398. 2007.

LOWE, R. Addressing the challenges of climate change for the built environment, Building Research \& Information, v.35, p. 343-350, 2007.

MATTAR, J.; SDERI, M. Edifício inteligente: a evolução de um conceito. Revista Cipa. São Paulo. 1994.

MIRACULINS, INC 2015. Miraculins Announces 2015 Plans for Its Scout DS® Non-Invasive Diabetes Screening Technology. Disponível em: <http://www.marketwired.com> Acesso em: 20 Maio 2017

MOREIRA, A. R. A., O papel da criatividade e do Design Thinking na inovação. Dissertação de Mestrado, 103 p., Faculdade de Engenharia. Universidade do Porto, Porto, Portugal, 2015.

MOZER M.C. The neural network house: An environment that's adapts to its inhabitants; Proceedings of the AAAI Spring Symposium on Intelligent Environments; Palo Alto, CA, USA. p. 110-114, 1998.

MUKHOPADHYAY, S.C., A Zigbee-based wearable physiological parameters monitoring system: IEEE Sensors Journal, v.12, n.3, p. 423-430, 2012.

MUKHOPADHYAY, S.C., Wearable Sensors for Human Activity Monitoring: IEEE Sensors Journal, v. 30, p. 3, 2015.

NASTRINI, C. Metodologia para projeto de Edifícios Inteligentes: Tecnologias. 184 p. Dissertação (Mestrado). Pontifícia Universidade Católica de Minas Gerais. Belo Horizonte. 1999..

NGUYEN, N.T.; VENKATESH, S.; WEST, G.; BUI, H.; PERTH, A., Multiple camera coordination in a surveillance system: Acta Automation, 2003.

NIYATO, D., XIAO, L., WANG, P., Machine-to-machine communications for home energy management system in smart grid: IEEE Communications Magazine, v.49, p.53-59, 2011.

OBARA, S., KONNO, D., UTSUGI, Y., \& MOREL, J. Analysis of output power and capacity reduction in electrical storage facilities by peak shift control of PV system with bifacial modules: Applied Energy, v.128, p. 35-48, 2014.

PARK H., BASARAN C.; PARK T.; HYUK SON S. Energy-efficient privacy protection for smart home environments using behavioral semantics, v.14, p. 16235-16257, 2014. 
PARRA, M. Optimum community energy storage for end user applications. Tese de Doutorado, 267 p., University of Nottingham, Inglaterra, 2014.

PARRY, M. et al. Climate Change 2007: Impacts, Adaptation and Vulnerability: Contribution of Working Group II to the Fourth Assessment Report of the Intergovernmental Panel on Climate Change. Cambridge University Press, Cambridge, UK, 982pp. 2007

PAVITT, K.; STEINMUELLER, W.E. Technology in corporate strategy: change, continuity, and the information revolution. In: Pettigrew, A.; Thomas H.; Whittington, R. (orgs.), Handbook of Strategy and Management, New York: Sage, 2002.

PERUMAL, T., et al. Design and Implementation of SOAP-Based Residential Management for Smart Home Systems, IEEE Transactions on Consumer Electronics, v. 54, 2008.

PINNOLA, C. Desenvolvimento e implementação de kit inteligente para sistemas de refrigeração, aquecimento, ventilação e ar condicionado. 2013. 90p. Dissertação (Mestrado). Universidade Federal do Paraná. Curitiba, 2013.

PLATTNER, H.; MEINEL, C.; LEIFER, L. Design Thinking. Berlin: Springer, 2011.

REED, B., Shifting from 'sustainability' to regeneration: Building Research \& Information, v.35, p. 674-680, 2007.

REZ, R. Marketing de conteúdo: a moeda do século XXI. Rio de Janeiro: DVS Editora. 2016.

ROSE, B. Home networks: a standards perspective. IEEE Communications Magazine, v.39, p.78-85, 2001.

SAATY, T. L. Método de análise hierárquica. São Paulo: McGraw Hill, 1991.

SAATY, T. L. A scaling method for priorities in hierarchical structures. Journal of Mathematical Psychology, v. 15, n. 3, p. 234-281, 1977.

SAATY, T. L. Decision making with the analytic hierarchy process. International Journal of Services Sciences, v.1, n.1, p. 83-98, 2008.

SAATY, T. L.; VARGAS, L. G. Models, methods, concepts \& applications of the analytic hieratchy process. New York: International Series in Operations Research \& Management Science, v.2, 2012.

SCHENK, E.; GUITTARD, C. Towards a characterization of crowdsourcing practices. Journal of Innovation Economics \& Management, v.1, n.7, p. 206- 223, 2011. 
SCHÖN, D. A. Designing as reflective conversation with the materials of a design situation. Knowledge-Based Systems, v.5, n.1, p. 3-14, 1992.

SCHÖN, D. A. Designing: Rules, types, and worlds. Design Studies, v.9, n.3, p. 181-190, 1988.

SIMON, H. A. The sciences of the artificial. 1st ed. Cambridge, MA: MIT Press, 1969.

SO, A; CHAN, A. Vertical Transportation Systems: The International Series on Asian Studies in Computer and Information Science. Intelligent Building Systems,v.5, p.27-34, 1996.

STANFORD D.SCHOOL. Bootcamp Bootleg. Palo Alto: Institute of Design at Stanford, 2011. Disponível em:

<http://dschool.stanford.edu/wpcontent/uploads/2011/03/BootcampBootleg2010v 2SLIM.pdf>. Acesso em: 15 abril 2017.

STUBER, E.C. Inovação pelo design: uma proposta para o processo de inovação através de worskshops utilizando o Design Thinking e o Design Estratégico. 2012. 203 p. Dissertação (Mestrado). Universidade Vale do Rio dos Sinos. São Leopoldo, 2012.

STUBER, E.C. O Design Thinking põe o foco no ser humano. HSM Management, v.115, p.24-27, 2016.

SYSALA, T; PRIBYSLAVSKY, J; NEUMANN, P. Using microcomputers for lighting appliance control using a DALI bus. Matec web of conferences. V.76, 2016.

TANG, P.; VENABLES, T. Smart homes and telecare for independent living, $J$. Telemed. Telecare, v. 6, p. 8-14, 2000.

TASCIKARAOGLU, A.; BOYNUEGRI, A. R.; UZUNOGLU, M. A demand side management strategy based on forecasting of residential renewable sources: A smart home system in Turkey. Energy and Buildings, v.80, p. 309-320, 2014.

UIA. Sustainable by Design Declaration. 2009. Disponível em: < http://www.uiaarchitectes.org/cop15 en.html>. Acesso em: 15 abr. 2017.

UNEP-SBCI, United Nations Environment Programme. Sustainable buildings \& climate initiative, buildings, and climate change: a summary for decision makers, 2009.

URBANETZ JR., J. Sistemas fotovoltaicos conectados a redes de distribuição urbanas: sua influência na qualidade da energia elétrica e análise dos parâmetros que possam afetar a conectividade. 2010. 210 p. Tese (Doutorado). Universidade Federal de Santa Catarina. Florianópolis. 
URBANETZ JR., J. Sistemas fotovoltaicos conectados a redes de distribuição urbanas: sua influência na qualidade da energia elétrica e análise dos parâmetros que possam afetar a conectividade. 2010. 210 p. Tese (Doutorado). Universidade Federal de Santa Catarina. Florianópolis.

VAXEVANAKIS, K,; ZAHARIADIS, T.; VOGIATZIS, N., A review on wireless home network technologies. Sigmobile Mobile Computer Communication, v.7, p.59-68, 2003.

VERGARA, S. C. Métodos de pesquisa em Administração. São Paulo: Atlas, v.9, 287 p, 2005.

VIANNA, M. et al. Design thinking: inovação em negócios. Rio de Janeiro: MJV Press, 2012.

WCED, World Commission on Environment and Development, Our common future. New York: Oxford University Press, 1987.

WELSH, M. A.; DEHLER, G. E. Combining critical reflection and Design Thinking to develop integrative learners. Journal of Management Education, v. 37 n. 6, p. 771-802, 2012.

WIGGINTON, M.; HARRIS, J. Intelligent skins. Oxford: Architectural Press, 2002.

WILSON, C.; HARGREAVES, T.; HAUXWELL-BALDWINB, R. Benefits and risks of smart home technologies, Energy Policy, v. 103, p. 72-83, 2017.

WILSON, C.; HARGREAVES, T.; HAUXWELL-BALDWIN, R., Smart homes and their users, a systematic analysis, and key challenges: Personal Ubiquitous Computer, v.19, p.463-476, 2015.

WONG, J. K. W.; LI, H. Application of the analytic hierarchy process (AHP) in multi-criteria analysis of the selection of intelligent building systems, Building and Environment, v.43, p.108-125, 2008.

WONG, J. K. W.; LI, W. Construction, Application and Validation of Selection Evaluation Model (SEM) for Intelligent HVAC Control System. Automation in Construction, v.19, p.261-269, 2010.

YAMAZAKI, T. The ubiquitous home. International Journal of Smart Home, v.1, n.1, p. 17-22, 2007.

YUAN B.; HERBERT J. Context-aware hybrid reasoning framework for pervasive healthcare. Personal and Ubiquitous Computing, v.18, p.865-881, 2014.

ZWICKY, F. Discovery, invention, research - through the morphological approach. New York. Macmillan Publisher, 276 p , 1969. 


\section{Anexo 1 - Descrição do método analítico hierárquico - AHP}

Este anexo é parte integrante da dissertação de Ariani Mello intitulada "Monitoramento e avaliação da regulamentação sobre recolhimento de alimentos no Brasil: proposição de indicadores e métricas" (Mello, 2015) e da dissertação de Luisa Fernanda Rivera Criollo intitulada "Monitoramento e avaliação da regulamentação sobre rotulagem de alimentos alergênicos no Brasil: proposição de indicadores e métricas" (Criollo, 2016).

Descreve-se a seguir o método AHP conforme o proposto por Saaty (1977, 1991, 2008).

O método AHP compreende quatro etapas, de acordo com a descrição de Saaty (1991) e Costa (2006):

- Organização da estrutura hierárquica, através da identificação do foco principal, dos critérios e subcritérios (quando existirem) e das alternativas, refletindo as relações existentes entre eles;

- Aquisição dos dados e coleta de julgamentos de valor, através da comparação dos elementos dois a dois e estabelecimento das matrizes de comparações;

- Análise das matrizes de comparações geradas na fase anterior, que indicarão a prioridade de cada alternativa em relação ao foco principal;

- Análise dos indicadores de desempenho derivados, como índices de consistência por exemplo.

No AHP, os elementos de uma hierarquia para a resolução de problemas de decisão são o foco principal (ou meta), o conjunto de alternativas viáveis e o conjunto de critérios, de acordo com o ilustrado na Figura 1.

O foco principal é o objetivo global, o que a resolução do problema trará. As alternativas viáveis são as possibilidades de escolha dentro do problema para que a decisão seja tomada. Por fim, os critérios são as características ou propriedades a partir das quais as alternativas devem ser avaliadas. 


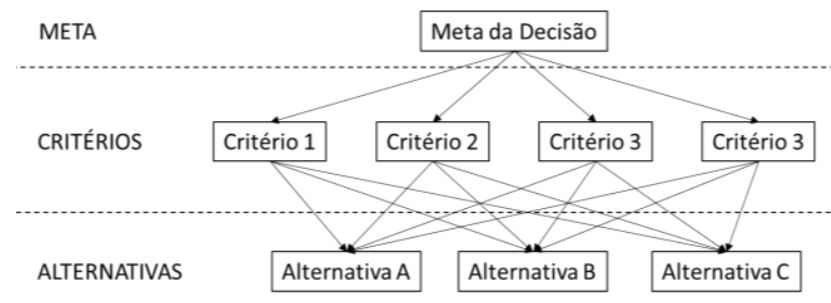

Figura 1 - Exemplo de estrutura hierárquica de problemas de decisão (em três níveis) Fonte: Saaty, 1991.

Após a hierarquização, o método aponta para os julgamentos de valor, onde o avaliador deve comparar os elementos dois a dois à luz de um determinado critério. O julgamento é então a representação numérica dessa relação e o grupo de todos os julgamentos, considerando a comparação de todos os elementos em relação a um critério específico, pode ser representado através de uma matriz quadrada (Saaty, 1991).

Para o estabelecimento do processo de julgamento, Saaty (1990) definiu uma escala específica para padronizar os julgamentos de valor, escala essa que capta a subjetividade natural existente em variáveis qualitativas. O Quadro 14, a seguir, apresenta essa escala.

Quadro 1 - Escala para padronizar os julgamentos de valor pelo método AHP

\begin{tabular}{c|l|l}
\hline $\begin{array}{l}\text { Intensidade de } \\
\text { importância }\end{array}$ & Definição & Explicação \\
\hline 1 & Mesma importância & $\begin{array}{l}\text { As duas atividades contribuem } \\
\text { igualmente para o objetivo. }\end{array}$ \\
\hline 3 & $\begin{array}{l}\text { Importância moderada de uma } \\
\text { sobre a outra }\end{array}$ & $\begin{array}{l}\text { A experiência e o julgamento favorecem } \\
\text { levemente uma atividade em relação à } \\
\text { outra. }\end{array}$ \\
\hline 5 & Importância grande ou essencial & $\begin{array}{l}\text { A experiência e o julgamento favorecem } \\
\text { fortemente uma atividade em relação à } \\
\text { outra. }\end{array}$ \\
\hline 9 & $\begin{array}{l}\text { Importância muito grande ou } \\
\text { demonstrada }\end{array}$ & $\begin{array}{l}\text { Uma atividade é muito fortemente } \\
\text { favorecida em relação à outra; sua } \\
\text { dominação de importância é } \\
\text { demosntrada na prática. }\end{array}$ \\
\hline $2,4,6,8$ & $\begin{array}{l}\text { Valores intermediários entre os } \\
\text { valores adjacentes. }\end{array}$ & $\begin{array}{l}\text { A evidência favorece uma atividade em } \\
\text { relação à outra com o mais alto grau de } \\
\text { certeza. }\end{array}$ \\
\hline $\begin{array}{l}\text { Importância absoluta } \\
\text { compromisso entre as duas definições. }\end{array}$ \\
\hline
\end{tabular}

Fonte: Saaty, 1991. 
O julgamento consiste no reflexo de duas perguntas: qual dos dois elementos é o mais importante, à luz do objetivo pretendido, e com qual intensidade ele é mais importante, utilizando-se a escala de 1 a 9 apresentada no Quadro 1.

Para o elemento mais importante, é utilizado um valor inteiro, enquanto que o menos importante recebe o inverso dessa unidade, como ilustrado no exemplo didático da Figura 2.

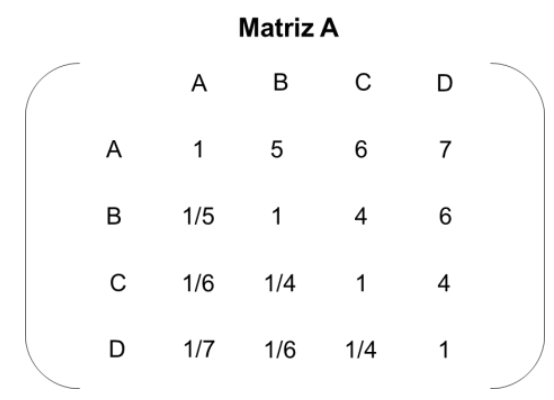

Figura 2 - Exemplo de matriz de julgamentos para o método AHP Fonte: Saaty, 1991.

As letras A, B, C e D representam os elementos a serem comparados dois a dois. A diagonal da matriz recebe sempre 1 pois é a comparação do elemento com ele mesmo. Para o preenchimento dos outros campos, são feitos os julgamentos para determinar a intensidade de importância, utilizando a escala determinada por Saaty. Para as comparações inversas, ou seja, o que está na parte inferior esquerda da matriz, são adicionados os valores recíprocos referentes à cada julgamento, que estão na parte superior direita da mesma.

Com as matrizes recíprocas devidamente estruturadas, obtém-se o vetor de prioridades, ou pesos, a partir do cálculo do autovetor normalizado do máximo autovalor. Existem métodos específicos para o cálculo aproximado desses valores (Saaty,1991). Tais aproximações foram desenvolvidas por limitações computacionais da época em que o método foi desenvolvido, sendo custoso o cálculo de autovetores e autovalores para matrizes de ordem elevada.

Para fins deste trabalho, será utilizado o valor preciso de ambas as grandezas, que são denotadas matricialmente por:

$$
A w=\lambda_{\max } w
$$


Onde:

$A$ é a matriz de julgamentos (quadrada, recíproca e positiva);

$w$ é o autovetor principal, referente aos pesos;

$\lambda_{\max }$ é o autovalor principal de $A$.

Com as características das matrizes de julgamentos em mãos, através do teorema de Perron-Frobenius, Saaty (1991) afirma que a solução tem um único maior autovalor que corresponde a um autovetor de componentes estritamente positivos. Os teoremas e as provas acerca das características envolvendo as matrizes geradas, a partir da avaliação de especialistas, são apresentados em seu trabalho. Computados os autovalores das respectivas matrizes, é necessário realizar análise da consistência dos julgamentos para avaliar o quão afastado da consistência os julgamentos estão. Utiliza-se uma medida para avaliar a probabilidade dos julgamentos terem sido realizados puramente ao acaso e esta medida é chamada Razão de Consistência (RC). Por exemplo, um $R C=0,3$ diz que há $30 \%$ de chance do especialista responder as perguntas aleatoriamente.

Saaty (1991) apresenta um desenvolvimento simples e intuitivo para compreender a análise de consistência. Vamos supor uma matriz consistente, onde as comparações são baseadas em medidas exatas, isto é, os pesos já são conhecidos, então:

$$
a_{i j}=\frac{w_{i}}{w_{j}}
$$

Como o julgamento é perfeito para todas as comparações, tem-se que $a_{i k}=$ $a_{i j} . a_{j k}$ para qualquer $\mathrm{i}, \mathrm{j}, \mathrm{k}$, variando de 1 até $n$, sendo $n$ a ordem da matriz.

Também vale a afirmativa:

$$
a_{i j}=\frac{w_{j}}{w_{i}}=\frac{1}{w_{i} / w_{j}}=\frac{1}{a_{i j}}
$$

Dessa forma caracteriza-se uma matriz consistente de comparações paritárias.

Considerando $x=\left(x_{1}, \ldots, x_{n}\right)$ e $y=\left(y_{1}, \ldots, y_{n}\right)$ pode-se escrever em notação matricial $A \cdot x=y$, onde A é a matriz de julgamentos:

$$
A=\left[\begin{array}{ccc}
\frac{w_{1}}{w_{1}} & \cdots & \frac{w_{1}}{w_{n}} \\
\vdots & \ddots & \vdots \\
\frac{w_{n}}{w_{1}} & \cdots & \frac{w_{n}}{w_{n}}
\end{array}\right]
$$


Algebricamente essa operação pode ser representada por:

$$
\begin{aligned}
& \qquad \sum_{j=0}^{n} a_{i j} \cdot x_{i}=y_{i} \\
& \operatorname{para} i=1, \ldots, n
\end{aligned}
$$

Como $a_{i j}=\frac{w_{i}}{w_{j}}$, obtém-se:

$$
\begin{gathered}
a_{i j} \frac{w_{j}}{w_{i}}=1 \\
\operatorname{para} i, j=1, \ldots, n
\end{gathered}
$$

Consequentemente:

$$
\begin{aligned}
& \qquad \sum_{j=0}^{n} a_{i j} \cdot w_{j} \frac{1}{w_{i}}=n \\
& \operatorname{para} i=1, \ldots, n
\end{aligned}
$$

$\mathrm{ou}$

$$
\begin{aligned}
& \sum_{j=0}^{n} a_{i j} \cdot w_{j}=n w_{i} \\
& \text { para } i=1, \ldots, n
\end{aligned}
$$

Que é equivalente a equação matricial:

$$
A w=n w
$$

Em álgebra linear, esta última equação expressa o fato de que $w$ é autovetor de $A$ com autovalor $n$.

Na prática $a_{i j}$ são os pesos atribuídos pelo julgamento dos especialistas, baseado na escala fundamental, e de certa forma subjetivos. Assim os valores $a_{i j}$ irão se afastar do "ideal" $w_{i} / w_{j}$, fazendo com que a equação $A w=n w$ não seja mais válida.

Se $\lambda_{1}, \ldots, \lambda_{n}$ são os números que satisfazem a equação $A w=\lambda w$, então $\lambda$ é autovalor de $A$ e, se $a_{i j}=1$ para todo i, então:

$$
\sum_{i=0}^{n} \lambda_{i}=n
$$

Assim, se $A w=n w$ é válida, somente um dos autovalores é diferente de zero e valerá $n$, sendo o maior autovalor de $A$.

Caso os elementos de uma matriz recíproca positiva sofrerem pequenas variações, seus respectivos autovalores também variarão em pequenas quantidades. 
Utilizando os resultados apresentados juntamente com o axioma acima, pode-se dizer que caso a diagonal principal de uma matriz possuir os elementos iguais a 1 e for consistente, pequenas variações nos elementos $a_{i j}$ farão com que o autovalor máximo $\lambda_{\max }$ permaneça próximo de $n$ e os outros autovalores próximos de zero. Sendo $\lambda_{\max } \geq n$.

Portanto, para calcular o autovetor de prioridades de uma matriz de comparações paritárias $A$, deve-se encontrar o vetor que satisfaça a equação $A w=$ $\lambda_{\max } w$.

O valor de interesse para o desenvolvimento da metodologia é o autovetor normalizado, de forma que a soma de $w$ seja igual a 1. Para isso cada elemento $w_{i}$ é dividido pelo seu somatório.

Uma medida de consistência, chamada Índice de Consistência (IC), é utilizada para calcular o desvio de $\lambda_{\max }$ em relação à $n$, uma vez que a utilização da escala para os julgamentos geram variações em $a_{i j}$, alterando $\lambda_{\max }$.

$$
I C=\frac{\lambda_{\max }-n}{n-1}
$$

É comum as avaliações realizadas pelos especialistas gerarem inconsistências, pois faz parte do julgamento humano, mas deseja-se que sejam as menores possíveis. Para verificar a coerência utiliza-se, como citado anteriormente, a Razão de Consistência, tendo como definição:

$$
R C=\frac{I C}{I R}
$$

IR (Índice Randômico) é o índice de consistência de uma matriz recíproca gerada randomicamente, baseada na escala de 1 a 9, com recíprocas forçadas (Saaty, 1991). Este valor é tabelado e varia de acordo com a ordem da matriz. Na Tabela 1 é apresentado o valor de IR para matrizes de ordem 1 até 10.

Tabela 1 - Índice randômico

\begin{tabular}{c|cccccccccc}
$\mathbf{n}$ & 1 & 2 & 3 & 4 & 5 & 6 & 7 & 8 & 9 & 10 \\
\hline $\mathbf{I R}$ & 0 & 0 & 0,52 & 0,89 & 1,11 & 1,25 & 1,35 & 1,40 & 1,45 & 1,49
\end{tabular}

Fonte: Adaptado de Saaty e Vargas, 2012.

A avaliação final da coerência do julgamento se dá ao comparar o valor de RC. Para o presente desenvolvimento faz-se as seguintes considerações: 
a) $R C \leq 0,1$ consiste em um julgamento coerente, premissa básica do método em relação a análise de coerência, proposta inicialmente para julgar uma avaliação como satisfatória;

b) $0,1<R C<0,2$ = Julgamento questionável, considerado para que especialista reveja seus julgamentos da respectiva etapa, analisando a matriz construída e busque melhorar alguma(s) comparação(ões) que tenha(m) sido inconsistente(s). Porém não é obrigatório que se altere algum julgamento;

c) $R C \geq 0,2=$ Julgamento incoerente, indica que as comparações pareadas daquela etapa geraram um alto índice de inconsistência e o especialista é obrigado a refazer seus julgamentos.

Uma vez alcançada a consistência no julgamento, são calculados os vetores de prioridades, ou seja, os pesos relativos de cada elemento do problema. Este cálculo é realizado através da multiplicação das matrizes de prioridades. Em outras palavras, para cada alternativa, o cálculo consiste na soma ponderada da importância relativa de cada atributo pelo nível de preferência de determinada alternativa em relação ao respectivo critério (Souza, 2013). No AHP cada alternativa receberá uma pontuação através de uma função de valor aditiva. As alternativas com maior valor serão as preferíveis (Passos, 2010). Formalizando, a função de valor para cada alternativa será:

$$
F(a)=\sum_{j=1}^{n} w_{j} v_{j}(a)
$$

Onde:

$F(a)$ é o valor final de alternativa $a$;

$w_{j}$ é o peso do j-ésimo critério;

$v_{j}$ é o desempenho da alternativa em relação ao j-ésimo critério.

\section{Referências}

SAATY, T. L. A scaling method for priorities in hierarchical structures. Journal of Mathematical Psychology, v. 15, n. 3, p. 234-281, 1977.

SAATY, T. L. Decision making with the analytic hierarchy process. International Journal of Services Sciences, v.1, n.1, p. 83-98, 2008.

SAATY, T. L. Método de análise hierarquica. São Paulo: Mc - Graw Hill, 1991.

SAATY, T. L.; VARGAS, L. G. Models, methods, concepts \& applications of the analytic hieratchy process. $2^{\text {nd }}$. ed. New York: International Series in Operations Research \& Management Science, 2012. 


\section{Anexo 2 - Descrição da técnica para avaliar o desempenho de alternativas pela similaridade com a solução ideal - TOPSIS}

Este anexo é parte integrante da dissertação de Ariani Mello intitulada "Monitoramento e avaliação da regulamentação sobre recolhimento de alimentos no Brasil: proposição de indicadores e métricas” (Mello, 2015) e da dissertação de Luisa Fernanda Rivera Criollo intitulada "Monitoramento e avaliação da regulamentação sobre rotulagem de alimentos alergênicos no Brasil: proposição de indicadores e métricas" (Criollo, 2016).

Descreve-se a seguir o método TOPSIS conforme o descrito por Hwang e Yoon, (1981)

Basicamente, a técnica compreende as seguintes etapas:

- Construção da matriz do problema ou matriz de decisão, que traz as alternativas e critérios selecionados juntamente com as notas e avaliações;

- Cálculo da matriz normalizada, utilizando normalização linear ou por vetor;

- Cálculo da matriz com os respectivos pesos de cada critério, definidos previamente por um ou mais decisores;

- Identificação da PIS e da NIS;

- Cálculo das distâncias entre a PIS e cada alternativa e entre a NIS e cada alternativa;

- Cálculo da similaridade para a posição ideal positiva, que vai definir a hierarquização das alternativas estudadas.

A matriz de decisão A composta por alternativas e critérios é apresentada abaixo:

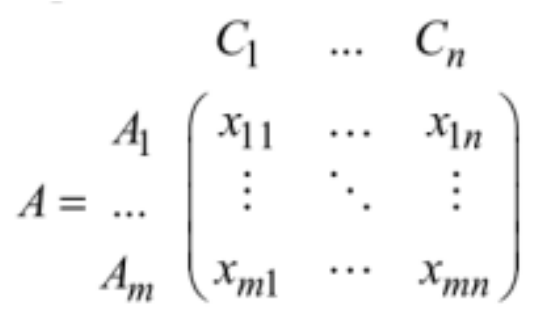

Onde $A_{1}, A_{2}, \ldots . A_{m}$ são alternativas viáveis e $C_{1}, C_{2}, \ldots . ., C_{n}$ são critérios; $x_{i j}$ indica o desempenho da alternativa $A_{i}$ segundo o ritério $C_{\mathrm{j}}$.

$\mathrm{O}$ vetor de peso $W=\left(w_{1}, w_{2}, \ldots . w_{n}\right)$ composto pelos pesos individuais para cada critério $C_{j}$ satisfaz 


$$
\sum_{i=1}^{n} w_{j}=1
$$

Os dados da matriz A têm origens distintas, devendo ser normalizada com o objetivo de transformá-la em uma matriz adimensional e com isso proceder a uma comparação entre os vários critérios. Para fins de aplicação nesta pesquisa, a matriz A deve ser normalizada para cada critério $C_{j}$, de acordo com a seguinte fórmula:

$$
p_{i j}=\frac{x_{i j}}{\sum_{i=1}^{m} x_{i j}}, \text { com } i=1, \ldots, m, j=1, \ldots, n
$$

Assim, uma matriz de decisão normalizada $A_{n}$ representa o desempenho relativo das alternativas e pode ser descrita por:

$$
A_{n}=\left(p_{i j}\right)_{m x n}, \operatorname{com} i=1, \ldots, m, \text { e } j=1, \ldots, n \text {. }
$$

O algoritmo para calcular a melhor alternativa segundo a técnica TOPSIS compreende os seguintes passos (Krohling e Souza, 2011):

Passo 1: Cálculo das soluções ideais positivas $A^{+}$(benefícios) e das soluções ideais negativas $A^{-}$(custos) da seguinte forma:

$$
\begin{aligned}
& A^{+}=\left(p_{1}^{+}, p_{2}^{+}, \ldots, p_{m}^{+}\right) \\
& A^{-}=\left(p_{1}^{-}, p_{2}^{-}, \ldots, p_{m}^{-}\right)
\end{aligned}
$$

Onde:

$$
\begin{aligned}
& p_{j}^{+}=\left(\max _{i} p_{i j}, j \in J_{1} ; \min _{i} p_{i j}, j \in J_{2}\right) \\
& p_{j}^{-}=\left(\min _{i} p_{i j}, j \in J_{1} ; \max _{i} p_{i j}, j \in J_{2}\right)
\end{aligned}
$$

Onde $j_{1} e j_{2}$ representam respectivamente o critério benefício e custo.

Passo 2: Cálculo das distâncias Euclideanas entre $A_{i}$ e $A^{+}$(benefícios) e entre $A_{i}$ e $A^{+}$(custos) da seguinte forma:

$$
\begin{gathered}
d^{+}=\sqrt{\sum_{j=1}^{n} w_{j}\left(p_{j}^{+}-p_{i j}\right)^{2}} \operatorname{com} i=1, \ldots, m . \\
d^{-}=\sqrt{\sum_{j=1}^{n} w_{j}\left(p_{j}^{-}-p_{i j}\right)^{2}} \operatorname{com} i=1, \ldots, m .
\end{gathered}
$$


Passo 3: Calculo da proximidade relativa $\xi_{\mathrm{i}}$ para cada alternativa $A_{i}$ em relação à solução ideal positiva $A^{+}$conforme:

$$
\xi_{i}=\frac{d_{i}^{-}}{d_{i}^{+}+d_{i}^{-}} .
$$

\section{Referências}

HWANG, C.-L.; YOON, K. Multiple Attribute Decision Making. Methods and applications New York: 1981.

KROHLING, R. A.; SOUZA, D. T. T. M. Dois exemplos da aplicação da técnica TOPSIS para tomada de decisão. Revista Sistemas de Informação da FSMA, v. 8, p. 31-35, 2011. 


\section{Anexo 3 - Resultados intermediários do método TOPSIS}

A seguir apresenta-se os resultados intermediários do método AHP-TOPSIS:

Tabela 1 - Distância euclidiana positiva dos critérios norteadores para as concepções de casas inteligentes

\begin{tabular}{|c|c|c|c|c|c|c|}
\cline { 2 - 7 } \multicolumn{2}{c|}{} & \multicolumn{5}{c|}{ Positiva } \\
\hline Concepções \Critérios & $\begin{array}{c}\text { Eficiência das } \\
\text { funcionalidades }\end{array}$ & $\begin{array}{c}\text { Aspectos } \\
\text { tecnológicos }\end{array}$ & Conforto & Saúde & Segurança & $\begin{array}{c}\text { Aspectos } \\
\text { ambientais }\end{array}$ \\
\hline Concepção 6: Casa NO.V.A (Brasil) & 0,00 & 0,00 & 0,75 & 0,25 & 0,00 & 0,00 \\
\hline Concepção 1: Gator Tech Smart House (EUA) & 0,50 & 0,60 & 0,75 & 0,75 & 0,75 & 0,50 \\
\hline Concepcão 5: CASAS Smart Home (EUA) & 0,25 & 0,40 & 0,75 & 0,50 & 0,75 & 0,25 \\
\hline Concepção 4: IOWA Smart Home (EUA) & 0,25 & 0,20 & 0,75 & 0,50 & 0,75 & 0,25 \\
\hline Concepção 3: Aware House (EUA) & 0,00 & 0,00 & 0,75 & 0,00 & 0,25 & 0,25 \\
\hline Concepção 2: Drexel Smart House (EUA) & 0,00 & 0,00 & 0,00 & 0,25 & 0,00 & 0,00 \\
\hline
\end{tabular}

Fonte: Própria

Tabela 2 - Distância euclidiana negativa dos critérios norteadores para as concepções de casas inteligentes

\begin{tabular}{|c|c|c|c|c|c|c|}
\cline { 2 - 7 } \multicolumn{1}{c|}{} & \multicolumn{7}{c|}{ Negativa } \\
\hline Concepções Critérios & $\begin{array}{c}\text { Eficiência das } \\
\text { funcionalidades }\end{array}$ & $\begin{array}{c}\text { Aspectos } \\
\text { tecnológicos }\end{array}$ & Conforto & Saúde & Segurança & $\begin{array}{c}\text { Aspectos } \\
\text { ambientais }\end{array}$ \\
\hline Concepção 6: Casa NO.V.A (Brasil) & $-0,50$ & $-0,60$ & 0,00 & $-0,50$ & $-0,75$ & $-0,50$ \\
\hline Concepção 1: Gator Tech Smart House (EUA) & 0,00 & 0,00 & 0,00 & 0,00 & 0,00 & 0,00 \\
\hline Concepção 5: CASAS Smart Home (EUA) & $-0,25$ & $-0,20$ & 0,00 & $-0,25$ & 0,00 & $-0,25$ \\
\hline Concepção 4: IOWA Smart Home (EUA) & $-0,25$ & $-0,40$ & 0,00 & $-0,25$ & 0,00 & $-0,25$ \\
\hline Concepção 3: Aware House (EUA) & $-0,50$ & $-0,60$ & 0,00 & $-0,75$ & $-0,50$ & $-0,25$ \\
\hline Concepção 2: Drexel Smart House (EUA) & $-0,50$ & $-0,60$ & $-0,75$ & $-0,50$ & $-0,75$ & $-0,50$ \\
\hline
\end{tabular}

Fonte: Própria

Tabela 3 - Solução ideal positiva (PIS) para as concepções de casas inteligentes

\begin{tabular}{|l|c|}
\hline \multicolumn{1}{|c|}{ Concepçães de casas inteligentes } & PIS \\
\hline Concepção 6: Casa NO.V.A (Brasil) & 0,38 \\
\hline Concepção 1: Gator Tech Smart House (EUA) & 0,67 \\
\hline Concepção 5: CASAS Smart Home (EUA) & 0,57 \\
\hline Concepção 4: IOWA Smart Home (EUA) & 0,55 \\
\hline Concepção 3: Aware House (EUA) & 0,40 \\
\hline Concepção 2: Drexel Smart House (EUA) & 0,10 \\
\hline
\end{tabular}

Fonte: Própria 
Tabela 4 - Solução ideal negativa (NIS) para as concepções de casas inteligentes

\begin{tabular}{|l|c|}
\hline \multicolumn{1}{|c|}{ Concepções de casas inteligentes } & NIS \\
\hline Concepção 6: Casa NO.V.A (Brasil) & 0,51 \\
\hline Concepção 1: Gator Tech Smart House (EUA) & 0,00 \\
\hline Concepção 5: CASAS Smart Home (EUA) & 0,18 \\
\hline Concepção 4: IOWA Smart Home (EUA) & 0,22 \\
\hline Concepção 3: Aware House (EUA) & 0,47 \\
\hline Concepção 2: Drexel Smart House (EUA) & 0,63 \\
\hline
\end{tabular}

Fonte: Própria 